\title{
Rehearsal: Um arcabouço para teste automatizado de coreografias de serviços web
}

\author{
Felipe Meneses Besson
}

\author{
DisSERTAÇÃO APRESENTADA \\ $\mathrm{AO}$ \\ Instituto DE MATEMÁticA E EstatísticA \\ DA \\ Universidade DE SÃo PAUlo \\ PARA \\ OBTENÇÃO DO TÍTULO \\ DE \\ Mestre EM CiênCIAS \\ Programa: Ciência da Computação \\ Orientador: Prof. Dr. Fabio Kon
}

Durante o desenvolvimento deste trabalho o autor recebeu auxílio financeiro da HP Brasil por meio do projeto Baile e do programa FP7/2007-2012 da Comissão Européia pelo projeto n ${ }^{\circ}$ 257178 (CHOReOS - Large Scale Choreographies for the Future Internet)

São Paulo, Outubro de 2012 


\section{Rehearsal: Um arcabouço para teste automatizado de coreografias de serviços web}

Esta versão da dissertação contém as correções e alterações sugeridas pela Comissão Julgadora durante a defesa da versão original do trabalho, realizada em 14/09/2012. Uma cópia da versão original está disponível no Instituto de Matemática e Estatística da Universidade de São Paulo.

Comissão Julgadora:

- Prof. Dr. Fabio Kon (orientador) - IME-USP

- Prof. Dr. Eduardo Martins Guerra - ITA

- Prof. Dr. Walter Figueiredo Mascarenhas - IME-USP 


\section{Agradecimentos}

Agradeço aos meus pais por sempre me apoiarem em tudo e por me ensinarem os principais valores de integridade e caráter, tornando-se assim, os principais responsáveis por toda a minha trajetória acadêmica e profissional.

Quero agradecer em especial a minha namorada Jaqueline, pelo apoio e compreensão no período do mestrado. Ela sempre esteve e estará comigo em todos os momentos bons e ruins da minha vida, obrigado Jaq.

Também agradeço ao meu orientador Fabio Kon, pela confiança depositada em mim e pela excelente orientação. Aprendi muito com ele, seu apoio, incentivo e cobrança nos momentos necessários, fizeram com que eu evoluisse bastante.

Não poderia deixar de agradecer o pessoal do CHOReOS. Agradeço ao Léo, Emílio, Guilherme, Pedro, Paulo Moura, Yanik e Cadu por todos os momentos passados, dentro e fora do projeto, vocês me ajudaram muito. Além deles, obrigado ao Dejan Milojicic, por todos os conselhos e incentivo, aos professores Alfredo, Gerosa e Daniel e a todos os alunos do projeto, nossas discussóes nas reuniões foram importantes para o direcionamento da minha pesquisa.

Agradeço a todos os meus amigos do LCPD e do IME em geral. Paulo Meireles, obrigado por seu apoio no começo do mestrado. Também agradeço ao Alvaro, Edwin, Beraldo, Kio, Fefo, pela amizade e bons momentos passados. A Claudia, Nathalia e Paulo Cheque, por suas revisões e dicas.

Em especial, agradeço aos projetos CHOReOS e Baile pelo financiamento e incentivo a minha pesquisa.

Quero também agradecer ao Daniel e ao excelente time da Elo\%. Apesar de estar trabalhando lá pouco tempo, apliquei muitas coisas aprendidas lá em meu projeto de mestrado.

Por fim, agradeço a todos aqueles que participaram do nosso estudo exploratório, além de todos os professores e funcionários do IME. 


\section{Resumo}

BESSON, F. M. Rehearsal: Um arcabouço para teste automatizado de coreografias de serviços web. 2012. 130 f. Dissertação (Mestrado) - Instituto de Matemática e Estatística, Universidade de São Paulo, São Paulo, 2012.

Serviços web são componentes de software fracamente acoplados projetados para promover a comunicação interoperável entre aplicações na Internet. O acesso a serviços web dá-se de maneira padronizada (via protocolos definidos pelo W3C), independente da linguagem de programação, sistema operacional ou plataforma em que são desenvolvidos. Devido a essas características, serviços simples podem ser combinados em serviços mais completos. Coreografia consiste em uma abordagem descentralizada para a composição de serviços. Diferentemente de orquestrações, abordagem na qual serviços distribuídos são coordenados de modo centralizado, a interação entre os serviços de uma coreografia é colaborativa e a coordenação descentralizada.

Apesar das vantagens, o desenvolvimento de coreografias, incluindo as atividades de testes, não é algo consolidado. O objetivo desta dissertação foi desenvolver uma arcabouço de teste que facilite o uso de Desenvolvimento Guiado por Testes (Test-Driven Development, TDD) em coreografias de serviços web. Rehearsal, o arcabouço proposto, fornece funcionalidades para o teste automatizado de (i) serviços web atômicos (teste de unidade); (ii) composição de serviços (teste de integração) e (iii) uma parte ou toda a coreografia (teste de aceitação).

Esses testes podem ser implementados utilizando funcionalidades do arcabouço, tais como a criação dinâmica de clientes para serviços web, o interceptador de mensagens e a abstração da coreografia em objetos Java. Além disso, Rehearsal facilita a criação e uso de Mocks de serviços web, uma importante prática de TDD. A fim de avaliar o arcabouço desenvolvido, um estudo exploratório qualitativo foi conduzido com estudantes de Ciência da Computação. De acordo com os resultados obtidos, as funcionalidades do Rehearsal mostraram-se adequadas para a utilização de TDD em coreografias de serviços web.

Palavras-chave: Testes automatizados, Desenvolvimento Guiado por Testes, Métodos Ágeis, Serviços web, Coreografias de serviços web. 


\section{Abstract}

BESSON, F. M. Rehearsal: A framework for automated testing of web service choreographies. 2012. 130 f. Dissertação (Mestrado) - Instituto de Matemática e Estatística, Universidade de São Paulo, São Paulo, 2012.

Web services are loosely-coupled software components designed to support interoperable machineto-machine interaction over the Internet. To achieve such interoperability, web services are accesible through W3C web standards, independently of which language, operating system, or hardware platform they are developed. Due to these characteristics, simple web services can be combined in more complex ones. Choreographies are a distributed approach for composing web services. Compared to orchestrations, which have a centralized approach to distributed service management, the interaction among the choreographed services is collaborative with decentralized coordination.

Despite the advantages, choreography development, including the testing activities, is not consolidated. The goal of this research is to develop a testing framework to support Test-Driven Development (TDD) of choreographies. Rehearsal, the proposed framework, provides features for automating the testing of (i) atomic web services (unit testing); (ii) their integration in the choreography (integration testing); and (iii) part of or the entire choreography (acceptance testing).

These several levels of testing are implemented by using framework features such as the dynamic generation of web service clients, message interception, and the abstraction of the choreography into Java objects. In addition, Rehearsal supports important practices of TDD such as service mocking. To assess the developed framework, we conducted a qualitative exploratory study with Computer Science students. According to the results obtained, the features of Rehearsal were adequate for applying TDD to web service choreography development successfully.

Keywords: Automated testing, Test-Driven Development (TDD), Agile Methods, Web services, Web service choreographies. 


\section{Sumário}

Lista de Figuras $\quad$ xi

Lista de Tabelas $\quad$ xiii

1 Introdução $\quad 1$

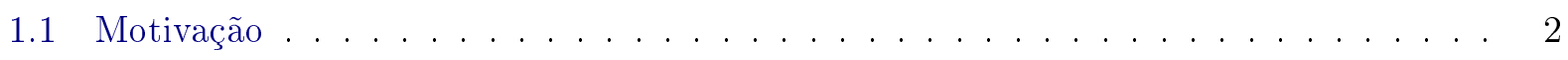

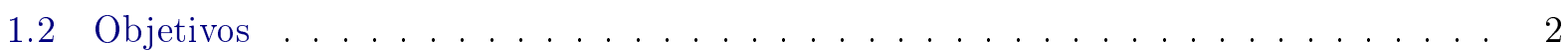

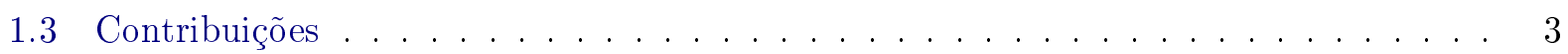

1.4 Organização do trabalho . . . . . . . . . . . . . . . . . . 3

2 Teste de software $\quad \mathbf{5}$

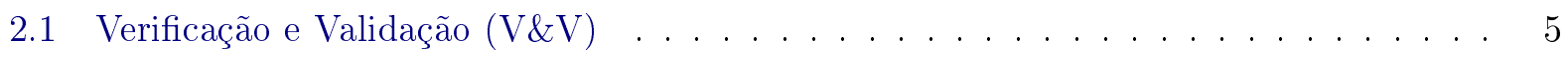

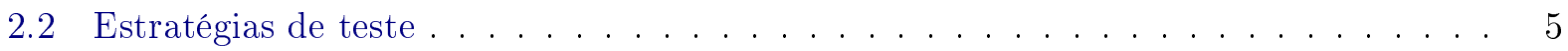

2.2 .1 Teste de unidade . . . . . . . . . . . . . . . . . . 5

2.2 .2 Teste de aceitação . . . . . . . . . . . . . . . . . . 6

2.2 .3 Teste de integração . . . . . . . . . . . . . . . . . . . . . . . 6

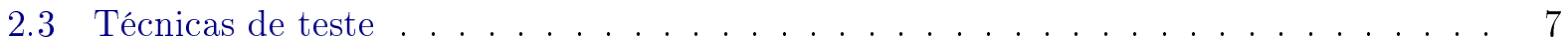

2.3 .1 Teste funcional $\ldots \ldots \ldots \ldots \ldots \ldots \ldots \ldots$

2.3 .2 Teste estrutural . . . . . . . . . . . . . . . . . . . 7

2.4 Objetos dublês . . . . . . . . . . . . . . . . . . . . 8

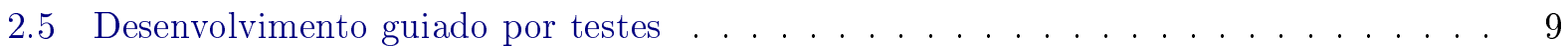

2.6 Considerações finais do capítulo . . . . . . . . . . . . . . . . . . . . . 10

3 Composição de serviços web $\quad 11$

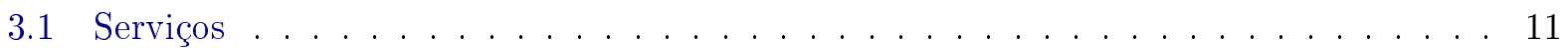

3.1 .1 Serviços Soap/WSDL . . . . . . . . . . . . . . 11

3.1 .2 Serviços REST . . . . . . . . . . . . . . . . . 12

3.2 Arquitetura orientada a serviços . . . . . . . . . . . . . . . . . . 13

3.3 Orquestração de serviços web . . . . . . . . . . . . . . . . . . 13

3.3.1 Business Process Execution Language (BPEL) . . . . . . . . . . . . . . . . . 14

3.3.2 Service Component Architecture (SCA) . . . . . . . . . . . . . . 15

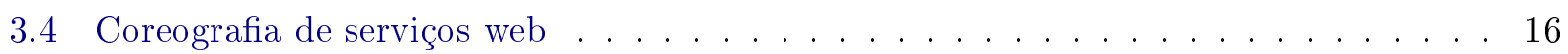

3.4 .1 Coreografia FutureMarket . . . . . . . . . . . . . . 17

3.5 Teste de composição de serviços . . . . . . . . . . . . . . . . . 19

3.5.1 Estratégias de teste . . . . . . . . . . . . . . . . . 19 
3.6 Considerações finais do capítulo . . . . . . . . . . . . . . . . . . 21

4 Trabalhos relacionados $\quad 23$

4.1 Teste de serviços atômicos . . . . . . . . . . . . . . . . . . 23

4.1 .1 Cliente de serviços . . . . . . . . . . . . . . . . . . . 23

4.1 .2 Repositório de serviços . . . . . . . . . . . . . . . . . . . . . 27

4.1 .3 Provedor de serviços . . . . . . . . . . . . . . . . . . 28

4.2 Teste de composições de coreografias de serviços web . . . . . . . . . . . . . . 28

4.2 .1 Pré-execução $($ pre-enactment $) \ldots \ldots \ldots \ldots \ldots$. . . . . . . . . . 29

4.2 .2 Pós-execução (pos-enactment) . . . . . . . . . . . . . . . . 30

4.3 Considerações finais do capítulo . . . . . . . . . . . . . . . . . . . . . 32

$5 \quad$ O arcabouço Rehearsal 33

5.1 Requisitos da Rehearsal . . . . . . . . . . . . . . . . . . . . . . 33

5.2 Geração dinâmica de clientes para serviços web . . . . . . . . . . . . . . . 34

5.2 .1 Suporte a serviços Soap/WSDL . . . . . . . . . . . . . . . . . . 35

5.2 .2 Suporte a serviços REST . . . . . . . . . . . . . . . . 38

5.3 Interceptador de mensagens . . . . . . . . . . . . . . . . . . . . 40

5.4 Emulação (Mocking) de serviços . . . . . . . . . . . . . . . . . . 42

5.5 Abstração da coreografia . . . . . . . . . . . . . . . . . . . . . 44

5.6 Execução de testes de conformidade . . . . . . . . . . . . . . . . . . 46

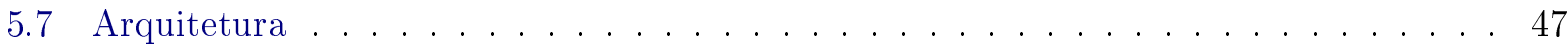

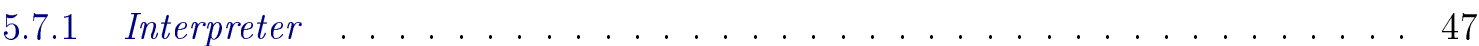

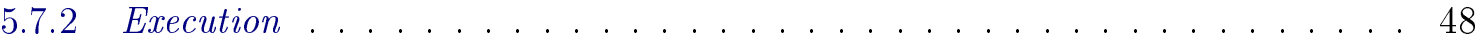

5.8 Exemplos de testes escritos com o Rehearsal . . . . . . . . . . . . . . . . . . . 48

5.9 Considerações finais do capítulo . . . . . . . . . . . . . . . . 56

6 Proposta de metodologia TDD para coreografias $\quad 57$

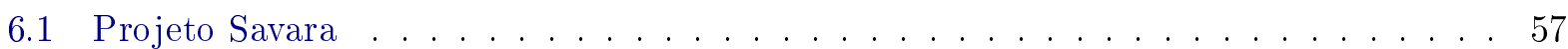

6.2 Uma proposta de metodologia TDD para coreografias . . . . . . . . . . . . . . 58

6.2.1 Fase 1: Criação ou adaptação de serviços web . . . . . . . . . . . . . . . 59

6.2.2 Fase 2: Integração de serviços para implementar os papéis da coreografia . . . 60

6.2.3 Fase 3: Integração dos papéis para implementar a coreografia . . . . . . . . . 60

6.2.4 Fase 4: Testes de aceitação e escalabilidade . . . . . . . . . . . . . . . 61

6.2 .5 Considerações finais do capítulo . . . . . . . . . . . . . . . . . . 61

7 Estudo exploratório $\quad 63$

7.1 Fases do estudo exploratório . . . . . . . . . . . . . . . . . . . 63

7.1.1 Fase 1: Avaliação da eficácia do Rehearsal e da metodologia . . . . . . . . . . 63

7.1.2 Fase 2: Avaliação da facilidade de utilização do Rehearsal e metodologia . . . 65

7.2 Organização do estudo exploratório . . . . . . . . . . . . . . . . . 66

7.3 Resultados qualitativos . . . . . . . . . . . . . . . . . . 67

7.3 .1 Avaliação do Rehearsal . . . . . . . . . . . . . . . . . . . . . . 69

7.3.2 Avaliação da proposta de metodologia TDD . . . . . . . . . . . . . . . . 73

7.4 Resultados quantitativos . . . . . . . . . . . . . . . . . 78 


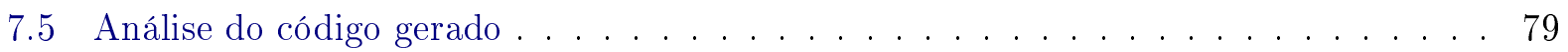

7.6 Considerações finais desse capítulo . . . . . . . . . . . . . . 79

8 Conclusão $\quad 81$

8.1 Considerações finais . . . . . . . . . . . . . . . . . . . . 81

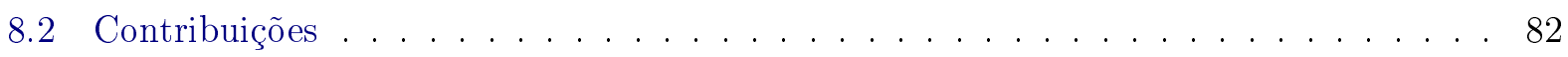

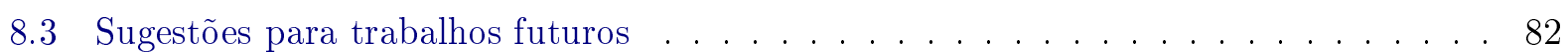

8.3 .1 Rehearsal . . . . . . . . . . . . . . . . . . . 82

8.3 .2 Metodologia TDD . . . . . . . . . . . . . . . . . . 83

8.3 .3 Avaliações do Rehearsal e metodologia . . . . . . . . . . . . . . . 83

$\begin{array}{lll}\text { A Exemplo de arquivo descritor para a coreografia FutureMarket } & 85\end{array}$

B Assessment proposal for the Rehearsal framework and TDD methodology for $\begin{array}{lr}\text { choreographies - Phase } 01 & 87\end{array}$

B.1 Change Record . . . . . . . . . . . . . . . . . . . . . . 87

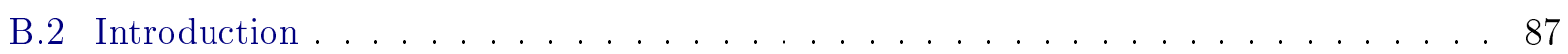

B.3 Exploratory study design $\ldots \ldots \ldots \ldots \ldots \ldots \ldots$

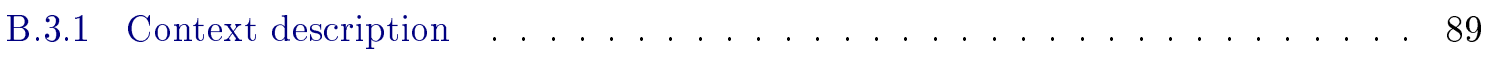

B.3.2 Subject Recruitment . . . . . . . . . . . . . . . . . . . . 89

B.3.3 Subject Training . . . . . . . . . . . . . . . . . . . . . 89

B.3.4 Unit of analysis . . . . . . . . . . . . . . . . . . 90

B.3.5 Development Tasks . . . . . . . . . . . . . . . . . . 92

B.4 Data Preparation and Collection . . . . . . . . . . . . . . . . 93

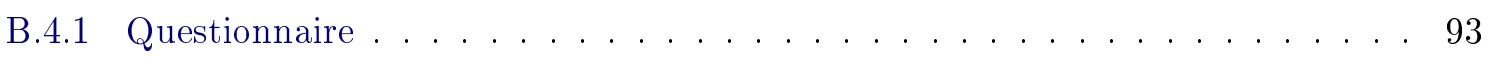

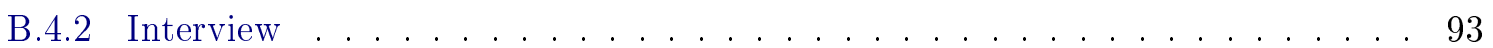

B.5 Data Analysis . . . . . . . . . . . . . . . . . . . . . . 94

B.5.1 RQ1: Do the Rehearsal features aid in the application of the proposed methodology steps? . . . . . . . . . . . . . . . . . . . . . . 95

B.5.2 RQ2: Does the proposed methodology provide adequate guidelines for developing a choreography? . . . . . . . . . . . . . . . 96

B.6 Study Limitations . . . . . . . . . . . . . . . . . . . . . . . . . 96

B.7 Schedule . . . . . . . . . . . . . . . . . . . . . . 97

B.8 Recruitment Questionnaire . . . . . . . . . . . . . . . . 98

B.9 Study Questionnaire . . . . . . . . . . . . . . . . . 101

$\begin{array}{ll}\text { Referências Bibliográficas } & 107\end{array}$ 


\section{Lista de Figuras}

3.1 Envelope Soap para requisição . . . . . . . . . . . . . . . . . . . . . . . 11

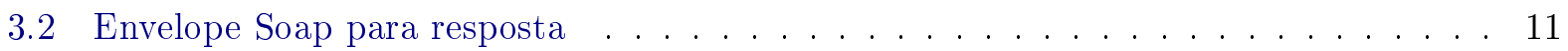

3.3 Triângulo de participantes e operações em SOA . . . . . . . . . . . . . . . 13

3.4 Exemplo de processo . . . . . . . . . . . . . . . . . . . . . . 14

3.5 Exemplo de assembly model em SCA [OAS11] . . . . . . . . . . . . . . 16

3.6 Orquestrações de serviços implementando papéis em uma coreografia [Pel03] . . . . . 17

3.7 Fluxo de compra da coreografia FutureMarket . . . . . . . . . . . . . . . . 19

3.8 Orquestração representando o papel customer . . . . . . . . . . . . . . . 20

4.1 Esqueleto de mensagem Soap gerado pelo soapUI [BBMP09] . . . . . . . . . . . . . . 24

4.2 Simulação de troca de mensagens no PI4SOA . . . . . . . . . . . . . . . . 29

5.1 Fluxo de execução para invocação de serviços Soap/WSDL. . . . . . . . . . . . 35

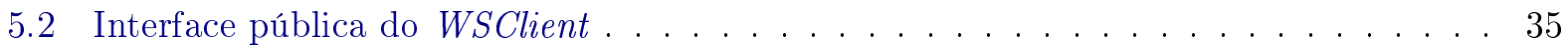

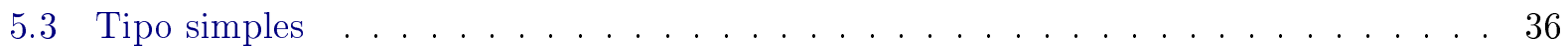

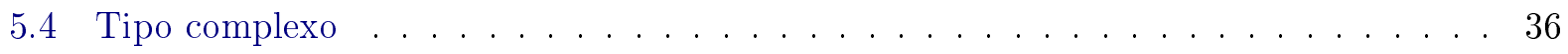

5.5 Envelope Soap de resposta . . . . . . . . . . . . . . . 36

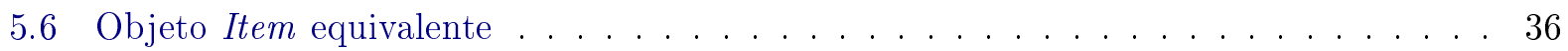

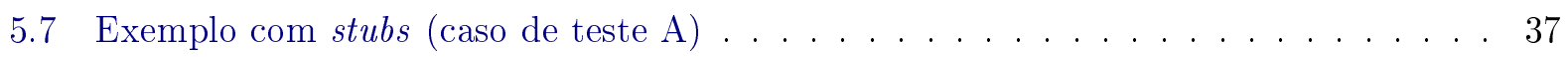

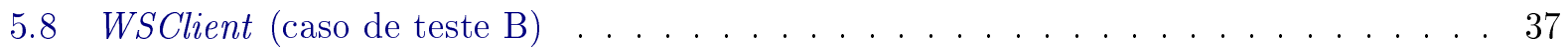

5.9 Invocação de uma operação de um serviço web . . . . . . . . . . . . . . . . . . . . . . . . . . . .

5.10 Ferramenta Item Explorer . . . . . . . . . . . . . . . . . . . . 38

5.11 Fluxo de execução para invocação de serviços REST . . . . . . . . . . . . . . . . . . . . . . . .

5.12 Interface pública do RSClient . . . . . . . . . . . . . . . . . . 39

5.13 RSClient: Exemplo de utilização . . . . . . . . . . . . . . . . . . . 39

5.14 Fluxo de interação para utilização do interceptador de mensagens . . . . . . . . . . . 40

5.15 Interface pública do Interceptador de mensagens . . . . . . . . . . . . . . . 41

5.16 Message Interceptor: Exemplo de utilização . . . . . . . . . . . . . . . . . . . 41

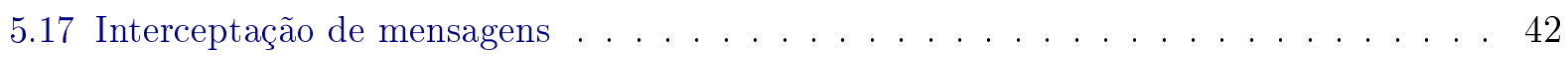

5.18 Fluxo de emulação de serviços . . . . . . . . . . . . . . . . . . . . . 42

5.19 Interface pública do WSMock . . . . . . . . . . . . . . . . . . . . . . . . . . . . . . . . . . . . . .

5.20 Criação e configuração de mock . . . . . . . . . . . . . . . . . . . 43

5.21 WSMock: Exemplo de utilização . . . . . . . . . . . . . . . . . . 44

5.22 Soap envelopes . . . . . . . . . . . . . . . . . . . . . . . 44

5.23 Interface pública da Abstração da Coreografia . . . . . . . . . . . . . . . . . . . 44 
5.24 Criação do objeto Choreography ． . . . . . . . . . . . . . . . . . 45

5.25 Exemplos de utilização da Abstração da Coreografia . . . . . . . . . . . . . . . . 46

5.26 Exemplo de aplicação de casos de conformidade . . . . . . . . . . . . . . . . . . 46

5.27 Arquitetura do Rehearsal . . . . . . . . . . . . . . . . . . . . . . . 47

6.1 Fases da metodologia . . . . . . . . . . . . . . . . . . 58

6.2 Exemplo de utilização do WSClient para especificação de um serviço . . . . . . . . . 60

7.1 Experiência dos participantes da Fase $1 \ldots \ldots \ldots$. . . . . . . . . . . 64

7.2 Experiência dos participantes da Fase $2 \ldots \ldots \ldots \ldots \ldots$. . . . . . . . . . . . . . .

7.3 Etapas do estudo exploratório. . . . . . . . . . . . . . . . 66

7.4 Exemplo de gráfico box plot . . . . . . . . . . . . . . . . . . . 67

7.5 Fase 1- Resultados de todas as perguntas . . . . . . . . . . . . . . . 68

7.6 Fase 2 - Resultados de todas as perguntas . . . . . . . . . . . . . . . 68

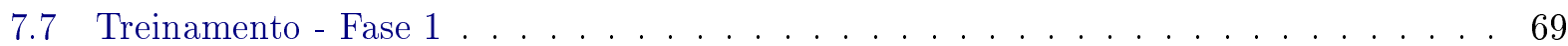

7.8 Treinamento - Fase $2 \ldots \ldots \ldots \ldots \ldots \ldots$

7.9 Resultados Grupo 1 - Fase $1 \ldots \ldots \ldots \ldots$. . . . . . . . . . . 70

7.10 Resultados Grupo 1 - Fase $2 \ldots \ldots \ldots$. . . . . . . . . . . 70

7.11 Resultados Grupo 2 - Fase $1 \ldots \ldots \ldots$. . . . . . . . . . . . . 71

7.12 Resultados Grupo 2 - Fase $2 \ldots \ldots \ldots$. . . . . . . . . . . . 71

7.13 Resultados Grupo 3 - Fase $1 \ldots \ldots \ldots$. . . . . . . . . . . . . . 72

7.14 Resultados Grupo 3 - Fase $2 \ldots \ldots$. . . . . . . . . . . . . . 72

7.15 Resultados Grupo 4 - Fase $1 \ldots \ldots \ldots \ldots$. . . . . . . . . . . . 73

7.16 Resultados Grupo 4 - Fase $2 \ldots \ldots \ldots$. . . . . . . . . . . 73

7.17 Resultados Grupo 5 - Fase $1 \ldots \ldots \ldots$. . . . . . . . . . . . . 74

7.18 Resultados Grupo 5 - Fase $2 \ldots \ldots \ldots$. . . . . . . . . . . . 74

7.19 Resultados Grupo 6 - Fase $1 \ldots \ldots \ldots$. . . . . . . . . . . . . 75

7.20 Resultados Grupo 6 - Fase $2 \ldots \ldots \ldots$. . . . . . . . . . . . 75

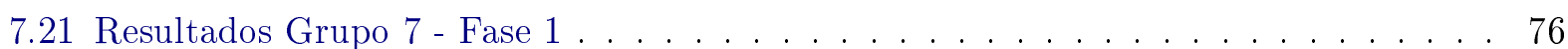

7.22 Resultados Grupo 7 - Fase $2 \ldots \ldots \ldots \ldots$. . . . . . . . . . . 76

7.23 Resultados Grupo 8 - Fase $1 \ldots \ldots$. . . . . . . . . . . . . . . 77

7.24 Resultados Grupo 8 - Fase $2 \ldots \ldots$. . . . . . . . . . . . . . 77

7.25 Resultados Grupo $9 \ldots \ldots \ldots \ldots \ldots \ldots$

B.1 Exploratory study phases. . . . . . . . . . . . . . . . . . . . 88

B.2 Global view of the Arrival at the airport choreography. . . . . . . . . . . . . . . 90

B.3 Process view of the Arrival at the airport choreography. . . . . . . . . . . . . . . . 91 


\section{Lista de Tabelas}

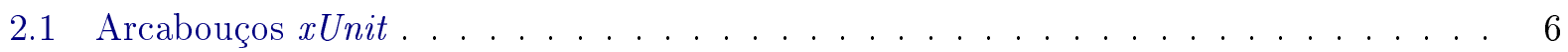

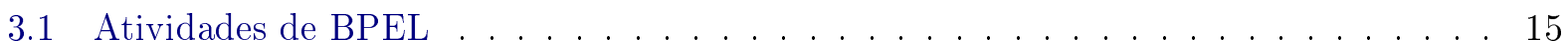

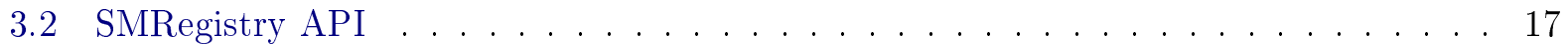

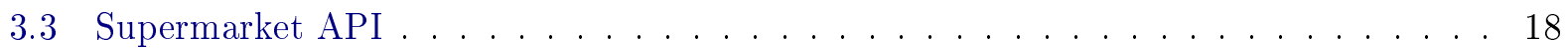

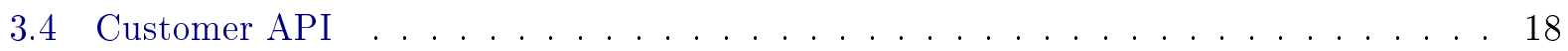

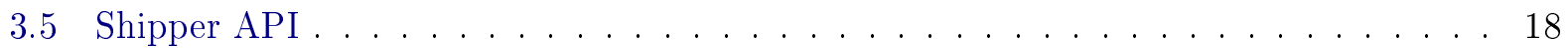

3.6 Estratégias de teste para composição de serviços . . . . . . . . . . . . . 20

5.1 Requisitos da Rehearsal . . . . . . . . . . . . . . . . . . . . . 34

5.2 Requisitos atendidos pelos trabalhos relacionados $\ldots \ldots \ldots \ldots \ldots$

6.1 Atividades internas de cada fase para cada cenário de desenvolvimento . . . . . . . . 59

7.1 Questões para avaliar o treinamento . . . . . . . . . . . . . 69

7.2 Perguntas para estudo do Grupo $1 \ldots \ldots \ldots$. . . . . . . . . . . 70

7.3 Perguntas para estudo do Grupo $2 \ldots \ldots \ldots \ldots \ldots$. . . . . . . . . . . . . . . . . . . .

7.4 Questões para avaliar o Grupo $3 \ldots \ldots \ldots \ldots \ldots \ldots \ldots$

7.5 Questões para avaliar o Grupo $4 \ldots \ldots \ldots \ldots \ldots \ldots$

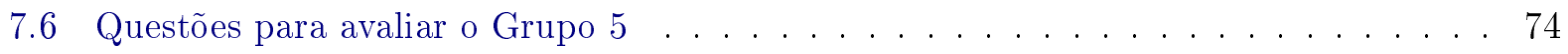

7.7 Questões para avaliar o Grupo $6 \ldots \ldots \ldots \ldots \ldots \ldots$

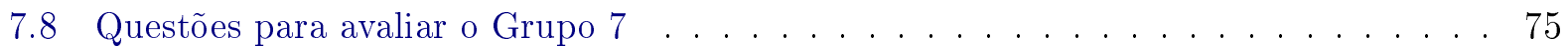

7.9 Questões para avaliar o Grupo $8 \ldots \ldots \ldots \ldots \ldots$

7.10 Questões para avaliar o Grupo $9 \ldots \ldots \ldots \ldots \ldots \ldots$

7.11 Experiência e Tempo gasto com o desenvolvimento . . . . . . . . . . 78

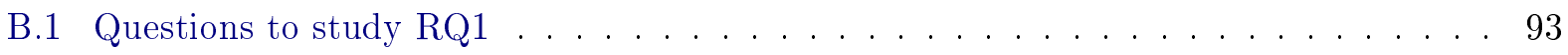

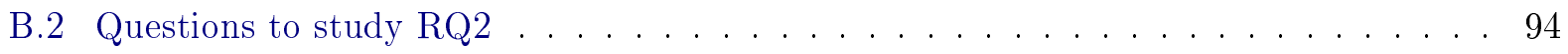

B.3 Questions to study the dynamic generation of web service client feature . . . . . 95

B.4 Questions to study the web service mocking feature . . . . . . . . . . . . 95

B.5 Questions to study the message interceptor feature . . . . . . . . . . . . . 95

B.6 Questions to study the abstraction of choreography feature . . . . . . . . . . . . 95

B.7 Questions to study the step 01 of the proposed methodology . . . . . . . . . . . 96

B.8 Questions to study the step 02 of the proposed methodology . . . . . . . . . . . . 96

B.9 Questions to study the step 03 of the proposed methodology . . . . . . . . . . 96

B.10 Questions to study the step 04 of the proposed methodology . . . . . . . . . . . . . 96 
B.11 Questions to study the acceptance of the proposed methodology . . . . . . . . . . . 96

B.12 Schedule . . . . . . . . . . . . . . . . . . . . . . . . 97 


\section{Capítulo 1}

\section{Introdução}

Computação Orientada a Serviços é considerada a nova geração de aplicações distribuídas, sendo amplamente adotada. Esse paradigma tem como objetivo promover a interoperabilidade entre sistemas de software heterogêneos, diminuindo, assim, o custo e a complexidade decorrentes da integração desses sistemas. Nesse contexto, a Arquitetura Orientada a Serviços (Service Oriented Architecture, SOA) consiste em um modelo arquitetural, que utiliza serviços web como os blocos de construção de aplicações para esse novo paradigma [Hew09].

Serviços web são componentes de software distribuídos que visam promover a comunicação interoperável entre os mais diferentes sistemas. Aplicações distribuídas podem ser desenvolvidas pela composição de serviços web. A habilidade de compor serviços atômicos efetivamente é um dos requisitos críticos para a aplicação dos conceitos fundamentais da computação orientada a serviços [Er107]. Do ponto de vista do usuário final, serviços compostos são visíveis da mesma forma que serviços atômicos e podem ser integrados em novas composições. A literatura apresenta duas abordagens principais para a composição de serviços web: orquestrações e coreografias.

Em uma orquestração, um nó central (orquestrador) coordena o fluxo de informação entre os demais serviços. Apesar da implementação e do gerenciamento desta abordagem serem mais simples, sua natureza centralizada é propensa a problemas de escalabilidade e tolerância a falhas. Como alternativa, coreografias de serviços foram propostas como uma solução decentralizada e escalável para a composição de serviços [GKB12]. Cada participante de uma coreografia desempenha um papel que determina seu comportamento na composição. A interação entre os serviços de uma coreografia dá-se de maneira colaborativa e a coordenação é decentralizada. Como resultado, coregrafias são boas arquiteturas para fluxos de negócio totalmente descentralizados [BBRW09].

O atendimento a pacientes em uma clínica médica é um bom exemplo de fluxo totalmente decentralizado de informação e pode ser modelado por um coreografia [BPRG09]. Normalmente, o atendimento a um paciente envolve os seguintes estágios: registro do paciente, consulta a um médico, exames e medicação. Cada um desses estágios pode ser executado ou apoiado por serviços web que podem se comunicar para implementar o fluxo de atendimento completo. Em uma orquestração, um serviço central controla o estágio de atendimento em que se encontra o paciente. Assim, o orquestrador é responsável por lidar com chamadas em paralelo, dado que muitos pacientes são atendidos em paralelo diariamente em uma clínica. Além disso, esse serviço central interage com os serviços utilizados pelos médicos, atendentes e enfermeiras que precisam extrair informações constantemente.

Dados o número de chamadas em paralelo, a natureza do fluxo e a quantidade de participantes envolvidos, o orquestrator pode se tornar um gargalo do sistema. Nesse cenário, coreografias podem ser uma alternativa mais adequada para a implementação deste fluxo. Cada participante (e.g., pacientes, atendentes, enfermeiras e médicos) pode ser associado a um serviço que desempenhe um determinado papel na coreografia. À medida que cada estágio do atendimento ao paciente se completa, o próximo serviço da interação recebe uma chamada diretamente do serviço atual. Ao contrário da orquestração, após a triagem ser completada, por exemplo, o serviço que desempenha o papel de enfermeira é notificado, executa sua regra de negócio e repassa uma mensagem para o 
serviço que representa o papel do médico. Este último extrai os resultados da triagem, deixando-os disponíveis para a posterior consulta do médico (ser humano).

Apesar de todos os benefícios promovidos pelo uso de coreografias, o teste automatizado de coreografias é uma tarefa desafiadora. Testes automatizados são programas ou scripts que exercitam funcionalidades do software testado e fazem verificações automáticas nos efeitos colaterais obtidos [BK08]. Assim como para todos os sistemas de software, o teste automatizado de coreografias faz-se necessário para atribuir maior qualidade aos fluxos de negócios representados na coreografia. No entanto, o caráter inter-organizacional de SOA introduz obstáculos ao teste automatizado e até mesmo manual de coreografias, tais como a impossibilidade de se invocar alguns serviços em modo de teste. Como consequência, alguns serviços candidatos à coreografia não podem ser testados isoladamente. Além disso, a dinamicidade, característica inerente a SOA, e a natureza descentralizada de coreografias dificultam a validação das mensagens trocadas pelos serviços participantes. Devido a essas questões, há poucas ferramentas e técnicas para o teste automatizado de coreografias [BMS07, CDP09].

\subsection{Motivação}

Apesar da existência de linguagens para a modelagem de coreografias, tais como: Web Service Choreography Interface (WSCI) ${ }^{1}$, Web Service Choreography Description Language (WS-CDL) ${ }^{2}$ e Business Process Model and Notation (BPMN2) ${ }^{3}$, nenhuma delas foi amplamente adotada como padrão para especificação de coreografias de serviços. Esse cenário repete-se para algumas propostas de metodologias para desenvolvimento de coreografias, como por exemplo o projeto Savara ${ }^{4}$. Assim, o processo de desenvolvimento de coreografias, incluindo as atividades de testes, não é disciplinado. Assim, muitas coreografias reais acabam sendo implementadas utilizando-se soluções ad hoc.

Algumas ferramentas (e.g., SoapUI ${ }^{5}$ ) vêm sendo desenvolvidas para o teste automatizado de serviços web atômicos. Do ponto de vista de usuários finais, composições de serviços são acessíveis como serviços atômicos. Logo, essas ferramentas podem ser utilizadas para validar coreografias. Porém, nessa abordagem, a coreografia é testada como uma "caixa-preta", impedindo que mensagens trocadas internamente sejam também validadas. Existem trabalhos [Pi410, $\left.\mathrm{WZZ}^{+} 10, \mathrm{ZPX}^{+} 10\right]$ que têm como objetivo validar essa troca de mensagens e modelos que descrevem uma coreografia por meio de simulação. Esse mecanismo possibilita a detecção de problemas de modelagem, porém é insuficiente para a detecção de problemas e falhas que podem ocorrer apenas com a real execução da coreografia.

A falta de metodologias, ferramentas, linguagens de modelagem, arcabouços e middlewares de suporte são obstáculos para as coreografias serem mais adotadas. Algumas iniciativas tais como os projetos CHOReOS $^{6}$ e Baile $^{7}$ visam estudar e desenvolver ferramentas para a utilização de coreografias de serviços web em ambientes de larga-escala. Em ambos os projetos, o arcabouço Rehearsal pertence a linhas de pesquisa relacionadas à Verificação e Validação (V\&V) de coreografias e tem como objetivo promover a utilização de uma abordagem guiada por testes para coreografias, a fim de agregar mais disciplina e qualidade ao seu processo de desenvolvimento.

\subsection{Objetivos}

O principal objetivo deste trabalho consiste em propor e desenvolver o Rehearsal, um arcabouço para o teste automatizado de coreografias que facilita o Desenvolvimento Guiado por Testes [Bec03]

\footnotetext{
${ }^{1}$ WSCI: http://www.w3.org/TR/wsci

${ }^{2}$ WS-CDL: http://www.w3.org/TR/ws-cdl-10

${ }^{3}$ BPMN2: http://www.omg.org/spec/BPMN/2.0

${ }^{4}$ Projeto Savara: http://www.jboss.org/savara

${ }^{5}$ SoapUI: http://www.soapui.org

${ }^{6}$ CHOReOS: http://www.choreos.eu

${ }^{7}$ Baile: http://ccsl.ime.usp.br/baile
} 
de coreografias de serviços web. Com esse arcabouço, durante o desenvolvimento, testes automatizados poderão ser aplicados (1) em serviços isolados (teste de unidade); (2) nas mensagens trocadas quando esses serviços forem compostos (teste de integração) e (3) na coreografia criada (teste de aceitação). Para fornecer essas estratégias de teste, o Rehearsal oferece as seguintes funcionalidades:

- Geração dinâmica de clientes para serviços web. A partir de uma URL apontando para a interface de um serviço web, as operações desse serviço podem ser invocadas dinamicamente, sem a necessidade de pré-compilação de stubs.

- Interceptador de mensagens. Por meio dessa funcionalidade, mensagens trocadas pelos serviços dentro da coreografia podem ser interceptadas, armazenadas e validadas, facilitando assim o teste de integração em coreografias.

- Emulação (Mocking) de serviços. Rehearsal fornece uma funcionalidade para criação de mocks [Mes07] de serviços web. Por meio dessa funcionalidade, operações de serviços reais podem ser emuladas, simulando, assim, cenários regulares e de falhas de um serviço web real.

- Abstração da coreografia. Para facilitar a utilização de todas as demais funcionalidades do Rehearsal, os elementos de uma coreografia podem ser mapeados em objetos da linguagem de programação Java. Assim, através desses objetos, o desenvolvedor pode manipular mais facilmente serviços, mensagens trocadas e os papéis da coreografia em teste.

\subsection{Contribuições}

As principais contribuições deste trabalho são:

- Um arcabouço de software livre para automatização de testes de unidade, integração e aceitação de coreografias;

- Uma proposta de metodologia para aplicação de Desenvolvimento Guiado por Testes para coreografias de serviços web;

- Um pacote com os resultados e elementos de um estudo exploratório para avaliar o arcabouço e a proposta de metodologia desenvolvida;

- Exemplos de coreografias e serviços web desenvolvidos durante o projeto;

- Publicações científicas e documentação para programadores sobre o arcabouço e a proposta de metodologia desenvolvida.

\subsection{Organização do trabalho}

No Capítulo 2 são apresentados os principais conceitos e terminologias referentes ao teste de software, no contexto deste trabalho.

De modo similar, o Capítulo 3, apresenta os principais conceitos e elementos relacionados à composição de serviços, além de alternativas para o teste de coreografias.

No Capítulo 4, são discutidos os principais trabalhos relacionados ao teste automatizado de coreografias de serviços.

No Capítulo 5, são apresentadas as principais funcionalidades, exemplos de utilização e a arquitetura do Rehearsal.

No Capítulo 6, são apresentadas as fases da nossa proposta de metodologia para aplicação de Desenvolvimento Guiado por Testes em coreografias de serviços web.

Um estudo exploratório foi conduzido a fim de avaliar o arcabouço e a proposta de metodologia. O protocolo e os resultados deste estudo são apresentados no Capítulo 7.

Por fim, no Capítulo 8, as conclusões e sugestões para trabalhos futuros são apresentadas. 


\section{Capítulo 2}

\section{Teste de software}

Teste de software é uma extensa área do desenvolvimento de software. Dependendo da comunidade de software, da cultura e do processo de desenvolvimento adotado e de outras peculiaridades, mesmos termos e conceitos relacionados ao teste de software podem assumir diferentes interpretações. Por essa razão, este capítulo apresenta os principais termos e conceitos e seus respectivos significados no contexto deste trabalho. Embora este capítulo aborde o teste de sistemas tradicionais (modelo cliente-servidor), seu entendimento faz-se necessário para uma maior compreensão das abordagens relacionadas a teste de coreografia de serviços que serão apresentadas.

\subsection{Verificação e Validação (V\&V)}

Verificação e Validação corresponde a um processo disciplinado que tem como objetivo garantir qualidade em todas as fases do desenvolvimento de software [AM04]. Verificação corresponde ao conjunto de atividades que visam garantir, por meio de padrões, processos e especificações prédefinidas, o correto desenvolvimento do software. Por outro lado, validação corresponde ao conjunto de atividades que visam analisar se o software desenvolvido atende aos requisitos do cliente. Boehm ([Som03] apud [Boe79]) define atividades de V\&V por meio das seguintes questões:

- Verificação: Estamos construindo o software corretamente?

- Validação: Estamos construindo o software correto?

Assim, as atividades pertencentes a $\mathrm{V} \& \mathrm{~V}$ não se limitam à disciplina de teste de software. $\mathrm{O}$ processo de $\mathrm{V} \& \mathrm{~V}$ pode envolver muitas outras atividades, tais como verificações formais de projeto e código, auditorias, monitoramento de desempenho da aplicação, revisão da documentação e análise dos algoritmos utilizados. Este trabalho está focado nas atividades referentes ao teste de software. Estratégias, técnicas e características dessa disciplina são apresentadas nas próximas seções deste capítulo.

\subsection{Estratégias de teste}

Durante o desenvolvimento de um projeto de software, diferentes estratégias de testes podem ser aplicadas. Independente do processo de desenvolvimento utilizado, é comum a utilização das estratégias de testes apresentadas nas subseções abaixo.

\subsubsection{Teste de unidade}

O objetivo desse tipo de teste é verificar o correto funcionamento da menor unidade de software, que pode ser um método ou até mesmo uma classe simples, presente no código fonte. Assim, esses testes são escritos pelos desenvolvedores do software. Testes de unidade não são diretamente 
relacionados aos requisitos do projeto, exceto quando algum elemento chave da lógica de negócio é encapsulado em uma classe ou método específico [Mes07].

Testes de unidade ajudam a testar uma responsabilidade de forma isolada e independente, isto é, em caso de falhas, o desenvolvedor, por meio do teste de unidade que falhou, consegue identificar mais facilmente qual método ou classe não está funcionando corretamente. Dado que esses testes são aplicados frequentemente durante o desenvolvimento, é essencial que estes sejam automatizados [Mes07]. A Tabela 2.1 apresenta alguns arcabouços (xUnit) para escrita e execução de teste de unidade para diferentes linguagens de programação.

\begin{tabular}{|l|l|l|l|}
\hline Nome & Linguagem & URL & Licença \\
\hline \hline JUnit & Java & http://junit.sourceforge.net & Common Public License - v 1.0 \\
TestNG & Java & http://testng.org & Apache 2.0 \\
CxxTest & C ++ & http://cxxtest.com & LGPL \\
CUnit & C & http://cunit.sourceforge.net & LGPL \\
Rspec & Ruby & http://rspec.info & MIT License \\
Nose & Pynthon & http://readthedocs.org/docs/nose & LGPL \\
ScalaTest & Scala & http://www.scalatest.org/ & Apache 2.0 \\
\hline
\end{tabular}

Tabela 2.1: Arcabouços xUnit

O primeiro arcabouço $x$ Unit foi o SUnit [Bec94], criado por Kent Beck em 1994 para o teste automatizado de programas desenvolvidos em Smalltalk. Este arcabouço é utilizado até hoje, sendo considerado uma referência de implementação para alguns dos arcabouços apresentados na tabela 2.1. Em 1998, por exemplo, Kent Beck e Erick Gama desenvolveram o arcabouço JUnit, utilizado no teste de programas em Java, baseando-se no SUnit [Ber11]. Embora inicialmente projetados apenas para o teste de unidade, muitas vezes, testes mais complexos, como integração ou aceitação, acabam sendo escritos utilizando os arcabouços $x$ Unit.

\subsubsection{Teste de aceitação}

O objetivo dessa estratégia de teste é verificar o correto funcionamento de um sistema ou funcionalidade completa. Normalmente, testes de aceitação são escritos com base em cenários de execução derivados de casos de uso, documentos de requisitos ou histórias de usuário que são especificados por clientes. Diferentemente dos testes de unidade, esses testes não dependem da implementação do sistema.

Em um teste de aceitação, o sistema é testado executando-se funcionalidades da maneira como são executadas pelo usuário final. Nesse processo, o ambiente de testes deve ser o mais próximo possível do ambiente de produção. Logo, todas ou pelo menos muitas camadas do sistema (interface gráfica, banco de dados, controladores) acabam sendo exercitadas [Mes07]. Por conta disso, esses testes tendem a ser mais lentos que outras estratégias de testes.

\subsubsection{Teste de integração}

Testes de integração são testes que possuem características de ambas estratégias mencionadas acima. O objetivo dessa estratégia de teste é identificar problemas que são gerados quando unidades já testadas isoladamente são integradas. Para isso, esses testes verificam as interfaces e interações dessas unidades. Um conjunto de testes de integração deve ser construído com intuito de exercitar as interações e interfaces ao invés das funcionalidades das unidades de software [Del97].

Devido a essas características, testes de integração são também conhecidos como testes de componentes, pois visam verificar a interação entre componentes (e.g., grupo de classes) que produzem coletivamente alguma funcionalidade ou serviço [Mes07]. Algumas estratégias são propostas para a integração desses componentes [Pre01]:

- Top-down. A integração nesse caso é conduzida a partir do módulo principal do sistema. Inicialmente, todos os componentes dos quais esse módulo depende são emulados (mocked). 
Em seguida, as dependências emuladas são incrementalmente substituídas pelos componentes reais. A cada substituição, testes de integração são aplicados para validar o correto funcionamento do sistema ou funcionalidade. Esse processo é repetido até que todas as dependências reais sejam integradas.

- Bottom-up. Nessa abordagem, a integração é iniciada a partir do módulos atômicos (unidades de software). Esses componentes são agrupados em aglomerados (clusters). Em seguida, a integração intra-aglomerados é conduzida. Quando todos os componentes de um aglomerado forem integrados, o aglomerado é integrado a outro aglomerado.

- Big bang. Todos os componentes reais são integrados de uma vez e testes de integração e/ou aceitação são conduzidos no sistema ou na funcionalidade testada.

\subsection{Técnicas de teste}

Dependendo dos objetivos do teste, disponibilidade dos recursos humanos e de software e outros fatores relacionados, as estratégias de testes previamente apresentadas são combinadas com diferentes técnicas de testes. A seguir são apresentadas duas técnicas muito utilizadas no teste de software do tipo cliente-servidor.

\subsubsection{Teste funcional}

No teste funcional, também conhecido com teste de caixa-preta, o programa em teste (e.g., método, classe ou sistema) é tomado com uma entidade isolada ("caixa-preta"), sendo sua implementação interna ignorada [Mye04]. Assim, quando valores de entrada, válidos e inválidos, são fornecidos para o programa em questão, o teste funcional apenas verifica se os valores de saída do programa estão em conformidade com os objetivos do teste.

A fim de detectar eventuais problemas do programa que está sendo testado, testes funcionais poderiam ser aplicados utilizando todas as entradas possíveis para o programa. Esse tipo de teste é chamado de teste exaustivo [Mye04]. No entanto, o domínio de entrada pode ser infinito ou muito grande, inviabilizando a execução do teste [DMJ07]. Assim, critérios de teste como o "particionamento de classes de equivalência" e "análise do valor limite" foram propostos como alternativas sistemáticas para o teste funcional [DMJ07].

No particionamento de classes de equivalência, o domínio de entradas de um sistema é dividido em classes de equivalência. Cada elemento de uma classe é tratado da mesma forma quando fornecido ao sistema. Assim, pode-se considerar que o elemento utilizado no teste é um representante daquela classe de equivalência. Logo, não há necessidade de se testar o sistema utilizando os demais elementos da classe.

De maneira complementar, o critério de análise do valor limite pode ser utilizado. A objetivo desse critério é testar os sistemas utilizando os valores de entradas acima ou abaixo do limite das classes de equivalência. Por exemplo, se uma classe de equivalência for válida no intervalo [-1.0 e +1.0], possíveis valores a serem utilizados na análise do valor limite seriam -1.0 $+1.0,-1.01$ e +1.01 .

\subsubsection{Teste estrutural}

No teste estrutural, também conhecido como teste de caixa-branca, aspectos da estrutura interna do sistema, como o fluxo lógico e de dados, são verificados e validados [Mye04]. Em geral, na maioria dos critérios de teste estrutural, o programa é representado por um grafo conhecido como "Grafo de Fluxo de Controle" (Control Flow Graph, CFG) [DMJ07].

Assim, um programa $P$ é representado por um CFG $G=(N, E, s)$, um grafo orientado, com um único nó de entrada $s \in N$ e um único nó de saída $o \in N$. Cada vértice $(\mathrm{N})$ representa um bloco indivisível de comandos do programa, sendo as arestas (E) possíveis desvios de um bloco a 
outro. Em cada bloco de comando, uma vez que o primeiro comando interno do bloco é executado, todos os demais são executados sequencialmente. Além disso, não existe desvio de execução para nenhum comando do bloco.

Com base nos elementos de um CFG, os seguintes tipos de critérios de teste estrutural podem ser definidos [DMJ07]:

- Critérios baseados na complexidade. Nesses critérios, informações sobre a complexidade do programa são utilizadas. Uma métrica muito utilizada é a complexidade ciclomática do CFG, que representa a complexidade lógica do programa. O valor da complexidade ciclomática corresponde ao número de caminhos linearmente independentes pertencentes ao CFG. Assim, casos de testes para esse tipo de critério visam cobrir esses caminhos. Em termos de CFG, um caminho é linearmente independente se sua execução incluir pelo menos um arco do grafo que ainda não havia sido visitado em execuções anteriores.

- Critérios baseados em fluxo de controle. Esses critérios baseiam-se em elementos de controle do CFG. Assim, casos de testes criados seguindo esse tipo de critério visam cobrir: (i) Todos-Nós ou seja, todos os comandos do programa; (ii) Todas-Arestas, ou seja, todos os desvios de execução do programa; ou (iii) Todos-Caminhos, todos os possíveis cenários de execução do programa, o que na maioria das vezes é impraticável.

- Critérios baseados em fluxo de dados. Informações sobre a análise de fluxo de dados são utilizadas nesses critérios. Para a derivação dos casos de testes, esse tipo de critério baseia-se nas associações entre a definição de uma variável e seus possíveis usos subsequentes. Os usos podem ser classificados em c-uso ou p-uso. O primeiro afeta diretamente o valor de uma computação (e.g., lenght ++ ), enquanto o segundo, afeta o diretamente o fluxo de controle, (e.g., $i !=42)$. Neste último caso, a execução segue um determinado fluxo, dependendo do valor da variável $i$.

\subsection{Objetos dublês}

Durante o teste de software, frequentemente, o sistema em teste depende de muitos componentes de software (e.g., classes, bancos de dados, outros sistemas) que não podem ser executados em "modo" de teste. Além disso, algumas vezes, invocar as dependências reais de um sistema deixa o testes muito mais lentos. Nessas situações, dependências reais podem ser substituídas por dublês de teste, objetos que podem prover a mesma interface que as dependências reais.

Além dessas vantagens, a utilização de objetos dublês auxilia a isolar o trecho de código testado do restante do ambiente. Dessa maneira, valida-se o trecho código testado, assumindo que todas suas dependências estão corretas [Ber11]. Segundo Meszaros [Mes07], existem cinco categorias de objetos dublês:

- Objetos Tolos (Dummy objects). Esses objetos são fornecidos como parâmetros de um método, porém, eles nunca são usados. A presença desses objetos faz-se necessária apenas para que métodos sejam invocados. Alguns métodos do sistema em teste exigem que certos objetos parâmetros estejam presentes quando invocados. Caso esses objetos não sejam utilizados pelo sistema testado nem pelos testes, eles são considerados objetos tolos.

- Objetos Falsificados (Fake objects). Esses objetos fornecem as mesmas funcionalidades de uma dependência real, porém utilizando uma implementação simplificada. Por exemplo, durante os testes, um banco de dados real pode ser substituído por um objeto falsificado, que é apenas um banco de dados em memória.

- Stub objects. São objetos pré-programados para retornar respostas pré-definidas para chamadas recebidas nos testes. Essas respostas podem ser definidas como válidas ou inválidas. O termo Stub pode ser utilizado para representar uma implementação temporária que é utilizada 
até que a implementação real esteja disponível. O objetivo da utilização de objetos Stub é emular o estado interno de um sistema, classe ou método. Por exemplo, um objeto Stub criado para emular um servidor de email pode guardar informações de quantas e quais mensagens foram enviadas [Fow07].

- Objetos Espiões (Spy object). São objetos Stub que também fornecem mecanismos para captura das respostas dos Stubs para uma posterior validação.

- Objetos Emulados (Mock Objects). São objetos pré-programados para dar respostas prédefinidas para chamadas recebidas nos testes. Porém, diferentemente dos Stubs, o objetivo da utilização dos Mocks é emular o comportamento de um sistema, classe ou método [Fow07]. Por exemplo, um objeto Mock criado para emular um sistema para consulta de estoque de mercadorias pode ser configurado para responder a quantidade de 50 exemplares sempre que um determinado produto é consultado. No entanto, nenhum estado é guardado sobre chamadas anteriores.

\subsection{Desenvolvimento guiado por testes}

Desenvolvimento guiado por testes (Test-Driven Development, TDD) consiste em um técnica de projeto que guia o desenvolvimento de software por meio de testes automatizados [Bec03, Fow11]. TDD pode ser definido por meio dos seguintes passos iterativos:

1. Escreva um teste automatizado para a próxima funcionalidade a ser adicionada ao sistema;

2. Execute todos os testes e veja o teste recém criado falhar;

3. Implemente o código funcional mais simples possível para fazer o novo teste passar;

4. Execute todos os testes e veja todos eles passarem;

5. Refatore o código antigo e recém criado para melhorar sua qualidade.

No terceiro passo, a ação de implementar o código funcional mais simples possível é conhecido pelos praticantes de TDD como passos de bebê (baby steps). Esse passo da prática de TDD acaba sendo muitas vezes compreendido erroneamente. Na utilização de passos de bebê, o codigo funcional mais simples deve corresponder à solução, e não à modificação, mais simples possível para fazer os testes passarem. Muitas vezes desenvolvedores acabam por implementar a modificação mais simples ao invés de uma solução mais genérica, prejudicando assim, a arquitetura do software [Ani12].

No último passo, refatoração refere-se a um processo de modificação realizado em uma aplicação de software visando melhorar sua estrutura interna sem alterar seu comportamento externo (interface). De acordo com Fowler [Fow99], refatoração é uma maneira disciplinada de deixar o código da aplicação mais claro, minimizando, assim, o aparecimento de novas falhas e melhorando o projeto do código-fonte após sua escrita.

Além desses passos, de acordo com Astels [Ast03], ao aplicar TDD, os desenvolvedores devem aplicar princípios como: (i) manter um vasto conjunto de testes de programador; (ii) apenas implantar, em ambiente de produção, código que possua testes associados. Um pouco diferente de testes de unidade, testes de programador são testes que são escritos para se definir o que deve ser implementado. Esses testes são similares a uma especificação funcional executável, dado que ajudam os desenvolvedores a entender por que determinada função é necessária, como deve ser chamada (interface), e quais são os seus resultados esperados (retorno) [Jef12].

Ter testes automatizados associados ao código-fonte dá ao desenvolvedor confiança e coragem para realizar mudanças e detectar imediatamente (ou em um curto período de tempo) eventuais problemas que foram introduzidos. Desse modo, com ausência de testes automatizados, não é possível garantir que um código implantado em ambiente de produção funcione corretamente. Dada essa 
importância, em Programação Extrema (eXtreme Programming, XP) [Bec00], uma funcionalidade é considerada inexistente, caso não haja testes automatizados associados a ela.

Sendo uma técnica de projeto, TDD não é apenas uma técnica de teste, mas também um processo de aprendizado. Durante a aplicação de diferentes tipos de teste, o time de desenvolvimento pode esclarecer e entender expectativas do cliente para, então, refinar os requisitos do sistema [FP09].

\subsection{Considerações finais do capítulo}

Neste capítulo, foram apresentadas as principais estratégias e técnicas de testes para sistemas tradicionais de software, ou seja, do tipo cliente-servidor. Embora o foco deste trabalho esteja voltado para o teste automatizado de composição de serviços web, o entendimento dessas técnicas e estratégias faz-se necessário para a compreensão dos próximos capítulos desta dissertação.

Conforme apresentado na Seção 1.2, um dos objetivo do Rehearsal é facilitar o uso de TDD em coreografias. Por esta razão, esse foi um dos tópicos cobertos neste capítulo. O capítulo também apresenta diferentes tipos de objetos dublês, que são práticas inerentes ao uso de TDD. Com base nesses conceitos, uma proposta de metodologia TDD para coreografias é apresentada no capítulo 6 .

No próximo capítulo, inicialmente, serão apresentados alguns conceitos chave relacionados à composição de serviços web. Então, serão apresentadas abordagens para o teste de aplicações SOA, que foram derivadas a partir das estratégias e técnicas apresentadas neste capítulo. 


\section{Capítulo 3}

\section{Composição de serviços web}

No contexto de Computação Orientada a Serviços, o elemento central deste novo paradigma é o serviço. Assim, neste capítulo, as principais características de serviços web e REST serão apresentadas detalhadamente. Em seguida, discutiremos como serviços web são utilizados seguindo as diretrizes da Arquitetura Orientada a Serviços (Service Oriented Architecture, SOA) e quais são os stakeholders envolvidos neste modelo arquitetural. Devido às suas características interoperáveis, serviços web simples podem ser compostos para formar serviços mais completos. Neste capítulo, apresentamos duas abordagens para composição de serviços e algumas alternativas para testar estas abordagens.

\subsection{Serviços}

No contexto de SOA, serviços web são considerados os blocos de construção de aplicações [Hew09]. Nesta seção, apresentamos serviços do tipo Soap/WSDL e REST. Embora serviços REST sejam popularmente chamados de serviços web, de acordo com a W3C $\left[\mathrm{BHM}^{+} 04\right]$, este termo é apenas utilizado para serviços que utilizam o protocolo Soap e são especificados via uma interface WSDL. No entanto, dado que o Rehearsal fornece mecanismos para o o teste de serviços desenvolvidos usando REST ou Soap/WSDL, apresentaremos ambas as tecnologias.

\subsubsection{Serviços Soap/WSDL}

De acordo com a W3C $\left[\mathrm{BHM}^{+} 04\right]$, um serviço web é um componente de software projetado para favorecer a comunicação interoperável entre máquinas, utilizando protocolos web. A troca de mensagens se dá por meio do uso do Simple Object Access Protocol (SOAP), normalmente sob o protocolo HTTP. Apesar do significado do nome, a partir da sua versão 1.2, Soap não é mais considerado um protocolo, mas um arcabouço para o empacotamento, processamento e envio de mensagens via XML. Assim, serviços web trocam mensagens seguindo as diretrizes de Soap. Um envelope (mensagem) Soap representa a requisição ou resposta à operação de um serviço, contendo, também, os tipos de dados e valores envolvidos na operação.

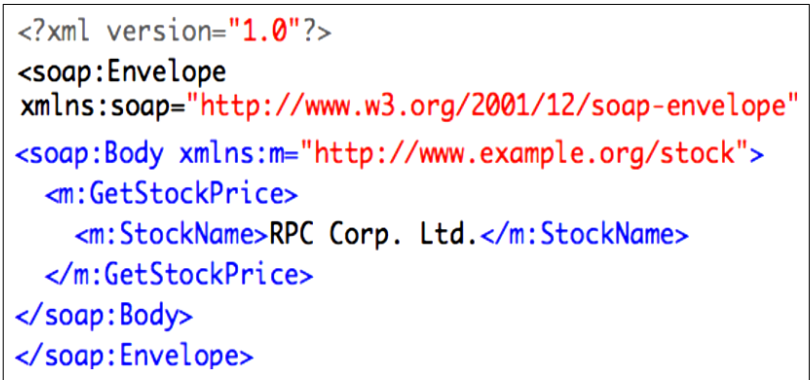

Figura 3.1: Envelope Soap para requisição

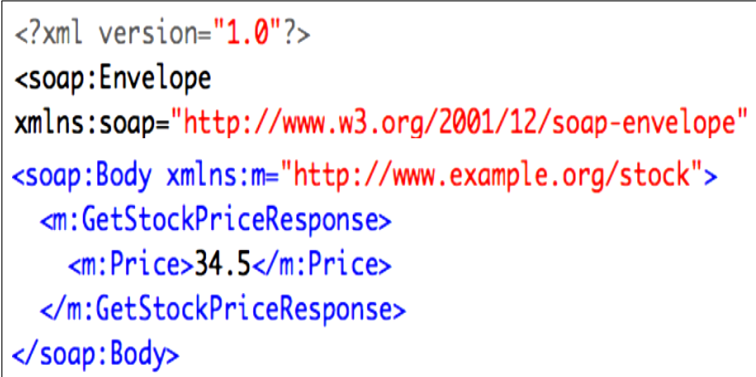

Figura 3.2: Envelope Soap para resposta 
As Figuras 3.1 e 3.2 apresentam exemplos de um envelope Soap de requisição e resposta, respectivamente. Na primeira figura, a operação GetStockPrice é invocada, passando-se como parâmetro uma String que representa o nome da ação (StockName). Na segunda figura, temos a resposta dessa operação, que neste caso, é o valor da ação consultada. Vale ressaltar que, neste exemplo, tanto os parâmetros de entrada quanto o retorno da operação são tipos primitivos (String e double). No entanto, em um envelope Soap tipos complexos também podem ser utilizados, por exemplo, objetos com atributos.

Um serviço web é descrito por meio de uma interface especificada em WSDL (Web Service Description Language), que é acessível por meio de um endpoint. Um especificação WSDL é representada por um arquivo XML que descreve as operações fornecidas por um serviço, assim como tipos de dados necessários para se invocar essas operações. Além disso, em uma especificação WSDL, um elemento denominado portType indica o endereço do serviços na rede e outras informações necessárias para a invocação (binding) do serviço. Do ponto de vista de um fluxo de negócio, a interface WSDL de um serviço é considerada o contrato do serviço.

\subsubsection{Serviços REST}

Uma das vantagens decorrentes da utilização de serviços Soap/WSDL é a interoperabilidade alcançada na comunicação com esses serviços. Além disso, por meio da especificação WSDL, podem-se construir facilmente clientes para serviços, dado que os tipos de dados para troca de mensagens estão formalmente descritos. Entretanto, apesar dessas vantagens, mensagens Soap podem ser extensas e, como consequência, sua manipulação pode acarretar em problemas de desempenho. Por exemplo, o mapeamento de XML em estruturas de dados em memória pode ser problemático e é a principal causa de problemas de desempenho [PZL08].

Devido a essas questões, em alguns casos, serviços REST ou Restful podem ser alternativas a serviços web Soap/WSDL. REST é o acrônimo de REpresentational State Transfer. Inicialmente, REST foi proposto como um estilo arquitetural para o desenvolvimento de sistemas hipermídia de grande escala. Porém, devido aos princípios apresentados abaixo, REST começou a ser usado como serviço web [PZL08].

- Recursos identificados. Um serviço REST expõe seus recursos via Internet. Um recurso pode ser, por exemplo, um livro em um serviço de livraria virtual. Independente do que representa, um recurso sempre contém um identificador e é acessível por meio de uma URI.

- Interface uniforme. As operações: PUT, GET, POST e DELETE são usadas para criar, atualizar e remover recursos, respectivamente. Apesar de serviços REST poderem ser invocados por meio de outros protocolos, normalmente é utilizado o protocolo HTTP.

- Mensagens auto-descritivas. Um determinado recurso possui apenas um identificador, mas pode ter várias representações (HTML, XML, JSON, PDF, JPEG, ....).

- Interações com estado por meio de hyperlinks. As requisições a serviços não armazenam estado (são stateless). Contudo, se forem utilizados os identificadores de recursos, interações com estado podem ser realizadas. Existem algumas técnicas para navegação entre as URI's dos recursos com armazenação de estado, tais como cookies, URI rewriting e hidden form fields.

Apesar das vantagens decorrentes da utilização de serviços REST, a maior parte das abordagens para composição de serviços e diretivas de SOA são voltadas para serviços Soap/WSDL. Conforme apresentaremos a seguir, em orquestrações e coreografias é necessário saber exatamente e em detalhes quais são as operações e tipos de dados envolvidos, ou seja, o contrato dos serviços, a priori. Isto nem sempre é possível em REST, dado que a padronização se dá no tipo de operação realizado, mas não na representação do recurso recebido ou enviado. 


\subsection{Arquitetura orientada a serviços}

Arquitetura orientada a serviços (Service Oriented Architecture, SOA) consiste em um modelo arquitetural que guia o desenvolvimento de aplicações baseadas em serviços. Na Figura 3.3, temos o ciclo de vida de uma aplicação SOA.

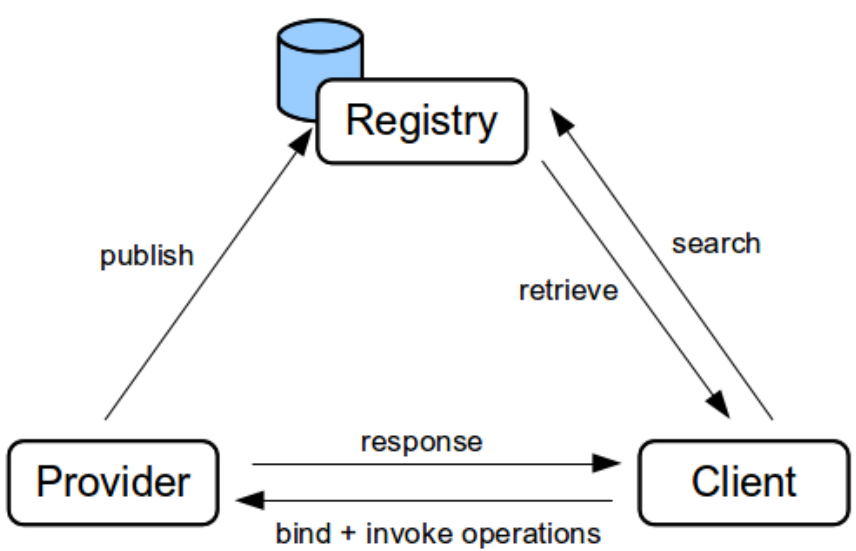

Figura 3.3: Triângulo de participantes e operações em SOA

Este ciclo consiste basicamente em três participantes e três operações (publicação, busca e associação (binding)) envolvendo serviços web [GGKS02]. As operações de busca e binding podem ser automatizadas [PGFT11]. Conforme ilustrado na Figura 3.3, os participantes são:

- Provedor (Provider). O fluxo tem início com esse participante. O provedor de serviços é responsável por implementar novos serviços e publicar suas interfaces (na forma de um arquivo WSDL) em um registro de serviços.

- Registro (Registry). Pode ser público ou privado. Serviços podem ser buscados nesses registros utilizando linguagens de busca, como por exemplo: Universal Description, Discovery and Integration (UDDI).

- Cliente (Client). Após a publicação, clientes podem realizar a busca por interfaces de serviços no registro e escolher aquele serviço que melhor satisfaz suas necessidades. Um vez escolhido o serviço desejado, o cliente faz a conexão (binding) com o serviço junto ao provedor e começa a invocar as operações do serviço escolhido.

\subsection{Orquestração de serviços web}

A capacidade de se compor serviços web para a implementação de fluxos de negócio complexos é um dos princípios de SOA [Er107]. Orquestrações, também chamadas de processos executáveis, correspondem a uma abordagem centralizada, na qual serviços web são compostos em um único processo de negócios executável [Pel03]. Nesse caso, o processo é representado sob a perspectiva de um nó central (orquestrador) que coordena o fluxo de informações entre os demais serviços.

Um dos benefícios decorrentes da implementação de orquestrações é a capacidade de adaptar facilmente um serviço, ou um conjunto de serviços, aos requisitos de um sistema [DKB08]. Na especificação WSDL de um serviço, suas operações estão formalmente definidas. No entanto, para fornecer uma operação mais completa, muitas vezes essas operações precisam ser executadas em uma determinada ordem. Orquestrações podem ser utilizadas para essas necessidades. Além disso, orquestrações são composições recursivas, ou seja, uma orquestração é acessível como um serviço web, podendo ser parte integrante de uma nova orquestração. 


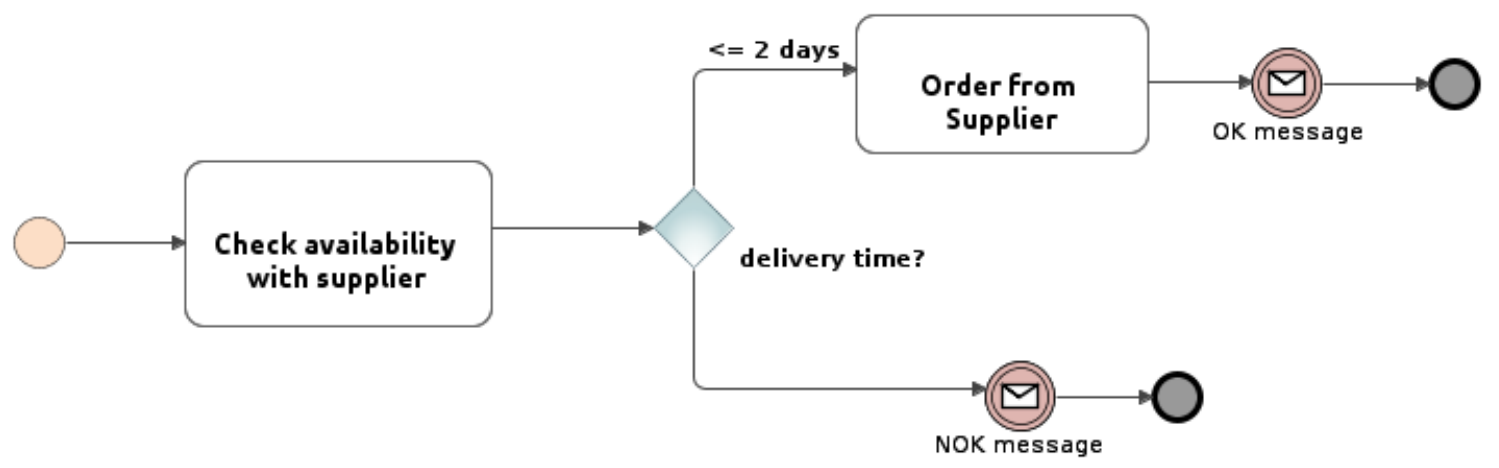

Figura 3.4: Exemplo de processo

A Figura $3.4^{1}$ apresenta um exemplo de processo simples. Nele, o requisito de negócio representado consiste em comprar um determinado produto, se seu prazo de entrega for inferior a 2 dias, e enviar uma mensagem de confirmação. Caso contrário, um mensagem informando que não foi possível realizar a compra deve ser enviada.

Na Figura 3.4, este requisito é implementado orquestrando-se as operações de um serviço web que representa um fornecedor de produtos (supplier). Este serviço fornece as funcionalidades de compra e consulta de prazos. Assim, a orquestração invoca essas operações em determinados momentos do fluxo e, no final do interação, retorna ao usuário mensagens de confirmação ou de negação da compra.

Após ser modelada, uma orquestração é interpretada por uma engine de execução, que é responsável por invocar os serviços envolvidos e aplicar a lógica da orquestração. Entre as linguagens para modelagem e execução de orquestrações, a principal delas é BPEL (Business Process Execution Language $)^{2}$. Embora seja menos popular que BPEL, SCA (Service Component Architecture) ${ }^{3}$ consiste em uma abordagem para composição de serviços baseada em componentes, sendo muito utilizadas para definição de processos executáveis. Nas seções seguintes, as principais características dessas duas abordagens para modelagem de orquestrações são apresentadas.

\subsubsection{Business Process Execution Language (BPEL)}

Esta linguagem foi inicialmente chamada Business Process Execution Language for Web Services (BPEL4WS) e consiste em uma linguagem XML para modelagem de orquestrações. Em 2005, foi lançada WS-BPEL (Web Service Business Process Execution Language), ou Business Process Execution Language (BPEL) 2.0, como é conhecida atualmente [OAS12].

Em uma orquestração modelada em BPEL, cada serviço Soap participante é denominado um partner link no fluxo de negócio. As operações de cada serviço são invocadas através de sua interface WSDL, que é conhecida, a priori, na modelagem do processo. Apenas a interface, e não a implementação do serviço, deve ser conhecida previamente. Durante a execução de uma orquestração, diferentes serviços que fornecem a mesma interface do partner link inicial podem ser utilizados no processo.

O fluxo lógico da orquestração é definido por meio de atividades (activities), ações lógicas e de controle, que são aplicadas nas operações dos serviços. Desse modo, um processo é constituído por um conjunto de atividades que são aplicadas nas operações dos partner links envolvidos. A Tabela 3.1 apresenta as atividades mais comuns a uma orquestração implementada em BPEL.

Conforme dito anteriormente, uma orquestração é acessível como um serviço web simples. Em BPEL, as operações fornecidas pelo serviço gerado com a orquestração são associadas às mensagens

\footnotetext{
${ }^{1}$ Esta figura foi baseada em um exemplo retirado da documentação de BPMN2: www.omg.org/spec/BPMN/ 20100601/10-06-02.pdf

${ }^{2}$ BPEL: www.oasis-open.org/committees/wsbpel

${ }^{3} \mathrm{SCA}:$ http://www.oasis-opencsa.org/sca
} 


\begin{tabular}{|l|l|}
\hline Atividade & Descrição \\
\hline \hline Invoke & Invoca as operações de um serviço web \\
\hline Receive & Recebe mensagens de requisições de um cliente \\
\hline Reply & Envia mensagens de resposta a um cliente \\
\hline Assign & Atribui valores ou expressões às variáveis do fluxo \\
\hline Throw & Sinaliza erros internos \\
\hline Wait & Especifica um tempo de espera \\
\hline Empty & Uma atividade que não toma nenhuma ação \\
\hline Rethrow & Relança erros internos que foram detectados \\
\hline Sequence & $\begin{array}{l}\text { Agrupa atividades para serem executadas sequencial- } \\
\text { mente }\end{array}$ \\
\hline If & Aplica desvios condicionais \\
\hline While & Aplica laços \\
\hline Pick & $\begin{array}{l}\text { Associa ações a determinados eventos (e.g., seguir um } \\
\text { caminho diferente no fluxo dependendo da mensagem } \\
\text { recebida na atividade Receive. }\end{array}$ \\
\hline Flow & Agrupa atividades para serem executadas em paralelo \\
\hline
\end{tabular}

Tabela 3.1: Atividades de BPEL

recebidas na atividade Receive, e enviadas pela atividade Reply.

Além das atividades apresentadas na Tabela 3.1, BPEL fornece mecanismos para manutenção de uma "sessão" entre as mensagens trocadas. Correlation Sets, são conjuntos de propriedades privadas a uma conversação. Uma orquestração pode receber chamadas em paralelo de diferentes clientes e cada uma dessas chamadas pode requerer muitas trocas de mensagens entre os serviços do processo. Com esse recurso, caso a orquestração receba várias chamadas deste tipo em paralelo, as propriedades (estado) de cada chamada serão restritas a conversação, impedindo que mensagens sejam entregues aos clientes incorretamente.

\subsubsection{Service Component Architecture (SCA)}

SCA consiste em um modelo para construção de aplicações que seguem os princípios de SOA, utilizando componentes de software. Nesse contexto, um componente de software pode ser um serviço web, um serviço REST ou uma aplicação desenvolvida em Java (ou em outra linguagem de programação). Em SCA, um componente deve implementar uma lógica de negócio e expor uma interface, sendo acessível como um serviço [Cha07]. Entretanto, o componente não necessariamente precisa expor uma interface WSDL. Caso seja uma aplicação Java, uma interface Java pode ser utilizada.

Uma aplicação em SCA consiste na integração de diversos componentes em um composite [GHJV95], que pode ser comparado a um processo executável. A composição de vários componentes em um composite é chamada de assembly model [Cha07]. A Figura 3.5 apresenta um exemplo de assembly model. Nessa Figura, pode-se inicialmente notar a presença dos componentes. Essas entidades são responsáveis pela implementação do fluxo lógico, sendo os blocos de construção de aplicações SCA. Um componente expõe sua interface por meio da diretiva service (seta verde). Além disso, a implementação de um componente pode depender de outros componentes. As dependências são explicitadas pela diretiva reference (seta rosa).

Assim como em BPEL, a composição em SCA possui natureza recursiva, ou seja, um composite também pode ser utilizado como um componente. Conforme pode ser observado na Figura 3.5, um elemento composite possui as diretivas service e reference, porém, diferente dos componentes, um composite não possui implementação. Assim, as chamadas recebidas pela diretiva service de um composite são repassadas a um de seus composites. Este processo é chamado promote, ou seja, um 


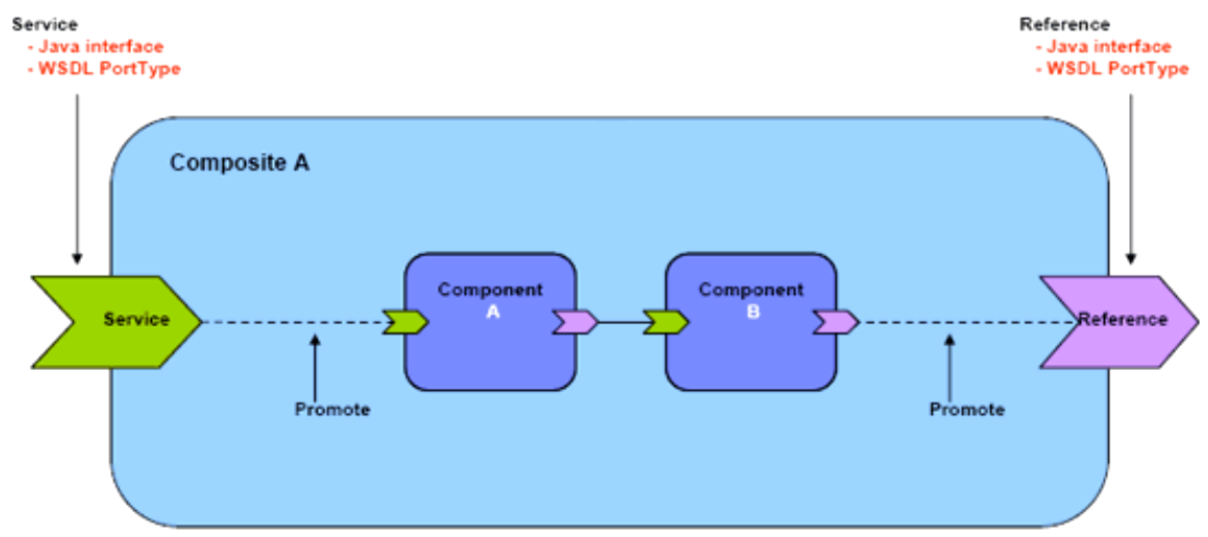

Figura 3.5: Exemplo de assembly model em SCA [OAS11]

componente é promovido para atender as requisições de seu composite.

\subsection{Coreografia de serviços web}

Diferentemente de orquestrações, coreografias consistem em uma abordagem distribuída para composição de serviços com coordenação descentralizada. Uma coreografia é uma interação colaborativa na qual cada nó envolvido desempenha um papel durante a interação. Esse papel define o comportamento que deve ser seguido pelo nó durante a execução da coreografia. Quando todos os papéis estiverem alocados, baseados nas mensagens especificadas no modelo global da coreografia, cada serviço participante sabe quando e com quem se comunicar [BBRW09]. Assim, quando a coreografia for iniciada, não haverá um só nó central coordenando toda a interação.

De acordo com Ross-Talbot [Rt05], uma coreografia consiste em uma descrição de interações peer-to-peer entre serviços web externamente observável. Ao contrário de orquestrações, onde as interações entre os serviços são especificadas sob a perspectiva do orquestrador, em uma coreografia as interações são apresentadas globalmente sob uma perspectiva neutra. Assim, uma especificação de uma coreografia descreve apenas as mensagens que devem ser trocadas entre as partes envolvidas, sem definir como os papéis são implementados [BDO05].

Algumas linguagens, tais como: Web Service Choreography Interface (WSCI) ${ }^{4}$, Web Service Choreography Description Language (WS-CDL) e Business Process Model and Notation (BPMN2) ${ }^{6}$ foram propostas para a modelagem de coreografias.

Dado que orquestrações são processos executáveis, coreografias podem ser executadas por meio de orquestrações distribuídas [CHO11]. Nessa abordagem, cada orquetração pode ser associada a um papel, assim, durante o fluxo de informações em uma coreografia, vários coordenadores (orquestrações) são responsáveis por diferentes partes do fluxo. Assim, não existirá uma entidade que armazena o estado global da interação, ou seja, coordena todo o fluxo de negócio.

Em um nível mais abstrato, as mensagens trocadas pelos papéis são especificadas utilizando alguma das linguagens de modelagem que serão apresentadas a seguir. No entanto, em um nível mais baixo, a implementação de um papel se dá pela orquestração de um serviço ou conjunto de serviços. Neste caso, a interface WSDL provida pela orquestração deve ser compatível com a interface do papel implementado.

A Figura 3.6 ilustra a implementação de papéis por meio de orquestrações. Nessa figura, a orquestração da direita fornece as operações Request purchase order e Accept purchase order. A orquestração da direita, por sua vez, invoca essas operações e processa as respostas obtidas. Na seção seguinte, será apresentada uma coreografia implementada seguindo essa abordagem.

\footnotetext{
${ }^{4}$ WSCI: http://www.w3.org/TR/wsci

${ }^{5}$ WS-CDL: http://www.w3.org/TR/ws-cdl-10

${ }^{6}$ BPMN2: http://www.omg.org/spec/BPMN/2.0
} 


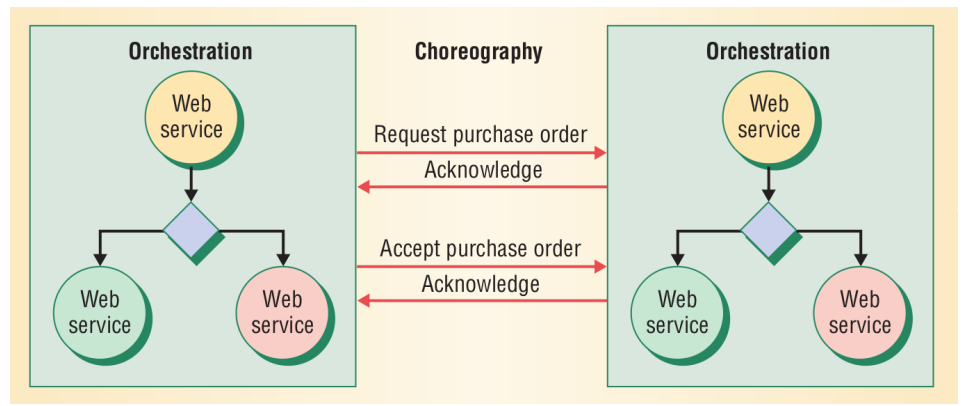

Figura 3.6: Orquestrações de serviços implementando papéis em uma coreografia [Pel03]

\subsubsection{Coreografia FutureMarket}

Durante este projeto de mestrado, algumas coreografias foram desenvolvidas utilizando diferentes tecnologias. Essas coreografias serviram como base para o levantamento e refinamento dos requisitos do Rehearsal. Nesta seção, será apresentada uma coreografia que foi desenvolvida utilizando BPEL. A "FutureMarket" é uma coreografia que fornece um serviço para compra distribuída baseado no seguinte workflow:

1. Um cliente (customer) fornece à coreografia uma lista de compras;

2. O preço de cada item dessa lista é verificado em vários supermercados que fazem parte da composição. O objetivo desta busca é selecionar o supermercado que oferece o item procurado pelo menor preço;

3. A coreografia retorna ao usuário o preço total mínimo de sua lista de compras. Em seguida, o cliente pode optar pela compra dos items de sua lista.

4. A coreografia interage com cada supermercado para comprar cada item.

5. Cada supermercado interage com um serviço de entrega que, por sua vez, notifica o cliente sobre os dados da entrega dos produtos ao cliente.

Seguindo a abordagem de implementar uma coreografia utilizando processos distribuídos, cada papel consiste em uma orquestração, desenvolvida em BPEL, que fornece uma interface WSDL compatível com os contratos esperados na coreografia. Assim, para implementar o fluxo acima, tem-se os seguintes papéis:

SMRegistry. Deve armazenar uma lista com os endpoints dos serviços que implementam o papel supermarket. A Tabela 3.2 apresenta a API que deve ser fornecida por serviços que implementam esse papel.

\begin{tabular}{|l|l|l|l|}
\hline Operação & Entrada & Saída & Descrição \\
\hline addSupermarket & endpoint: String & $\begin{array}{l}\text { confirmation: } \\
\text { String }\end{array}$ & $\begin{array}{l}\text { Cadastra um endpoint de um ser- } \\
\text { viço que implementa o papel } \text { su- } \\
\text { permarket }\end{array}$ \\
\hline getList & & $\begin{array}{l}\text { Supermarkets: } \\
\text { List }<\text { String }>\end{array}$ & Retorna uma lista de endpoints \\
\hline
\end{tabular}

Tabela 3.2: SMRegistry API

Supermarket. Serviços que implementam esse papel devem fornecer operações para busca e compra de produtos. Além disso, esse papel deve permitir que o serviço seja registrado junto ao SmRegistry. Assim, dois serviços fazem parte da orquestração que implementa esse papel. Nesse caso, os serviços participantes são o serviço fornecendo o papel SmRegistry e o serviço que representa o supermercado real. A interface das operações desse papel deve ser padronizada seguindo a API apresentada 
na Tabela 3.3.

\begin{tabular}{|l|l|l|l|}
\hline Operação & Entrada & Saída & Descrição \\
\hline \hline searchForProduct & name: String & $\begin{array}{l}\text { name: String, price: } \\
\text { Double }\end{array}$ & Obtém o preço do produto \\
\hline registerSupermarket & endpoint: String & $\begin{array}{l}\text { confirmation: } \\
\text { String }\end{array}$ & $\begin{array}{l}\text { Registra o serviço junto ao sm- } \\
\text { Registry }\end{array}$ \\
\hline purchase & $\begin{array}{l}\text { id: String, data: } \\
\text { personalDataType }\end{array}$ & $\begin{array}{l}\text { confirmation: } \\
\text { String }\end{array}$ & $\begin{array}{l}\text { Realiza a compra do pedido refe- } \\
\text { renciado (order ID) }\end{array}$ \\
\hline
\end{tabular}

Tabela 3.3: Supermarket API

Customer. Esse papel representa o "gatilho" da coreografia, ou seja, por meio dele clientes (pessoas) podem interagir com a coreografia para a busca e compra de produtos. A Tabela 3.4 apresenta a API que deve ser fornecida por serviços implementando esse papel.

\begin{tabular}{|l|l|l|l|}
\hline Operação & Entrada & Saída & Descrição \\
\hline \hline getPriceOfProductList & $\begin{array}{l}\text { products: } \\
\text { List }<\text { String }>\end{array}$ & order: Order & $\begin{array}{l}\text { Retorna o preço total mínimo da } \\
\text { compra e um ID de pedido }\end{array}$ \\
\hline purchase & $\begin{array}{l}\text { id: String, account: } \\
\text { accountType }\end{array}$ & shipper: String & $\begin{array}{l}\text { Realiza a compra do pedido in- } \\
\text { formado }\end{array}$ \\
\hline getDeliveryData & $\begin{array}{l}\text { shipper: String, or- } \\
\text { derID: String }\end{array}$ & delivery: String & $\begin{array}{l}\text { Obtém informações de entrega } \\
\text { do pedido comprado }\end{array}$ \\
\hline
\end{tabular}

Tabela 3.4: Customer API

Shipper. O serviço que implementa esse papel é responsável por realizar a entrega do produto ao cliente. Assim, por meio desse papel, entregas podem ser agendadas e rastreadas. A API dessas operações é apresentada na Tabela 3.5.

\begin{tabular}{|l|l|l|l|}
\hline Operação & Entrada & Saída & Descrição \\
\hline \hline setDelivery & $\begin{array}{l}\text { id: String, zipcode: } \\
\text { String }\end{array}$ & $\begin{array}{l}\text { confirmation: } \\
\text { String }\end{array}$ & Cadastra a entrega do pedido \\
\hline getDataAndTime & id: String & time: String & $\begin{array}{l}\text { Retorna a data e hora de entrega } \\
\text { do pedido }\end{array}$ \\
\hline
\end{tabular}

Tabela 3.5: Shipper API

Para exemplificar a interação entre esses papéis, a Figura 3.7 apresenta o fluxo de compra em um diagrama de processos BPMN2. Nessa figura, são apresentadas três raias. Cada uma delas representa um processo, ou seja, um papel da coreografia. Além disso, nesse tipo de diagrama é possível visualizar as atividades que acontecem dentro do processo e entre os processos da coreografia.

Conforme apresentado na Figura 3.7, pode-se observar que a coordenação das mensagens trocadas na coreografia é descentralizada. Enquanto novas requisições são recebidas pelo serviço Customer, requisições previamente recebidas são tratadas pelos demais papéis da coreografia.

Como dito anteriormente, cada processo é implementado como uma orquestração em BPEL. Na Figura 3.8, a orquestração que implementa o papel customer é apresentada. Essa orquestração é exposta como um serviço web que oferece a API apresentada na Tabela 3.4. Para cada operação fornecida, há um fluxo de tratamento associado que executa as atividades pertencentes a cada bloco marcado pela atividade sequence.

Para a operação getPriceOfProductList, por exemplo, a orquestração inicialmente invoca o SmRegistry para obter a lista de endpoints de serviços que representam os supermercados. Isso é realizado na atividade getSupermarkestList. Em seguida, essa lista é enviada para um outro serviço web chamado CustomerWS, o qual buscará o menor preço de cada produto em todos os supermercados desta lista (atividade setProdutsList. Por fim, a orquestração invocará esse serviço novamente 


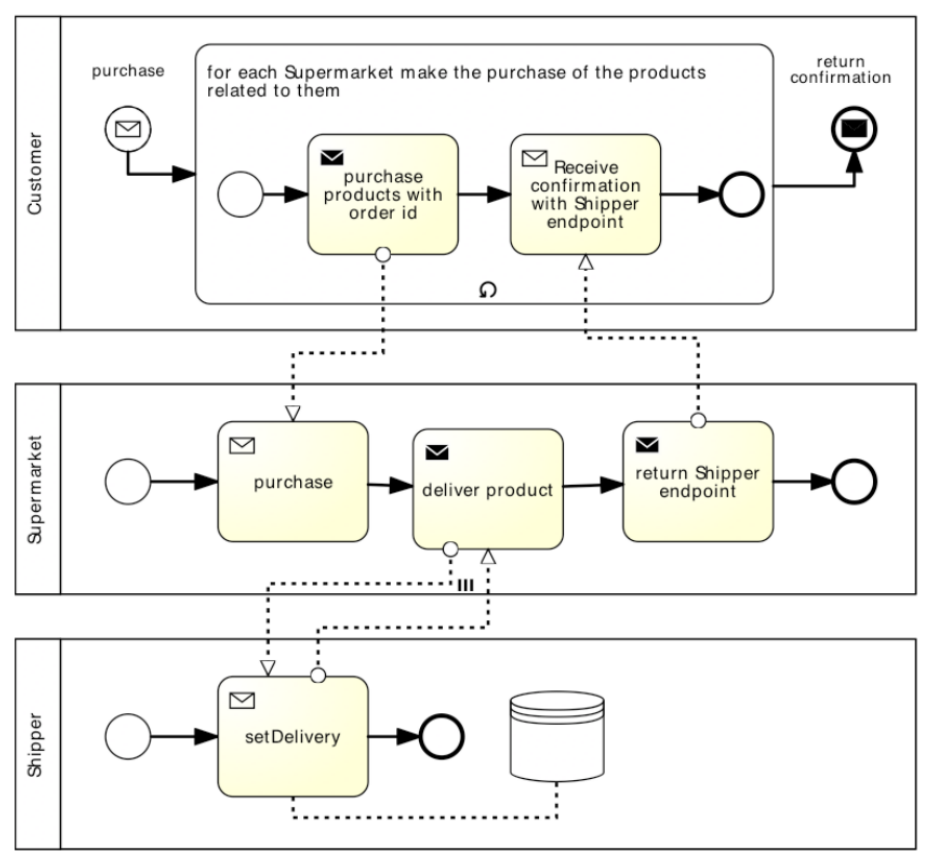

Figura 3.7: Fluxo de compra da coreografia FutureMarket

para obter o menor preço que, em seguida, é retornado ao cliente na atividade Reply.

Tratamentos semelhantes são realizados para as demais operações oferecidas, no caso, getPriceOfProductList e getDeliveryData. Como pode ser observado na Figura 3.8, muitas atividades do tipo Assign são utilizadas. Essas atividades são responsáveis por atribuir e obter valores de variáveis utilizadas no fluxo.

\subsection{Teste de composição de serviços}

As estratégias de teste apresentadas na Seção 2.2 podem ser classificadas em online ou offline, dependendo de onde e quando são aplicadas. O teste online consiste em verificar se o sistema em teste está em conformidade, em relação ao seu comportamento esperado, avaliando-o em seu ciclo de vida real, ou seja, em ambiente de produção [GGvD10]. Assim, técnicas e estratégias de testes, simulações e análise de rastros de execução, quando aplicadas a um sistema em seu ambiente de teste ou desenvolvimento, são consideradas teste offline.

Na literatura, teste online também é conhecido como runtime monitoring ou passive testing [Ber07]. Contudo, dado que as atividades de um teste online podem não se restringir à observação passiva do sistema, o termo teste online também pode ser utilizado para abordagens de teste que visam tomar ações durante sessões de teste (e.g., bloquear certas funcionalidades) [BAP11].

No contexto de teste de coreografia, essa classificação é amplamente utilizada. Rehearsal foi desenvolvida para apoiar o teste offline de coreografia de serviços web, também conhecido como teste em tempo de desenvolvimento (development-time). A seguir, serão apresentadas algumas estratégias utilizadas no teste offline de orquestrações ou coreografias de serviços web.

\subsubsection{Estratégias de teste}

Um estudo inicial realizado por Bucchiarone [BMS07] foi realizado para compreender o estado atual das técnicas de teste para orquestrações e coreografias de serviços web. Algum tempo depois, Canfora e Di Penta [CDP09] realizaram uma pesquisa mais avançada, apresentando mais trabalhos relacionados ao teste de composição de serviços. Em relação às técnicas levantadas por ambos os estudos, essas são baseadas em técnicas de software para sistemas tradicionais (Seção 2.2). Nesta seção, a discussão acerca das estratégias de teste para composição de serviços web baseia-se nos resultados de ambos os trabalhos. 


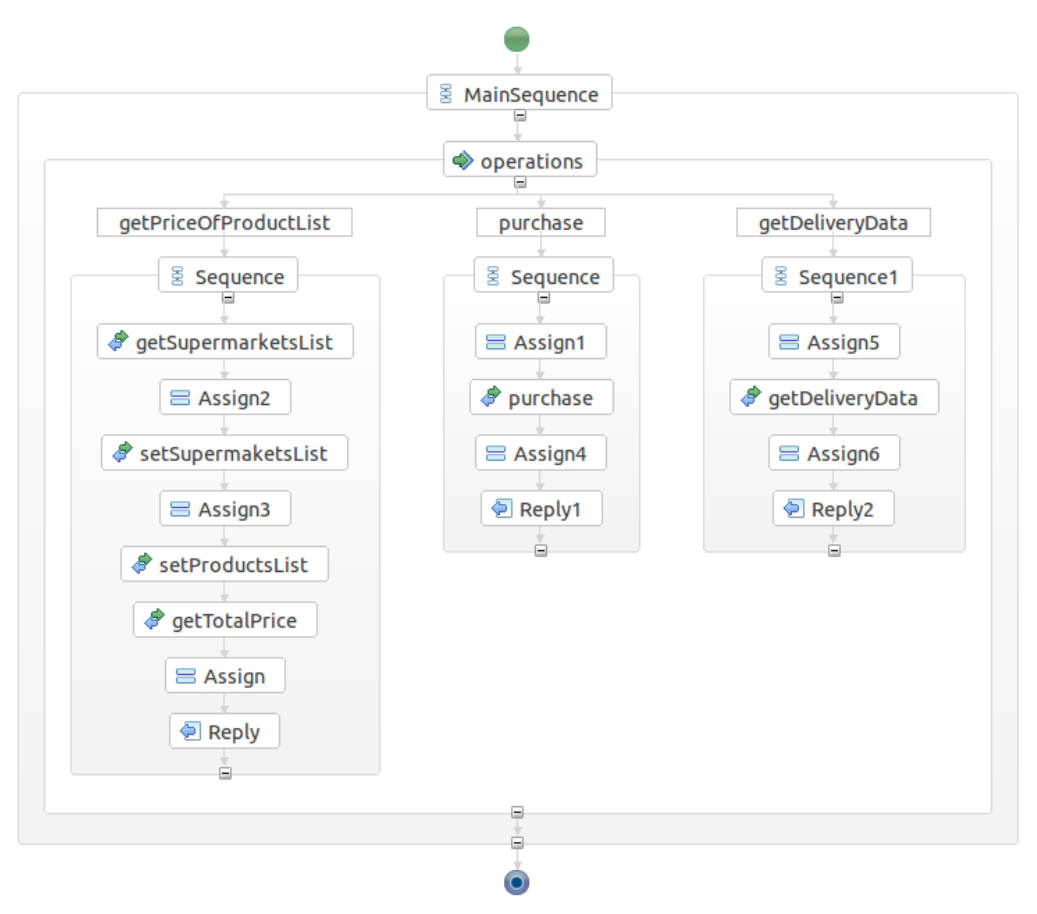

Figura 3.8: Orquestração representando o papel customer

De acordo com ambos os estudos, as estratégias e técnicas de testes a serem utilizadas dependem diretamente do ponto de vista de quem está testando (e.g., desenvolvedor, usuário final) e também da disponibilidade dos recursos necessários aos testes. A Tabela 3.6 ilustra a relação existente no teste de composição de serviços web.

\begin{tabular}{|l|l|l|}
\hline Estratégia & Quando aplicar & $\begin{array}{l}\text { Por quem é } \\
\text { aplicada }\end{array}$ \\
\hline \hline Teste de integração & $\begin{array}{l}\text { Quando a especificação da orquestração (e.g., BPEL) } \\
\text { e/ou da coreografia estiverem disponíveis, assim como } \\
\text { as interfaces e URIs do serviços participantes. }\end{array}$ & Desenvolvedor \\
\hline Teste de unidade & $\begin{array}{l}\text { No modelo de sistema de composição de serviços, não } \\
\text { há nada menor do que os serviços atômicos. Assim, es- } \\
\text { ses são considerados as unidades de uma orquestração } \\
\text { ou coreografia. }\end{array}$ & $\begin{array}{l}\text { Desenvolvedor } \\
\text { e/ou usuário final }\end{array}$ \\
\hline Teste de aceitação & $\begin{array}{l}\text { Sob a perspectiva do usuário final, a orquestração ou } \\
\text { coreografia é acessível como um serviço web atômico. } \\
\text { Logo, as mesmas ferramentas para o teste de unidade } \\
\text { podem ser utilizadas nessa estratégia. }\end{array}$ & Usuário final \\
\hline
\end{tabular}

Tabela 3.6: Estratégias de teste para composição de serviços

No teste de integração, caso a implementação dos serviços esteja disponível, abordagens da técnica de teste de caixa-branca, como fluxo de controle ou de dados podem ser utilizadas. Caso contrário, testes de caixa preta podem ser utilizados em cada serviço (teste de unidade) e nas mensagens por eles trocadas (teste de integração). Nesse último caso, os serviços podem ser simulados se não for possível invocá-los. No caso de orquestração, os testes validam a integração dos serviços. No caso de coreografia, há dois níveis de integração: a integração entre os serviços de um processo e a integração entre os processos (coordenadores). Em relação ao teste de aceitação, ambas as coreografias e orquestrações são tomadas como uma caixa-preta e são testadas como se fossem serviços web simples. 


\subsection{Considerações finais do capítulo}

Neste capítulo, foram discutidos os principais conceitos relacionados à composição de serviços web. A primeira discussão enfatizou as diferenças entre serviços web do tipo Soap/WSDL e REST. Então, apresentamos uma visão geral sobre o ciclo de uma aplicação em SOA. Em seguida, discutimos as principais diferenças entre orquestrações e coreografias e, por fim, algumas alternativas possíveis para o teste dessas composições

Essas discussões são fundamentais para os próximos capítulos desta dissertação. No próximo capítulo, os principais trabalhos relacionados ao Rehearsal são apresentados. Esses trabalhos são divididos em trabalhos voltados para o teste de unidade, aceitação ou integração de coreografias. 


\section{Capítulo 4}

\section{Trabalhos relacionados}

Apesar de todas as vantagens decorrentes da utilização de coreografias, o teste automatizado, e até mesmo manual, desse tipo de composição de serviços é desafiador. Além das dificuldades decorrentes da natureza distribuída de coreografias, seu caráter inovador também consiste em um obstáculo, sendo muito difícil encontrar exemplos reais de coregrafias. Levando em conta este cenário, neste capítulo, são apresentados os principais trabalhos relacionados ao teste automatizado de coreografias de serviços web. Esses trabalhos foram agrupados seguindo a classificação apresentada na Seção 3.5. Assim, os trabalhos referentes ao teste de serviços atômicos representam as estratégias para teste de unidade e aceitação, enquanto que os trabalhos para validação de trocas de mensagens de uma coreografia, representam estratégias para o teste de integração.

\subsection{Teste de serviços atômicos}

No ciclo de vida de aplicações desenvolvidas seguindo as características de SOA (Seção 3.2), diferentes participantes são envolvidos. Os trabalhos apresentados nesta seção apresentam abordagens para o teste de serviços atômicos sob as perspectivas de cada um desses participantes.

\subsubsection{Cliente de serviços}

Alguns trabalhos focam no teste de serviços web a partir da perspectiva do cliente desses serviços. Para a seleção e análise desses trabalhos, considerou-se que o cliente pode ser um usuário final que utiliza o serviço diretamente para suas necessidades, ou um desenvolvedor que durante a criação de uma composição integra os serviços web. Os trabalhos apresentados abaixo são aplicados após a interação com os serviços.

SoapUI. Esta ferramenta [Evi10] foi desenvolvida em Java e oferece mecanismos para o teste funcional de serviços web. A partir de uma interface WSDL (Web Service Description Language) válida, o SoapUI oferece funcionalidades para a criação automática de casos de teste para cada operação do serviço. Além disso, utilizando essa ferramenta é possível emular, por meio de mocks, serviços web. Nessa funcionalidade é possível publicar o mock criado por meio de um servidor embarcado disponível na própria ferramenta. Apesar do nome sugerir uma restrição à utilização de serviços Soap, SoapUI também provê funcionalidades para o teste de serviços REST e JMS (Java Message Service). Todas essas funcionalidades são oferecidas na versão de código aberto (sob a licença LGPL) da SoapUI. Porém, uma versão comercial da ferramenta oferece mais recursos como por exemplo, teste de desempenho de sistemas de grande escala.

Pode-se classificar o SoapUI como uma dependência interna do Rehearsal. As funcionalidades de geração dinâmica de clientes para serviços web, emulação de serviços e interceptação de mensagens, utilizam o SoapUI. Originalmente, a ferramenta SoapUI consiste em um ambiente gráfico para aplicação de teste funcional e de desempenho. No entanto, uma vez que esta ferramenta possui 
licença LGPL, utilizou-se suas classes internas para prover algumas funcionalidades do Rehearsal.

WS-TAXI. SoapUI oferece mecanismos para a geração automática de casos de teste para as operações de um serviço web. Embora esse recurso automatize a criação de testes, os casos de teste produzidos são incompletos. A Figura 4.1 ilustra um caso de teste criado utilizando o SoapUI. Conforme pode ser observado nesta figura, os parâmetros de entrada (conteúdo das requisições) e saídas esperadas (conteúdo das respostas) devem ser preenchidos manualmente. Por padrão, esses parâmetros vêm preenchidos pelo SoapUI com o símbolo "?".

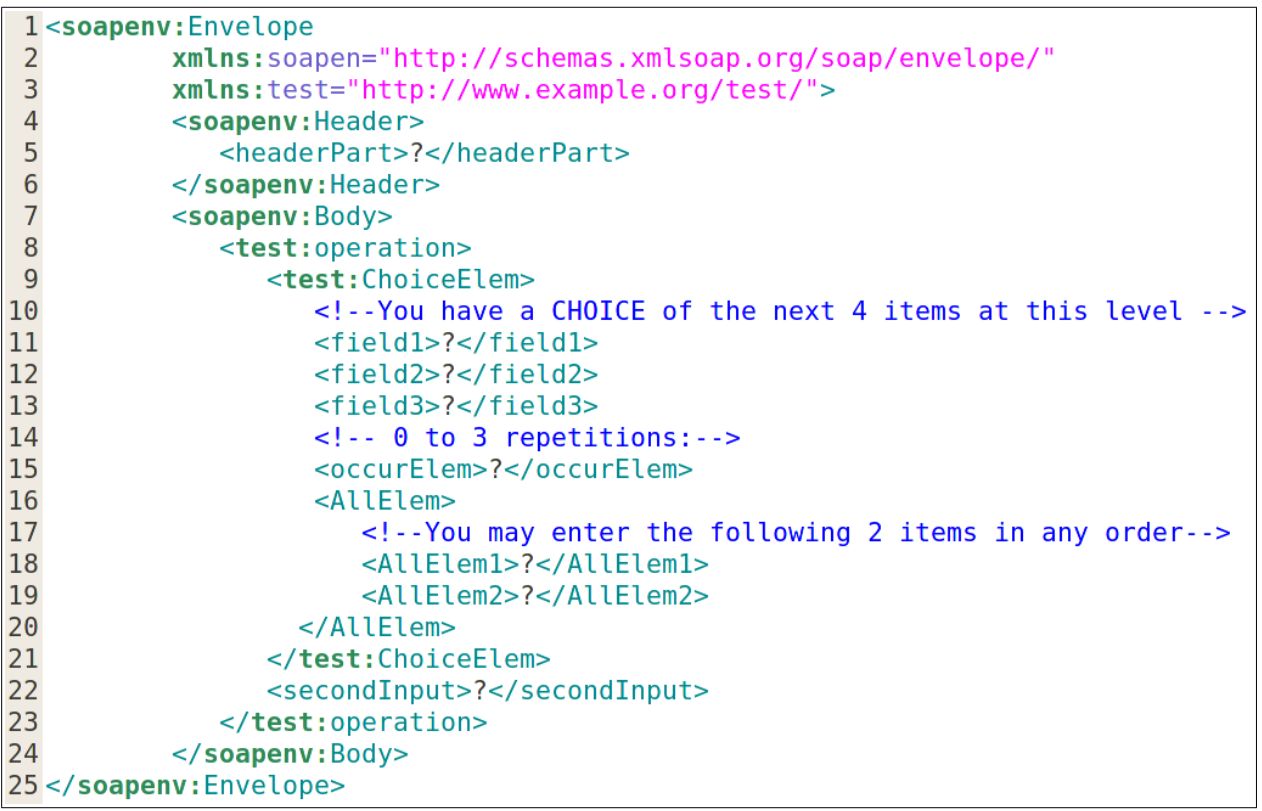

Figura 4.1: Esqueleto de mensagem Soap gerado pelo soapUI [BBMP09]

WS-TAXI [BBMP09] é uma ferramenta proposta para melhorar essa funcionalidade do SoapUI. Seu objetivo é preencher automaticamente esses campos em branco (marcados com "?") com valores derivados do XML schema do envelope Soap. Com essa ferramenta, a partir desse esqueleto gerado pelo SoapUI, casos de teste são gerados para todas as combinações de dados possíveis. No exemplo apresentado na Figura 4.1, WS-TAXI é capaz de gerar casos de teste, pela permutação dos campos de entrada, para cobrir todas as possibilidades do campos com "?" (linhas 09 - 22). Por exemplo, para o esqueleto XML desta figura, WS-TAXI geraria casos de teste para todas as combinações de dados possíveis envolvendo os elementos $\langle$ ChoiceElem $\rangle,\langle$ occurElem $\rangle,\langle$ AllElem $\rangle$ e $\langle$ secondInput $\rangle$. Para reduzir o universo de combinações, utiliza-se informações presentes na especificação WSDL, tais como o tipo de dados de entrada aceito e o número de ocorrências de cada campo.

A geração automática de casos de teste é um dos objetivos futuros do Rehearsal. No entanto, os testes gerados serão especificados em Java ao invés de XML.

TTR. Esta ferramenta é específica para o teste de serviços REST. TTR (Test-The-REST) [CK09] oferece mecanismos para o teste funcional e não-funcional (e.g., teste de desempenho). De maneira similar a SoapUI, esta ferramenta auxilia no teste das operações CRUD ((Create, Read, Update e Delete)) de recursos de um serviço REST (Seção 3.1.2). TTR provê uma linguagem de script para especificação e execução de casos de teste. Cada um desses casos de teste é composto por um ID, uma URL de acesso ao recurso, a operação HTTP a ser executada, dados de entrada e os dados de saída esperados. Assim como definido no SoapUI, casos de teste para a ferramenta TTR devem ser escritos em XML.

Diferente da ferramenta TTR (Test-The-REST), a abordagem provida pelo Rehearsal para teste de serviço REST não é baseada em XML. A funcionalidade RSClient, que será apresentada no pró- 
ximo capítulo, foi desenvolvida tendo como base a ferramenta TestAssured ${ }^{1}$ e fornece mecanismos para escrita de testes utilizando Java, facilitando assim a integração com outros arcabouços desta linguagem.

wsrbench. Este trabalho [LVM12] consiste em uma abordagem para a avaliação de robustez de serviços web. O objetivo do teste de robustez é avaliar o comportamento do sistema testado utilizando condições de entrada errôneas e inválidas. Esta abordagem tem como objetivo fornecer aos utilizadores de serviços web Soap (clientes, integradores e desenvolvedores) indicadores de robutez, auxiliando assim, na seleção de serviços mais confiáveis. A ferramenta wsrbech consiste em uma aplicação web que implementa todos os passos desta abordagem. A análise de robustez proposta por este trabalho baseia-se nos seguintes passos:

1. Preparação dos testes. Cada operação presente na interface WSDL do serviço em teste é analisada. Nesta análise, os tipos de dados dos parâmetros de entrada e saída de cada operação são registrados. Testes de robustez são gerados para validar todos os parâmetros de entrada. Por exemplo, caso o domínio de entrada de um parâmetro seja um String com tamanho mínimo de 2 e máximo de 16 caracteres, serão gerados testes com Strings pertencentes e não pertecentes a este intervalo.

2. Geração e execução da carga de trabalho. Nesta parte do processo, uma carga de trabalho é aplicada ao serviço em teste para identificar o comportamento real de suas operações mediante parâmetros de entrada válidos. A carga de trabalho utilizada pode ser aleatória ou definida pelo usuário. Quando aleatória, requisições utilizando alguns dos parâmetros válidos identificados no passo anterior são realizadas.

3. Geração e execução dos testes de robustez. Testes de robustez utilizando os parâmetros inválidos levantados na passo 1 são aplicados. Além disso, são gerados e aplicados testes utilizando parâmetros errôneos comuns, tais como, valores nulos e formatos de data inválido e paramêtros errôneos malicioso (e.g., comandos de injeção SQL).

4. Caracterização do serviço web. Neste passo final, o serviço web testado é classificado. Como resultado, o serviço pode apresentar comportamento correto, crash ou errôneo. Essa classificação foi definida com base em um experimento realizado com 1024 operações provenientes de 250 serviços públicos e 29 serviços desenvolvidos por colaboradores que não são autores desse trabalho relacionado. Para cada operação, os 3 passos acima especificados foram aplicados. Com base nas respostas obtidas desenvolveu-se esta classificação.

Testes de robustez podem ser aplicados utilizando o Rehearsal, porém, os mesmos devem ser gerados pelos desenvolvedores. Como dito anteriormente, a geração automática de casos de teste consiste em um objetivo futuro deste trabalho de mestrado. De acordo com aos autores da wsrbench, o passo 2 da abordagem proposta pode ser realizado utilizando-se diferentes ferramentas para invocação de serviços web, como por exemplo, o SoapUI. Deste modo, Rehearsal poderia ser utilizado no passo 2 da abordagem, possibilitando ao desenvolvedor escrever casos de teste em Java ao invés de XML, como é feito utilizando o SoapUI.

SOCT. Em todas as ferramentas apresentadas previamente, o cliente limitava-se a aplicar técnicas de caixa-preta para validar as operações do serviços web sob teste. O objetivo da ferramenta Service Oriented Coverage Testing (SOCT) [BBEM09] é oferecer serviços web associados a informações de cobertura de teste de suas operações. Assim, clientes podem receber serviços já testados. Como benefício dessa abordagem, o desenvolvedor responsável pela integração de serviços em uma composição, pode escolher o melhor serviço em termos de confiabilidade, com base nos seus dados de cobertura.

\footnotetext{
${ }^{1}$ Test Assured: http://code.google.com/p/rest-assured
} 
Para atingir os objetivos desse trabalho, os autores do SOCT propõem a adaptação das entidades envolvidas no workflow básico de aplicações SOA (Seção 3.2). Na adaptação proposta, inicialmente, os serviços web devem ser instrumentados, sendo então chamados de "Serviços Testáveis" (ST). Em seguida, uma entidade denominada "Provedor TCov" é introduzida no triângulo da Figura 3.3, entre o provedor de "Serviços Testáveis" e o cliente desses serviços. Assim, o novo fluxo de operações SOA é definido por meio dos seguintes passos:

1. O testador SOCT, que pode ser representado por um cliente, envia testes ao ST desejado.

2. Os testes são executados no provedor do "Serviço Testável". Após os testes, o provedor envia logs de cobertura de teste para um serviço denominado "Serviço de Coleta de Cobertura". Este serviço pertence a entidade "Provedor TCov".

3. Quando os teste tiverem sido concluídos, o testador SOCT pode extrair relatórios de cobertura do serviço desejado junto a um serviço chamado "Serviço de Reportagem de Cobertura", outro serviço interno ao "Provedor TCov".

BISTWS. Assim como o trabalho anterior, BISTWS (Built-in Structural Testing of Web Services) [EDMM10] consiste em uma abordagem para a aplicação automatizada de testes estruturais em web services. Este trabalho propõe uma arquitetura genérica para automatização das atividades de instrumentação de web services, escrita e execução de casos de teste e análise de cobertura. Uma implementação desta arquitetura utilizando a ferramenta JaBUTiWS ${ }^{2}$ é também apresentada pelos autores deste trabalho. Com esta implementação, serviços web desenvolvidos na linguagem Java podem ser testados de maneira automatizada. O fluxo de utilização da BISTWS, utilizando a ferramenta JaBUTiWS, pode ser resumido nos seguintes passos:

1. Desenvolvimento e instrumentação de serviços web. Após serem desenvolvidos, serviços web são enviados à JaBUTiWS para serem instrumentados. Durante a instrumentação, a ferramenta JaBUTiWS insere probes diretamente no bytecode do programa Java. Como resultado deste processo, serviços testáveis são gerados. Esses serviços oferecem as mesmas operações dos serviços originais, porém, também oferecem operações extras que permitem ao testador iniciar e terminar sessões de testes e obter dados de cobertura dos serviços.

Além disso, os serviços instrumentados possuem a capacidade de coletar um trace de execução quando estão sendo testados. Nesta fase do fluxo, o provedor de serviços pode enviar à JaBUTiWS seus casos de teste, a ferramenta por sua vez, executará esses casos de teste e coletará informações de cobertura. Os casos de teste e os resultados de cobertura poderão ser utilizados pelos testadores para efeito de comparação.

2. Publicação e teste de serviços web. Após a instrumentação, clientes podem submeter casos de teste para os serviços testáveis. Uma ferramenta chamada WSMTS (Web Service Monitoring and Testing System) auxilia os testadores em suas atividades. Por meio desta ferramenta, testadores podem escrever os casos de teste que serão submetidos automaticamente para o serviço testável.

O objetivo desta ferramenta é automatizar o processo, uma vez que os testadores poderiam invocar as operações extras providas pelos serviços testáveis para conduzir as sessões de teste. A ferramenta WSMTS também auxilia os provedores/desenvolvedores na instrumentação de serviços web.

3. Análise de resultados. Após a execução dos casos de teste, o testador, usando a ferramenta WSMTS, pode extrair os testes de cobertura obtidos. Nesse processo, a ferramenta JaBUTiWS analisa o trace de execução e analisa quais e quanto dos requisitos de testes (e.g., all-nodes) foram cobertos pelos casos de teste executados. A fim de melhorar a cobertura de seus testes,

\footnotetext{
${ }^{2}$ JaBUTiWS: http://www.labes.icmc.usp.br / jabutiservice
} 
e avaliar a confiabilidade dos serviços web invocados, os testadores também podem obter os casos de teste dos desenvolvedores e seus dados de coberturas, por meio da operações getMetadata e getRelativeCoverage.

O objetivo principal deste trabalho assemelha-se ao objetivo SOCT, porém, utilizando BISTWS, o testador pode aplicar, de maneira automatizada, seus próprios casos de teste e comparar os valores de cobertura obtidos com aqueles disponibilizados junto ao serviço. Além disso, no SOCT a instrumentação e análise de cobertura é feita manualmente. Por meio de ferramentas como a JaBUTiWS e a WSMTS, o fluxo de utilização da BISTWS é automatizado.

No presente momento desde trabalho de mestrado, Rehearsal provê mecanismos apenas para escrita e execução de testes funcionais (caixa-preta). Além disso, este trabalho não fornece mecanismos para a medição de cobertura de testes. Como trabalho futuro, Rehearsal poderia ser integrado a um trabalho da natureza do SOCT ou BISTWS para prover também dados de cobertura dos testes de coreografias.

\subsubsection{Repositório de serviços}

Os trabalhos apresentados a seguir descrevem abordagens para aplicação de testes online automatizados nos registros de serviços.

Audition framework. Este trabalho foi inicialmente proposto no projeto PLASTIC (Pervasive and Trustworthy Network) $)^{3}$ sendo posteriormente, utilizado no projeto TAS ${ }^{3}$ (Trusted Architecture for Securely Shared Services). O objetivo do $\mathrm{TAS}^{3}$ é prover uma infra-estrutura confiável e segura para a troca de informações confidenciais entre usuários e serviços web. Audition framework [BDAP09] consiste em um arcabouço para validar os serviços utilizados no TAS ${ }^{3}$ Para assegurar a troca segura de informações, os serviços participantes devem estar em conformidade com seus papéis esperados, além de prover os mecanismos de autenticação requeridos pelo TAS ${ }^{3}$.

Por meio deste arcabouço, antes de serem publicados no Audition Service Registry (ASR), os serviços são auditados. Inicialmente, ASR cria, em tempo de execução, disparadores de testes (test triggers) para cada serviço registrado. Então, ASR cria e atribui asserções para os casos de teste que serão implementados. As asserções verificam se cada serviço está implementando corretamente em relação ao comportamento esperado. Por fim, os testes automatizados são disparados, invocando as operações dos serviços, e o ASR coleta as respostas. Se as respostas forem os resultados esperados, o serviço é aceito, caso contrário, o serviço é negado e não fará parte do TAS ${ }^{3}$. Quando os testes passam, o ASR indexa o serviço testado no diretório de serviços e atribui a ele uma certificado de aprovação. $\mathrm{O}$ arcabouço realiza testes online, uma vez que os serviços reais são testados na infraestrutura e funcionamento reais do ASR.

(role)CAST. Este trabalho consiste em uma implementação da arquitetura para teste online proposta pelo arcabouço Auditor, descrito acima. Em uma federação de serviços, ou seja, uma rede de serviços de diferentes organizações, (role)CAST (ROLE CompliAnce Service online Testing $)^{4}$ [BAP11] propõe mecanismos para a validação da autenticação, autorização e identificação dos serviços participantes. Essas validações são aplicadas por entidades denominadas Test Driver e Test Robot. O Test Driver configura e executa instâncias de Test Robot. Uma instância de Test Robot é responsável por:

1. Extrair casos de teste de um repositório de casos de teste;

2. Por meio de um canal de comunicação Soap seguro, verificar se um serviço possui permissão de participar da federação checando sua identificação junto a um provedor de IDs;

\footnotetext{
${ }^{3}$ http://www.ist-plastic.org

${ }^{4}$ http://labsewiki.isti.cnr.it/labse/tools/rolecast
} 
3. Realizar chamadas (requisições) ao serviço sob teste;

4. Verificar os resultados dessas chamadas realizadas nos casos de teste junto a uma entidade Oráculo;

5. Salvar os resultados dos casos de teste em um repositório de resultados.

Para gerar casos de teste automaticamente, role(Cast) oferece mecanismos para a criação de Test Drivers e casos de teste a partir e diagramas UML.

Ao contrário desses dois trabalhos, o objetivo do Rehearsal é automatizar testes aplicados durante o desenvolvimento da coreografia, ou seja, o teste offline. No entanto, testes de integração, conformidade e aceitação utilizados durante o desenvolvimento devem continuar funcionando quando a coreografia estiver em produção. Deste modo, testes gerados utilizando o Rehearsal podem ser aplicados de maneira online juntamente com ferramentas da natureza do Audition framework e (role)CAST.

\subsubsection{Provedor de serviços}

Antes de publicar e oferecer serviços, o provedor de serviços (desenvolvedor) pode aplicar testes de unidade e/ou aceitação em um ambiente de desenvolvimento ou até mesmo no ambiente de produção. Na abordagem proposta por Jia Zhang [Zha11], os testes são disparados por uma entidade externa, no entanto, são executados no ambiente do provedor, que pode ser um ambiente de desenvolvimento ou produção. Em seu trabalho, Zhang propõe um arcabouço para a automatização de testes de serviços web utilizando uma infra-estrutura baseada em agentes móveis. Um agente móvel consiste na composição de software e dados que são capazes de "viajar" de uma máquina a outra e, de maneira autônoma e independente, continuar sua execução na máquina destino. Assim, a ideia principal deste relacionado é utilizar agentes para diminuir os custos de comunicação que são inerentes ao teste online de serviços web, principalmente, quando são aplicados testes de desempenho.

Ao contrário das abordagens nas quais os casos de teste são disparados e seus resultados analisados na máquina do cliente (e.g., SoapUI), a ideia desta abordagem é enviar os casos de teste a um agente localizado no servidor do serviço web a ser testado. Então, o agente executa todos os casos de teste, o que envolve realizar chamadas Soap localmente, e então envia os resultados de execução a máquina do cliente. O arcabouço proposto é desenvolvido com base nas ferramentas HP LoadRunner [HP11] e IBM Aglet [IBM11]. A primeira ferramenta é um ambiente para automatização de sistemas em geral, não apenas serviços web. A ferramenta da IBM por sua vez, é uma biblioteca de código aberto para desenvolvimento de agentes móveis em Java.

Rehearsal é utilizado junto ao cliente de serviços web. No entanto, o suporte ao teste de desempenho de serviços web é uma de suas melhorias futuras. Neste caso, uma abordagem semelhante a este trabalho relacionado poderia ser integrada ao Rehearsal para a execução dessa natureza de teste.

\subsection{Teste de composições de coreografias de serviços web}

Os trabalhos apresentados até o momento testam de maneira automatizada, serviços web. Nesta seção, são apresentados trabalhos para teste de coreografias. Os trabalhos foram divididos em abordagens aplicáveis nas fases de pré-execução (pre-enactment) de coreografias, como por exemplo, na modelagem, e abordagens aplicáveis na pós-execução (pos-enactment) de coreografias. Na terminologia de coreografias, enactment corresponde a uma fase de desenvolvimento onde todos os serviços participantes da coreografia estão corretamente implantados, seja em ambiente de desenvolvimento ou produção, fazendo com que a coreografia esteja pronta para ser executada.

Foram selecionados os trabalhos que possuem maior relação com o escopo e os principais objetivos deste trabalho. No entanto, algumas revisões sistemáticas [PGFT11, RPIT11] apresentam mais trabalhos relacionados ao teste de coreografias de serviços web. 


\subsubsection{Pré-execução (pre-enactment)}

Nesta seção, são apresentados os principais trabalhos relacionados ao teste automatizado de coreografias nas fases que antecedem sua execução (pré-enactment).

PI4SOA. Com esta ferramenta [Pi410] é possível validar as mensagens trocadas nas interações entre os participantes de uma coreografia especificada em WS-CDL (Web Service Choreography Description Language). O propósito da PI4SOA é modelar coreografias especificadas em WS-CDL, e a partir deste modelo global, gerar automaticamente processos em BPEL para cada papel da coreografia. A ferramenta é disponibilizada como um plugin do Eclipse IDE, favorecendo a modelagem gráfica da coreografia. Após a fase de modelagem, conforme ilustrado na Figura 4.2 é possível validar o fluxo de mensagens por simulação.

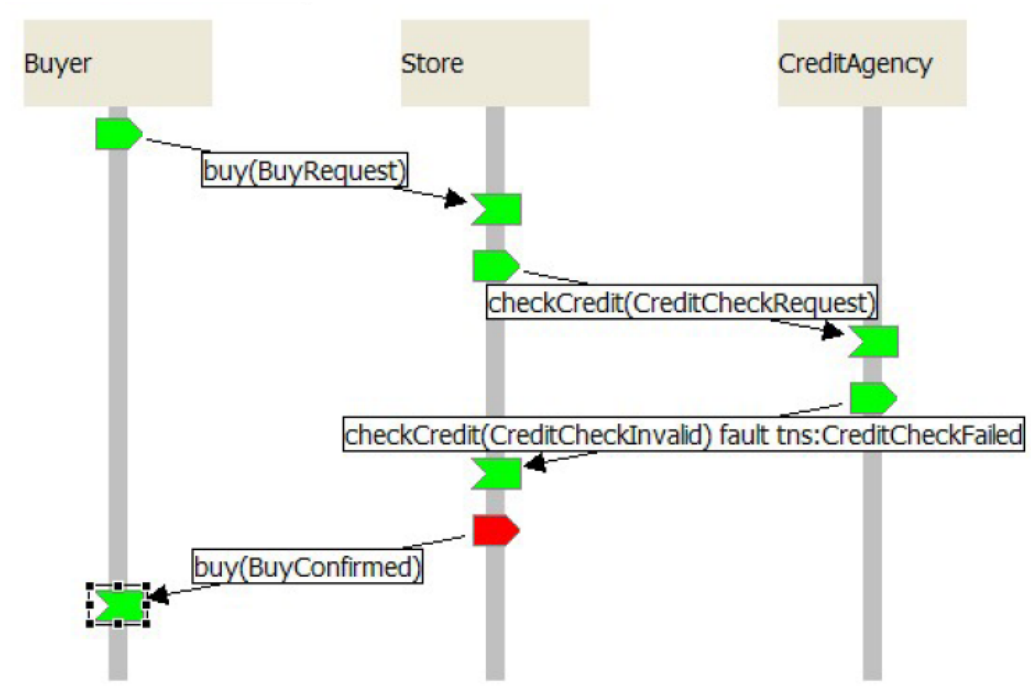

Figura 4.2: Simulação de troca de mensagens no PI4SOA

Na Figura 4.2, os participantes Buyer, Store e CreditAgency não são invocados realmente, ou seja, a troca de mensagens é simulada. Em caso de algum erro de modelagem, como por exemplo, incompatibilidade dos tipos de dados envolvidos, o erro é sinalizado por um seta vermelha na interface gráfica da ferramenta.

CDLChecker. Esta ferramenta valida e simula os modelos que especificam uma coreografia a fim de detectar erros de projeto. CDLChecker [ $\left.\mathrm{WZZ}^{+} 10\right]$ é disponibilizada como um plugin do Eclipse IDE e um de seus componentes é um engine de simulação que mapeia o modelo WS-CDL de coreografia em estruturas de dados. Após esse mapeamento, variáveis, interações e atividades do modelo são mapeados em estruturas de dados. Cada elemento do tipo atividade encontrado é exercitado por meio de simulação para validar o comportamento dinâmico da coreografia.

Além dessa funcionalidade, CDLChecker contém um módulo para aplicação de verificações estáticas no modelo que descreve uma coreografia. Todas as restrições entre os nós da coreografia especificada em WS-CDL são verificadas de maneira estática. O objetivo deste módulo é facilitar a detecção de erros referentes à especificação e projeto o mais cedo possível.

Baseado neste engine de simulação, os autores desenvolveram um arcabouço [ZPX $\left.{ }^{+} 10\right]$ para gerar automaticamente entradas para casos de teste de documentos WS-CDL. A técnica de execução simbólica é aplicada para geração de entrada para os casos de teste, enquanto as asserções são tratadas com os oráculos da abordagem. De acordo com Sen [SMA05], na execução simbólica, o programa é executado utilizando variáveis simbólicas no lugar dos valores concretos das entradas. Cada expressão condicional do programa é um restrição do documento WS-CDL e representa um caminho diferente de execução. O objetivo é gerar valores concretos para executar diferentes caminhos. Assim os modelos da coregrafia são simulados usando os valores de entrada gerados e 
validados mediante as asserções definidas.

Embora essas ferramentas estejam relacionadas ao teste de coreografias de serviços web, estas provêm mecanismos para validação da troca de mensagens utilizando técnicas de simulação. O Rehearsal valida essas trocas de mensagens invocando realmente a coreografia. CDLChecker pode ser utilizada durante a especificação da coreografia para validar sua modelagem. No entanto, ambas as ferramentas, PI4SOA e CDLChecker, são voltadas para coreografias especificadas em WS-CDL. Um dos objetivos do Rehearsal é a integração com ferramentas de modelagem de coregrafias especificadas em outras linguagens, como por exemplo, BPMN2.

Abordagem para teste de conformidade. Hwang [HHL11] propõe um método para aplicação de testes de conformidade em serviços web, ou orquestrações, candidatos a participantes de uma coreografia. O objetivo do trabalho é verificar se serviços web são compatíveis com os papéis especificados no modelo global de uma coreografia. Nesta abordagem, os papéis de uma coreografia especificada em WS-CDL ou BPMN2, e serviços candidatos à implementação desses papéis, são representados por máquinas de estados finitas (Finite State Machine (FSM)).

Nesta representação, as funções de transição entre os estados dão-se pela invocação ou recebimento de requisições a operações de serviços. Por exemplo, seja uma orquestração representada por uma FSM, estando em um estado $r$, ao receber uma requisição para a chamada orderRequest, a execução na FSM move-se para o estado $r^{\prime}$. Uma vez nesse novo estado, a execução move-se para o estado $r^{\prime \prime}$ caso a orquestração faça uma chamada a um outro serviço. Em tempo de design, a ideia central desta abordagem consiste em primeiramente mapear serviços web em FSM e então verificar quais deles estão em conformidade com os papéis da coreografia. Esta segunda parte do processo é chamada de "poda" de serviços incompatíveis. Para cada serviço candidato é verificado se o serviço provê todas as operações previstas pelas especificações dos papéis e se essas operações são chamadas no fluxo esperado.

Após esta "poda", serviços incompatíveis com os papéis esperados são identificados. Como resultado a descoberta de serviços durante a execução da coreografia é facilitada, uma vez que os serviços identificados como incompatíveis não serão buscados. Além disso, esta abordagem auxilia na adaptação desses serviços não compatíveis para que estes se tornem compatíveis com a especificação da coreografia. Um dos problemas desta abordagem é que a análise dá-se apenas em tempo de design, ou seja, eventuais problemas detectáveis apenas em tempo de execução (e.g., respostas incorretas ou ausência de respostas) não são cobertas pela abordagem.

Ao contrário deste trabalho, nossa abordagem para teste de conformidade é aplicada em serviços da coreografia que já estão em execução. Neste trabalho relacionado, testes similares são conduzidos nas especificações (e.g., arquivo WSDL) dos serviços em fases de pré-execução da coreografia. Rehearsal poderia ser aplicada de maneira complementar a esta abordagem. Assim, após a "poda" de serviços incompatíveis durante a modelagem da coreografia, testes de conformidade do Rehearsal poderiam ser aplicados nos serviços que não foram "podados' a fim de verificar a compatibilidade prática e a disponibilidade desses serviços.

\subsubsection{Pós-execução (pos-enactment)}

Os trabalhos apresentados nesta seção são aplicáveis a coreografias em execução, ou seja, que já passaram pelo processo de enactment em um ambiente de desenvolvimento, testes ou produção.

ValiBPEL-Web. Esta ferramenta aplica testes de integração estruturais para composições de serviços web. Inicialmente, com a utilização da ValiBPEL-Web [ESaSS08], um processo BPEL é mapeado em um grafo de fluxo de controle paralelo (Parallel Control Flow Graph, PCFG). Este tipo de grafo é constituído por grafos CFG (Seção 2.3.2) que representam cada um dos serviços web, ou processos, participantes da composição a ser testada. As atividades do tipo Receive, Reply, Invoke e Pick representam os nós desses grafos. Enquanto que, as mensagens trocadas, internamente e externamente, entre essas atividades representam as arestas desses grafos.

Em seguida, a ferramenta instrumenta os processos BPEL e arquivos WSDL envolvidos na 
composição. Após a instrumentação, esses artefatos são implantados no Vali-Exec module, um engine para execução da composição e armazenamento de seus traces de execução. Este módulo utiliza o ActiveBPEL $L^{5}$, um software-livre para interpretação e execução de processos BPEL. Em seguida, casos de teste podem ser submetidos aos processos instrumentados. Durante a execução desses testes, traces que registram os critérios e requisitos de testes a serem analisados, tal como requisitos cumpridos, são gravados.

No contexto deste trabalho, os critérios de teste assemelham-se àqueles utilizados para grafos CFG. Para grafos CFG, critérios como cobertura de todos os nós que enviam ou recebem mensagens (all-nodes-s e all-nodes-r), tal como, arestas envolvidas na comunicação podem ser definidos. Levando em conta esses e outros critérios de teste, um relatório de cobertura é gerado pela ValiBPELWeb com base na análise dos traces de execução obtidos. Uma das vantagens desta ferramenta é sua disponibilidade como ferramenta Web, facilitando assim, o acesso aos arfefatos utilizados e gerados na condução do teste.

Um dos objetivos do Rehearsal é prover suporte ao teste de integração de coreografias de serviços. No entanto, os testes de integração aplicados pela ValiBPEL utilizam a técnica de teste estrutural, enquanto que, Rehearsal provê suporte ao teste funcional. Como trabalho futuro, Rehearsal poderia ser integrada a esta ferramenta para ser compatível ao teste estrutural e prover dados de cobertura de processos (e.g., BPEL) presentes na coreografia.

BPELUnit. Mayer e Lübke propõem uma arquitetura para criação de arcabouços para testes automatizados de processos BPEL. Esta arquitetura é dividida em quatro camadas [ML06]. A camada de especificação dos testes descreve como o testador expressa os testes. Duas abordagens extremas são propostas: (i) abordagem centrada nos dados, que consiste na validação de estrutura de dados, por exemplo, mensagens Soap pré-definidas são comparadas com as mensagens retornadas pelo processo testado; e (ii) abordagem centrada na lógica, que consiste em utilizar uma linguagem de programação para descrever a lógica dos testes.

A camada de organização dos testes caracteriza a disposição dos testes no arcabouço de testes. Uma abordagem consiste em agrupar os testes em suítes para auxiliar na utilização por parte do desenvolvedor. As especificações dos testes são executadas por um arcabouço criando-se wrappers em torno do processo sob teste. O objetivo dos wrappers é validar as saídas do processo com base nas entradas programadas. Na camada de execução de testes, duas abordagens são propostas para a execução de especificações. Na abordagem por simulação, o processo BPEL é simulado em um ambiente controlado por um engine que oferece mecanismos para depuração, controle das saídas e simulação das entradas do teste. Na abordagem de vida real, o processo é implantado realmente e dependências reais são emuladas.

A última camada, chamada de resultados dos testes, é responsável por agrupar os resultados e estatísticas de execução e apresentá-las ao usuário final. Baseando-se nesta arquitetura em camadas, Mayer e Lübke desenvolveram o arcabouço BPELUnit. Por meio deste arcabouço, o desenvolvedor especifica os testes em XML. Para auxiliar na escrita dos testes, alguns detalhes técnicos do envelope Soap são abstraídos para o desenvolvedor. O arcabouço suporta a especificação de três tipos de comunicação com o processo sob teste: one-way, two-way synchronous e two-way asynchronous. A camada de organização, além de agrupar os casos de teste, oferece mecanismos para utilização de métodos de configuração de ambiente (e.g., métodos da natureza tear down e set up). Em relação à abordagem e propriedades utilizadas na camada de execução do arcabouço, estas dependem do engine no qual o BPELUnit está sendo executado.

A arquitetura apresentada por esta ferramenta para testes de processos BPEL foi levada em consideração no desenvolvimento do Rehearsal. No entanto, no contexto do Rehearsal, a unidade de teste é o serviço web e não um processo, que é o caso da BPELUnit. Além disso, as funcionalidades do Rehearsal, tal como os casos de testes, são especificados em Java ao invés de XML.

Um arcabouço para teste online. Greiler propõe uma ferramenta para deteç̧ão de falhas

\footnotetext{
${ }^{5}$ ActiveBPEL: www.activebpel.org
} 
durante a reconfiguração dinâmica de uma composição de serviços [GGvD10]. O objetivo deste trabalho é aplicar teste online para detectar cinco tipos de falhas:

- Publicação: problemas de implantação (deployment);

- Busca: buscas mal sucedidas ou vazias (sem resultado);

- Composição: problemas de integração (e.g., falta de algum componente de software);

- Binding: acesso negado ou referência a serviço incorreto

- Execução: Serviço "quebrado", ou retornando valores incorretos.

$\mathrm{Na}$ abordagem proposta por Greiler, durante a reconfiguração dinâmica e online, o serviço a ser integrado (novo serviço) é implantado, no ambiente de produção, em paralelo ao serviço antigo. Então, a integração do novo serviço com os serviços que se comunicam com ele é verificada. Cada serviço, incluindo o novo serviço, contém uma suíte de casos de teste para validar os serviços como os quais se comunica. Assim, a integração do novo serviço é testada por todos os serviços que se comunicam com ele.

Antes de ser publicado, o serviço é testado em três etapas. Primeiro, testes de busca são aplicados para verificar se todos os serviços requeridos pelo novo serviço podem ser descobertos no registro. Segundo, testes de binding são aplicados para verificar se os serviços requeridos podem ser invocados e se suas interfaces estão em conformidade com aquelas esperadas. Por fim, testes de composição (integração) são executados para validar as mensagens trocadas pelos serviços. Caso todos os testes passem, o novo serviço é publicado, substituindo o antigo.

De acordo com Greiler, principalmente durante o teste online. os serviços devem estar conscientes de que estão sendo testados e as atividades de testes, devem ser isoladas. Assim, nesta abordagem, os serviços são implantados em dois modos: operacional e testável. O serviço operacional atende as requisições reais da composição. O serviço testável estende o operacional, por exemplo, utilizando herança ou delegação, e provê mecanismos que facilitam o teste de integração. Para validar esta abordagem, um protótipo foi desenvolvido usando um arcabouço SOA da OSGI (Open Services Gateway Initiative) para publicação e implantação dos serviços.

Diferentemente deste trabalho, o objetivo do Rehearsal é prover suporte ao teste em tempo de desenvolvimento, também conhecido com teste offline. Além disso, outra diferença significativa refere-se as tecnologias utilizadas. Os testes online propostos neste trabalho relacionado são aplicáveis apenas em serviços desenvolvidos para o arcabouço OSGI SOA. No entanto, Rehearsal é compatível com servicos web Soap tradicionais e serviços REST. Apesar dessas diferenças, algumas semelhanças podem ser destacadas. Os mecanismos para controle e isolamento de sessões de testes apresentados assemelham-se a utilização de mocks proposta pelo Rehearsal. Nesta proposta, serviços de terceiros dependentes podem ser emulados para testar um determinado serviço isoladamente.

\subsection{Considerações finais do capítulo}

Este capítulo apresentou os principais trabalhos relacionados à Rehearsal. Inicialmente, foram apresentados aqueles trabalhos voltados para o teste de serviços web isoladamente, denominados testes de unidade. Alguns desses trabalhos (e.g., SoapUI) também podem ser utilizados para a prática de teste de aceitação, uma vez que composições de serviços web são acessíveis como serviços web.

Em seguida, apresentamos abordagens para o teste de integração de composições de serviços web. Algumas dessas abordagens são voltadas para fases que antecedem a implantação de coreografias ou orquestrações. No entanto, conforme discutido, há trabalhos voltados para o teste de integração de coreografias ou orquestrações em execução. Além disso, discutimos as principais diferenças e semelhanças entre o Rehearsal e os trabalhos apresentados.

No próximo capítulo apresentaremos as principais funcionalidades do Rehearsal, tal como sua arquitetura e exemplos práticos de sua utilização. 


\section{Capítulo 5}

\section{O arcabouço Rehearsal}

No contexto de composição de serviços web, enactment (encenação) corresponde ao termo utilizado quando todos os serviços de uma coreografia estão devidamente configurados, ou seja, a coreografia está pronta para ser utilizada. Os testes propostos neste trabalho auxiliam na concepção e desenvolvimento de uma coreografia. Por esse motivo, consideramos que durante essas atividades de testes, a coreografia está sendo "ensaiada" (rehearsed). Rehearsal visa facilitar o uso de Desenvolvimento Guiado por Testes para coreografias por meio da automatização de testes de unidade, integração e aceitação. Para atingir esse objetivo, o arcabouço fornece as funcionalidades descritas neste capítulo.

O Rehearsal ${ }^{1}$ é disponibilizado sob a licença GNU Lesser General Public License (LGPL) e faz parte dos projetos CHOReOS ${ }^{2}$ e Baile ${ }^{3}$. Os objetivos desses projetos consistem em estudar, desenvolver e utilizar coreografias de serviços web em ambientes de larga-escala, em particular, aqueles relacionados a Cloud Computing. Em ambos os projetos, esse arcabouço pertence as linhas de pesquisa relacionadas à Verificação e Validação (V\&V) de coreografias.

Neste capítulo, inicialmente, apresentamos o protótipo inicial, que serviu como base para a concepção do Rehearsal. Em seguida, descrevemos as principais funcionalidades, a arquitetura do arcabouço e exemplos reais de utilização

\subsection{Requisitos da Rehearsal}

Um protótipo do Rehearsal [BLK $\left.{ }^{+} 11 \mathrm{c}, \mathrm{BLK}^{+} 11 \mathrm{~b}\right]$ foi desenvolvido para entender melhor como as estratégias de teste podem ser aplicadas no contexto de coreografias de serviços. Esse protótipo consistia em: (a) scripts ad hoc bash para a implantação da coreografia; (b) casos de testes escritos em JUnit ${ }^{4}$ e (c) um console para que o usuário executasse os scripts e os testes.

Para validar o protótipo, implementamos uma coreografia exemplo para reserva de passagens áreas utilizando o OpenKnowledge $(\mathrm{OK})^{5}$, um arcabouço para comunicação peer-to-peer entre sistemas de software. Nessa coreografia de exemplo, um usuário informa ao serviço Traveler para onde e quando pretende viajar. Em seguida, o usuário pode reservar um bilhete de embarque eletrônico e, no decorrer do fluxo, confirmar ou cancelar sua compra. Para prover essas funcionalidades, o serviço Traveler interage com outros serviços como: Airline, Acquire, e Travel Agency. Os participantes dessa coreografia eram serviços Soap/WSDL e Restful.

Baseando-se na experiência e resultados adquiridos com este protótipo, derivamos os requisitos que o Rehearsal deveria implementar a fim de facilitar a aplicação de TDD para coreografias. A Tabela 5.1 apresenta esses requisitos.

\footnotetext{
${ }^{1}$ Página do Rehearsal: http://ccsl.ime.usp.br/baile/VandV

${ }^{2}$ CHOReOS: http://www.choreos.eu

${ }^{3}$ Baile: http://ccsl.ime.usp.br/baile

${ }^{4}$ JUnit: http://www.junit.org

${ }^{5}$ OpenKnowledge: http://www.openk.org
} 


\begin{tabular}{|c|l|}
\hline Sigla & Requisito \\
\hline \hline R1 & Criar clientes para invocar operações de serviços web Soap \\
\hline R2 & Criar clientes para interagir com recursos de serviços REST \\
\hline R3 & Permitir escrita de casos de testes para serviços ainda não existentes \\
\hline R4 & Interceptar mensagens trocadas entre os serviços de uma composição \\
\hline R5 & Emular serviços web \\
\hline R6 & Ajustar o tempo de resposta máximo ao se invocar uma operação de um serviço web \\
\hline R7 & Prover objetos que representam os elementos de uma coreografia \\
\hline R8 & Validar o contrato (papel) dos serviços de uma coreografia \\
\hline R9 & $\begin{array}{l}\text { Prover funcionalidades que não sejam acopladas a tecnologias, linguagens ou ferramentas especificadas de } \\
\text { orquestrações e coreografias }\end{array}$ \\
\hline
\end{tabular}

Tabela 5.1: Requisitos da Rehearsal

Na Tabela 5.2, apresentamos quais dos requisitos da Tabela 5.1 são atendidos pelos trabalhos relacionados apresentados no Seção 4.

\begin{tabular}{|c|c|c|c|c|c|c|c|c|c|}
\hline & R1 & $\mathbf{R 2}$ & R3 & R4 & R5 & $\mathbf{R 6}$ & R7 & $\mathbf{R 8}$ & R9 \\
\hline \multicolumn{10}{|c|}{ Teste de serviços web atômicos } \\
\hline 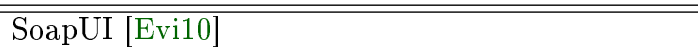 & •• & • & & & - & - & & - & -• \\
\hline TTR [CK09] & & $\bullet$ & $\bullet$ & & & & & & $\bullet$ \\
\hline WS-TAXI [BBMP09] & $\bullet$ & & & & & & & $\bullet$ & $\bullet$ \\
\hline wsrbench [LVM12] & $\bullet$ & & & & & & & $\bullet$ & $\bullet$ \\
\hline SOCT [BBEM09] & $\bullet$ & & & & & & & $\bullet$ & $\bullet$ \\
\hline BISTWS [EDMM10] & $\bullet$ & & & & & & & $\bullet$ & $\bullet$ \\
\hline Audition framework [BDAP09] & $\bullet$ & & & & & & & $\bullet$ & $\bullet$ \\
\hline (role)CAST [BAP11] & $\bullet$ & & & & & & & $\bullet$ & $\bullet$ \\
\hline Arcabouço multi-agentes [Zha11] & $\bullet$ & & & & & & & $\bullet$ & $\bullet$ \\
\hline \multicolumn{10}{|c|}{ Teste de coreografias } \\
\hline PI4SOA [Pi410] & & & & - & & & - & • & \\
\hline CDLChecker $[W Z Z+10]^{+}$ & & & & $\bullet$ & & & $\bullet$ & $\bullet$ & \\
\hline Abordagem para teste de conformidade [HHL11] & & & & $\bullet$ & & & & $\bullet$ & $\bullet$ \\
\hline ValiBPEL-Web [ESaSS08] & & & & $\bullet$ & & & & $\bullet$ & \\
\hline BPELUnit [ML06] & $\bullet$ & & & $\bullet$ & & & & $\bullet$ & \\
\hline Arcabouço para teste online [GGvD10] & & & & $\bullet$ & & & & $\bullet$ & \\
\hline Rehearsal & - & - & - & - & - & - & - & - & - \\
\hline
\end{tabular}

Tabela 5.2: Requisitos atendidos pelos trabalhos relacionados

Como pode ser observado na Tabela 5.2, nenhum dos trabalhos relacionados atende a todos os requisitos que definimos para o Rehearsal. Em particular, pode-se observar que a ferramenta que atende a mais requisitos é o SoapUI, uma dependência interna do Rehearsal. Com exceção da abordagem para teste de conformidade, todas as ferramentas voltadas para o teste de coreografias de serviços web são voltadas para uma tecnologia, linguagem ou ferramenta específica. Além disso, apesar de todas atenderem ao requisito R4 (interceptação de mensagens), apenas a ValiBPEL-Web e o BPELUnit interceptam mensagens reais trocadas na coreografia. Nas demais ferramentas, a interceptação e validação acontece em uma simulação das trocas de mensagens da coreografia.

As funcionalidades providas pelo Rehearsal atendem a todos os requisitos apresentados na Tabela 5.1. Essas funcionalidades, assim como a arquitetura do Rehearsal, são apresentadas nas próximas seções deste capítulo.

\subsection{Geração dinâmica de clientes para serviços web}

No contexto de composições, os serviços web são considerados as menores unidades do sistema. $\mathrm{Na}$ abordagem proposta pelo Rehearsal, essas unidades podem ser validadas utilizando-se a técnica de teste funcional (caixa-preta). Conforme explicado anteriormente, orquestrações e coreografias, são acessíveis como serviços web do ponto de vista de usuário final. Conforme discutido na Seção 3.5, 
testes conduzidos nesse cenário são denominados testes de aceitação. Todavia, como a unidade sob teste é um serviço web, técnicas e ferramentas utilizadas no teste de unidade também podem ser aplicadas no teste de aceitação de coreografias.

\subsubsection{Suporte a serviços Soap/WSDL}

Para a aplicação de testes de unidade e aceitação, o Rehearsal prove mecanismos para o desenvolvedor invocar operações de serviços web e validar suas respostas de maneira automatizada. Durante o desenvolvimento do protótipo, identificamos algumas ferramentas para este fim, tais como: Apache Axis ${ }^{6}$ e JAX-WS . Com essas ferramentas é possível criar objetos stubs, também chamados de clientes, a partir de uma especificação WSDL para comunicação com serviços web. Esse processo não é totalmente automatizado, é necessária intervenção humana para criação e utilização desses objetos. Além disso, caso a especificação WSDL do serviço invocado nos teste sofra alteração, os clientes existentes precisam ser gerados novamente.

Como alternativa à utilização de stubs, Rehearsal facilita a geração dinâmica de clientes para serviços web. Com esta funcionalidade, o desenvolvedor pode interagir com o serviços web sem a criação prévia de stubs. A partir de uma interface de um serviço (em WSDL) válida, suas operações podem ser invocadas dinamicamente. Dessa forma, casos de testes para validar as operações de um serviço podem ser escritos antes mesmo da interface WSDL deste serviço estar disponível. Além disso, caso a interface WSDL do serviço sofra alteração, não será necessário gerar novos stubs para os testes existentes.

A solução implementada no Rehearsal utiliza o SoapUI (Seção 4.1.1) para construção, envio e recebimento de envolopes Soap. A Figura 5.1 apresenta o fluxo simplificado de execução para invocação de serviços Soap/WSDL utilizando esta funcionalidade.

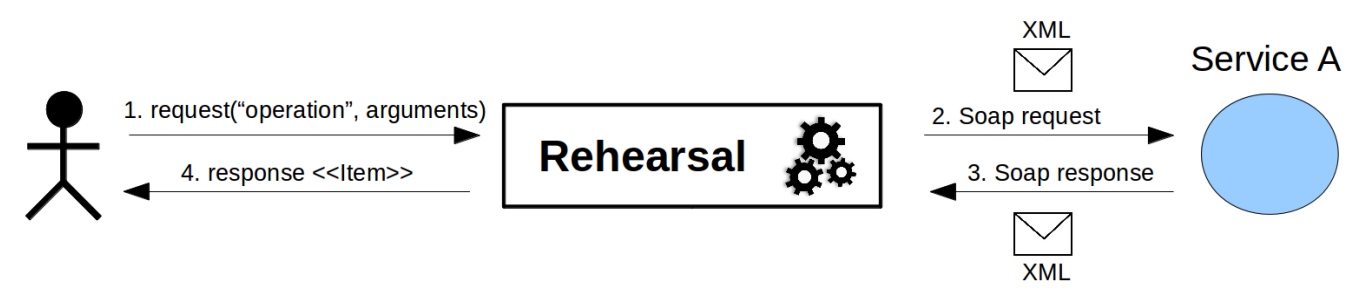

Figura 5.1: Fluxo de execução para invocação de serviços Soap/WSDL.

No primeiro passo da Figura 5.1, o desenvolvedor, utilizando o objeto WSClient, especifica qual operação precisa ser invocada. Este objeto representa o cliente dinâmico fornecido pelo Rehearsal. A interface pública do WSClient é apresentada na Figura 5.2.

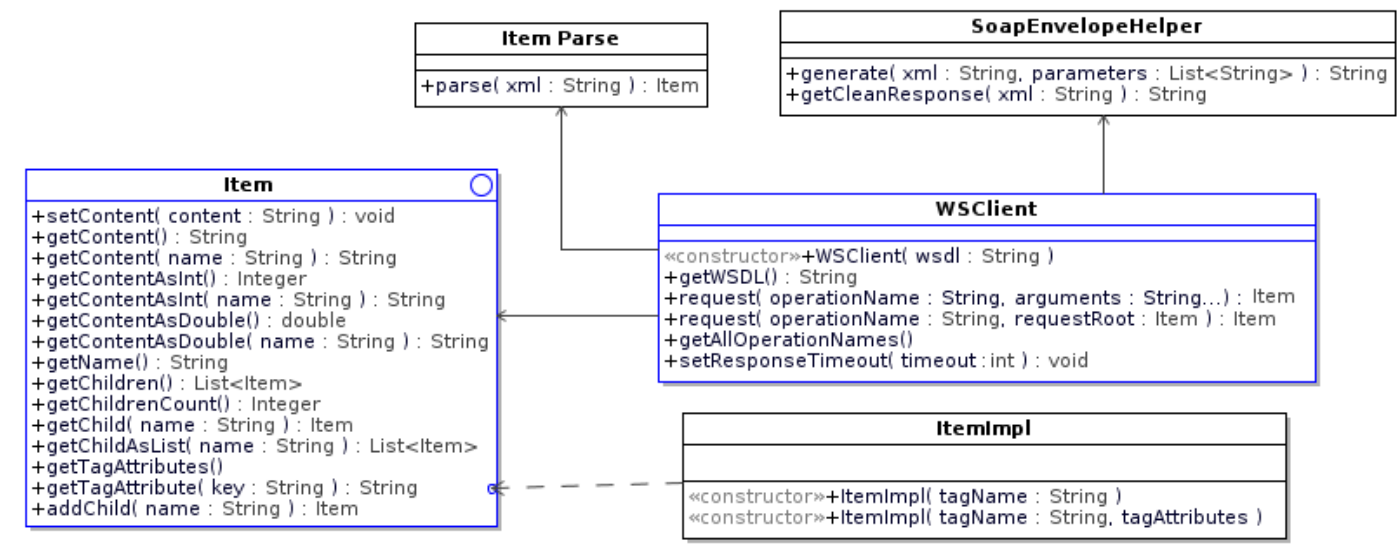

Figura 5.2: Interface pública do WSClient

\footnotetext{
${ }^{6}$ Apache Axis: http://axis.apache.org/axis

${ }^{7}$ JAX-WS: http://jax-ws.java.net
} 
Para invocar a operação desejada, o desenvolvedor utiliza o método request, fornecendo o nome da operação e seus argumentos. Esse método suporta parâmetros tipos primitivos (e.g., int e String), que são fornecidos ao arcabouço no formato de texto, ou tipos complexos, que são representados como objetos do tipo Item.

No contexto de utilização do Rehearsal, envelopes Soap que contenham uma sub-árvore com raiz no elemento XML, que representa a operação do serviço web, de altura maior que 1, são considerados tipos complexos. A Figuras 5.3 e 5.4, representam tipos simples e complexos, respectivamente. Conforme observado na Figura 5.3, a sub-árvore com raiz no elemento getProductStatusResponse possui altura 1 , dado que os elementos $i d$, name e status, não possuem filhos. Logo, são considerados folhas. No caso da Figura 5.4, a sub-árvore com raiz em getProductStatusResponse possui altura 2, sendo, portanto, um tipo complexo.

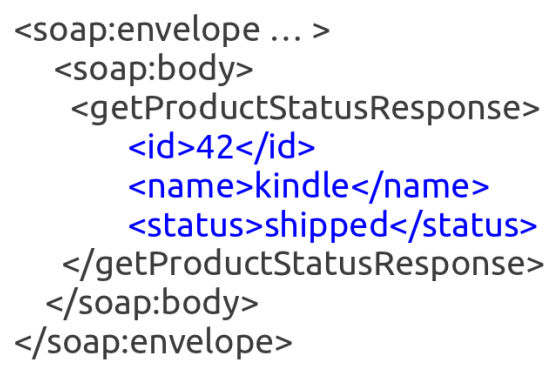

Figura 5.3: Tipo simples

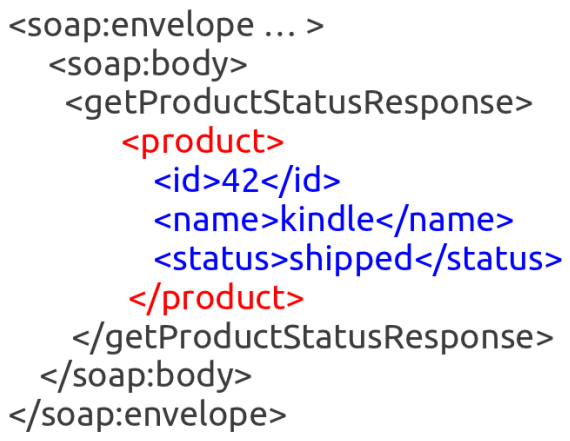

Figura 5.4: Tipo complexo

A fim de evitar a manipulação de tipos complexos por meio de XML, foi criado o objeto Item. Este objeto consiste em uma estrutura de dados recursiva que representa tipos complexos em XML, podendo ser utilizado para manipulação de envelopes de requisição ou resposta Soap. Assim, durante o teste de composições de serviços, objetos Item, que representam um resposta de serviço, podem ser utilizados diretamente como requisição a outros serviços para teste de uma nova operação.

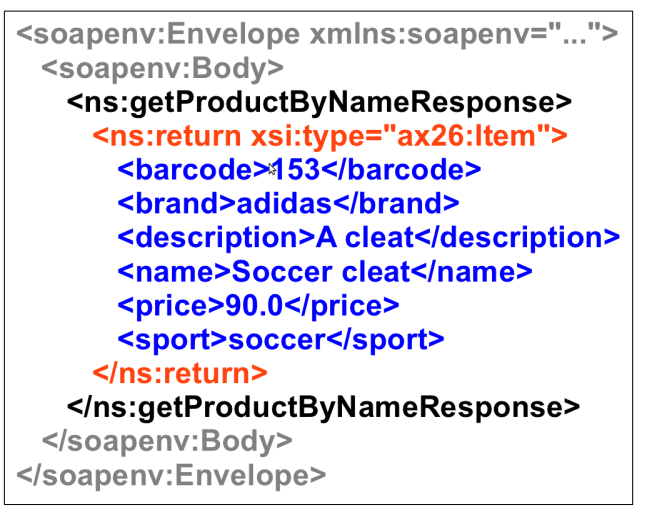

Figura 5.5: Envelope Soap de resposta

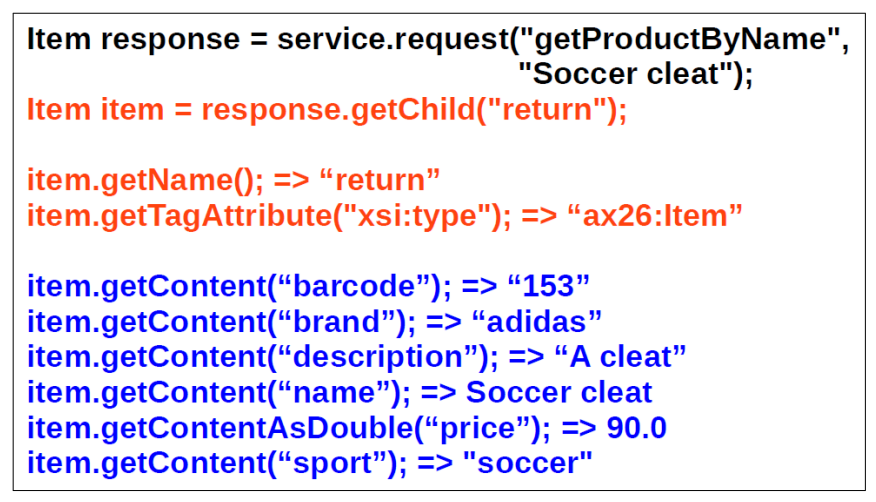

Figura 5.6: Objeto Item equivalente

As Figuras 5.5 e 5.6 ilustram um envelope Soap com um tipo complexo e seu objeto Item equivalente. A raiz da sub-árvore representando o tipo complexo é o elemento getProductByNameResponse. No objeto Item correspondente, esse elemento é obtido após a chamada service.request(...). A partir do objeto obtido como resultado desta chamada, os outros níveis da árvore podem ser alcançados. Como pode ser observado nessas figuras, o desenvolvedor não precisa especificar o endereço de nomes do XML. No exemplo, o endereçamento "ns" associado à operação getProductByName não precisa ser informado nas chamadas envolvendo os objetos Item.

No fluxo de execução do WSClient (Figura 5.1), uma vez que uma operação de serviço é invocada, o Rehearsal cria e submete o envelope Soap de requisição, em XML, para o serviço web testado (passo 2). Então, no passo 3, o arcabouço coleta o envelope Soap de resposta obtido. Finalmente, 
no passo 4, o arcabouço mapeia a resposta para um objeto Item, que é retornado ao usuário.

Para avaliar os casos de teste escritos usando o WSClient, um caso de teste foi escrito utilizando esta funcionalidade e utilizando a ferramenta JAX-WS. As Figuras 5.7 e 5.8, ilustram ambos os casos de teste. Como pode ser observado nessas figuras, para o trecho de código mostrado, o caso de teste A é quatro linhas menor do que aquele escrito utilizando o WSClient. Porém, esse caso de teste utiliza o objeto FlightResult que consiste em um stub gerado pelo JAX-WS. Dado que o serviço testado contém outras operações, outros objetos stub foram criados e precisam ser explorados pelo desenvolvedor para testar as outras operações do serviço.

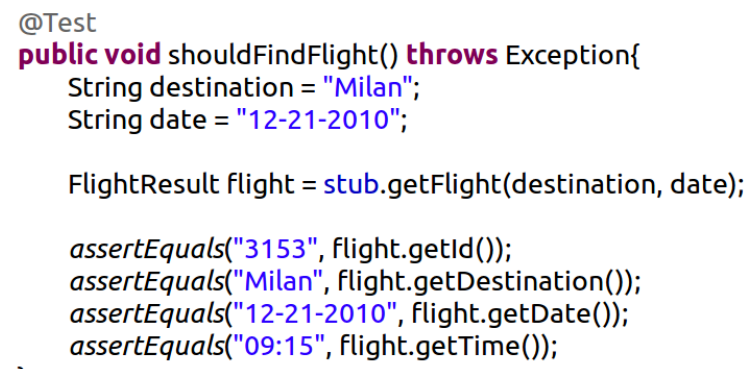

Figura 5.7: Exemplo com stubs (caso de teste A)

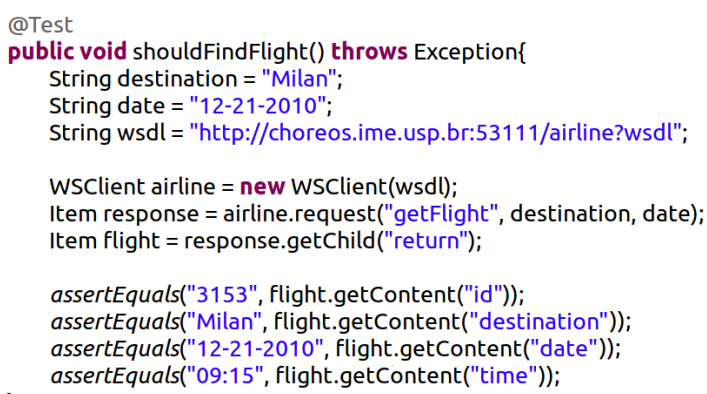

Figura 5.8: WSClient (caso de teste B)

O caso de teste B, por sua vez, é independente de geração de stubs. O trecho de código apresentado é tudo o que o desenvolvedor precisa para testar a operação getFlight. Além disso, se a interface WSDL do serviço mudar, apenas o nome da operação e parâmetros precisarão ser alterados, caso necessário.

O diagrama da Figura 5.9 ilustra como os passos do fluxo de execução interno do WSClient (Figura 5.1) são executados pelas classes da Figura 5.2 para a invocação de uma operação de um serviço web.

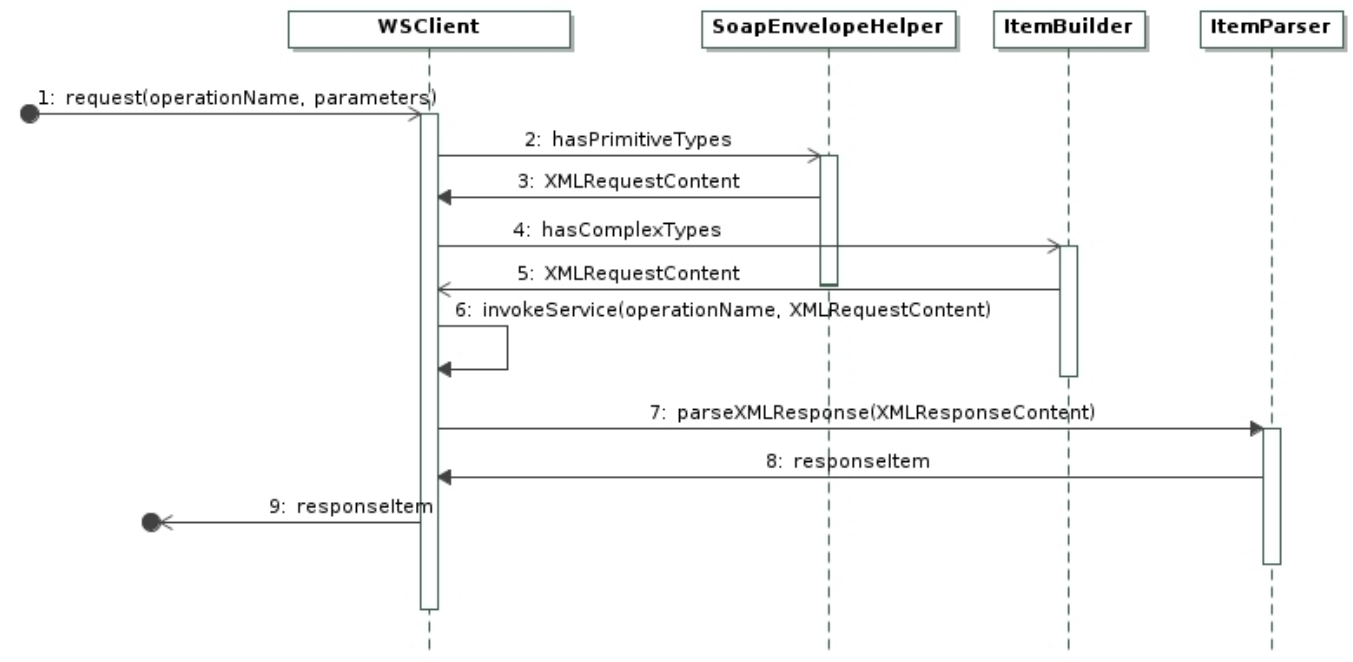

Figura 5.9: Invocação de uma operação de um serviço web

\section{Item Explorer}

Para auxiliar o desenvolvedor na escrita dos objetos Item, criamos a ferramenta Item Explorer, que automatiza a criação desses objetos. A partir de um arquivo WSDL válido, essa ferramenta cria automaticamente esqueletos de objetos Item para realizar a invocação das operações do serviços, assim como objetos Item para representar a resposta. A Figura 5.10 ilustra essas funcionalidades da Item Explorer. 


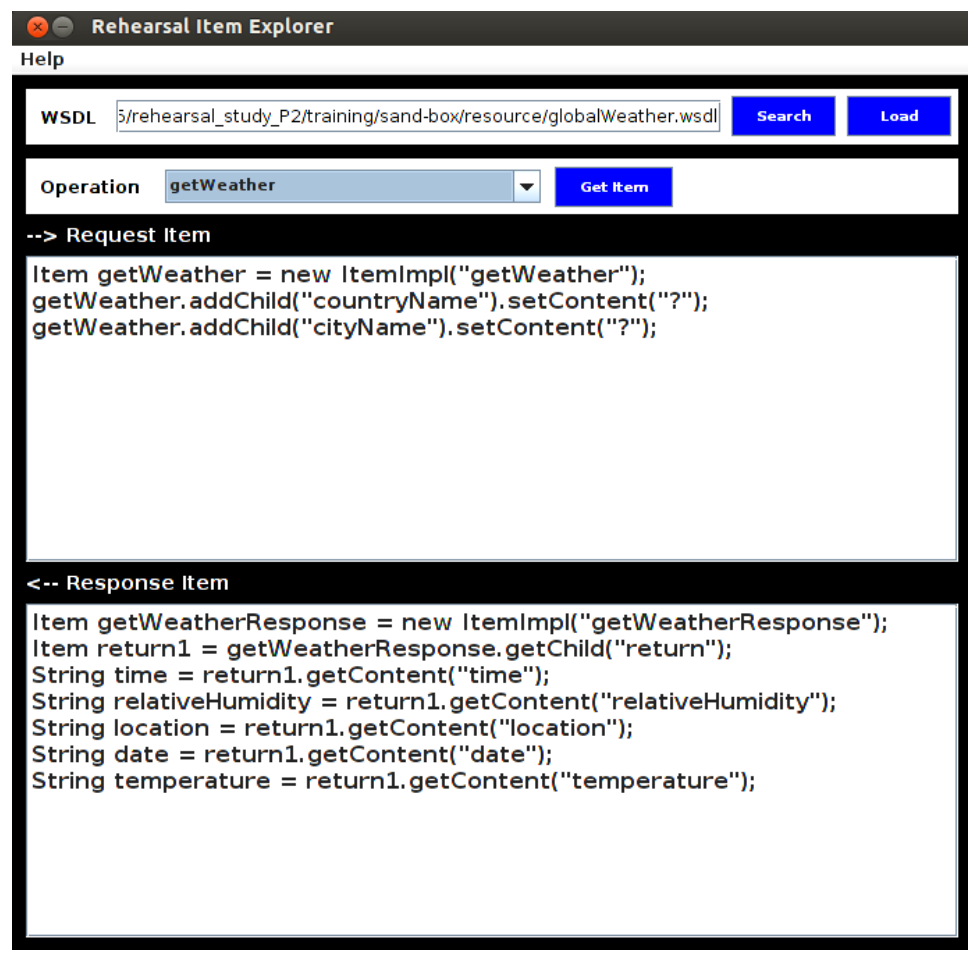

Figura 5.10: Ferramenta Item Explorer

Uma vez que objetos Item são gerados pelo Item explorer, eles podem ser reutilizados pelo desenvolvedor em seus testes, facilitando a invocação e tratamento de respostas dos serviços em teste.

\subsubsection{Suporte a serviços REST}

Embora a maioria das linguagens para modelagem e execução de composição de serviços utilizem serviços Soap/WSDL, o Rehearsal também oferece uma funcionalidade para invocação e teste de serviços REST. Essa funcionalidade, chamada RSClient, facilita a invocação de operações CRUD (Create, Read, Update e Delete) de recursos. Com base em uma URI, o arcabouço auxilia o desenvolvedor na aplicação das operações POST, GET, PUT ou DELETE.

RSClient foi desenvolvida a partir da ferramenta de código-livre REST-assured ${ }^{8}$. A Figura 5.11 apresenta o fluxo de execução para a invocação de serviços REST.

operation: GET, POST, PUT, DELETE
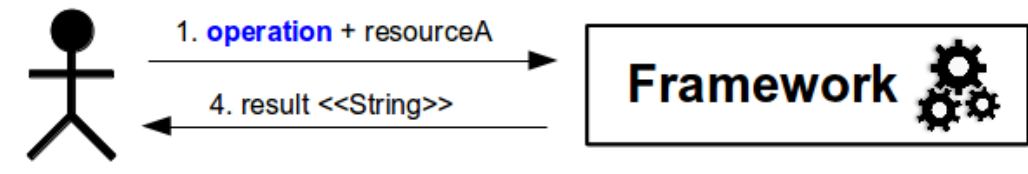

Resource A

Figura 5.11: Fluxo de execução para invocação de serviços REST

No passo 1, para interagir com o recurso desejado, o desenvolvedor fornece sua URI e a operação desejada (GET, POST, PUT e DELETE), que deve ser aplicada no teste. Conforme mostrado na Figura 5.11, RSClient invoca o recurso testado (passo 2), coleta a resposta e então, apresenta os resultados ao desenvolvedor, nos passos 3 e 4 , respectivamente.

${ }^{8}$ REST-assured: http://code.google.com/p/rest-assured 
A resposta de um serviço REST não é definida utilizando padrões tais como WSDL, assim, o arcabouço apenas retorna o conteúdo recebido pelo serviço em teste. Dado que essa resposta pode ser representada em diferentes formatos tais como HTML, texto, XML, JSON, PDF, entre outros, na versão corrente desta funcionalidade, a validação do conteúdo recebido deve ser realizada pelo desenvolvedor.

As principais vantagens decorrentes do uso do RSClient são: (i) a abstração de questões ligadas à comunicação, por exemplo, enviar, receber e tratar chamadas HTTP; (ii) o oferecimento de uma interface simples para aplicação das operações CRUD nos recursos. A Figura 5.12 apresenta a interface pública do RSClient.

\begin{tabular}{|c|}
\hline RSClient \\
\hline 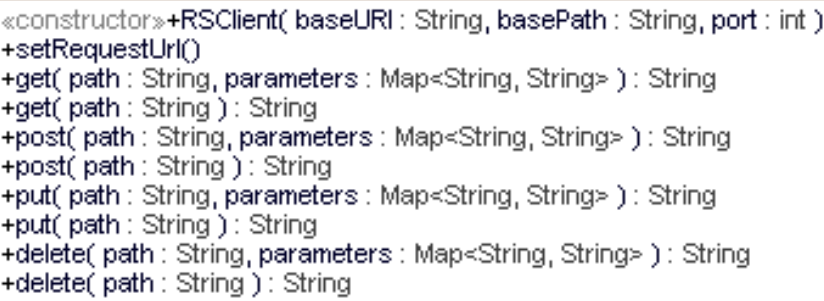 \\
\hline
\end{tabular}

Figura 5.12: Interface pública do RSClient

A Figura 5.13 apresenta um exemplo de aplicação da operações GET, POST e DELETE utilizando o RSClient. Neste exemplo, primeiramente, o desenvolvedor especifica informações do serviços tais como sua URI, localização de um recurso e a porta onde o serviço está disponível. Essas informações são fornecidas ao se criar o construtor do RSClient. Então, a operação POST é aplicada para a criação de um novo livro (linhas 20-24). Para validar a criação do recurso, a operação GET é aplicada no recurso "book" que acabou de ser criado.

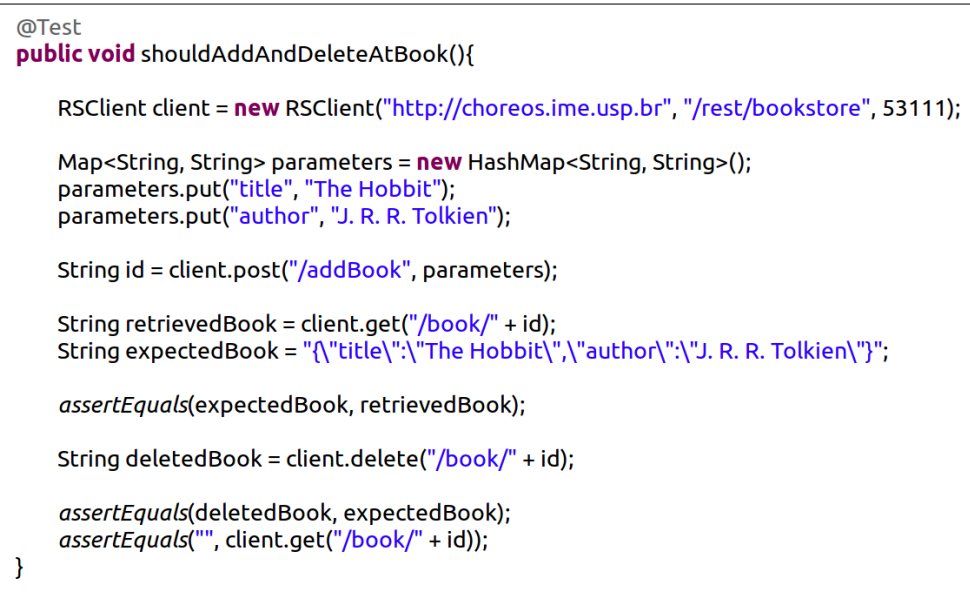

Figura 5.13: RSClient: Exemplo de utilização

Como resultado, um objeto JSON é obtido e validado, conforme ilustrado nas linhas 26-29. Para finalizar o teste e não influenciar na execução de demais testes, o recurso recém criado é apagado. Seguindo as convenções de REST, a operação DELETE é aplicada sob a URI que contém o identificador do recurso. Para validar o resultado da remoção, a aplicação GET é novamente aplicada no identificador do recurso, e espera-se que ela devolva um resultado vazio. As linhas 31-34 ilustram a operação DELETE e a posterior aplicação da operação GET para a validação. Conforme pode ser observado, neste exemplo o desenvolvedor apenas teve que escrever os casos de testes, ou seja, não houve a necessidade de tratar nenhuma chamada HTTP. 


\subsection{Interceptador de mensagens}

No contexto de coreografias, testes de integração podem ser aplicados pela validação das mensagens trocadas pelos serviços em uma composição. Durante o desenvolvimento de uma coreografia, há dois níveis de integração:

1. Intra-papéis da coreografia. Conforme discutido na Seção 3.4, um papel da coreografia pode ser implementado como uma composição de serviços web. Nesse nível de integração, as mensagens trocadas internamente nesta composição são validadas.

2. Inter-papéis da coreografia. Neste nível de integração, as mensagens trocadas entre os papéis de uma coreografia são validadas. Essas mensagens correspondem àquelas especificadas no modelo global da coreografia.

O Rehearsal suporta ambos níveis de integração em um ambiente offline para a execução dos testes. De maneira incremental, após um novo serviço ou papel ser adicionado à coreografia, o desenvolvedor pode validar mensagens recebidas ou enviadas por este novo serviço ou papel da coreografia. Em nosso protótipo (Seção 5.1), a interceptação de mensagens foi implementada com a instrumentação da coreografia em teste. Assim, dentro da coreografia, quando uma mensagem devia ser enviada a um serviço, inicialmente ela era enviada a um repositório de mensagens. Após os testes, o desenvolvedor podia invocar esse repositório, coletar e validar as mensagens desejadas. Embora fosse eficiente, a abordagem [BLK $\left.{ }^{+} 11 b\right]$ estava acoplada ao arcabouço OpenKnowledge. Além disso, o protótipo apenas suportava a interceptação de mensagens de conteúdo simples, basicamente Strings.

Para solucionar os problemas identificados no protótipo, Rehearsal fornece um Interceptador de mensagens. Por meio dessa funcionalidade, mensagens mais complexas (XML) podem ser coletadas e validadas. Além disso, essa funcionalidade pode ser utilizada juntamente com qualquer arcabouço compatível com serviços Soap/WSDL. A interceptação de mensagens acontece por meio de proxies de serviços. A Figura 5.14 ilustra o fluxo básico de utilização dessa funcionalidade.

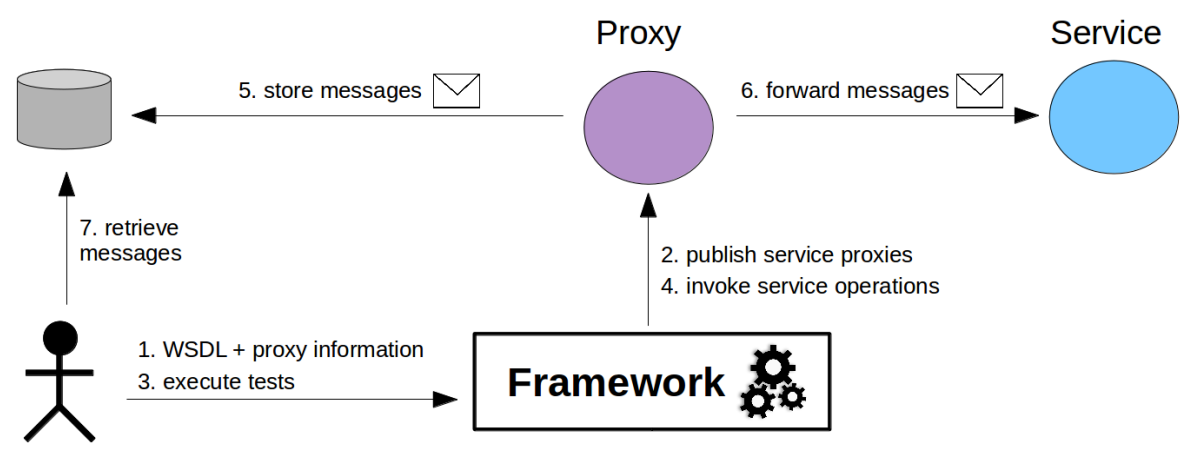

Figura 5.14: Fluxo de interação para utilização do interceptador de mensagens

No primeiro passo do fluxo apresentado na Figura 5.14, o desenvolvedor informa a URL onde a especificação WSDL do serviço está disponível, assim como a porta e o nome do host (domínio) onde o proxy será publicado. No passo 2, o proxy é publicado automaticamente pelo Rehearsal. Nesse ponto do processo, o desenvolvedor pode solicitar a publicação de mais de um proxy. Uma entidade proxy consiste em objeto que fornece fielmente o mesmo contrato (interface WSDL) que o serviço que será interceptado. O proxy é criado e publicado utilizando uma API para mocks do SoapUI.

No passo 3, os testes escritos pelo desenvolvedor são executados pelo Rehearsal. Na execução, os proxies recém criados são invocados ao invés dos serviços reais (passo 4). Quando um proxy é invocado, a mensagem recebida é armazenada e repassada para o serviço real. Finalmente, o desenvolvedor pode, no passo 7, extrair as mensagens interceptadas e validá-las.

As mensagens são interceptadas em uma instância de MessageInterceptor. Como pode ser observado na Figura 5.15, por meio dos métodos providos pela classe MessageInterceptor, o desenvolvedor 


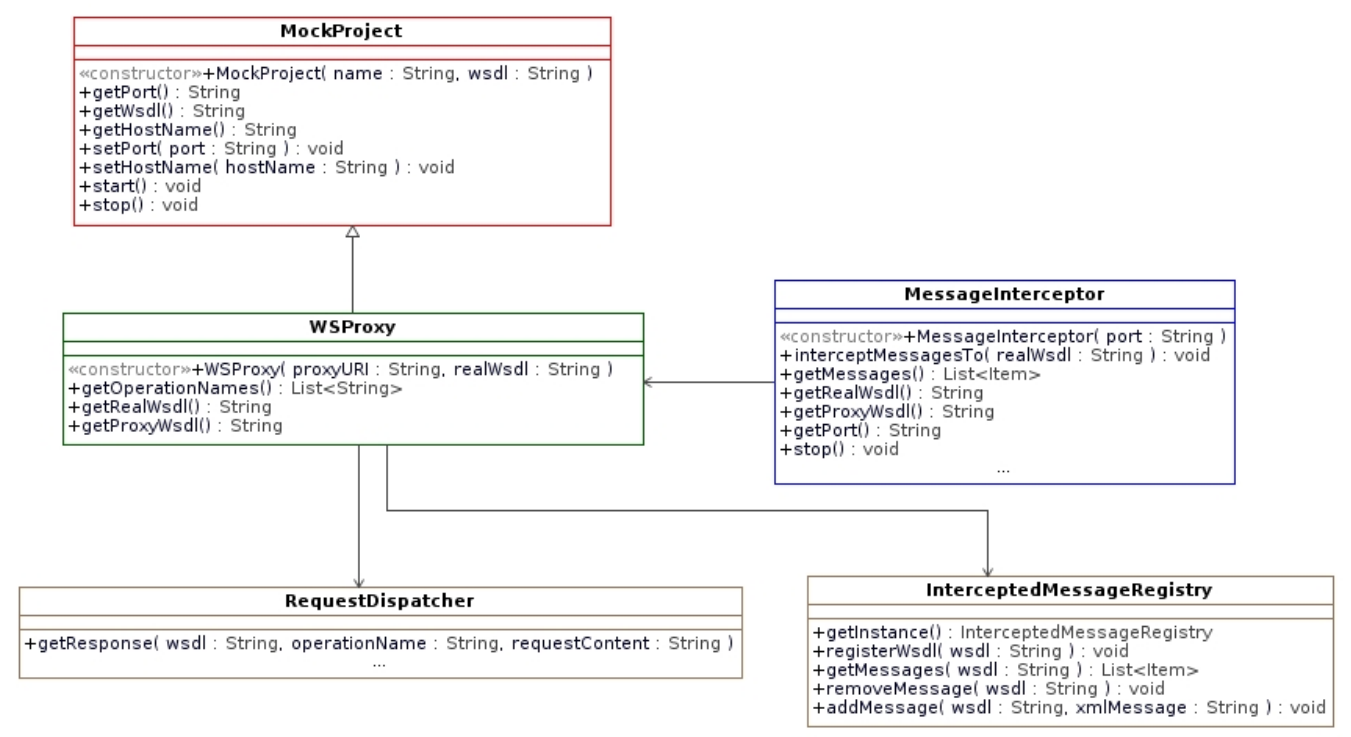

Figura 5.15: Interface pública do Interceptador de mensagens

pode extrair as mensagens interceptadas, reconfigurar o proxy e parar sua execução. A Figura 5.16 ilustra um exemplo de utilização dessa funcionalidade. Nas linhas 39-40, o interceptador é instanciado, configurado para ser publicado na porta " 4321 " e para interceptar as mensagens enviadas para a URL especificada.

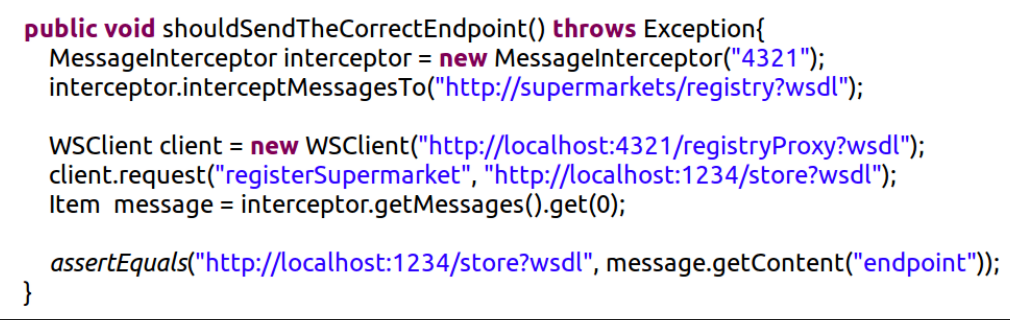

Figura 5.16: Message Interceptor: Exemplo de utilização

Nas linhas 42-43 da Figura 5.16, o proxy é invocado, por meio da operação "registerSupermarket". Em seguida, a mensagem interceptada é recuperada e validada, conforme ilustrado nas linhas 44-47. Esse exemplo é bem simples, pois a mensagem interceptada é a mesma disparada pelo teste, ou seja, a mensagem é conhecida, logo, não precisaria ser interceptada. O objetivo desse teste é apenas demonstrar o funcionamento da devida funcionalidade.

Nos testes de integração para a coreografia, proxies são criados para interceptar mensagens trocadas no fluxo interno de informações da coreografia. O relacionamento entre as classes envolvidas na interceptação das mensagens é apresentado no diagrama de sequência da Figura 5.17.

$\mathrm{Na}$ versão atual do interceptador de mensagens, para a aplicação dos testes de integração, a coreografia deve ser reconfigurada para enviar e receber as mensagens do proxies, ao invés dos serviços reais. Além disso, em nossa implementação, os proxies devem ser publicados na máquina do desenvolvedor. Algumas linguagens para composição de serviços, tais como BPEL, fornecem mecanismos para a reconfiguração dinâmica de composições, porém, até o momento da escrita deste trabalho, não há ferramentas que implementem isso corretamente.

Em um trabalho futuro, o Rehearsal poderá integrado às ferramentas que implementem esses mecanismos. Além disso, a ferramenta pode ser estendida para permitir a implementação de proxies remotos. 


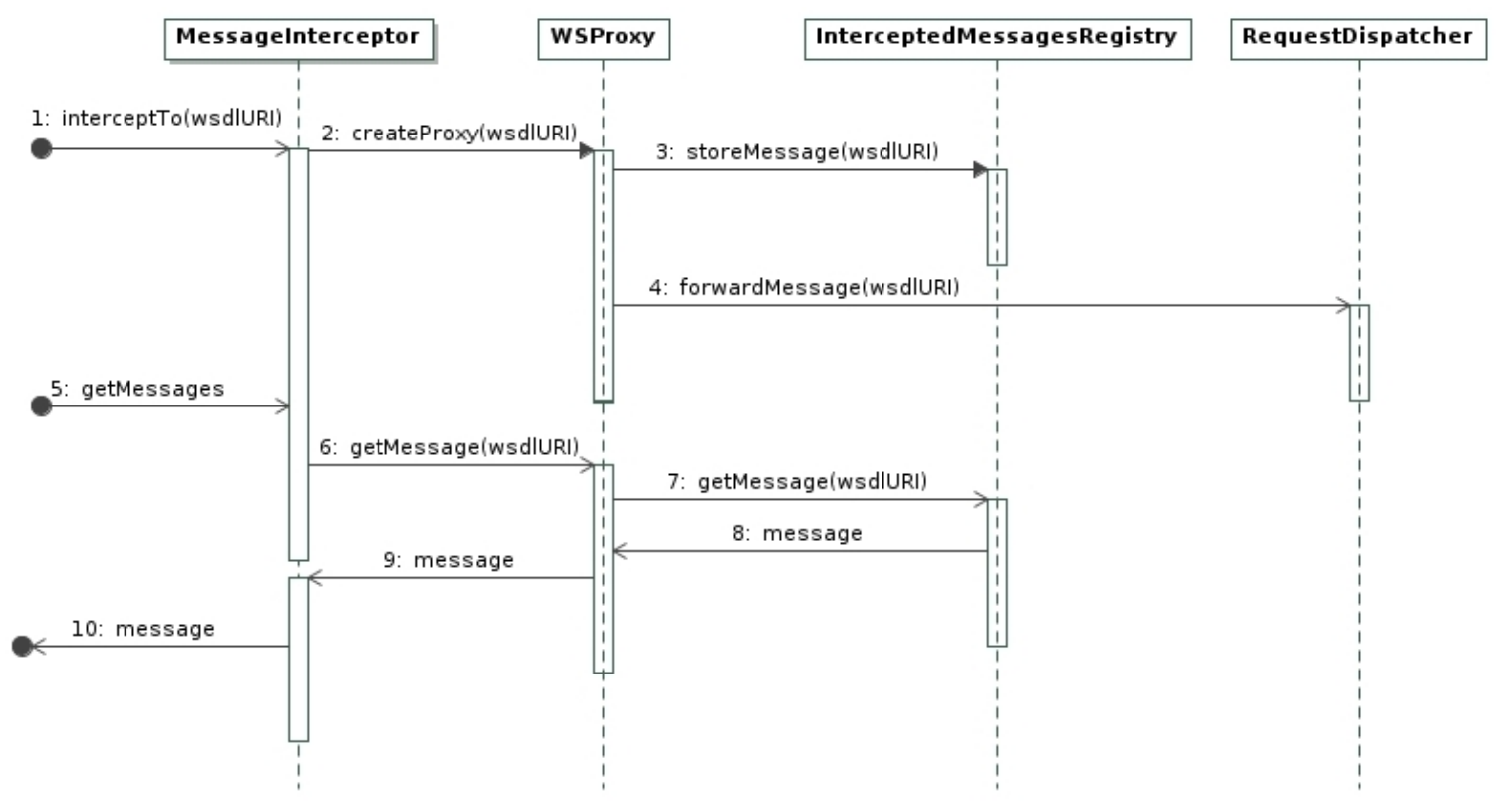

Figura 5.17: Interceptação de mensagens

\subsection{Emulação (Mocking) de serviços}

A integração inter-organizacional entre serviços web é uma das características inerentes de SOA. Apesar da vantagens, esta integração também introduz alguns problemas para o teste dos serviços, como, por exemplo, a ausência de um ambiente de testes para a invocação dos serviços.

Com a falta de um ambiente dessa natureza, algumas operações de serviços (e.g., operações não idempotentes) não podem ser testadas completamente. Consequentemente, testes completos de integração de composições que envolvam serviços com essas restrições não podem ser conduzidos. Para amenizar este problema, o Rehearsal fornece uma funcionalidade para a emulação (mocking) das operações desses serviços.

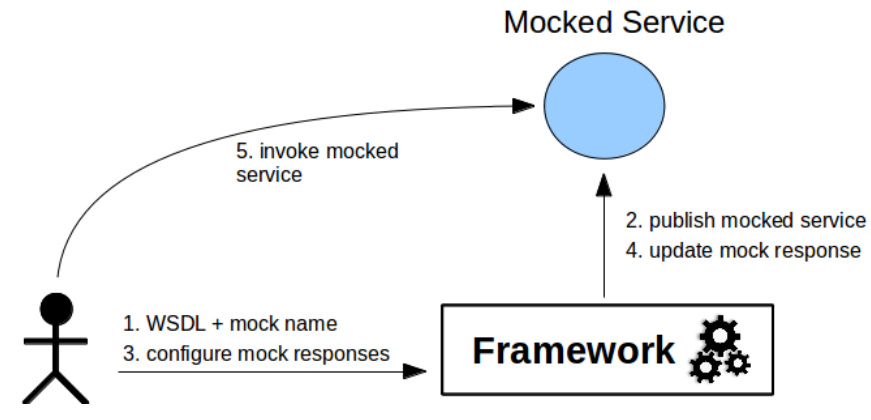

Figura 5.18: Fluxo de emulação de serviços

A Figura 5.18 apresenta o fluxo básico de utilização desta funcionalidade do Rehearsal. No primeiro passo, o desenvolvedor informa ao arcabouço a URL da especificação WSDL do serviço real e o nome do mock a ser criado. Então, o Rehearsal, por meio da API de mocks do SoapUI, cria e publica um objeto mock utilizando o nome para o mock fornecido (passo 2). Também é possível definir a porta e o nome do host (domínio) onde será publicado o mock. É possível mudar o comportamento do serviço emulado mesmo quando este já estiver em execução.

Conforme apresentado na Figura 5.19, o objeto WSMock representa o serviço emulado. Como pode ser observado nos construtores, o objeto WSMock também pode ser um interceptador, ou seja, pode armazenar as mensagens recebidas para posterior validação do desenvolvedor. O diagrama de 


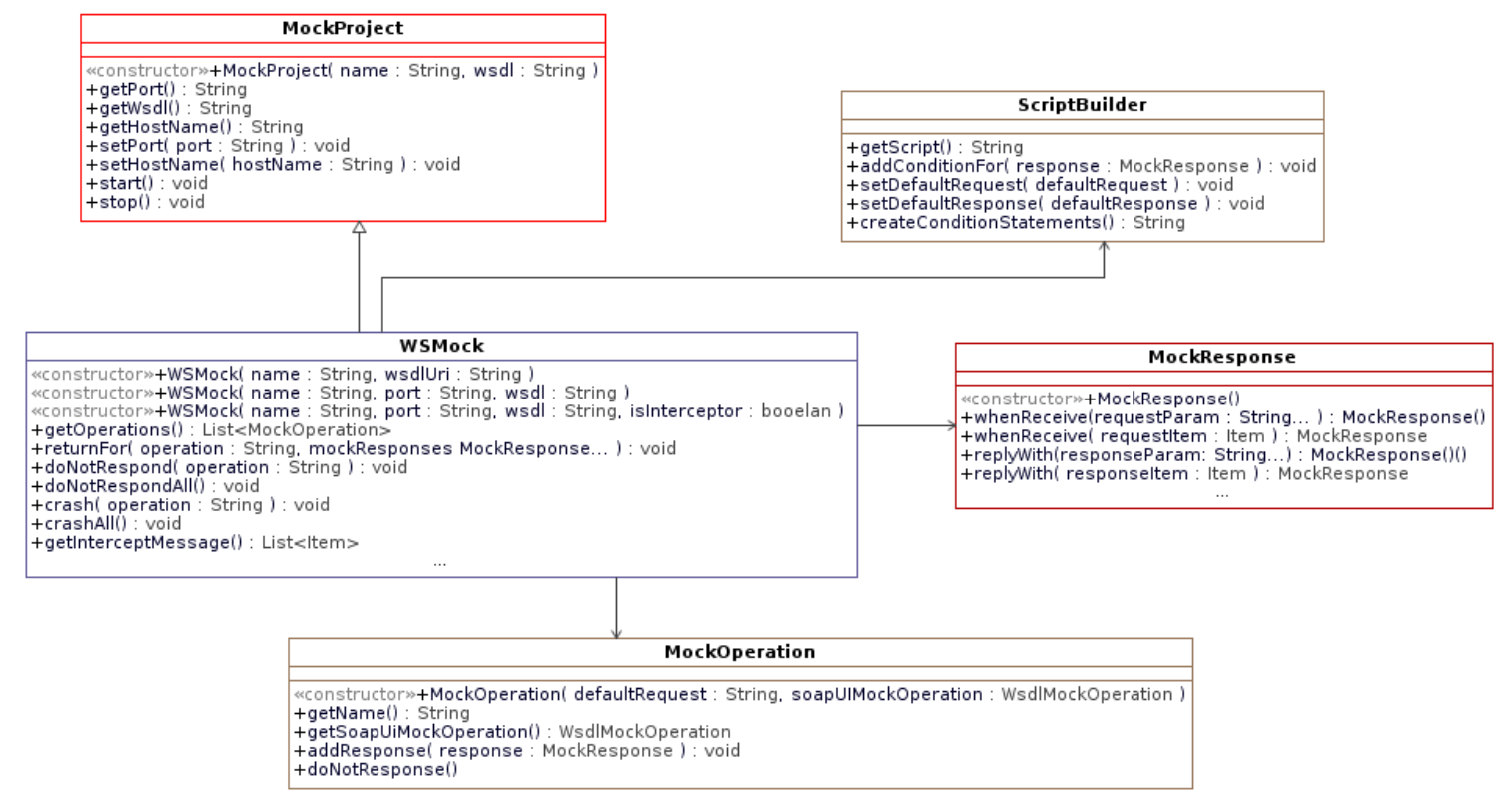

Figura 5.19: Interface pública do WSMock

sequência da Figura 5.20 apresenta o relacionamento entre as classes internas do Rehearsal no processo de criação e configuração do objeto WSMock.

Por meio do objeto WSMock, o desenvolvedor pode configurar diferentes respostas a serem retornadas pelo serviço emulado. Além disso, esta funcionalidade pode auxiliar no teste de cenários de falhas. A classe WSMock fornece os métodos doNotRepond e doNotRepondAll para simular a ausência de resposta (timeout); e os métodos crash e crashAll, para simular uma queda do serviço.

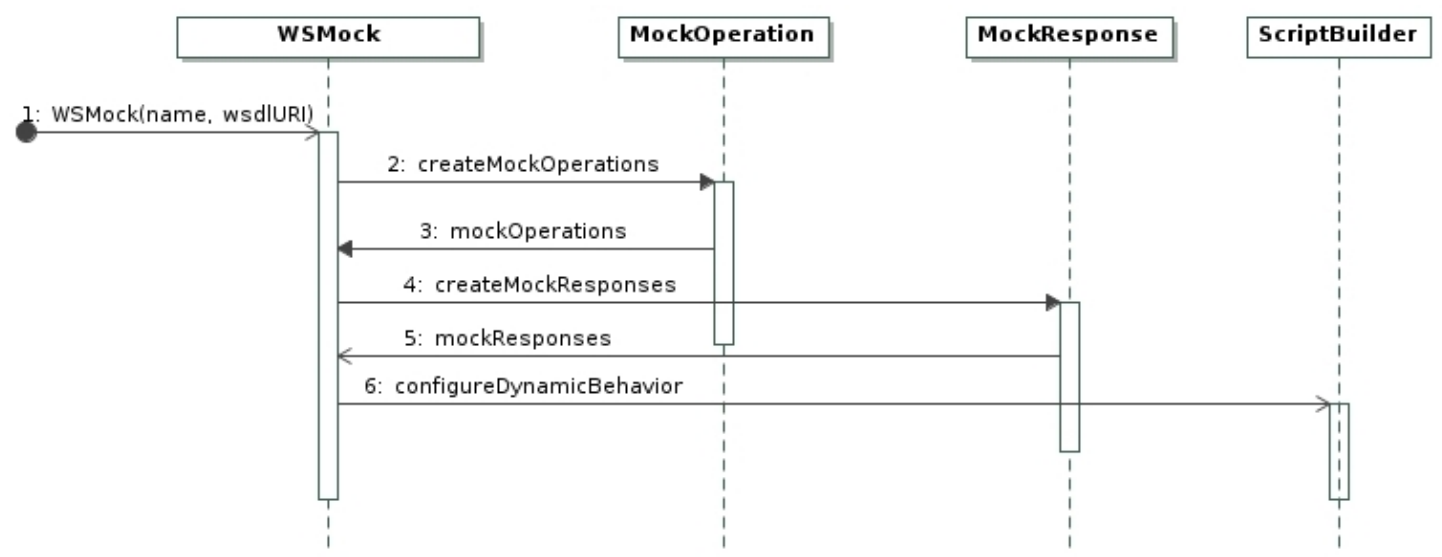

Figura 5.20: Criaçãa e configuração de mock

No terceiro passo da Figura 5.18, o desenvolvedor configura novas ou atualiza respostas existentes para o serviço emulado. Essas respostas são aplicadas ao serviço pelo arcabouço no passo 4. A fim de simular cenários específicos, o desenvolvedor pode definir respostas condicionais que são retornadas pelo serviço emulado caso determinadas condições sejam cumpridas. As Figuras 5.21 e 5.22 ilustram um cenário simples de utilização de mensagens condicionais.

Na linha 21 do trecho de código da Figura 5.21, um mock, de nome "smMock", é criado para o serviço disponível na URL especificada na variável SM_WSDL_URI. O serviço emulado fornece o mesmo contrato (interface WSDL) do serviço real e é publicado na URL: http://localhost:4321/smMock. Um condicional é definido na linha 23. Caso o conteúdo da mensagem recebida pelo mock contenha a palavra coke, a mensagem respondida deve mostrar o preço 3.50. Um condicional similar é definido na linha 24. Por fim, o condicional da linha 25 define que para as demais mensagens, ou 


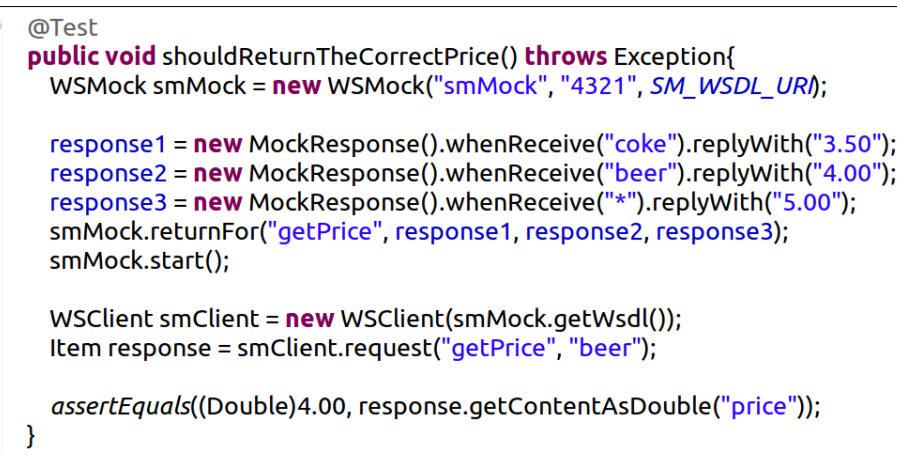

Figura 5.21: WSMock: Exemplo de utilização

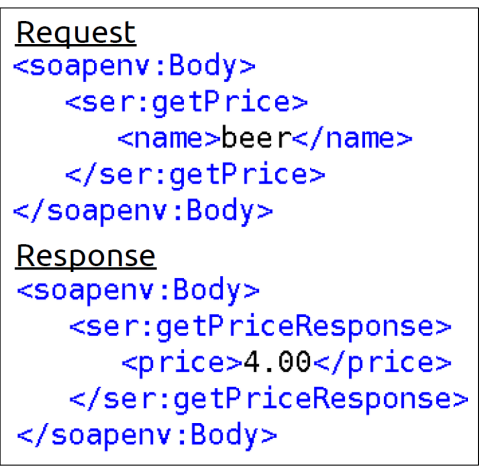

Figura 5.22: Soap envelopes

seja, àquelas que não contiverem as palavras coke ou beer, o preço retornado será 5.00.

Nas linhas 26-27, o serviço emulado é configurado para retornar as mensagens condicionais definidas quando a operação "getPrice" é invocada. Nas linhas 29-32, o teste invoca o serviço emulado e valida sua resposta. A Figura 5.22 apresenta as mensagens XML que são trocadas quando a linha 29 é executada.

Nesse exemplo, as mensagens condicionais e as respostas definidas contêm apenas um parâmetro de entrada e saída, e representam apenas tipos primitivos. Por essa razão, não foi preciso informar ao arcabouço que os condicionais estavam relacionados aos campos "name" e "price" das mensagens de requisição e resposta, respectivamente. No entanto, o Rehearsal também fornece mecanismos para a definição de mensagens condicionais usando tipos complexos. Neste caso, pode-se usar objetos Item como parâmetros dos métodos whenReceive e replyWith.

Assim como na utilização do interceptador de mensagens, a coreografia deve ser reconfigurada para invocar os mocks criados. Como trabalho futuro, mocks poderiam ser introduzidos automaticamente por meio da reconfiguração dinâmica da coreografia.

\subsection{Abstração da coreografia}

Para facilitar a escrita dos testes e a utilização das funcionalidades descritas previamente, o Rehearsal provê uma funcionalidade para a abstração de uma coreografia em objetos. Com esta funcionalidade, elementos de uma coreografia, tais como serviços, papéis e mensagens, podem ser representados por objetos Java.

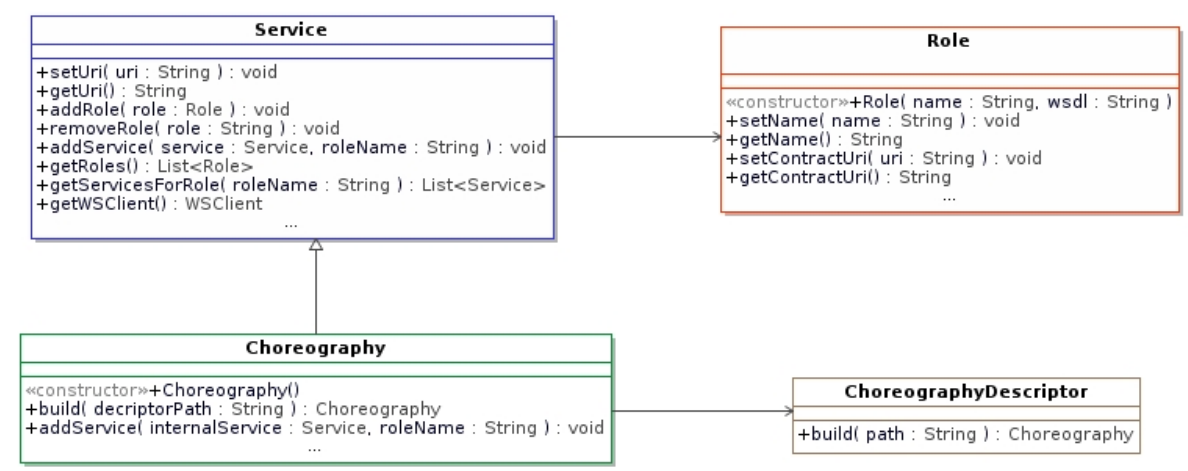

Figura 5.23: Interface pública da Abstração da Coreografia

Como pode ser observado na Figura 5.23, o objeto coreografia é criado a partir de um arquivo descritor e corresponde a um composite por meio do qual o desenvolvedor pode interagir com todos os serviços da coreografia. Cada serviço está associado a um ou mais papéis da coreografia. Por meio do objeto Choreography, o desenvolvedor pode extrair a URI da especificação WSDL do serviço 
desejado. Devido à natureza recursiva de uma composição de serviços, um objeto Service pode ser uma composição de outros serviços. Como pode ser observado, o próprio objeto Choreography é um Service. Assim, a partir de um objeto Service, uma lista de seus serviços internos pode ser extraída.

Utilizando esses objetos, o desenvolvedor pode escrever testes antes de implementar a coreografia. Durante o desenvolvimento, os testes são escritos utilizando os objetos Service e não os endpoints específicos. Em tempo de execução, o Rehearsal interagirá com o sub-sistema Synthesis Processor $^{9}$ do projeto CHOReOS para mapear os objetos Services utilizados em endpoints reais.

O sub-sistema Synthesis Processor extrai os endpoints do serviços a partir de um modelo de coreografia especificado em BPMN2. Na versão atual da funcionalidade da abstração da coreografia, Rehearsal ainda não está integrada com esse sub-sistema. Nesta versão, os elementos da coreografia são extraídos de um arquivo descritor.

O descritor consiste em um arquivo YAML (YAML Ain't Markup Language) ${ }^{10}$ que contém os endpoints do serviços e papéis envolvidos na coreografia. Um exemplo deste arquivo para a coreografia FutureMarket (Seção 3.4.1) pode ser encontrado no Apêndice A deste trabalho. Em tempo de execução, Rehearsal extrai do arquivo descritor os endpoints dos objetos Service utilizados nos testes.

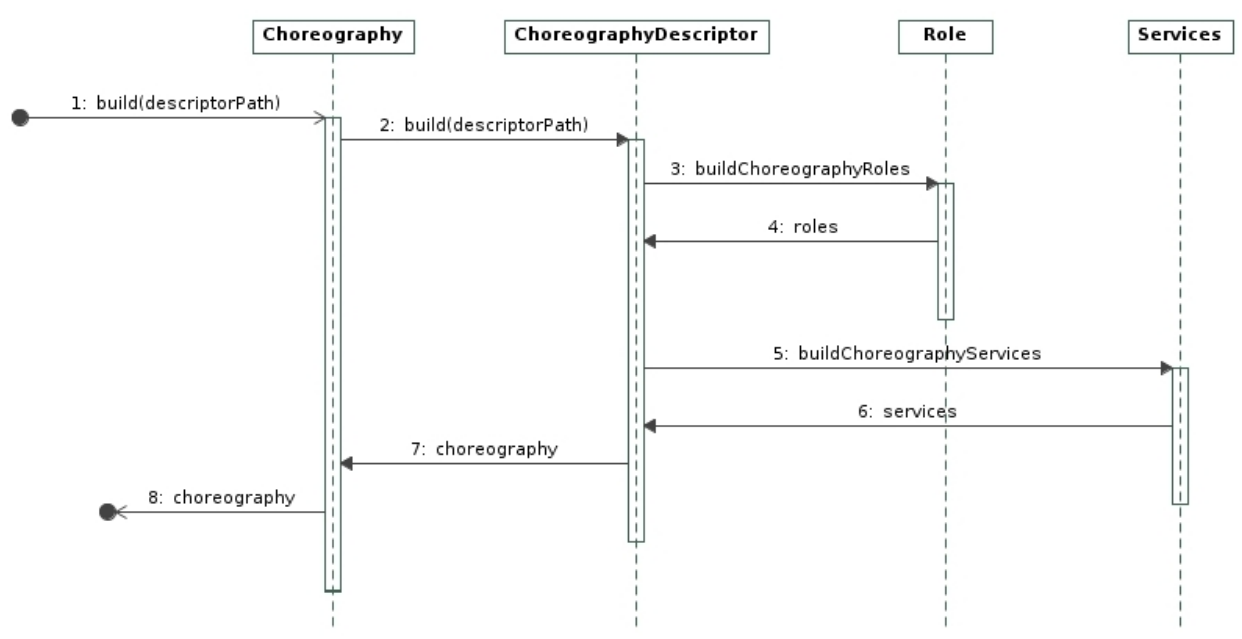

Figura 5.24: Criação do objeto Choreography

Embora não seja totalmente automatizado, o uso do descritor permite ao desenvolvedor aplicar os mesmos testes para serviços localizado em diferentes hosts. Assim, testes escritos para serviços em um ambiente de testes funcionarão para serviços de um ambiente de produção uma vez que apenas os endpoints do arquivo descritor, do ambiente de produção, serão diferentes.

A Figura 5.24 ilustra a interação entre as classes desta funcionalidade durante a construção de um objeto Choreography a partir de uma arquivo descritor. Com a abstração da coreografia em objetos é possível utilizar as funcionalidades descritas previamente mais facilmente.

A Figura 5.25 ilustra exemplos de como utilizar os elementos da coreografia como entrada para o WSClient, WSMock e Interceptador de mensagens. Nos três exemplos apresentados, as funcionalidades utilizam os endpoints vindos de objetos Service. No caso do WSMock, por exemplo, por meio da chamada "getServicesByRole("airline").get(0)", é possível extrair o objeto Service que implementa o papel airline. A partir desse objeto, por meio da chamada "arline1.getURI()", é possível extrair a URI da especificação WSDL do serviço que implementa esse papel na coreografia. Como pode ser observado, em nenhum dos três exemplos, os endpoints reais precisaram ser informados.

\footnotetext{
${ }^{9}$ Synthesis Processor: http://choreos.eu/bin/Download/Deliverables

${ }^{10}$ YAML: http://www.yaml.org
} 


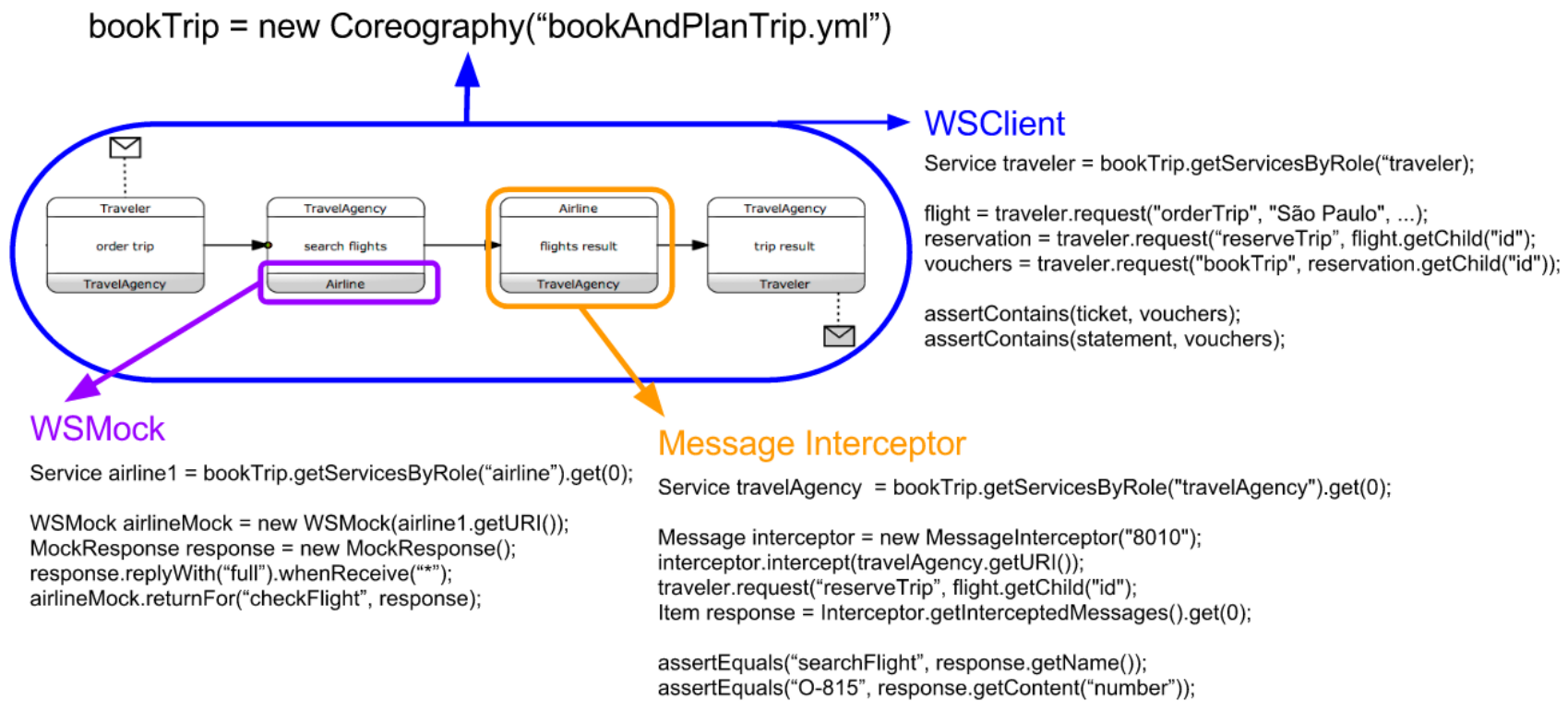

Figura 5.25: Exemplos de utilização da Abstração da Coreografia

\subsection{Execução de testes de conformidade}

Testes de conformidade têm como objetivo verificar se um determinado serviço da coreografia está desempenhando o seu papel corretamente. Esses testes consistem em um caso especifico dos testes de unidade e são aplicados após os testes de integração internos a um papel da coreografia. A abordagem para execução de testes de conformidade provida pelo Rehearsal contém três elementos principais:

- Oráculo. O oráculo consiste em uma especificação WSDL (contrato) de um papel da coreografia. Este contrato deve ser obrigatoriamente oferecido pelo serviço que desempenha o papel.

- Testes de conformidade. São casos de testes genéricos associados a um determinado papel da coreografia.

- Asserção de papel. Esta asserção verifica se um serviço candidato a participante da coreografia está em conformidade com o papel implementado.

A Figura 5.26, ilustra a utilização dos três elementos definidos acima. Na linha 35, um oráculo é fornecido ao Rehearsal, informando-se a URL da especificação WSDL de um papel da coreografia. Em seguida, um objeto Service é criado e uma URL apontando para sua especificação WSDL é definida (linha 37). Este objeto poderia ser também criado automaticamente utilizando a funcionalidade de abstração da coreografia, mostrada na seção anterior.

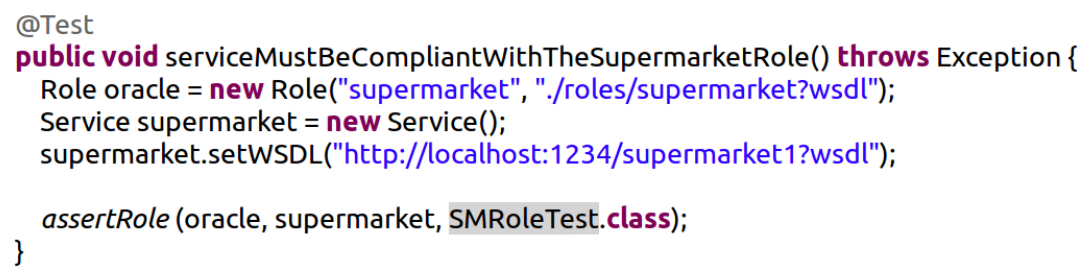

Figura 5.26: Exemplo de aplicação de casos de conformidade

Nesse exemplo, os casos de teste de conformidade foram definidos na classe "SMRoleTest". Esses casos de teste são simples e foram especificados em JUnit. O desenvolvedor pode defini-los livremente 
com base nos requisitos mínimos que devem ser fornecidos para aquele papel da coreografia. Nesses casos de testes, o endpoint para qual os testes devem ser aplicados não é definido. Essa informação é fornecida pelo Rehearsal em tempo de execução, com base no serviço passado como parâmetro na asserção.

Na linha 39, a asserção "assertRole" verifica se o serviço está de acordo com o papel implementado. Durante a execução desta asserção é verificado se: (a) o serviço fornece a mesma interface (nome das operações, parâmetros de entrada, e retorno) do oráculo definido; e (b) todos os testes de conformidade são executados com sucesso. Se ambas as condições forem cumpridas, o serviço está em conformidade com o papel implementado.

Essa funcionalidade é particularmente útil quando há muitos serviços para um determinado papel, e deseja-se verificar se todos estão em conformidade com base em um conjunto de testes padrão. A funcionalidade também tem bastante utilidade para verificar se serviços de terceiros implementam corretamente os papéis da coreografia.

\subsection{Arquitetura}

Nesta seção, será apresentada a arquitetura do Rehearsal para prover as funcionalidades explicadas previamente. Com exceção do teste de conformidade, o arcabouço não possui módulos para aplicação de asserções de teste. Deste modo, Rehearsal fornece funcionalidades para automatizar as ações que são tomadas no teste (e.g., invocar serviços ou capturar mensagens trocadas) e precisa ser utilizado em conjunto com outros arcabouços de testes, tais como JUnit ${ }^{11}$ ou TestNG ${ }^{12}$, para a execução de casos de teste. A Figura 5.27 apresenta a arquitetura do Rehearsal, levando em conta essa interação com os arcabouços. Em seguida cada um dos módulos da arquitetura é explicado em detalhes.

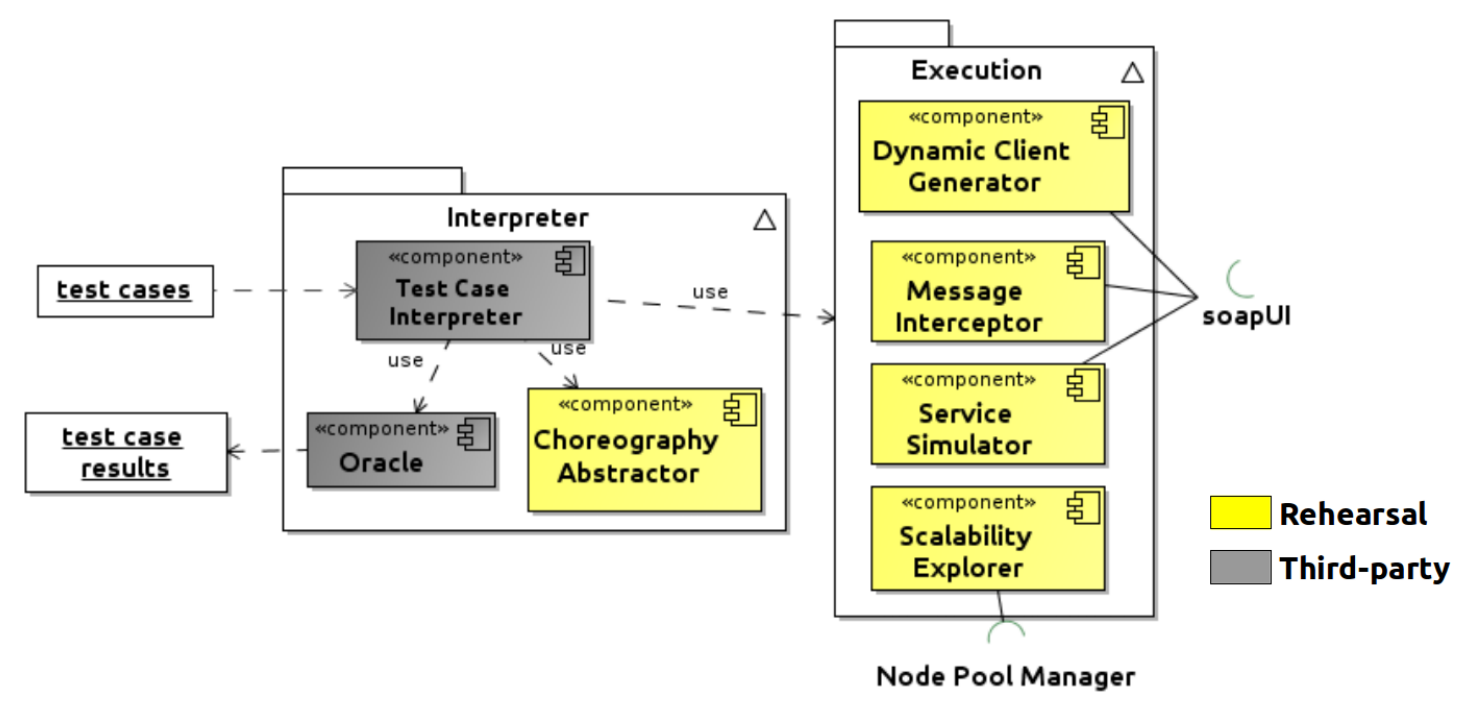

Figura 5.27: Arquitetura do Rehearsal

\subsubsection{Interpreter}

Este módulo contém os componentes responsáveis por "processar" os casos de testes. Esse processo é guiado pelo componente Test case interpreter que corresponde aos componentes de terceiros utilizados na execução dos casos de testes. No caso do JUnit, por exemplo, este componente corresponde ao JUnit Test Executor, uma classe interna do JUnit. Rehearsal não está acoplado a esta classe a nível de implementação. No entanto, conforme ilustrado nos exemplos da funcionalidades

\footnotetext{
${ }^{11}$ JUnit: www.junit.org

${ }^{12}$ TestNG: http://testng.org
} 
do Rehearsal, é necessário a utilização do JUnit ou TestNG para criação e execução de asserções de testes.

Durante a execução dos casos de teste, os endpoints do serviços e funcionalidades do Rehearsal são identificados. Esses elementos são processados pelo componente Choreography Abstractor. Para cada comando e funcionalidade do Rehearsal presente nos casos de testes, o componente responsável pela execução é chamado.

Por exemplo, quando um comando interceptMessagesTo(...) é encontrado, o componente Message Interceptor é chamado. Nesta chamada, todas as informações necessárias para interceptação (e.g., endpoint do serviço) são extraídas do componente Choreography Abstrator e utilizadas no Message Interceptor.

Cada asserção definida nos casos de testes é processada pelo componente Oracle. Em TDD, os resultados esperados de um caso de teste são definidos pelo próprio desenvolvedor durante a escrita do teste. Assim, pode-se considerar que o desenvolvedor é o oráculo. Dado que no Rehearsal os casos de testes são especificados utilizando arcabouços de terceiros (e.g., JUnit), o processo de verificar se os valores obtidos nos testes correspondem àqueles esperados é realizado pelo arcabouço de testes escolhido.

\subsubsection{Execution}

Este módulo contém os componentes necessários para a execução das funcionalidades do Rehearsal. O componente Dynamic client generator é responsável pela criação, utilização e execução dos clientes dinâmicos para serviços web. O componente MessageInterceptor tem como objetivo criar os proxies, interceptar e armazenar as mensagens. Por meio do componente Service Simulator, os serviços podem ser emulados. Esses três componentes utilizam algumas funcionalidades do SoapUI para fornecer as funcionalidades do Rehearsal.

O componente Scalability Explorer tem como objetivo o suporte ao teste de escalabilidade. De acordo com Quinn [Qui94], uma aplicação é escalável ao atingir o mesmo desempenho quando sua capacidade arquitetural aumenta na mesma proporção que a carga de trabalho. Rehearsal visa promover uma funcionalidade que auxilie o desenvolvedor a conduzir avaliações de escalabilidade. Essa funcionalidade está fora do escopo desta dissertação de mestrado e está sendo desenvolvida por outro aluno do grupo de pesquisa no qual este trabalho está inserido. No entanto, futuramente, a devida funcionalidade será integrada ao Rehearsal. Um dos objetivos dessa funcionalidade será gerenciar automaticamente os nós de uma infra-estrutura de computação em nuvem para desenvolver e conduzir os testes de escalabilidade. Para atingir este objetivo, o Rehearsal será integrado ao Node Pool Manager ${ }^{13}$, um componente do projeto CHOReOS para criação, remoção e implantação de novos serviços automaticamente em uma nuvem.

\subsection{Exemplos de testes escritos com o Rehearsal}

Nesta seção, são mostrados casos de testes para a coreografia "FutureMart", que foi apresentada na Seção 3.4.1, utilizando as funcionalidades do Rehearsal. Esses testes foram aplicados em uma versão da "FutureMart" escrita em Java ao invés de BPEL. Apesar dessa diferença, as interfaces dos serviços e os testes aplicados em ambas as versões são os mesmos.

Todos os testes apresentados nesta seção estão relacionados à validação da funcionalidade de busca e consulta de preços de produtos ("getPriceOfProductList"). Inicialmente, os serviços atômicos participantes da coreografia são testados. o Código 5.1 apresenta testes de unidade para os serviços SM1 e SM2. Nesses testes, as funcionalidades de busca por produtos de ambos os serviços são validadas.

package eu.choreos.unit;

2

\footnotetext{
${ }^{13}$ Node Pool Manager: https://github.com/choreos/choreos_middleware
} 


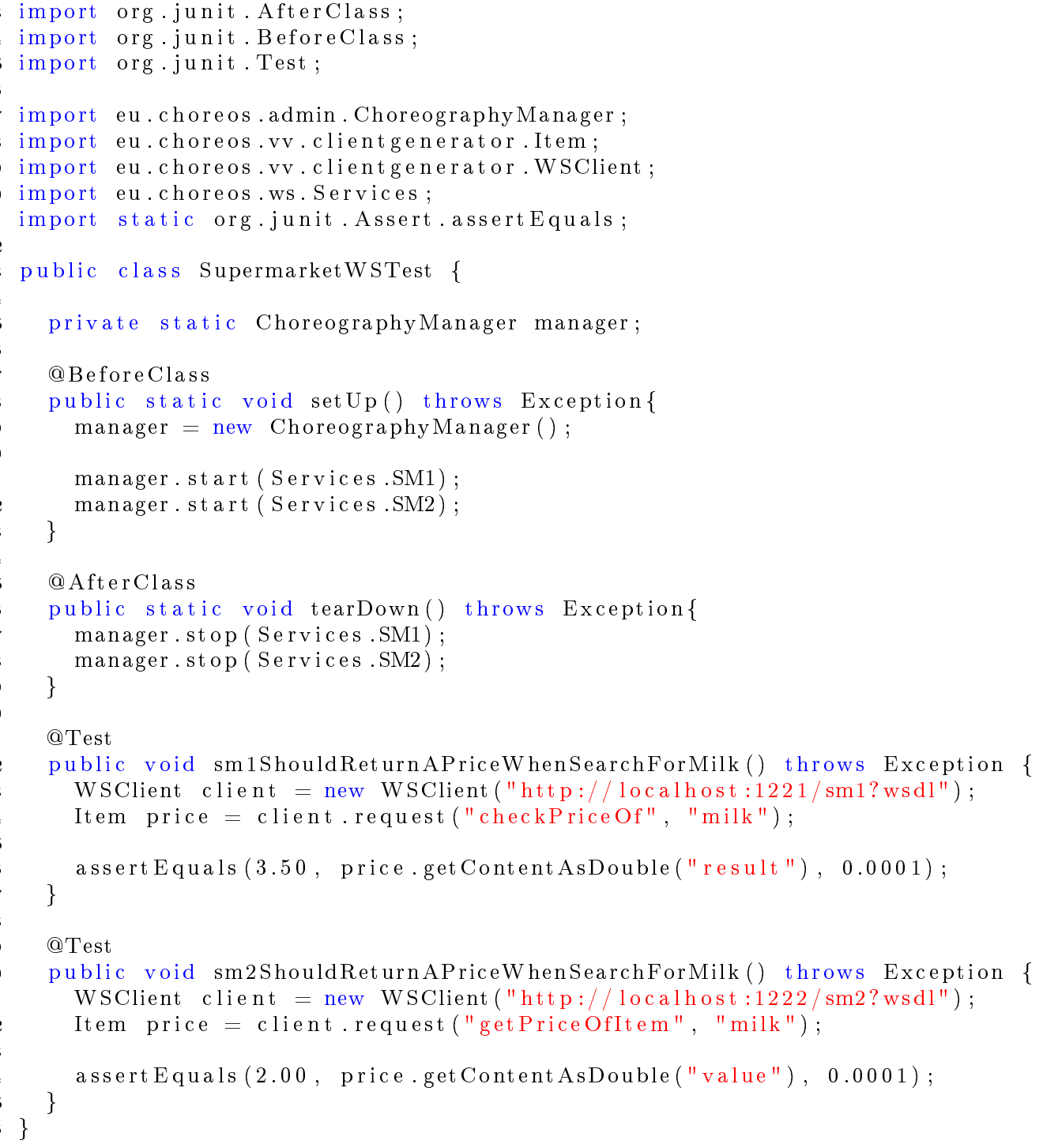

Código 5.1: Testes de unidade para os serviços atômicos

Como pode ser observado no Código 5.1, nos blocos de código referentes às anotações @BeforeClass e @AfterClass,os serviços testados são iniciados e parados antes do início e após a execução dos testes, respectivamente. Essas ações são realizadas pela classe ChoreographyManager, que é apresentada no Código 5.2. Esta classe foi criada para realizar a implantação de todos os serviços utilizados na coreografia. Além disso, essa classe contém alguns métodos administrativos, por exemplo, métodos para formatação de URI dos serviços. Em ambos os casos testes de unidade apresentados, utilizou-se a funcionalidade "WSClient" para invocar as operações de cada serviço e assim validar os resultados obtidos.

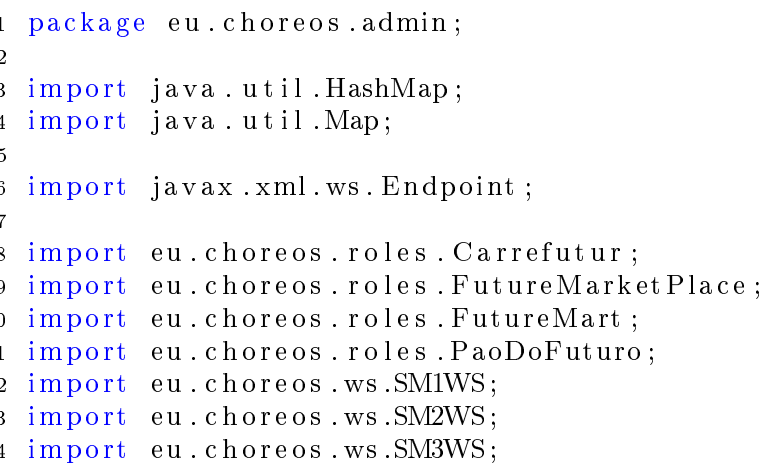




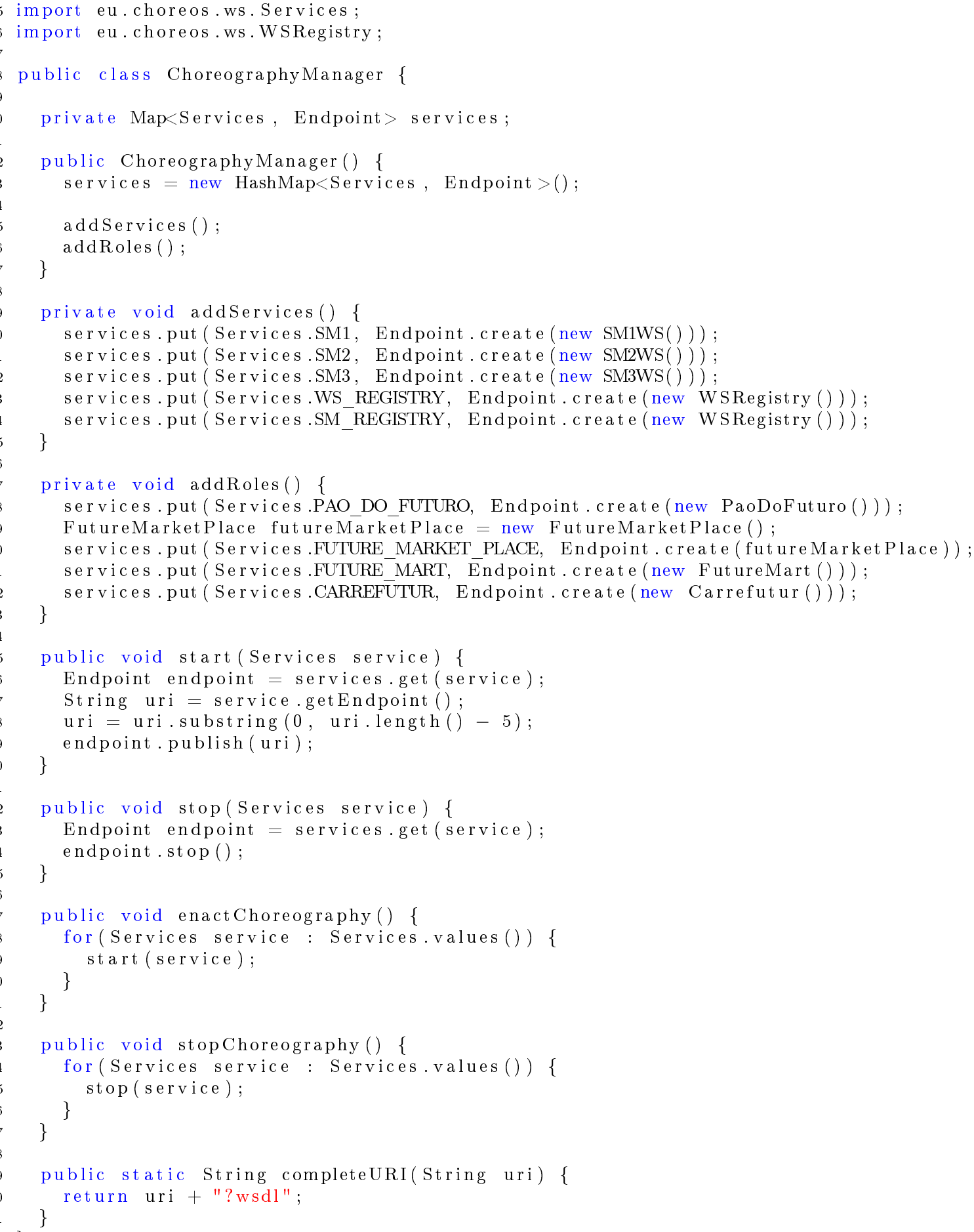

Código 5.2: Choreography manager

Após o testes de unidade, os serviços atômicos são orquestrados para implementar os papéis da coreografia. Na FutureMart, o papel supermarket é composto por quaisquer serviços que contenham operações de busca de preços de produtos e por um serviço de registro de supermercados. $\mathrm{O}$ serviço de registro abrigará a URI do arquivo WSDL de cada supermercado (como descrito da Seção 3.4.1). O Código 5.3 apresenta os testes de integração para a validação das mensagens trocadas internamente ao serviço PaoDoFuturo, que implementa o papel supermarket orquestrando o serviço atômico "SM1". 


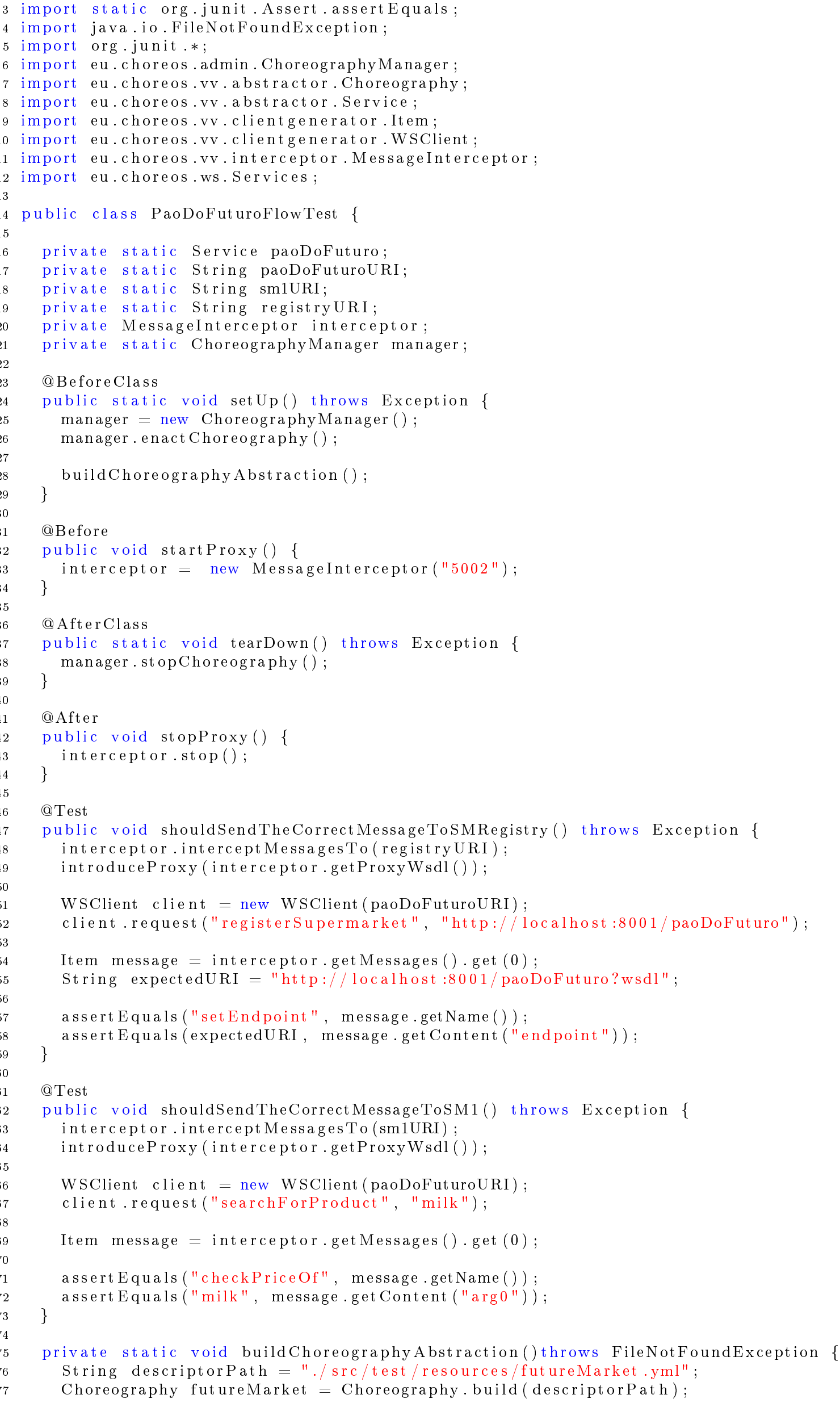




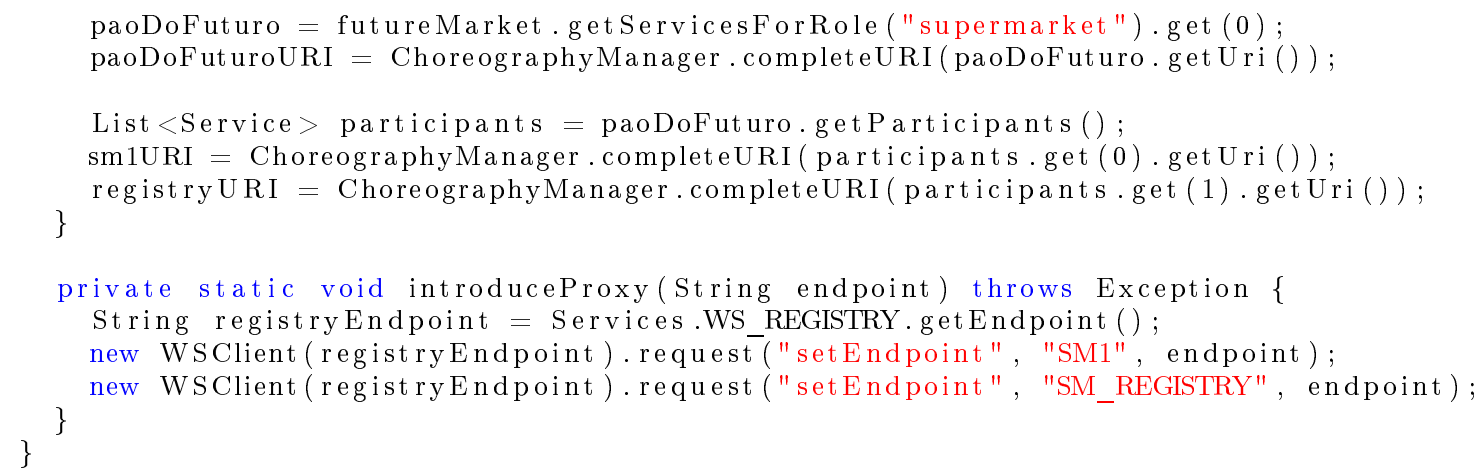

Código 5.3: Testes de integração (intra papel)

No Código 5.3, utilizou-se o ChoreographyManager para iniciar a coreografia. Como pode ser observado, nas linhas 75-85, utilizou-se a funcionalidade de abstração da coreografia para extrair os URIs do serviços envolvidos no teste. Nas linhas 48-49, um objeto Message Interceptor é criado e adicionado à coreografia. Nessa implementação da coreografia, além do registro de serviços (SM_REGISTRY) que implementam o papel supermarket, há um registro de serviços geral (WS_REGISTRY) que contém todos os endpoints utilizados na coreografia. Esse registro é invocado na implementação interna de cada papel para coreografia. Assim, para interceptar as mensagens enviadas a um serviço específico, basta configurar a entrada no WS REGISTRY do serviço que será interceptado para apontar para o proxy criado.

Após a configuração dos proxies, utilizou-se o interceptador para interceptar e validar as mensagens enviadas ao Registro de serviços (linhas 54-58). O primeiro teste tem como objetivo verificar se a operação "registerSupermarket" é implementada corretamente. Como pode ser observado, as asserções validam a mensagem enviada ao SM_REGISTRY e não o valor devolvido pela operação "registerSupermarket". O segundo teste dessa classe ("shouldSendTheCorrectMessageToSM") verifica se a busca por produtos é realizada corretamente mediante o serviço SM1. Para isso, de maneira similar ao teste de anterior, intercepta-se e valida-se a mensagem enviada ao serviço SM1 (linhas $66-72)$.

A fim de verificar se serviços desenvolvidos contemplam corretamente a interface prevista para o papel supermarket, testes de conformidade podem ser aplicados. O Código 5.4 apresenta testes de conformidade para todos os serviços que implementam esse papel, enquanto que o Código 5.5 apresenta a classe oráculo desses testes (vide Seção 5.6).

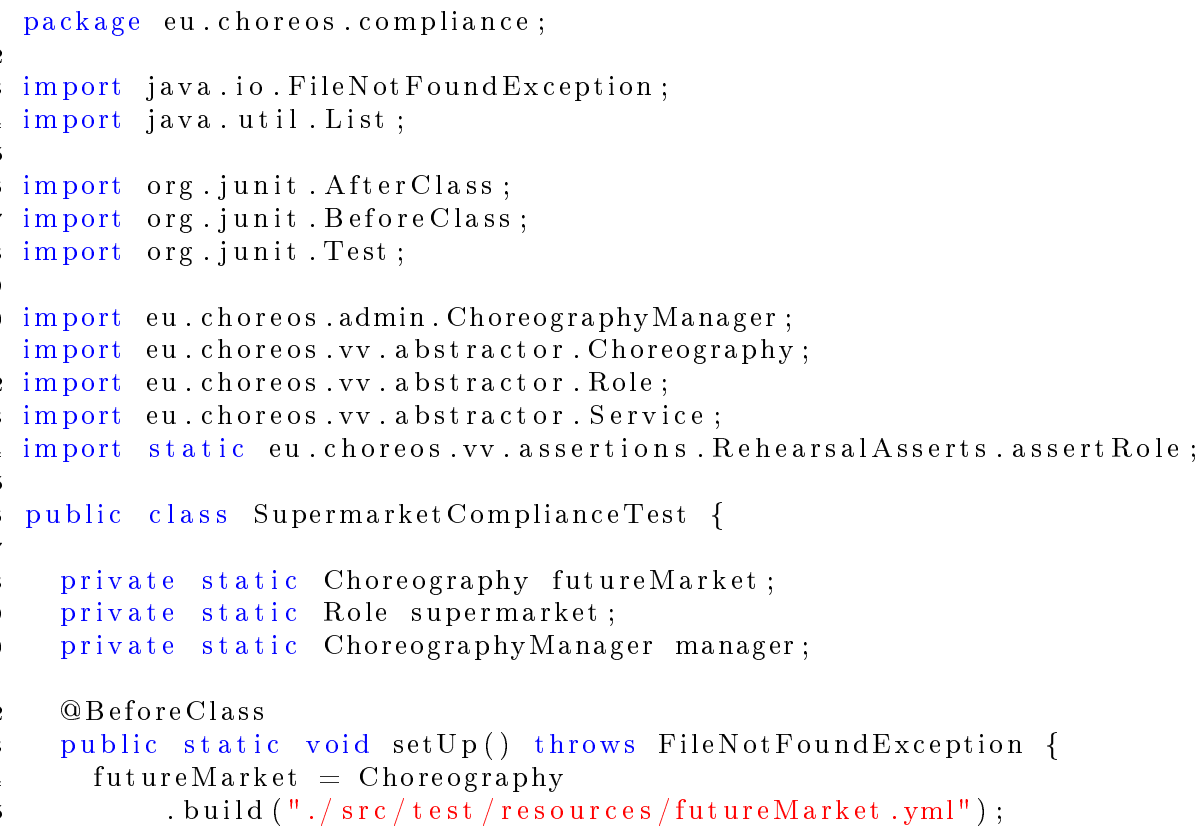




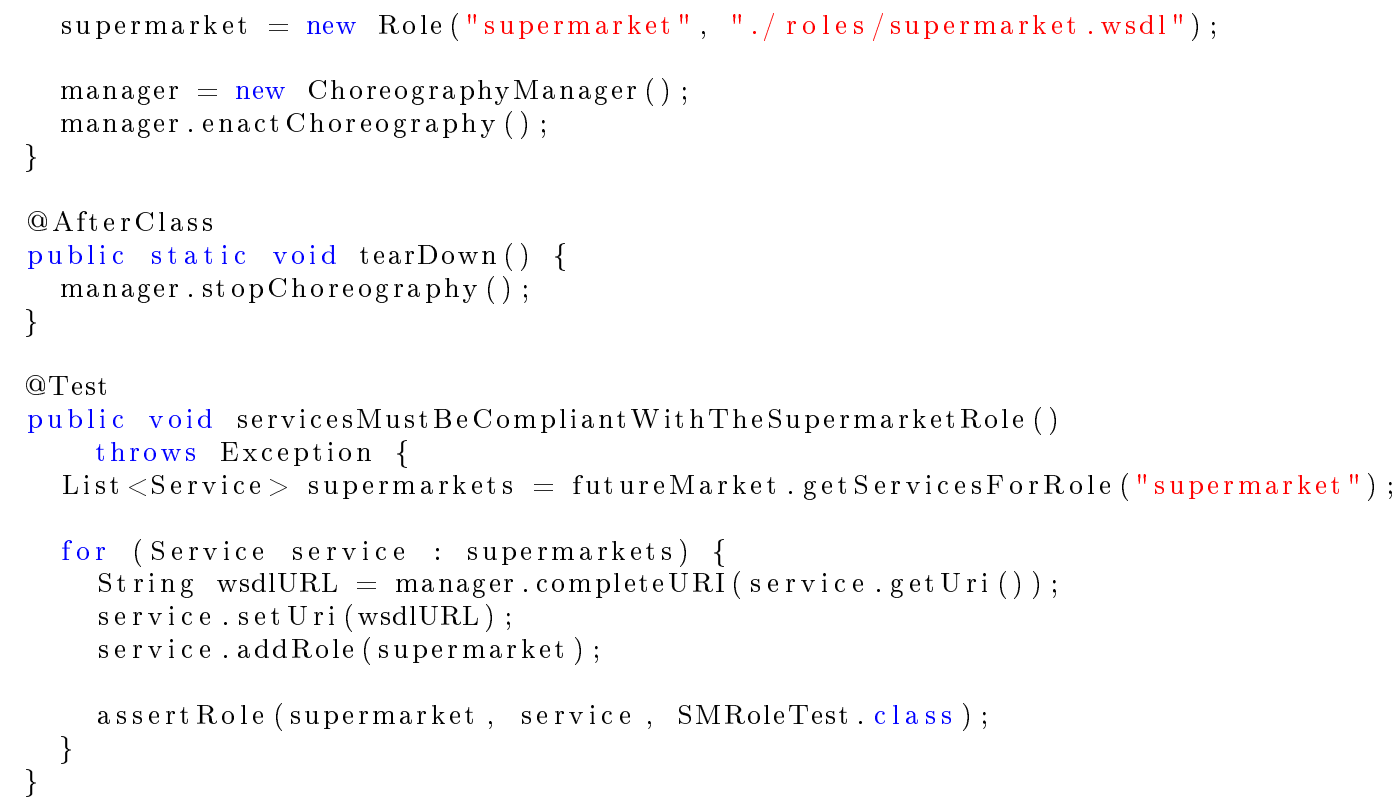

Código 5.4: Testes de conformidade

Nas linhas 42-47, os testes da classe oráculo são aplicados para cada serviço que implementa o papel supermarket. Nesse exemplo, os testes da classe oráculo (Código 5.5) são bem simples e têm como objetivo validar apenas a interface de cada um desses serviços. Apesar de simples, esses testes podem ser considerados uma "triagem" (pré-validação) de serviços de terceiros. Caso a interface desses serviços não seja compatível com o oráculo, esses serviços não podem participar da coreografia.

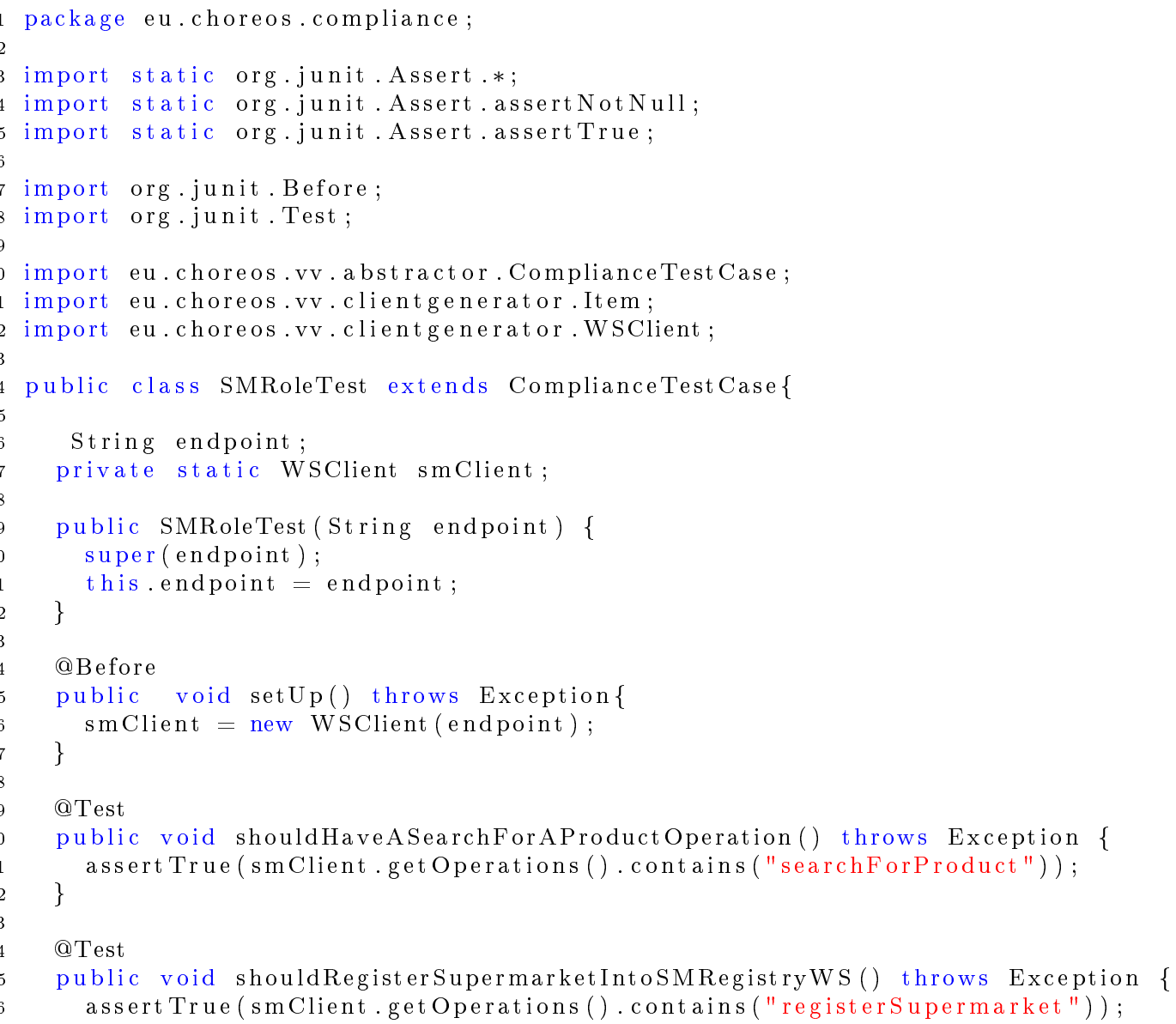




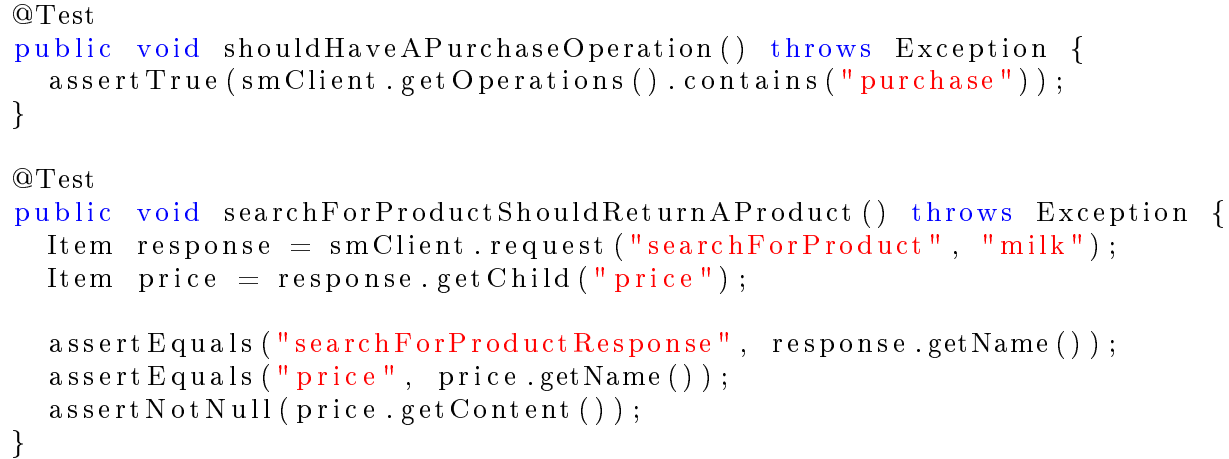

Código 5.5: Classe oráculo para testes de conformidade

O Código 5.6 apresenta testes que validam a integração do serviços "FutureMarketPlace", que implementa o papel "customer" na coreografia, e "PaoDoFuturo", que foi apresentado anteriormente, sendo portanto considerado um teste de integração entre (inter) papel.

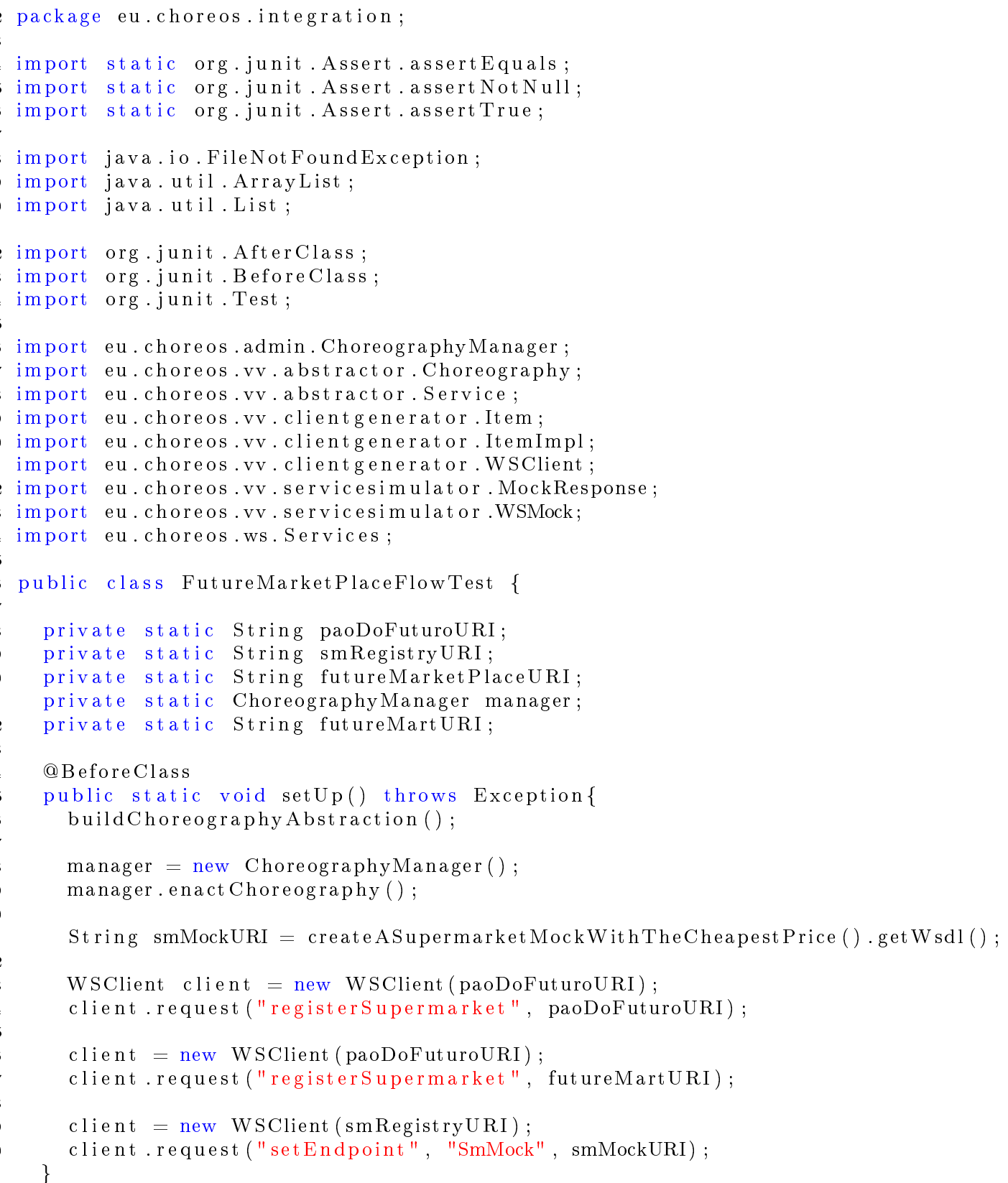




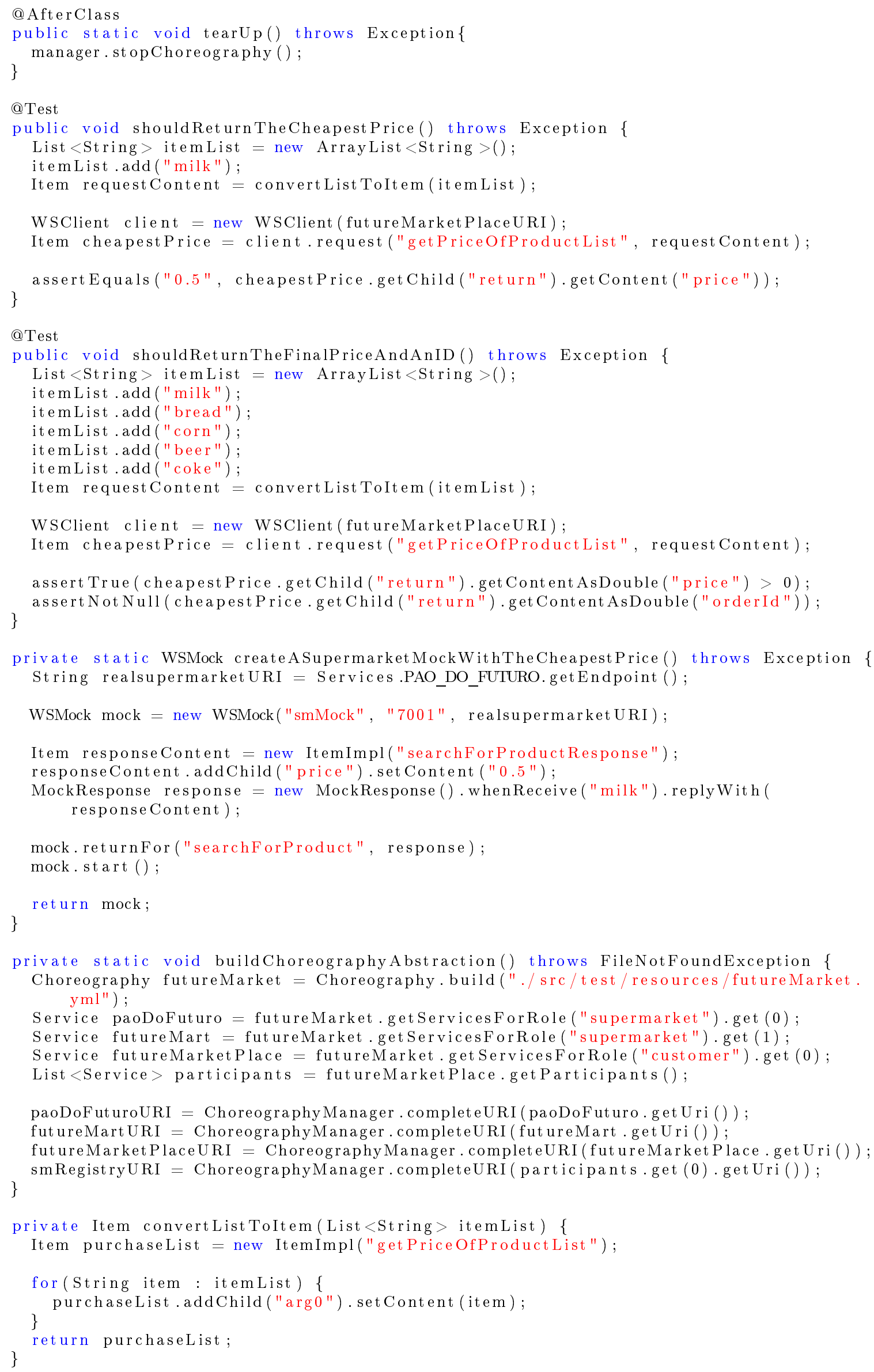




\section{Código 5.6: Testes de integração (inter papel)}

Como pode ser observado nas linhas 35-51, as pré-condições (método setUp) encarregam-se de iniciar a coreografia e criar um mock de um serviço que implementa o papel "supermarket". Esse mock é criado nas linhas 87-99, em seguida, configurou-se o mock para retornar o preço "0.5" quando a operação "searchForProduct" é invocada com o parâmetro "milk".

Essa condição é necessária para o teste de busca por menor preço. Conforme apresentado na Seção 3.4.1, a coreografia busca em serviços que implementam o papel supermarket, o menor preço de cada item de uma lista de compra. No teste shouldReturnTheCheapestPrice(), é verificado se a coreografia retorna de fato o menor preço para o produto "milk". Esse produto é buscado nos serviços registrados no método setUp desta classe. No teste, o serviço com menor valor é justamente o mock criado. Assim, nas linhas 64-67, invoca-se a operação "getPriceOfProductList", que consulta o preço em cada serviço de supermercado, e valida-se o menor preço obtido.

O segundo teste dessa classe ("shouldReturnTheFinalPriceAndAnID") consiste em um teste de aceitação da funcionalidade de busca por menor preço. O objetivo desse teste é verificar que a busca de preços de uma lista de compra fornecida pelo usuário retorna obrigatoriamente um valor (preço) e um identificador de compras. Para isso, invoca-se a operação de busca ("getPriceOfProductList") por meio do WSClient e verifica-se os resultados obtidos.

Além desses testes, mais testes de unidade, integração e aceitação para todas as demais funcionalidades da coreografia foram desenvolvidos. O objetivo desta seção foi demonstrar a utilização das funcionalidades da Rehearsal em testes reais de um cenário de utilização de uma coreografia de serviços web.

\subsection{Considerações finais do capítulo}

Este capítulo apresentou as principais funcionalidades do Rehearsal. O objetivo dessas funcionalidades é automatizar testes de unidade, integração e aceitação, seguindo os princípios do Desenvolvimento guiado por testes (Test-Driven Development, TDD).

Embora o objetivo do Rehearsal seja o suporte à TDD, este arcabouço pode ser utilizado com outras técnicas de desenvolvimento de sistemas. No próximo capítulo deste trabalho, será apresentada uma proposta de metodologia de TDD para coreografias. O objetivo dessa metodologia é fornecer as diretrizes básicas para que o desenvolvedor possa utilizar o Rehearsal seguindo as práticas e princípios de TDD no contexto de coregrafias de serviços web. 


\section{Capítulo 6}

\section{Proposta de metodologia TDD para coreografias}

Experimentos e observações empíricas realizadas na indústria têm mostrado que a aplicação da técnica de Desenvolvimento Dirigido a Testes (Test-Driven Development, TDD) aumenta a qualidade do código produzido e reduz a densidade de defeitos. Um experimento conduzido por George e Williams [GW03] com 24 desenvolvedores profissionais demonstrou que 87,5\% dos programadores consideram que o uso de TDD facilita o entendimento dos requisitos e $95,8 \%$, consideram que TDD reduziu o tempo gasto com depuração. Um estudo de caso [NB006] conduzido na Microsoft avaliou o impacto da utilização de TDD em dois times diferentes. No primeiro, embora o tempo de desenvolvimento inicial de um projeto conduzido com TDD subiu $35 \%$, a densidade de defeitos caiu $62 \%$. No segundo time, o tempo inicial de desenvolvimento subiu $15 \%$ enquanto que a densidade caiu $76 \%$.

Com base nesse retrospecto favorável, um dos objetivos deste trabalho consiste na aplicação dos princípios de TDD em coreografias. Com isso, pretende-se agregar mais disciplina no desenvolvimento de coreografias de serviços web, favorecendo assim sua adoção. Por definição, um arcabouço pode ser considerado um sistema de software incompleto, que precisa ser estendido ou integrado a outras classes para tornar-se uma aplicação concreta e executável [JF88]. Logo, a utilização do Rehearsal por si só, não implica na utilização de TDD em coreografias. Por esta razão, foi desenvolvida uma proposta de metodologia para guiar o desenvolvedor na aplicação de TDD em coreografias utilizando o Rehearsal. Neste capítulo, inicialmente apresentamos o projeto Savara que propõe uma metodologia para desenvolvimento de coreografias utilizando WS-CDL. Em seguida, as fases desta proposta de metodologia TDD são apresentadas em detalhes.

\subsection{Projeto Savara}

O projeto Savara [Red10] oferece um conjunto de ferramentas para o desenvolvimento de coreografias seguindo os princípios de uma metodologia intitulada "Arquitetura Testável" (Testable Architecture). Essa metodologia tem como objetivo assegurar que qualquer artefato, definido em um determinada fase do desenvolvimento de uma coreografia, possa ser validado mediante outros artefatos produzidos nas fases posteriores ou subsequentes do processo de desenvolvimento.

A metodologia de Arquitetura Testável é fundamentada em pi-calculus, um método formal para modelagem de sistemas paralelos e distribuídos. No projeto Savara, algumas funcionalidades da ferramenta PI4SOA, que foi apresentada na Seção 4.2.1, são utilizadas para verificar e validar alguns modelos de coreografia desenvolvidos em WS-CDL [Mad09]. O processo de desenvolvimento de uma coreografia no Savara é dividido nas seguintes fases [Red10]:

1. Modelagem dos cenários. Cenários representando os requisitos de negócio são modelado em documentos e diagramas de casos de uso em UML. Esses cenários correspondem à sequência de mensagens que devem ser trocadas pelas entidades participantes da coreografia. 
2. Definição do modelo global. Com base nos cenários definidos, um modelo global representando o fluxo externo de informação, ou seja, as mensagens trocadas entre os papéis da coreografia, é desenvolvido. Este modelo pode ser definido em WS-CDL ou BPMN2.

3. Modelo local. Define a interface (contrato) para cada papel da coreografia. Esses artefatos são utilizados para validar o modelo global a fim de garantir a correta troca de mensagens. Essa verificação é feita utilizando simulação por meio do Pi4SOA. Nessa parte do processo, essas interfaces podem ser publicadas em um repositório de serviços.

4. Projeto dos serviços. Nesta fase, serviços são projetados para a execução dos modelos locais definidos na fase anterior. Neste ponto, especificações BPEL, ou SCA, e interfaces WSDL para serviços atômicos, são geradas.

5. Implementação e testes dos serviços. A partir dos artefatos gerados na fase anterior, os serviços são implementados e os processos são implantados em engines de execução. Uma vez que os artefatos (e.g., processos BPEL) são gerados com base em modelos, supõe-se que a lógica dos processos está correta, supondo também que o engine BPEL utilizado está correto. Nesta fase, testes de unidade são conduzidos nos serviços web desenvolvidos.

6. Monitoramento. O projeto Savara propõe ferramentas para monitoramento que têm como objetivo assegurar que os processos de negócio são executados corretamente. Essa verificação é feita com base nos cenários e modelos globais definidos nas fases anteriores do processo de desenvolvimento.

\subsection{Uma proposta de metodologia TDD para coreografias}

O projeto Savara serviu como base para o desenvolvimento da nossa proposta de metodologia TDD para coreografias. Como pode ser observado na seção anterior, o projeto Savara possui maior foco nas atividades de especificação, definição e modelagem da coreografia. Entre as cinco fases propostas, apenas em duas delas há atividades relacionadas ao desenvolvimento e teste de software. Diferentemente do projeto Savara, nossa proposta de metodologia TDD para coreografias é voltada para o desenvolvedor. O princípio básico dessa proposta é o desenvolvimento incremental da coreografia utilizando uma abordagem guiada por testes.

Baseando-se nas funcionalidades do Rehearsal (Capítulo 5), essa proposta de metodologia TDD para coreografias é composta por quatro fases, que são apresentadas na Figura 6.1. As atividades internas de cada fase são aplicadas em ambiente de desenvolvimento (offline). O ambiente pode ser a própria máquina do desenvolvedor ou máquinas virtuais em um ambiente de nuvem. $\mathrm{O}$ ambiente utilizado depende diretamente do tipo de teste e recursos necessários e disponíveis para a execução dos testes.

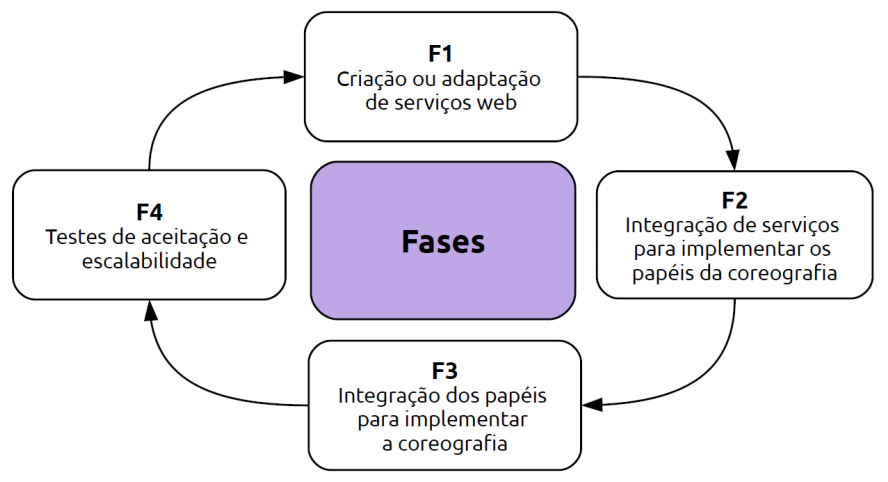

Figura 6.1: Fases da metodologia

Durante o desenvolvimento de coreografias, nem sempre as atividades internas das fases apresentadas na Figura 6.1 são passíveis de serem aplicadas. Coreografias podem ser implementadas 
por profissionais de diferentes organizações. Assim, dependendo da cultura, recursos envolvidos e processos da organização, o desenvolvedor pode estar inserido em diferentes cenários de desenvolvimento. Nesta proposta de metodologia, considerou-se três cenários genéricos para o desenvolvimento de uma coreografia de serviços web:

- Cenário 1 (C1). O desenvolvedor é responsável pela definição de um novo papel ou um conjunto de novos papéis para uma coreografia existente.

- Cenário 2 (C2). Os papéis da coreografia já estão definidos, logo, o desenvolvedor é responsável pelo desenvolvimento de serviços que implementem um determinado papel da coreografia.

- Cenário 3 (C3). A organização está iniciando o desenvolvimento de uma coreografia. Nessa situação, o desenvolvedor é responsável por implementar a coreografia inteira, ou grande parte dela.

A Tabela 6.1 apresenta as atividades internas de cada fase da metodologia que podem ser aplicadas nesses cenários de desenvolvimento. Cada atividade, tal como as fases dessa proposta de metodologia, são apresentadas nas próximas seções deste capítulo. As fases são aplicadas iterativamente. Assim, para cada papel implementado, as quatro fases são aplicadas.

\begin{tabular}{|l|l|l|l|}
\hline & Cenário 1 (C1) & Cenário 2 (C2) & Cenário 3 (C3) \\
\hline \hline \multirow{2}{*}{ F1 } & $\begin{array}{l}\text { - abordagem guiada por testes } \\
\text { - teste de unidade } \\
\text { (interface do serviço) }\end{array}$ & $\begin{array}{l}\text { - abordagem guiada por contratos } \\
\text { - teste de unidade } \\
\text { (interface do serviço) }\end{array}$ & $\begin{array}{l}\text { - abordagem guiada por testes } \\
\text { - teste de unidade } \\
\text { (interface do serviço) }\end{array}$ \\
\hline \multirow{3}{*}{ F2 } & $\begin{array}{l}\text { - emulação de serviços } \\
\text { - testes de integração } \\
\text { (troca interna de mensagens) }\end{array}$ & $\begin{array}{l}\text { - emulação de serviços } \\
\text { - testes de integração } \\
\text { (troca interna de mensagens) } \\
\text { - testes de conformidade }\end{array}$ & $\begin{array}{l}\text { - emulação de serviços } \\
\text { - testes de integração } \\
\text { (troca interna de mensagens) }\end{array}$ \\
\hline \multirow{2}{*}{ F3 } & $\begin{array}{l}\text { - emulação do papel } \\
\text { - testes de integração } \\
\text { (troca externa de mensagens) }\end{array}$ & $\begin{array}{l}\text { - emulação do papel } \\
\text { - testes de integração } \\
\text { (troca externa de mensagens) }\end{array}$ & $\begin{array}{l}\text { - testes de integração } \\
\text { (troca externa de mensagens) }\end{array}$ \\
\hline F4 & $\begin{array}{l}\text { - teste da coreografia } \\
\text { - avaliação da escalabilidade }\end{array}$ & $\begin{array}{l}\text { - teste da coreografia } \\
\text { - avaliação da escalabilidade }\end{array}$ & $\begin{array}{l}\text { - teste da coreografia } \\
\text { - avaliação da escalabilidade }\end{array}$ \\
\hline
\end{tabular}

Tabela 6.1: Atividades internas de cada fase para cada cenário de desenvolvimento

\subsubsection{Fase 1: Criação ou adaptação de serviços web}

Durante o desenvolvimento dos papéis de uma coreografia, novos serviços precisam ser criados ou serviços existentes precisam ser adaptados para implementar os requisitos da coreografia. Em metodologias convencionais, como por exemplo a proposta do projeto Savara, uma abordagem orientada a contratos é usada para a criação ou adaptação desses serviços. Nesse caso, as operações dos serviços já estão definidas em um contrato e, baseado nele, o serviço é codificado. Nos casos dos cenários $\mathrm{C} 1$ e $\mathrm{C} 3$ definidos acima, ao invés de utilizar uma abordagem orientada a contratos, o desenvolvedor, utilizando o Rehearsal, pode aplicar uma abordagem guiada por testes.

Conforme explicado em detalhes na Seção 5.2, o Rehearsal fornece uma funcionalidade para a criação dinâmica de clientes para serviços web. Por meio dessa funcionalidade, é possível escrever testes para serviços web mesmo quando suas interfaces ainda não estiverem disponíveis. Desse modo, os testes podem ser utilizados para especificar as interfaces dos serviços, tornando-se assim, especificações executáveis.

Na Figura 6.2, o serviço em teste ainda não existe. Utilizando a funcionalidade WSClient do Rehearsal, esse teste pode guiar o desenvolvimento e a especificação do serviço. Como pode ser observado, nesse teste é possível especificar funcionalmente o serviço. Inicialmente, é possível definir onde este serviço deve ser publicado. Em seguida, é definido o nome da operação (getPrice) e sua assinatura (receber um objeto String e retornar um objeto do tipo Double). Além disso, um exemplo 


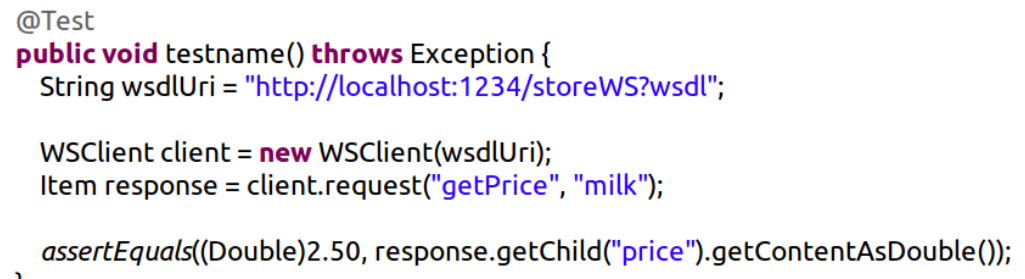

Figura 6.2: Exemplo de utilização do WSClient para especificação de um serviço

de funcionamento correto é apresentado. No caso, o exemplo consiste no próprio teste funcional que é definido pela entrada "milk" e retorno " 2.50 ".

Após a escrita dos testes para os serviços atômicos, o desenvolvedor deve implementar os serviços. Nesta parte do processo, artefatos especificando a coreografia podem ser consultados para saber quais serviços devem ser implementados. No caso do cenário C2, embora TDD não possa ser aplicado, o desenvolvedor pode utilizar o Rehearsal para escrever os testes para serviços já implementados.

\subsubsection{Fase 2: Integração de serviços para implementar os papéis da coreografia}

Após os serviços serem criados ou adaptados corretamente, eles devem ser integrados para a implementação dos papéis da coreografia. Conforme discutido na Seção 3.4, um papel da coreografia corresponde a um processo executável definido por um serviço ou um conjunto de serviços web. Quando um conjunto de serviços é utilizado para a criação do papel da coreografia, serviços de terceiros podem não estar disponíveis em tempo de desenvolvimento. A fim de resolver este problema de integração, a funcionalidade WSMock fornecida pelo Rehearsal pode ser utilizada para emulação desses serviços web.

Uma vez que todas as dependências reais que não podem ser utilizadas nos testes estiverem emuladas, os serviços (reais e mocks) são integrados para compor um determinado papel da coreografia. Nesta etapa do desenvolvimento, o interceptador de mensagens do Rehearsal (vide Seção 5.3) pode ser utilizado para validar as mensagens trocadas internamente no papel da coreografia. Assim, testes de integração podem ser escritos antes da próprio processo (orquestrador) que representa o papel a ser implementado.

No caso do cenário $\mathrm{C} 2$, no qual os contratos dos papéis da coreografia já estão definidos, o desenvolvedor pode utilizar o contrato como um oráculo e assim, aplicar testes de conformidade (Seção 5.6). Os testes de conformidade e integração asseguram que o serviço implementado desempenha corretamente um papel da coreografia. Além disso, esses testes podem prover ao desenvolvedor confiança e coragem para : (i) integrar o novo papel à coreografia; (ii) refatorar o código implementado; (iii) modificar o código implementado em caso de mudanças de requisitos, por exemplo.

\subsubsection{Fase 3: Integração dos papéis para implementar a coreografia}

Após a implementação de um processo que representa um papel da coreografia, conforme descrito na segunda fase desta proposta de metodologia, o desenvolvedor pode integrar esse processo aos demais para implementar a coreografia. Levando em conta os cenários C1 e C2, os processos dos demais papéis da coreografia podem não estar disponíveis. Neste caso, uma vez que as interfaces (contratos) WSDL desses papéis são conhecidas, mocks dos papéis podem ser criados utilizando a funcionalidade WSMock.

No caso do cenário C3, no início do desenvolvimento, os papéis da coreografia podem não estar prontos. Assim, o desenvolvedor pode desenvolver os papéis e integrá-los incrementalmente. Durante este processo, pode não haver a necessidade de utilização de mocks, uma vez que os serviços estão sob controle do desenvolvedor. No entanto, caso a execução dos testes leve muito tempo, mocks podem ser utilizados. 
Assim como na fase anterior, uma vez que todas as dependências reais tiverem sido emuladas, os componentes são integrados. Nesta terceira fase, testes são criados para validar a correta integração dos processos representando os papéis da coreografia. De maneira similar à Fase 2, o interceptador de mensagens é utilizado para validar as mensagens trocadas por esses processos. No entanto, as mensagens interceptadas e validadas neste caso correspondem àquelas especificadas no modelo global da coreografia.

\subsubsection{Fase 4: Testes de aceitação e escalabilidade}

Nesta fase final da proposta de metodologia, a coreografia como um todo é avaliada sob a perspectiva do usuário final. Assim, testes de aceitação e escalabilidade são aplicados. O objetivo dos testes de aceitação é validar todas as funcionalidades da coreografia. Uma vez que a coreografia é acessível ao usuário como um serviço atômico, a funcionalidade WSClient pode ser utilizada para invocar as funcionalidades da coreografia.

No caso do teste de escalabilidade, Rehearsal proverá uma funcionalidade que auxiliará o desenvolvedor a especificar diferentes cenários de execução formados por diferentes cargas de trabalho, e avaliar o comportamento da coreografia nessas situações. Este componente está sendo desenvolvido pelo doutorando Paulo Moura do nosso grupo de pesquisa e não faz parte do escopo deste trabalho de mestrado.

Os testes de aceitação e escalabilidade são conduzidos e aplicados em um ambiente offline utilizando configurações mais próximas possíveis do ambiente de produção

\subsubsection{Considerações finais do capítulo}

Este capítulo apresentou as fases de um proposta de metodologia TDD para coreografias. Embora o escopo deste trabalho seja o arcabouço Rehearsal, esta proposta de metodologia tem como objetivo guiar o desenvolvedor para aplicação de TDD utilizando as funcionalidades do arcabouço proposto.

A fim de avaliar a eficácia e facilidade de uso do Rehearsal e dessas proposta de metodologia, conduziu-se um estudo exploratório com alunos de graduação e pós-graduação em Ciência da Computação. Esse estudo é apresentado no próximo capítulo. 


\title{
Capítulo 7
}

\section{Estudo exploratório}

\begin{abstract}
A fim de avaliar a efetividade do Rehearsal quando a proposta de metodologia TDD é aplicada no desenvolvimento de coreografias, conduziu-se um estudo exploratório [KPP $\left.{ }^{+} 02\right]$. Esse estudo foi aplicado em alunos de graduação e pós-graduação em Ciência da Computação do Instituto de Matemática e Estatística da Universidade de São Paulo. O objetivo do estudo foi levantar as principais dificuldades e benefícios encontrados na utilização do Rehearsal e da metodologia proposta. Além disso, buscou-se refinar o Rehearsal e a metodologia com o feedback obtido. Para tal, o estudo foi dividido em duas fases. Neste Capítulo, as duas fases do estudo são apresentadas, assim como os resultados obtidos e as melhorias levantadas.
\end{abstract}

\subsection{Fases do estudo exploratório}

O arcabouço Rehearsal e a metodologia proposta introduzem alguns conceitos novos ao desenvolvimento de coreografias, tais como a utilização de uma abordagem guiada por testes ao invés do foco em contratos. Por esta razão, em ambas as fases do estudo conduzido, buscou-se explorar potenciais benefícios e problemas decorrentes da aplicação do Rehearsal e da metodologia TDD proposta no desenvolvimento real de uma coreografia.

\subsubsection{Fase 1: Avaliação da eficácia do Rehearsal e da metodologia}

Os sujeitos (participantes) desta fase foram 8 alunos de pós-graduação do IME-USP especialistas no problema estudado. Esses alunos possuíam experiência prévia em desenvolvimento de coreografias de serviços web e/ou TDD, graças ao seu envolvimento nos projetos de pesquisa BAILE, financiado pela HP, e CHOReOS, financiado pela Comissão Europeia. A Figura 7.1 ilustra a experiência dos participantes desta fase.

Como pode ser observado na Figura 7.1, todos os participantes tinham experiência em TDD e em desenvolvimento de serviços web. Em relação à experiência em composição de serviços, pode-se observar que metade dos participantes tiveram experiência neste tópico. Utilizou-se esse fator como critério para divisão das duplas do estudo. Assim, cada dupla possuía uma membro com experiência em composição de serviços. Buscou-se, com isso, obter certa homogeneidade das duplas.

Antes das atividades de desenvolvimento, os participantes receberam um treinamento com duração de 3 horas. Este treinamento abordou os tópicos: Service-Oriented Architecture (SCA), Rehearsal, a proposta de metodologia TDD e uma explicação sobre as etapas do estudo exploratório. O treinamento de Rehearsal envolveu exercícios práticos. Os resultados desses exercícios podem ser encontrados no pacote do estudo explorátorio que é apresentado na Seção 7.2.

O objetivo dessa fase foi avaliar a eficácia e adequação do Rehearsal e da proposta de metodologia no contexto de desenvolvimento de coreografias de serviços web. Uma vez que a metodologia foi desenvolvida pelo mesmo autor do Rehearsal, buscou-se validar e incorporar a ambos os feedbacks obtidos nessa fase, para eliminar, assim, possíveis distorções decorrentes de sua concepção. 


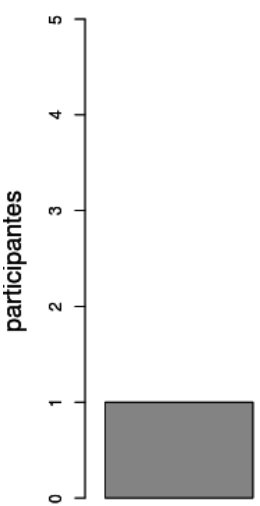

1-3

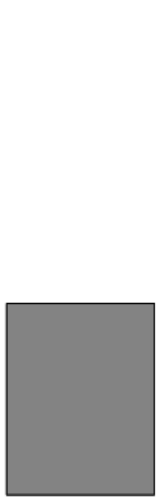

3-5

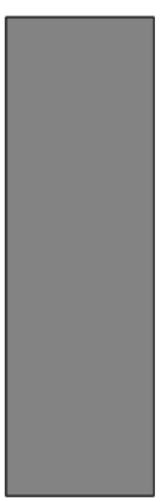

mais de 5

Exp. em desenvolvimento de software (em anos)

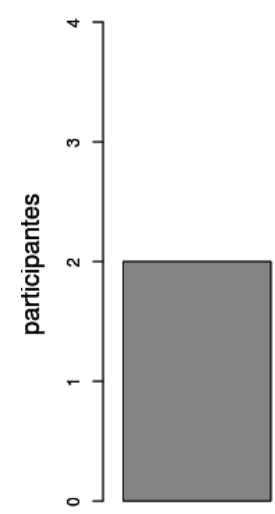

$1-3$

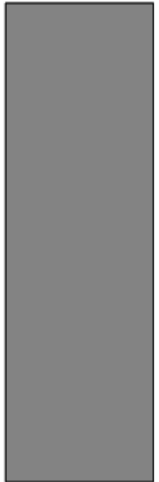

3-5

Exp. em Java (em anos)

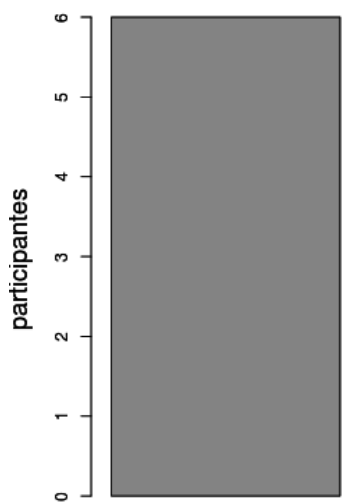

0-2

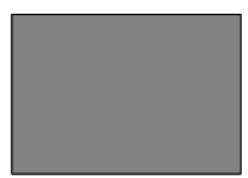

mais de 3

Exp. em desenvolvimento guiado por testes (em anos)

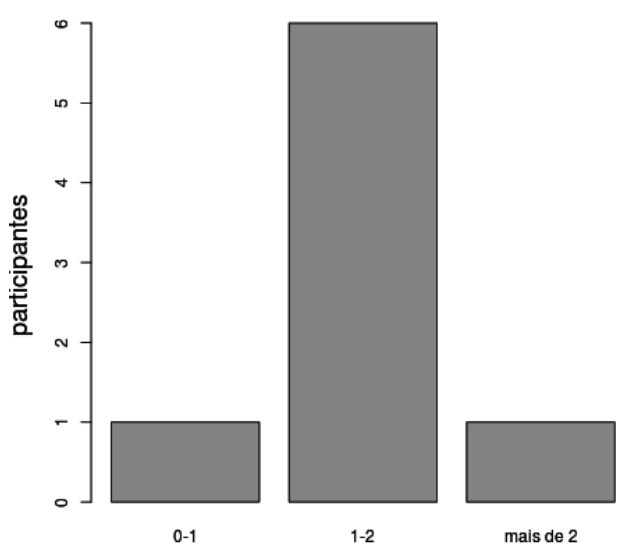

Exp. em desenvolvimento de serviços web (em anos)
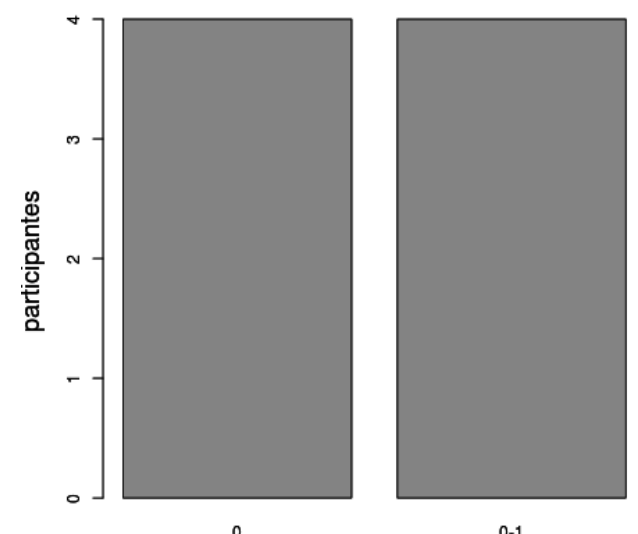

$0-1$

Exp. em composição de serviços web (em anos)

Figura 7.1: Experiência dos participantes da Fase 1

Para atingir esses objetivos, as seguintes perguntas de pesquisa (Research Questions - RQ) foram estudadas:

\footnotetext{
RQ1: As funcionalidades do Rehearsal auxiliam na aplicação dos passos da metodologia proposta?

RQ2: A metodologia proposta fornece diretrizes adequadas para o desenvolvimento de uma coreografia?
} 
Por meio da primeira pergunta de pesquisa (RQ1), estudou-se a eficácia e facilidade em se aplicar as funcionalidades do Rehearsal nas quatro fases da metodologia proposta (Capítulo 6). Em relação à pergunta RQ2, buscou-se identificar quais passos da metodologia proposta realmente auxiliam ou dificultam o desenvolvimento de uma coreografia. Diferentemente do desenvolvimento de software tradicional, o desenvolvimento de serviços web, simples ou compostos, envolve peculiaridades como: descobrimento dos serviços, baixo acoplamento entre serviços e restrições de serviços de terceiros. O termo "diretrizes adequadas" definido na pergunta RQ2 refere-se à compatibilidade e utilidade dos passos da metodologia para abranger essas peculiaridades.

\subsubsection{Fase 2: Avaliação da facilidade de utilização do Rehearsal e metodologia}

Com base nos resultados obtidos na primeira fase do estudo, a metodologia e o arcabouço Rehearsal foram refinados e as novas versões desses artefatos foram utilizadas nessa fase do estudo. Os sujeitos da fase em questão foram 4 alunos de pós-graduação e 7 alunos de graduação em Ciência da Computação da Universidade de São Paulo. Os 11 alunos possuíam conhecimento básico ou nenhum conhecimento em desenvolvimento de serviços web e TDD. A Figura 7.2 apresenta a experiência dos participantes desta fase.

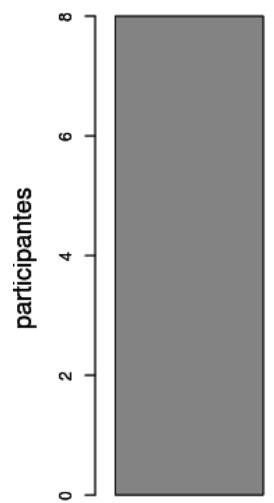

$1-3$

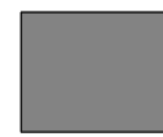

3-5

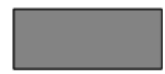

mais de 5

Exp. em desenvolvimento de software (em anos)

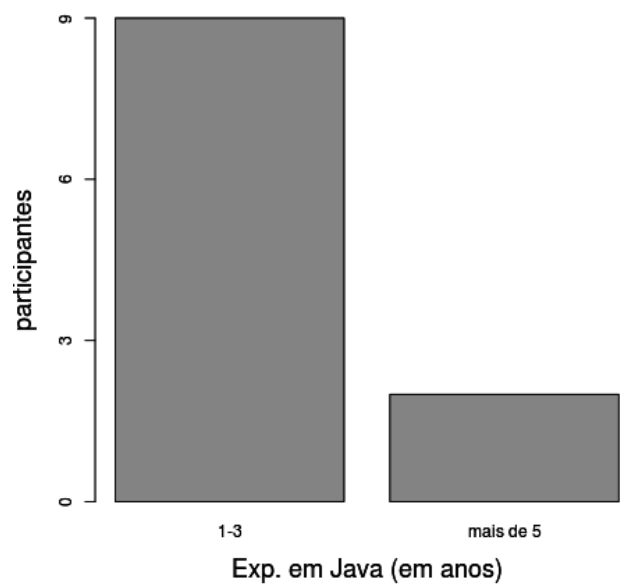

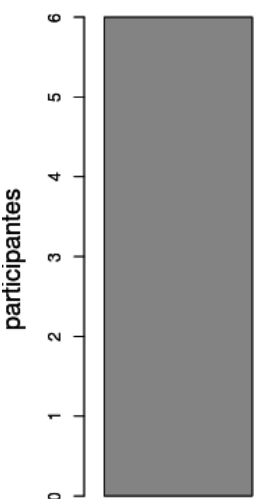

0

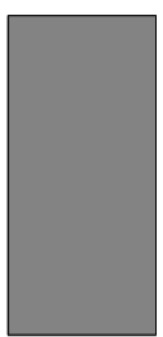

$0-1$

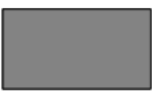

1-2
Exp. em desenvolvimento guiado por testes (em anos)
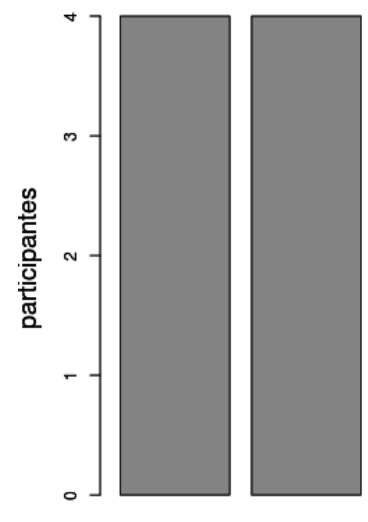

$0-1$

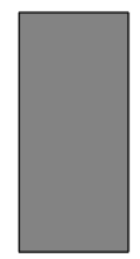

1-2 mais de 2

Exp. em desenvolvimento de serviços web (em anos)

Figura 7.2: Experiência dos participantes da Fase 2

Como pode ser observado na Figura 7.2, os participantes tinham bastante experiência em Java e desenvolvimento de software tradicional. Em relação à experiência em TDD e desenvolvimento de serviços web, pode-se observar que grande parte não possuía conhecimento básico nesses tópicos. No entanto, buscou-se homogenização organizando em duplas os mais experientes com aqueles com 
menos experiência nos tópicos levantados no questionário de recrutamento.

Assim como na primeira fase do estudo, os participantes desta fase receberam um treinamento no ínicio do estudo exploratório. No entanto, esse treinamento foi bem mais abrangente do que o treinamento realizado na primeira fase. Na segunda fase, o treinamento teve duração de $6 \mathrm{~h}$ e abordou os tópicos: desenvolvimento de serviços web, orquestrações e coroegrafias de serviços web, desenvolvimento guiado por testes, Rehearsal, a proposta de metodologia de TDD e uma explicação sobre as etapas do estudo exploratório. De modo similar à primeira fase, os participantes realizaram exercícios práticos no treinamento da Rehearsal. Os resultados desses exercícios podem ser encontrados no pacote do estudo explorátorio que é apresentado na Seção 7.2.

O objetivo dessa fase foi estudar a facilidade de utilização do Rehearsal e da metodologia para iniciantes em desenvolvimento de coreografias. Um dos objetivos deste trabalho é facilitar o desenvolvimento de coreografias, visando assim aumentar a adoção de coreografias de serviços web. Para atingir os objetivos dessa fase do estudo, as seguintes perguntas de pesquisa (Research Questions ( $R Q$ ) foram estudadas:

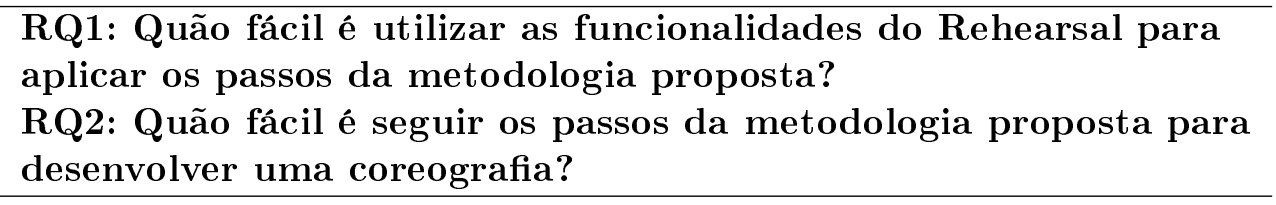

A pergunta RQ1 visa estudar o quão fácil é para desenvolvedores com básico conhecimento de serviços web e TDD, aprender a utilizar as funcionalidades do Rehearsal e aplicar essas funcionalidades seguindo os passos da metodologia proposta. Os alunos não possuíam contato prévio com coreografias, porém, possuíam experiência no desenvolvimento de sistemas de software tradicional (modelo cliente-servidor). Por esta razão, buscou-se com a pergunta RQ2 estudar o quão fácil é seguir os passos da metodologia proposta.

\subsection{Organização do estudo exploratório}

Ambas as fases do estudo exploratório foram projetadas seguindo diretrizes referentes a estudos desta natureza [Sea99, Kit96]. Embora esse estudo seja essencialmente um estudo qualitativo, alguns procedimentos, tais como a definição das variáveis estudadas e análise dos resultados, foram baseados em diretrizes comuns a experimentos de Engenharia de Software [WRH $\left.{ }^{+} 00, \mathrm{JM} 01\right]$.

Dado que a metodologia e o Rehearsal introduzem novos conceitos em relação ao problema estudado, em ambas as fases buscou-se identificar benefícios e problemas que não foram previstos na concepção desses artefatos. Por esta razão, optamos por um estudo exploratório, ao invés de um experimento controlado. Além disso, são analisados os benefícios do ponto de vista do desenvolvedor, ou seja, usuário do Rehearsal e da metodologia. Dessa forma, dados qualitativos são mais adequados, dado que os resultados serão as percepções do usuário, coletadas por meio de questionários e entrevistas.

Em relação à organização e a condução do experimento, as duas fases são idênticas. Para cada uma das fases, o estudo exploratório foi conduzido levando em consideração as etapas apresentadas na Figura 7.3.

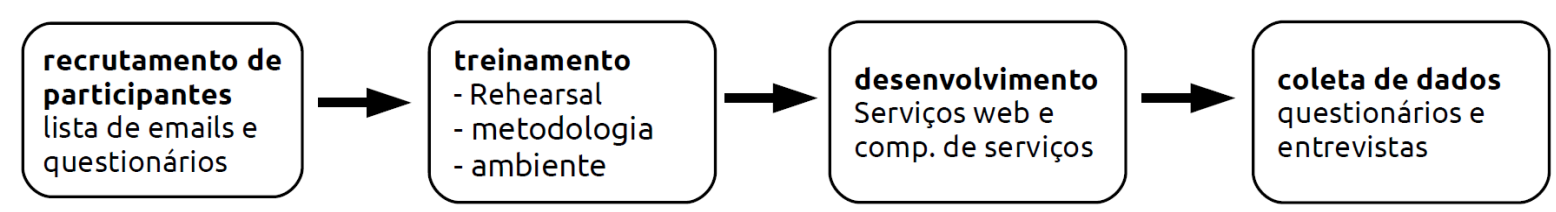

Figura 7.3: Etapas do estudo exploratório.

Antes da execução de cada fase do estudo, desenvolveu-se um protocolo que descrevia em detalhes as etapas da Figura 7.3, além da unidade de estudo (coreografia) utilizada e procedimentos 
para análise e apresentação dos resultados obtidos. O Apêndice B apresenta o protocolo completo da primeira fase do estudo. O conteúdo das duas primeiras seções deste protocolo já foi abordado nesse capítulo e nos capítulos anteriores deste trabalho, porém, as demais seções descrevem em detalhes o estudo; logo, sua leitura é necessária para o entendimento dos resultados obtidos, sendo considerada parte do conteúdo principal desta dissertação.

Ambas as fases do estudo exploratório estão publicamente disponíveis em um pacote do estudo acessível em: http://ccsl.ime.usp.br/baile/VandV\#rehearsal-study. O pacote contém para cada uma das fases:

- Protocolo do estudo exploratório

- Termo de consentimento

- Questionário de recrutamento (formulário e resultados obtidos)

- Questionário de coleta dos resultados do estudo (formulário e resultados obtidos)

- Guia de desenvolvimento (tarefas de desenvolvimento que foram executadas pelos participantes durante o estudo)

- Slides de treinamento

- Código-fonte inicial com as tarefas de desenvolvimento e treinamento

- Código-fonte gerado pelos participantes

- Relatório apresentando os resultados obtidos

- Áudio das entrevistas

\subsection{Resultados qualitativos}

Esta seção apresenta os resultados de cada uma das perguntas de pesquisa de ambas as fases do estudo do exploratório. Os resultados são apresentados em box plots que representam os dados em três quartis. Inicialmente, o conjunto de dados é ordenado. O quartil inferior (Q1) contém o valor do dado que está localizado exatamente na posição que representa um quarto do conjunto de dados. O segundo quartil (Q2) representa a mediana, enquanto que o quartil superior (Q3) contém o valor do dado que está localizado exatamente na posição que representa três quartos do conjunto de dados [Eas97].
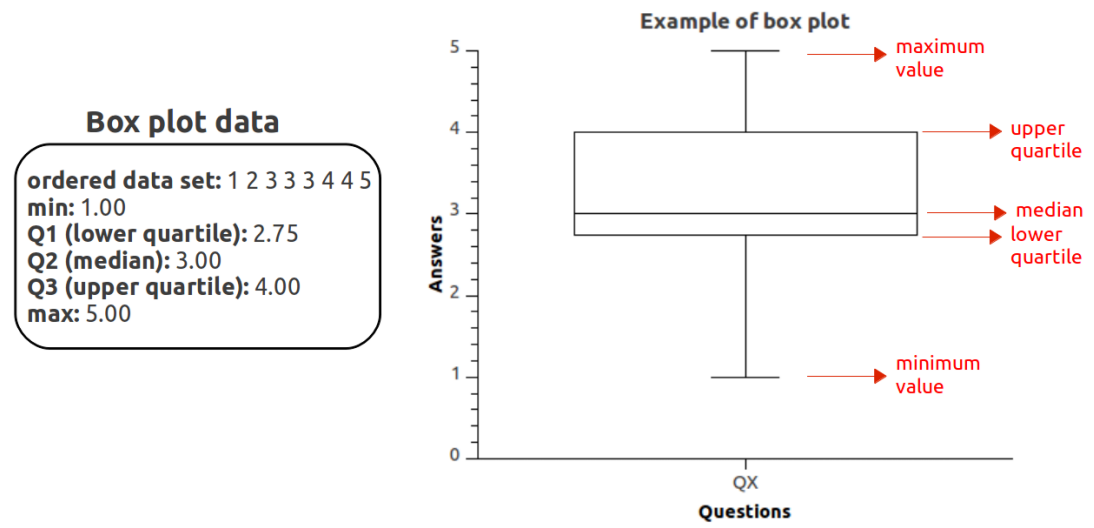

Figura 7.4: Exemplo de gráfico box plot 
Esses valores foram calculados usando a função percentile do software QtiPlot ${ }^{1}$ com parâmetros $25 \%$ para cálculo de Q1, e 75\% para cálculo de Q3. Os box plots utilizados também apresentam os pontos Whisker [Eas97] que são os valores mínimos e máximos presentes na amostra (conjunto de dados ordenado).

A Figura 7.4 apresenta um exemplo de blox plot no formato utilizado neste estudo. Este blox plot foi gerado com base nos dados apresentados no lado esquerdo da figura. Como pode ser observado, para a questão $\mathrm{Qx}$, os valores mínimos e máximos são apresentados, assim como os quartis. Uma vez que o eixo y representa as respostas, pode-se avaliar o quão positivas (ou negativas) foram as respostas, e o quanto estão dispersas.

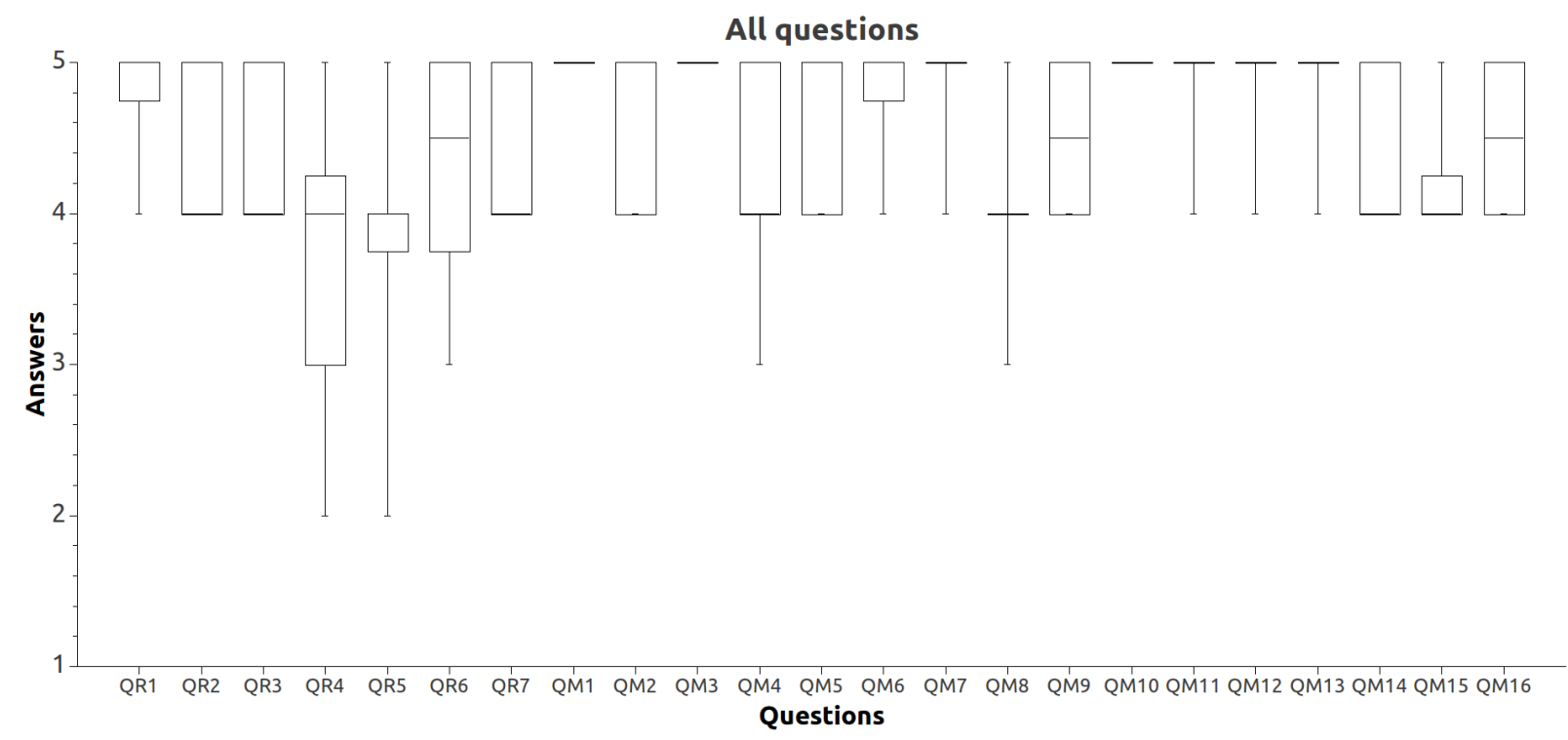

Figura 7.5: Fase 1- Resultados de todas as perguntas

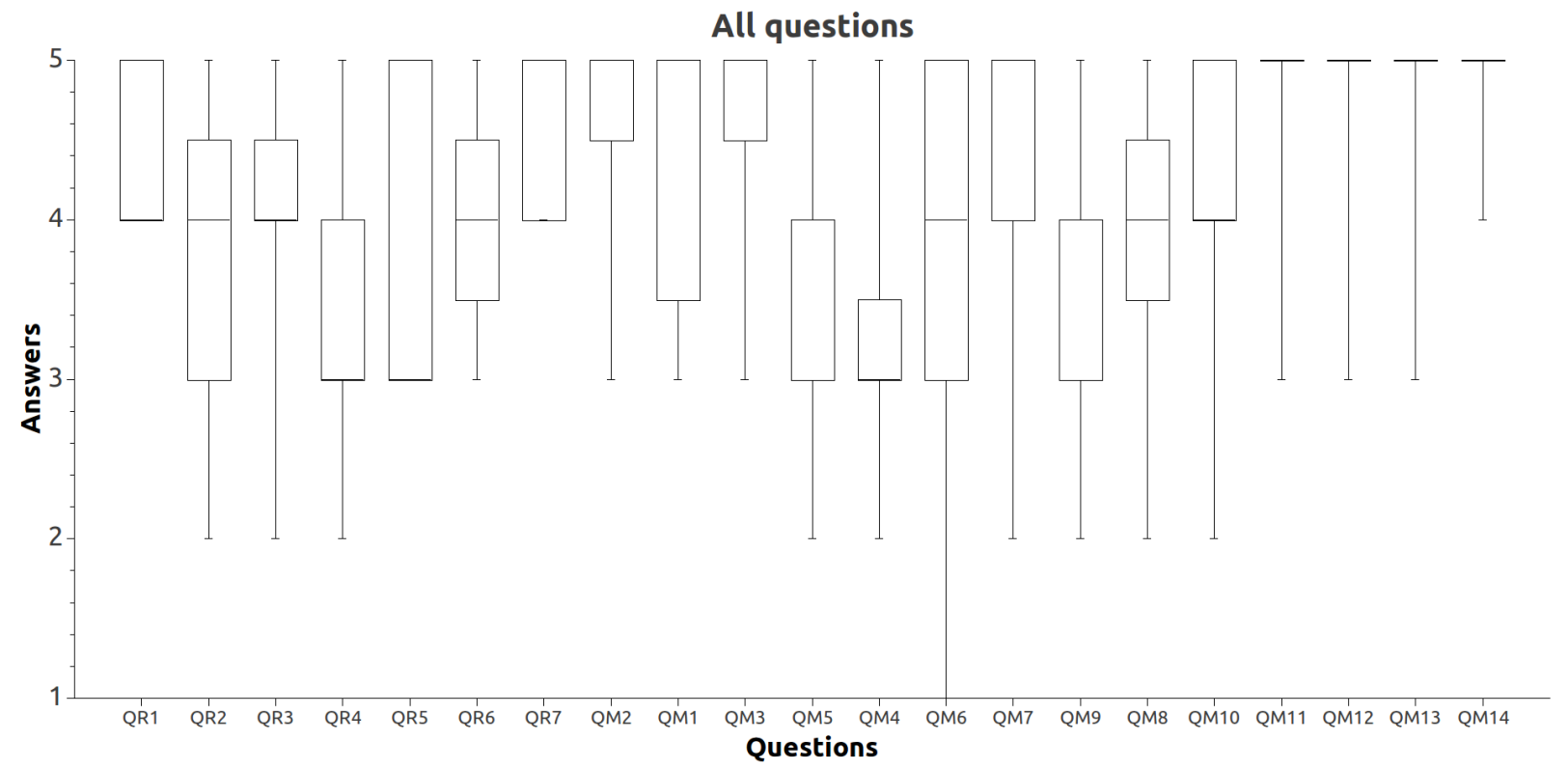

Figura 7.6: Fase 2-Resultados de todas as perguntas

As Figuras 7.5 and 7.6 apresentam box plots com as respostas de todas as perguntas da primeira e segunda fase, respectivamente. A sigla RQ, que é utilizada nas perguntas apresentadas a seguir,

\footnotetext{
${ }^{1}$ QtiPlot: http://soft.proindependent.com/qtiplot.html
} 
refere-se as questões relacionadas ao Rehearsal, enquanto que a sigla QM refere-se as questões relacionadas à metodologia proposta.

No decorrer desta seção, os resultados de todas as perguntas serão apresentados. No entanto, para uma discussão inicial, pode-se observar que essas figuras fornecem uma visão geral evidenciando a presença de mais respostas positivas do que negativas em ambas as fases. As respostas concentram-se no topo do eixo y, ao redor dos valores 4 e 5 . Tentou-se contextualizar todos os gráficos apresentados com os resultados obtidos nas entrevistas. A lista completa das 16 perguntas apresentadas na Figura 7.5 pode ser encontrada no Apêndice B, enquanto que a lista completa das 14 perguntas apresentadas na Figura 7.6 pode ser encontrada no pacote do estudo exploratório (vide Seção 7.2).

Antes de iniciar a discussão detalhada de cada questão, pode-se constatar que os participantes, de ambas as fases, foram bem treinados ou, pelo menos, aprovaram o treinamento. Essa constatação fundamenta-se na observação das Figuras 7.7 and 7.8 que contém as respostas para as questões da Tabela 7.1. De acordo com os seus gráficos, os sujeitos responderam à apenas 4 ou 5 , ou seja, "partially agree" ou "strongly agree", respectivamente.

\begin{tabular}{|l|l|}
\hline ID & Question \\
\hline \hline QR7 & The researcher provided adequate training in Rehearsal before the development. \\
\hline QM16 and QM14 & The researcher provided adequate training in the methodology before the development. \\
\hline
\end{tabular}

Tabela 7.1: Questões para avaliar o treinamento

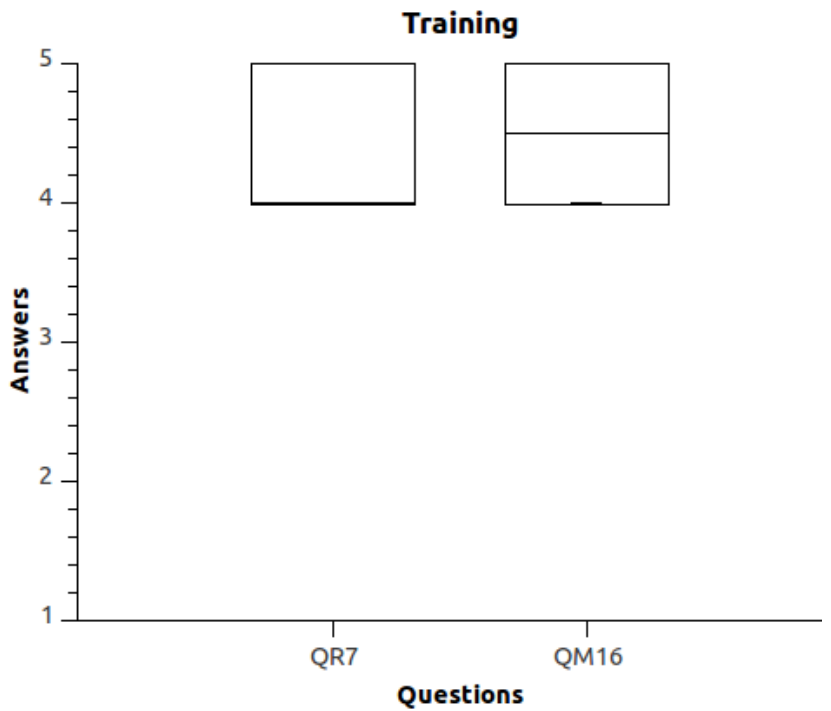

Figura 7.7: Treinamento - Fase 1

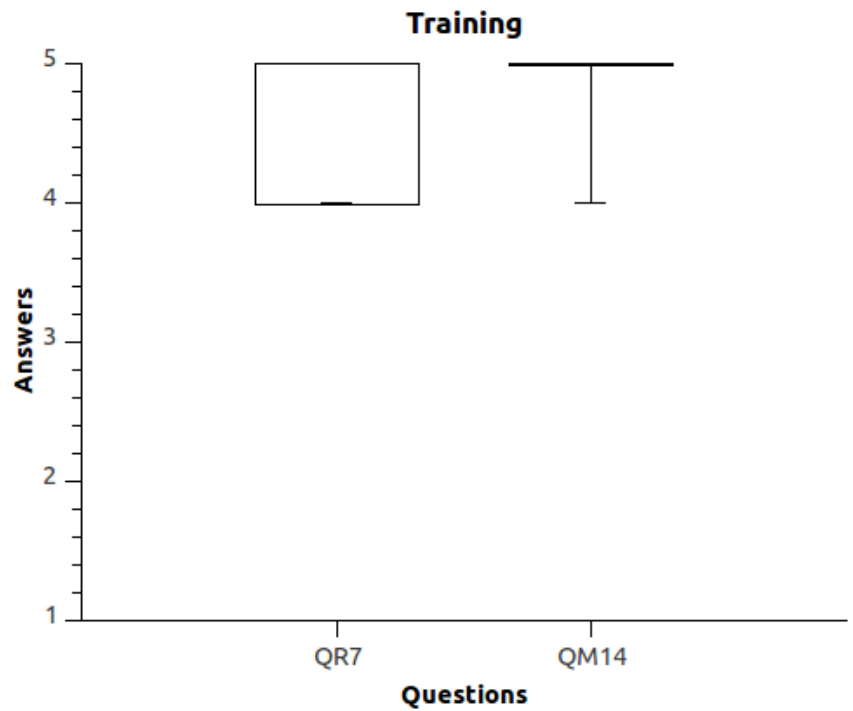

Figura 7.8: Treinamento - Fase 2

\subsubsection{Avaliação do Rehearsal}

Na primeira fase do estudo, estudamos as seguintes perguntas: "As funcionalidades do Rehearsal auxiliam na aplicação dos passos da metodologia proposta ?", ao passo que, na segunda fase, estudou-se a pergunta: "Quão fácil é utilizar as funcionalidades do Rehearsal para aplicar os passos da metodologia proposta ?". Ambas as perguntas são relacionadas à principais funcionalidades do Rehearsal. Conforme definido nos protocolos de estudo, as perguntas dos questionários foram agrupadas por similaridade, e cada grupo foi analisado separadamente. Cada grupo corresponde a uma funcionalidade do Rehearsal.

Grupo 1 - Geração dinâmica de clientes para serviços web. O estudo concentrou-se na funcionalidade "WSClient", ou seja, apenas a utilização de clientes para serviços Soap/WSDL. As 
perguntas relacionadas a esta funcionalidade são apresentadas na Tabela 7.2. Os resultados obtidos são ilustrados nos box plots das Figuras 7.9 e 7.10 .

\begin{tabular}{|l|l|}
\hline ID & Question \\
\hline \hline QR1 & It was easy to learn how to use the WSClient feature. \\
\hline QM3 (p1) & The use of the WSClient feature is useful in Task 01. \\
\hline QM3 (p2) & It was easy to use the WSClient feature in Task 01. \\
\hline QM13 (p1) & The use of the WSClient feature is useful in Task 04. \\
\hline QM13 (p2) & It was easy to use the WSClient feature in Task 04. \\
\hline & p1 = phase 1 and p2 = phase 2 \\
\hline
\end{tabular}

Tabela 7.2: Perguntas para estudo do Grupo 1

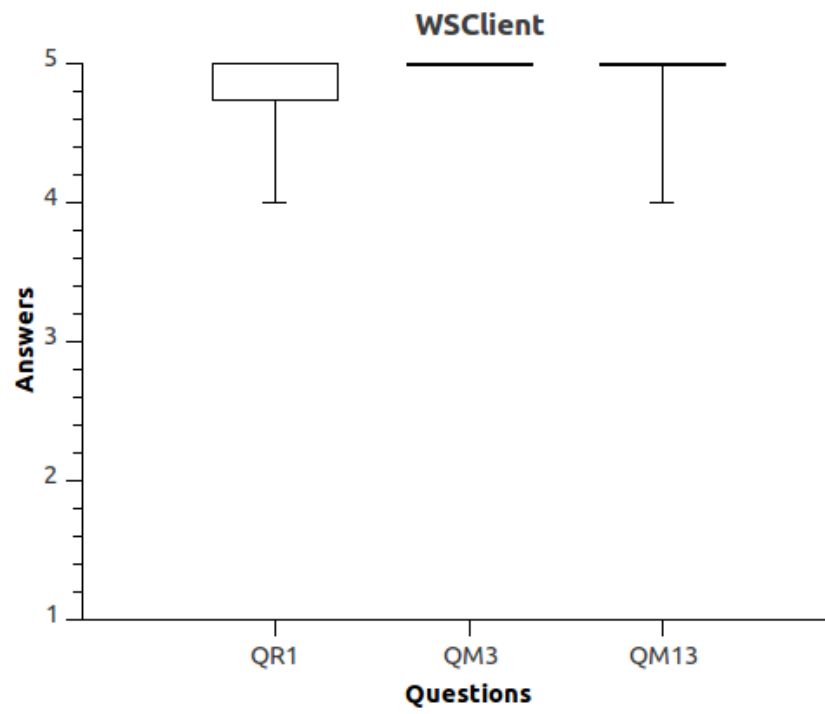

Figura 7.9: Resultados Grupo 1 - Fase 1

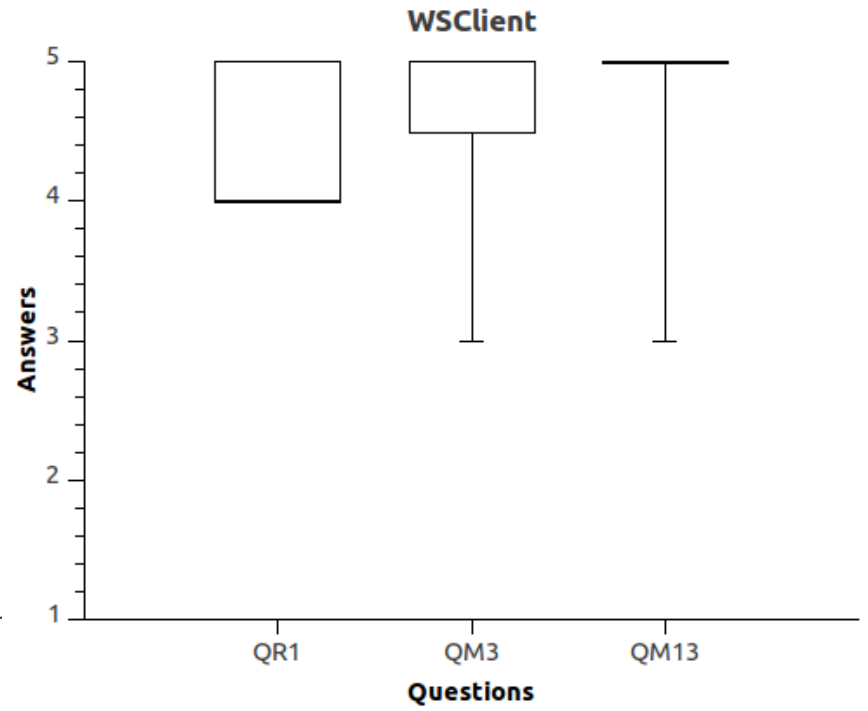

Figura 7.10: Resultados Grupo 1 - Fase 2

Na primeira fase, como mostra a Figura 7.9, todas as respostas foram as opções 4 ou 5 . Embora tenhamos obtido bons resultados para essas questões, aprender a usar a funcionalidade WSClient não foi tarefa trivial para os participantes (pergunta RQ1). Durante o treinamento, notou-se que esta funcionalidade foi a mais difícil de ser aprendida. Aparentemente, a construção do objeto Item para envio e recebimento dos envelopes Soap agrega complexidade à escrita dos testes.

Essa conclusão é reforçada pelos resultados das entrevistas: os participantes aprovaram a funcionalidade e acharam-na útil para o teste de unidade. No entanto, grande parte deles gostaria que o objeto Item fosse mais simples. Alguns times sugeriram, inclusive, melhorias de interface e implementação.

De acordo com o blox plot apresentado na Figura 7.9, todos os participantes acharam a funcionalidade WSClient útil para aplicação da primeira e quarta fase da metodologia, questões QM3 e QM13, respectivamente.

Com base nesses feedbacks, a interface do objeto Item e a ferramenta Item Explorer foram modificadas. Assim, na segunda fase do estudo, os participantes utilizaram uma versão do Rehearsal que continha essas modificações.

Em relação à segunda fase do estudo (Figura 7.10), foram obtidos resultados similares aos da primeira fase. Embora tenhamos obtido algumas respostas 3 ("indifferent"), não houve resposta negativa. Assim, pode-se concluir que mesmo para usuários inexperientes, o aprendizado do Rehearsal não se mostra difícil.

Grupo 2 - Emulação Mocking de serviços web. Para estudo dessa funcionalidade, foram propostas as questões apresentadas na Tabela 7.3. Os resultados obtidos para essas questões são 
apresentados nos box plots abaixo (Figura 7.11 e 7.12).

\begin{tabular}{|l|l|}
\hline ID & Question \\
\hline \hline QR2 & It was easy to learn how to use the WSMock feature. \\
\hline QM6 (p1) & The use of the WSMock feature is useful in Task 02. \\
\hline QM6 (p2) & It was easy to use the WSMock feature in Task 02. \\
\hline & $\mathrm{p} 1=$ phase 1 and $\mathrm{p} 2=$ phase 2 \\
\hline
\end{tabular}

Tabela 7.3: Perguntas para estudo do Grupo 2

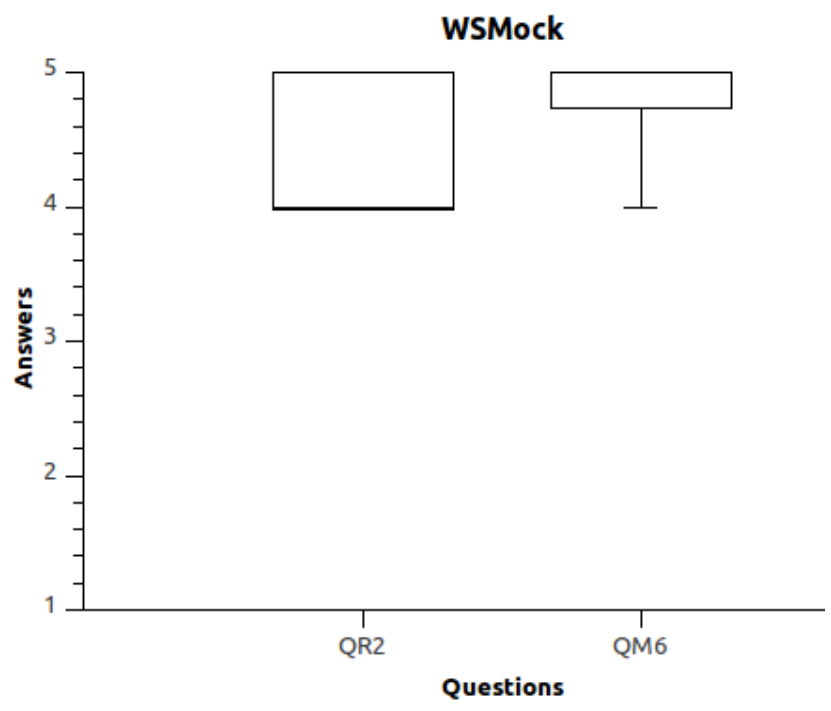

Figura 7.11: Resultados Grupo 2 - Fase 1

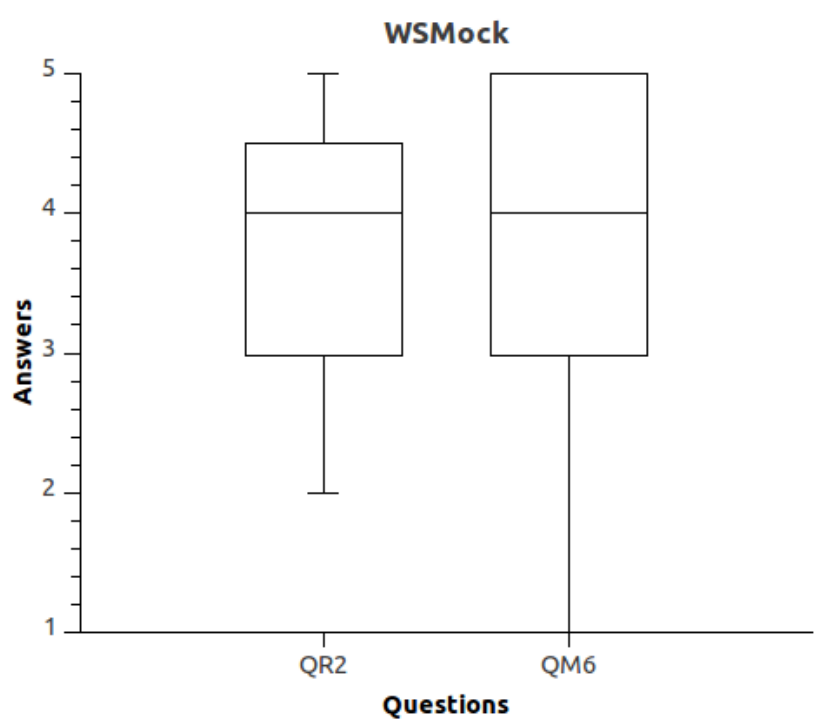

Figura 7.12: Resultados Grupo 2 - Fase 2

$\mathrm{Na}$ primeira fase, embora quase todos os participantes tenham concordado com a utilidade desta funcionalidade na aplicação da segunda fase da metodologia (questão QM6 da Figura 7.11), aparentemente, foram encontrados problemas no aprendizado dela. Conforme mostra a Figura 7.11, a mediana para a questão RQ2 foi 4, o que significa que aprender essa funcionalidade não foi trivial para muitos participantes. Nas entrevistas, muitos participantes aprovaram a interface fluente desta funcionalidade, porém, de acordo com eles, o tratamento das exceções Java implementado dificultou sua utilização. De acordo com alguns times, as mensagens dessas exceções deveriam ser mais intuitivas.

Após a primeira fase, o tratamento das exceções desta funcionalidade foi modificado a fim de conter mensagens mais intuitivas para o desenvolvedor. Esse novo tratamento de exceções foi incorporada a versão do Rehearsal que é utilizado na segunda fase deste estudo exploratório.

Na segunda fase do estudo, metade dos alunos teve problemas em aprender e aplicar esta funcionalidade na tarefa 2. Esta conclusão deriva-se da análise da Figura 7.12 e dos resultados das entrevistas. De acordo com o gráfico, o ponto representando $50 \%$ dos dados contém valor 4 . Logo, acima desse ponto, obtiveram-se apenas respostas 4 ou 5 para as questões QR2 e QM6. Abaixo desse ponto, obtiveram-se resultados negativos.

Nas entrevistas, constatou-se que alguns alunos tiveram problemas em saber o que deveria ser emulado nas tarefas e como introduzir os mocks na coreografia. De acordo com eles, aprender a funcionalidade em si não é complicado, porém, aplicá-la em situações reais não é trivial.

Grupo 3 - Interceptador de mensagens. Para avaliação dessa funcionalidade, as questões da Tabela 7.4 foram propostas. As Figuras 7.13 e 7.14 apresentam os resultados obtidos para essas questões.

De acordo com o box plot apresentado na Figura 7.4, pode-se inferir que, na primeira fase, essa funcionalidade foi realmente útil no teste de integração. Todos os participantes concordaram 


\begin{tabular}{|l|l|}
\hline ID & Question \\
\hline \hline QR3 & It was easy to learn how to use the Message Interceptor feature. \\
\hline QM7 (p1) & The use of the Message Interceptor feature is useful in Task 02. \\
\hline QM7 (p2) & It was easy to use the Message Interceptor feature in Task 02. \\
\hline QM10 (p1) & The use of the Message Interceptor feature is useful in Task 03. \\
\hline QM10 (p2) & It was easy to use the Message Interceptor feature in Task 03. \\
\hline & $\mathrm{p} 1=$ phase 1 and p2 = phase 2 \\
\hline
\end{tabular}

Tabela 7.4: Questões para avaliar o Grupo 3

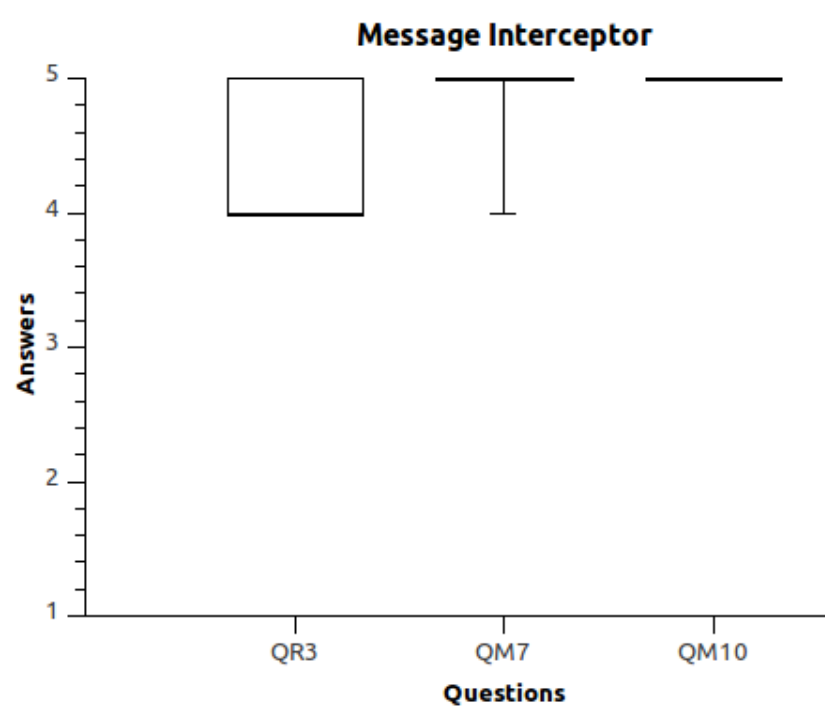

Figura 7.13: Resultados Grupo 3 - Fase 1

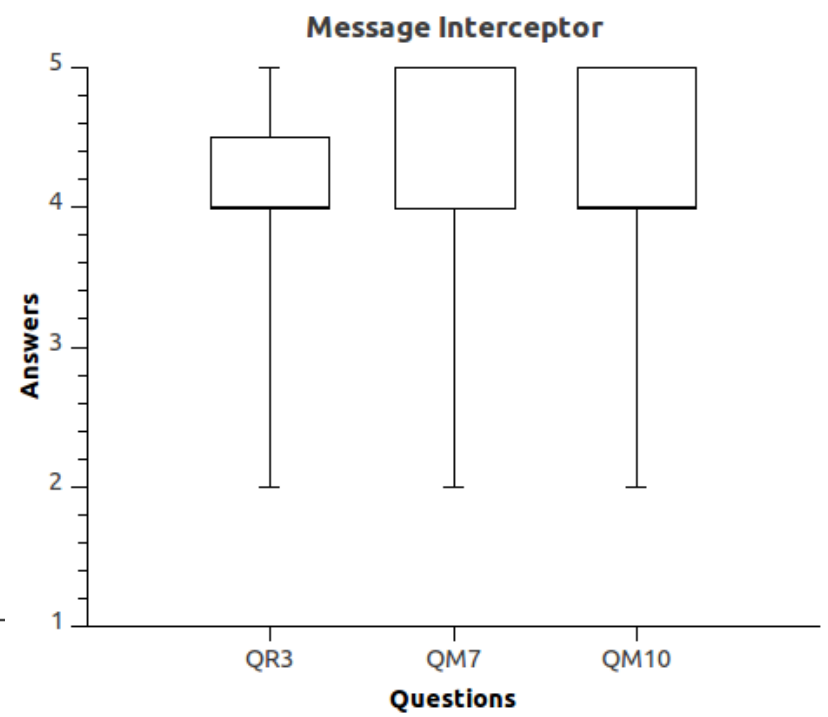

Figura 7.14: Resultados Grupo 3 - Fase 2

fortemente com o fato de a funcionalidade ser útil para a validação das mensagens trocadas entre os papéis de uma coreografia (questão QM10). Pode-se constatar que essa funcionalidade também é útil para validação das mensagens trocadas dentro de um papel da coreografia. Isso é evidenciado pelos resultados obtidos para a questão QM7. Na tarefa 2 da metodologia, os participantes tiveram que validar as mensagens trocadas dentro do papel (processo) desenvolvido.

Em relação à questão QR3, que visava estudar a facilidade de se aprender a (essa) funcionalidade, obtiveram-se resultados semelhantes àqueles obtidos para a funcionalidade WSMock. Com base nos resultados das entrevistas, observou-se que os participantes não tiveram dificuldades em criar, configurar ou utilizar os interceptadores de mensagens.

Os problemas reportados decorrem da reconfiguração da coreografia. Para utilizar o interceptador de mensagens, o desenvolvedor deve reconfigurar a coreografia para utilizar os proxies criados ao invés dos serviços da coreografia. Em ambas as fases do estudo, foram fornecidos scripts para automatizar essa tarefa, no entanto, para outras coreografias, isso deve ser feito pelos desenvolvedores.

Na segunda fase do estudo, também houve bons resultados. Embora tenham sido obtidos alguns resultados negativos (opção 2) para todas as questões desta fase, mais de $75 \%$ dos alunos tiveram facilidade em utilizar o interceptador de mensagens. Nas entrevistas, de maneira similar à primeira fase, alguns alunos reprovaram a reconfiguração manual da coreografia para inserção dos proxies.

Grupo 4 - Abstração da coreografia. Para estudar os benefícios e problemas decorrentes da utilização dessa funcionalidade, foram propostas as questões da Tabela 7.5. Os resultados obtidos para essas questões são apresentados nos box plots das Figuras 7.15 e 7.16.

Em ambas as fases do estudo, foram obtidos resultados negativos. Na primeira fase, como pode ser observado na Figura 7.15, alguns alunos tiveram problemas para aprendê-la e utilizá-la (QR4). Apesar desta funcionalidade não ter ajudado todos os participantes na utilização das demais fun- 


\begin{tabular}{|l|l|}
\hline ID & Question \\
\hline \hline QR4 & It was easy to learn how to use the Abstraction Choreography feature. \\
\hline QR5 & The Abstraction Choreography feature helped me to use other Rehearsal features. \\
\hline QR6 & The Abstraction Choreography feature helped me to write the test cases. \\
\hline
\end{tabular}

Tabela 7.5: Questões para avaliar o Grupo 4

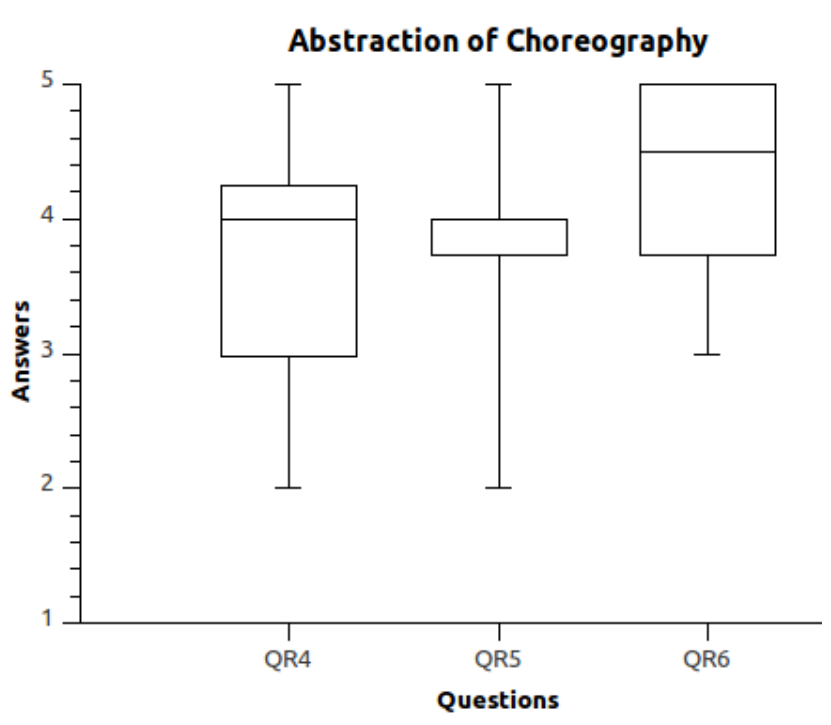

Figura 7.15: Resultados Grupo 4 - Fase 1

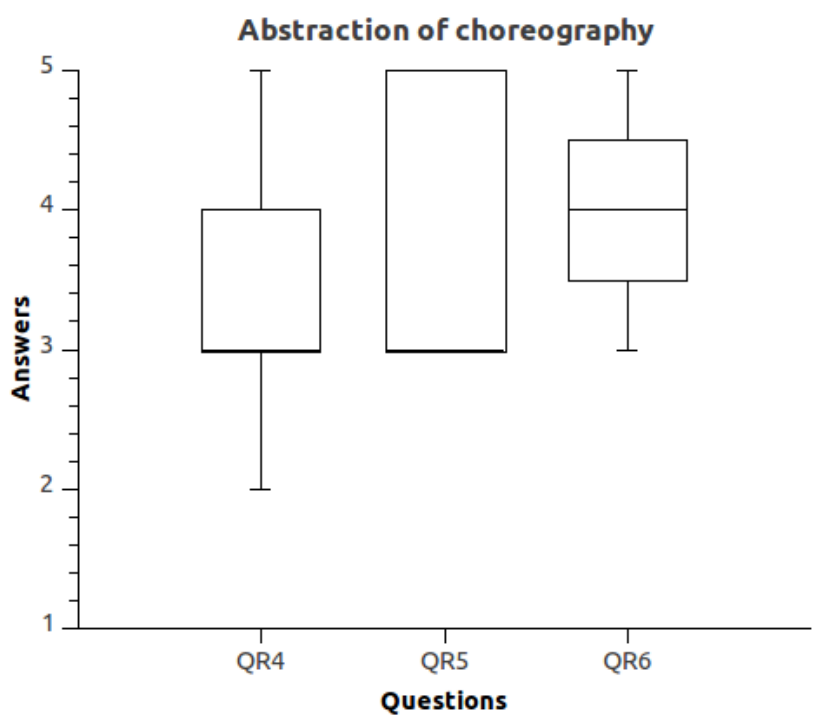

Figura 7.16: Resultados Grupo 4 - Fase 2

cionalidades do Rehearsal (questão QR5), ela ajudou a maioria dos participantes a escrever casos de testes (questão QR6). Para essa última questão, a mediana foi próxima a 5, e nenhum resultado negativo foi obtido.

Nas entrevistas, os participantes reprovaram a interface e a criação do descritor da coreografia. De acordo com eles, a definição recursiva dos papéis e serviços da coreografia no descritor não é intuitiva. Além disso, o descritor deveria ser gerado automaticamente.

$\mathrm{Na}$ segunda fase, os resultados foram negativos, o que é compreensível dado que nenhum dos estudantes tinha conhecimento prévio sobre coreografias. Em relação às questões QR4 e QR5, metade dos participantes foram indiferentes em relação a essas questões. No entanto, houve bons resultados para a questão QR6, o que demonstra que esta funcionalidade auxiliou os participantes na escrita dos testes. Assim, pode-se concluir que, embora seja difícil de utilizar, essa funcionalidade é útil no desenvolvimento de coreografias. Conforme discutido na Seção 5.5, Rehearsal será integrado a outros subsistemas e, com esta integração, o descritor será gerado automaticamente.

\subsubsection{Avaliação da proposta de metodologia TDD}

Na primeira fase do estudo, estudamos a questão: "A metodologia proposta fornece diretrizes adequadas para o desenvolvimento de uma coreografia?". Na segunda fase, a fim de avaliar a facilidade em se aplicar a metodologia proposta, estudamos a questão: "Quão fácil é seguir os passos da metodologia proposta para desenvolver uma coreografia ?".

Conforme descrito nos protocolos de estudo, a análise de ambas as questões foi realizada com base nos grupos apresentados a seguir. Cada grupo representa um passo da metodologia. Durante o estudo, cada tarefa executada pelos participantes representava um passo da proposta de metodologia.

Grupo 5 - Passo 1. Neste passo da metodologia, serviços atômicos são criados ou adaptados por meio de uma abordagem guiada por testes. Para estudar esse processo, propusemos as perguntas da Tabela 7.6. Os box plots das Figuras 7.17 e 7.18 contêm as respostas obtidas para essas perguntas. 


\begin{tabular}{|l|l|}
\hline ID & Question \\
\hline \hline QM1 (p1) & It was easy to follow the steps from Task 01. \\
\hline QM1 (p2) & The steps of Task 01 were perfectly clear to me. \\
\hline QM2 (p1) & The steps of Task 01 are appropriate for the development of a choreography. \\
\hline QM2 (p2) & It was easy to follow the steps from Task 01. \\
\hline & $\mathrm{p} 1=$ phase 1 and $\mathrm{p} 2=$ phase 2 \\
\hline
\end{tabular}

Tabela 7.6: Questões para avaliar o Grupo 5

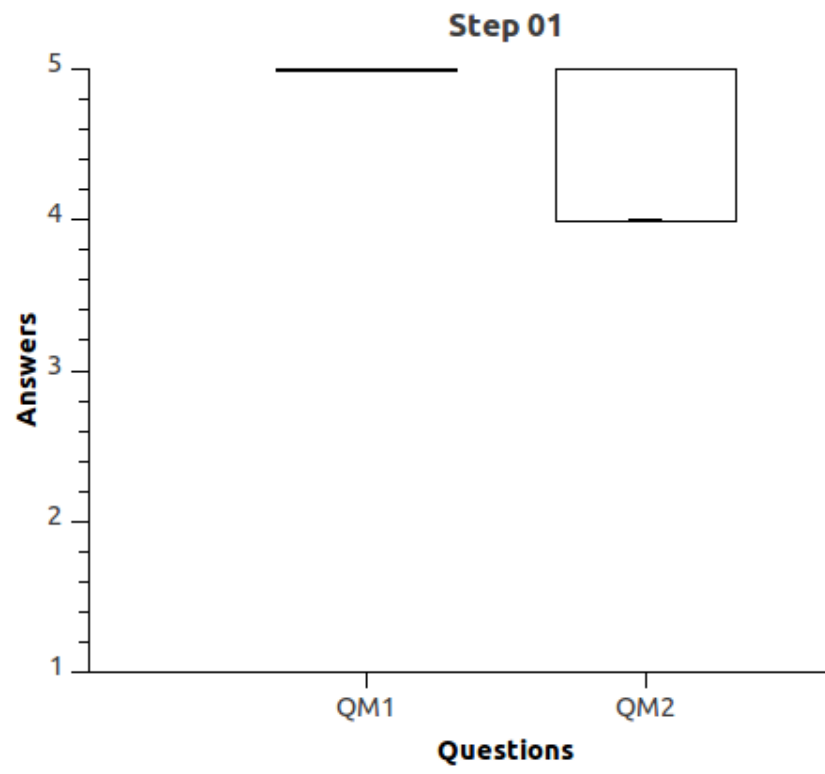

Figura 7.17: Resultados Grupo 5 - Fase 1

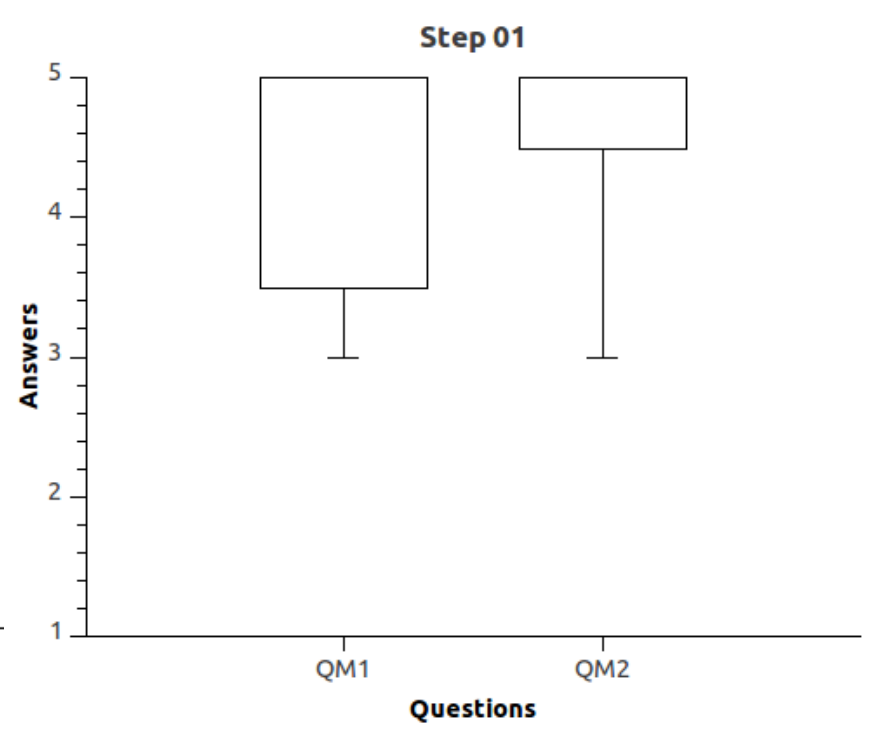

Figura 7.18: Resultados Grupo 5 - Fase 2

De acordo com o gráficos acima, em ambas as fases, os participantes não tiveram muitos problemas na aplicação da tarefa 1. Na questão QM1 (Figura 7.17), houve apenas respostas 5, ao passo que na questão QM2 (Figura 7.18), a maioria das respostas foi 5. Além disso, a maioria dos alunos não teve problemas para entender os passos da tarefa 1 (questão QM1 da fase 2). Em relação à adequação deste passo da metodologia ao desenvolvimento de coreografias (questão QM2 da fase 1), houve também resultados positivos.

Grupo 6 - Passo 2. Nesta tarefa, os serviços atômicos desenvolvidos na fase anterior são integrados em um processo que representa um papel da coreografia. O desenvolvimento também segue uma abordagem guiada por testes e todas as mensagens trocadas no processo são validadas. A Tabela 7.7 apresenta as perguntas para estudo desse passo da metodologia. As Figuras 7.19 e 7.20 apresentam os box plots com os resultados dessas questões.

\begin{tabular}{|l|l|}
\hline ID & Question \\
\hline \hline QM4 (p1) & It was easy to follow the steps from Task 02. \\
\hline QM4 (p2) & The steps of Task 02 were perfectly clear to me. \\
\hline QM5 (p1) & The steps of Task 02 are appropriate for the development of a choreography. \\
\hline QM5 (p2) & It was easy to follow the steps from Task 02. \\
\hline & $\mathrm{p} 1=$ phase 1 and $\mathrm{p} 2=$ phase 2 \\
\hline
\end{tabular}

Tabela 7.7: Questões para avaliar o Grupo 6

Como pode ser observado na Figura 7.19, obtivemos apenas respostas com a opção 4 para a questão QM5. Assim, pode-se considerar que os participantes da primeira fase do estudo acharam esse passo apropriado ao desenvolvimento de uma coreografia. No entanto, nem todos participantes acharam este passo fácil de ser serguido. A mediana para a questão QM4 foi 4 e pelo menos um 


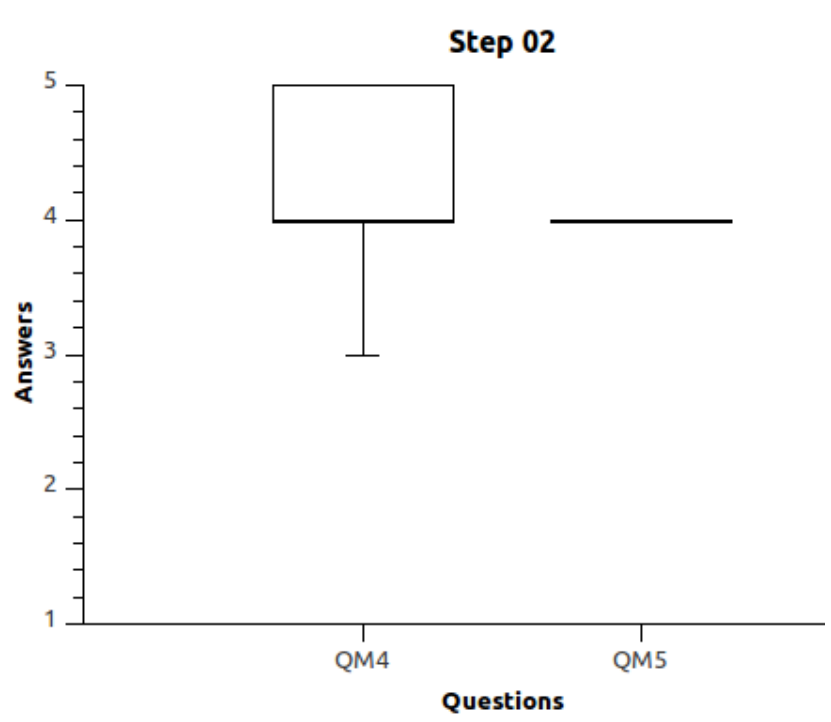

Figura 7.19: Resultados Grupo 6 - Fase 1

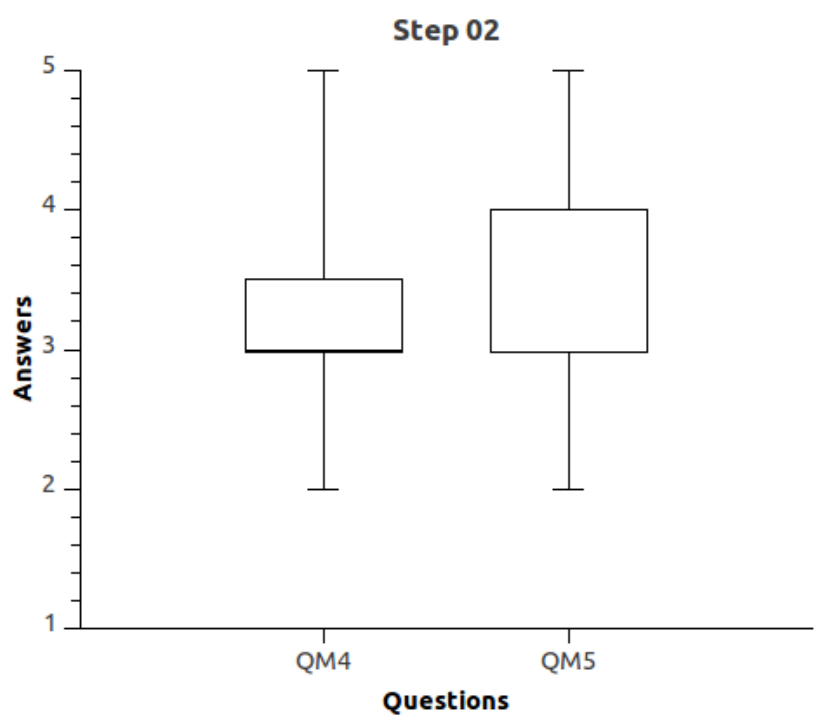

Figura 7.20: Resultados Grupo 6 - Fase 2

participante foi indiferente em relação a esta questão. Esses resultados podem estar relacionados àqueles obtidos para as funcionalidades WSMock e interceptador de mensagens, uma vez que essas funcionalidades são utilizadas nesta tarefa. As dificuldades encontradas pelos participantes na utilização dessas funcionalidades podem ter dificultado a execução das atividades pertencentes à ela.

Em relação à segunda fase, houve alguns resultados negativos, o que é compreensível dado que essa tarefa é a mais complexa do estudo. Como pode ser observado na Figura 7.20, para ambas as questões do box plot, a maior parte dos resultados concentra-se entre os valores 3 e 4 e alguns resultados apresentam valor 2 ou 5 . De fato, durante o desenvolvimento, os estudantes tiveram problemas em seguir este passo. Alguns desses problemas eram referentes à utilização do WSMock. Como pode ser observado na Figura 7.12, houve resultados negativos em relação a essa funcionalidade na segunda fase do estudo.

Grupo 7 - Passo 03. Após a criação de processos executáveis para implementar os papéis da coreografia, os processos são integrados para compor a coreografia. Interceptadores de mensagens são utilizados para validar a integração. As perguntas para estudar esse passo são apresentadas na Tabela 7.8. As Figuras 7.21 e 7.22 apresentam as respostas para estas questões.

\begin{tabular}{|l|l|}
\hline ID & Question \\
\hline \hline QM8 (p1) & It was easy to follow the steps from Task 03. \\
\hline QM8 (p2) & The steps of Task 03 were perfectly clear to me. \\
\hline QM9 (p1) & The steps of Task 03 are appropriate for the development of a choreography. \\
\hline QM9 (p2) & It was easy to follow the steps from Task 03. \\
\hline & p1 = phase 1 and 2 2 = phase 2 \\
\hline
\end{tabular}

Tabela 7.8: Questões para avaliar o Grupo 7

De maneira semelhante ao passo anterior, em ambas as fases os participantes não seguiram a tarefa 3 facilmente. Na primeira fase (Figura 7.21), a mediana para a questão QM8 foi 4. Esse passo da metodologia é semelhante ao anterior, logo, os mesmos problemas levantados no passo 2 (Grupo 6) são aplicáveis neste passo. Em relação à questão QM9, houve apenas resultados positivos, o que evidencia a importância deste passo no desenvolvimento de uma coreografia.

Na segunda fase do estudo, comparados à tarefa anterior, os estudantes tiveram um melhor entendimento da tarefa (questão QM8 da Figura 7.22). No entanto, não foi trivial seguir a tarefa (questão QM9). Tais dificuldades eram esperadas devido à falta de experiência dos participantes em 


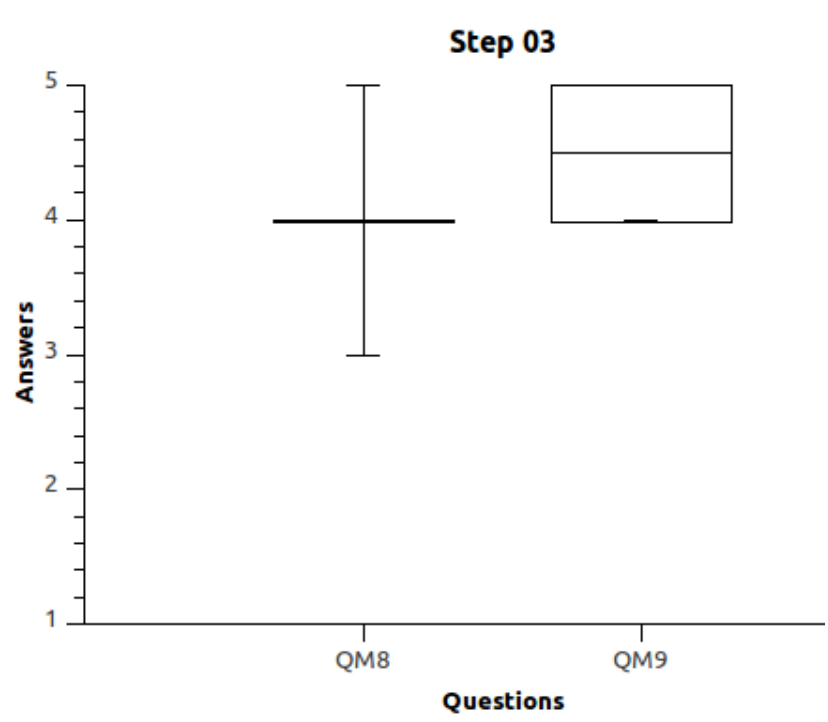

Figura 7.21: Resultados Grupo 7 - Fase 1

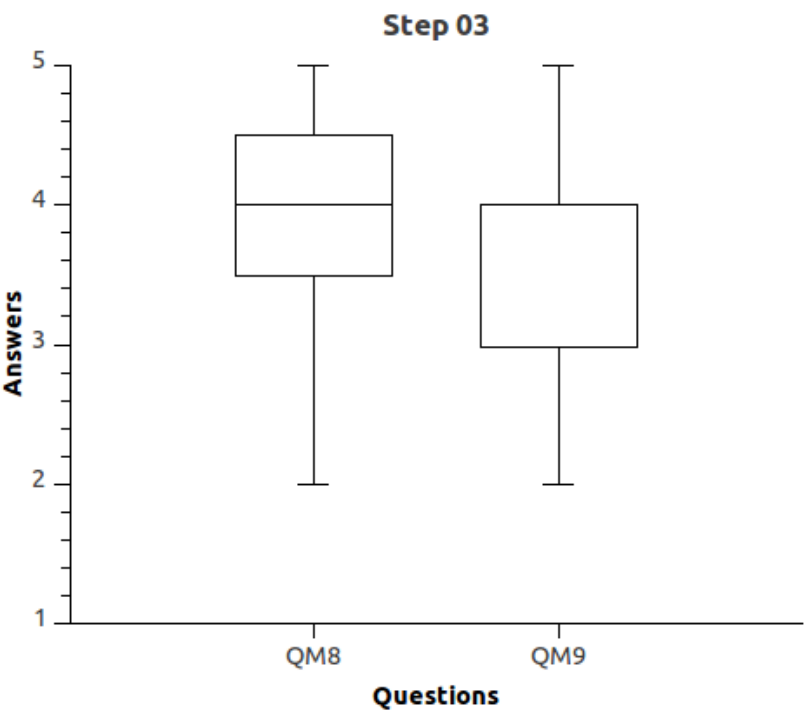

Figura 7.22: Resultados Grupo 7-Fase 2

composição de serviços. De acordo com os estudantes, a principal dificuldade consistia em entender o funcionamento de uma composição de serviços. Aparentemente, como pode ser observado nos gráficos relacionados à avaliação do Rehearsal (seção anterior), os participantes não tiveram sérios problemas em aprender a utilizar o interceptador de mensagens e o WSMock, que são funcionalidades utilizadas no teste de integração.

Grupo 8 - Passo 04. Nesta tarefa final, a coreografia é testada sob a perspectiva do usuário final. As questões utilizadas para estudar esse passo da metodologia são apresentadas na Tabela 7.9. Nos gráficos apresentados nas Figuras 7.23 and 7.24, são apresentados os resultados das questões a seguir.

\begin{tabular}{|l|l|}
\hline ID & Question \\
\hline \hline QM11 (p1) & It was easy to follow the steps from Task 04. \\
\hline QM11 (p2) & The steps of Task 04 were perfectly clear to me. \\
\hline QM12 (p1) & The steps of Task 04 are appropriate for the development of a choreography. \\
\hline QM12 (p2) & It was easy to follow the steps from Task 04. \\
\hline & $\mathrm{p} 1=$ phase 1 and $\mathrm{p} 2=$ phase 2 \\
\hline
\end{tabular}

Tabela 7.9: Questões para avaliar o Grupo 8

Aparentemente os participantes de ambas as fases do estudo tiveram facilidade em seguir esse passo da metodologia, como pode ser observado nos resultados obtidos para as questões QM11 (Figura 7.23) e QM12 (Figura 7.24). No estudo exploratório, a tarefa 4 era simples, nada deveria ser implementado pelo desenvolvedor se as tarefas anteriores tivessem sido completadas corretamente. Na proposta de metodologia, os testes de aceitação são similares aos testes conduzidos no Passo 3, no entanto, não são utilizados interceptadores e mocks (quando possível). Apesar de os testes de aceitação serem simples, quase todos os participantes da primeira fase consideraram-nos apropriados e necessários no desenvolvimento de uma coreografia (questão QM12 da Figura 7.23).

Grupo 9 - Aceitação do Rehearsal e proposta de metodologia. Com base em todos os resultados obtidos e apresentados nas seções anteriores, pode-se considerar que a metodologia e o arcabouço Rehearsal são apropriados para o desenvolvimento de coreografias. Além das análises apresentadas, na primeira fase do estudo, investigou-se a aceitação da metodologia e do Rehearsal em relação a suas adequações aos projetos SOA que os participantes do estudos já tinham participado. Para isso, as questões da Tabela 7.10 foram propostas. Os seus resultados são apresentados na 


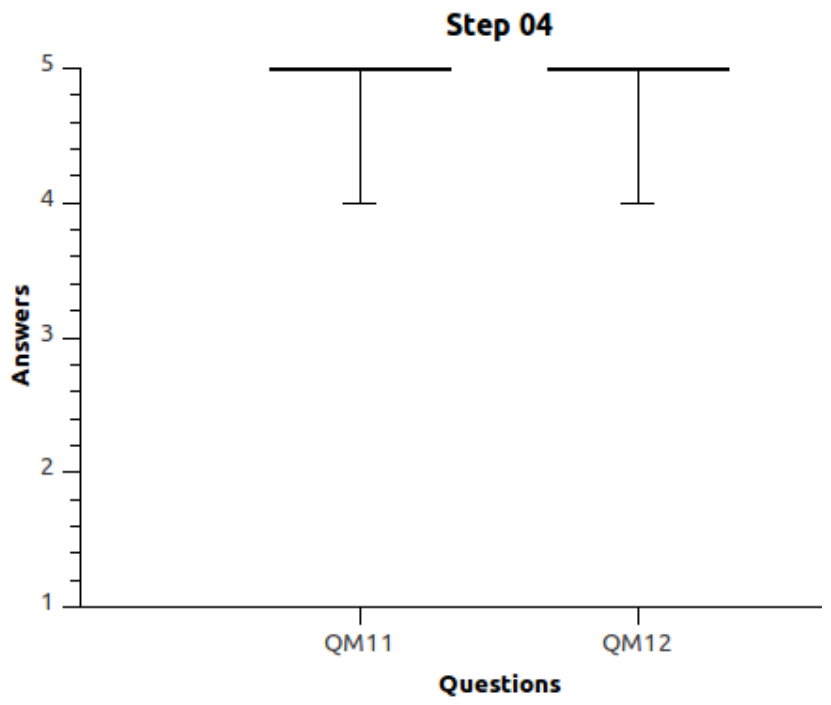

Figura 7.23: Resultados Grupo 8 - Fase 1

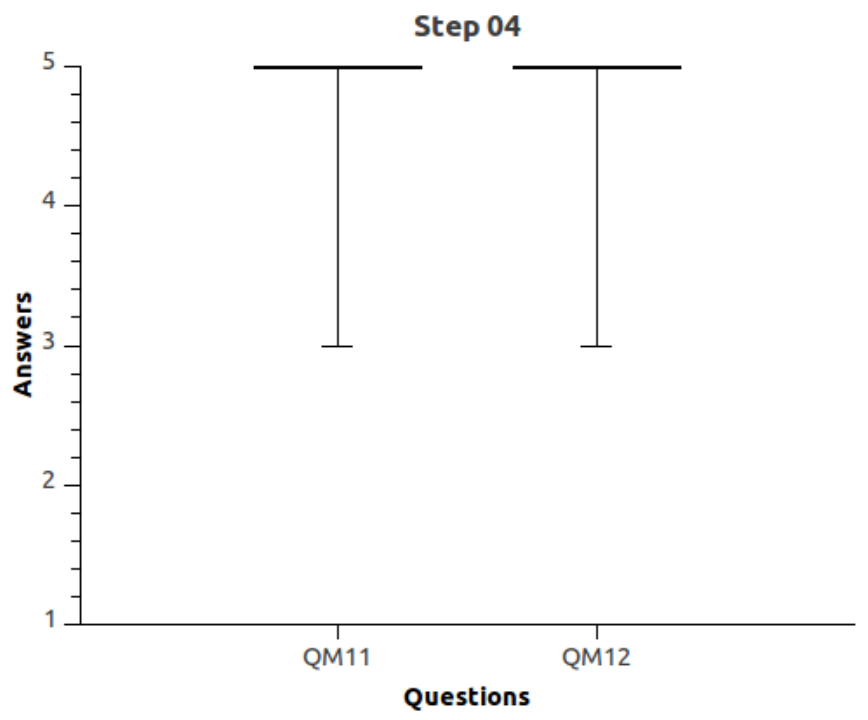

Figura 7.24: Resultados Grupo 8 - Fase 2

Figura 7.25.

\begin{tabular}{|l|l|}
\hline ID & Question \\
\hline \hline QM14 & I think the use of the methodology and Rehearsal would be useful for projects I have participated. \\
\hline QM15 & I would use the methodology and Rehearsal in future projects I may participate. \\
\hline
\end{tabular}

Tabela 7.10: Questões para avaliar o Grupo 9

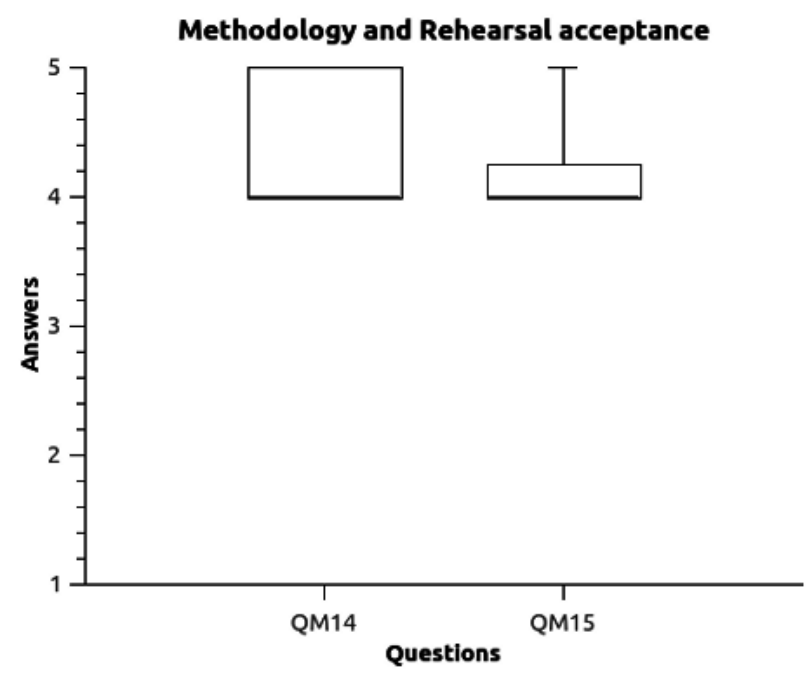

Figura 7.25: Resultados Grupo 9

Como pode ser observado na Figura 7.25, apenas resultados positivos foram obtidos. Todos os participantes usariam a metodologia e o arcabouço em projetos futuros (questão QM15). Na entrevista, um dos participantes sugeriu que a metodologia deveria ser mais integrada a documentos que descrevem os requisitos da coreografia (e.g., diagramas BPMN2). Esta melhoria poderia ser um trabalho futuro com um bom potencial para auxiliar na adoção da metodologia. Em relação à questão QM14, segundo os participantes, a proposta de metodologia e o Rehearsal seriam úteis para a resolução de problemas já enfrentados.

De um modo geral, todas as funcionalidades do Rehearsal, com exceção da abstração da co- 
reografia, receberam boas avaliações. Essa funcionalidade mostrou-se de difícil aprendizado para os participantes de ambas as fases. Assim, treinamentos e documentações, existentes e futuras, do Rehearsal devem dar atenção especial a essa funcionalidade.

Em relação à proposta de metodologia, todas as fases receberam boas avaliações, com exceção da segunda fase, que consiste na implementação dos papéis da coreografia. Essa fase, chamada de tarefa 2 no estudo, não foi bem avaliada por alguns participantes da segunda fase do estudo. Dada que essa tarefa representa a fase mais complexa da metodologia, treinamentos devem abordar suas atividades internas com mais detalhes e exemplos, ajudando assim, desenvolvedores com pouca experiência em SOA, que foi o caso dos participantes da segunda fase.

\subsection{Resultados quantitativos}

Embora este estudo exploratório seja principalmente qualitativo, algumas variáveis quantitativas foram coletadas e analisadas. Em cada fase do estudo, coletou-se o tempo levado por cada dupla para completar todas as tarefas de desenvolvimento. Então, estudou-se a correlação linear entre as variáveis: tempo levado para completar as tarefas $(v 2)$ e a experiência em desenvolvimento de software tradicional $(v 1)$ de cada dupla. O objetivo dessa análise não paramétrica [Sie75] é avaliar a influência da experiência em desenvolvimento de software tradicional (não relacionado a composição de serviços), no desenvolvimento de uma composição usando a Rehearsal e a proposta de metodologia TDD. Para isso, selecionaram-se aquelas duplas nas quais os desenvolvedores tinham a mesma experiência, conforme ilustrado na Tabela 7.11.

\begin{tabular}{|c|c|c|c|}
\hline Dupla & Experiência (anos) & Classe & Tempo (minutos) \\
\hline \hline \multicolumn{4}{|c|}{ Fase 1 } \\
\hline time 1 & mais de 5 & 3 & 140 \\
\hline time 2 & mais de 5 & 3 & 155 \\
\hline \multicolumn{3}{|c|}{ Fase 2 } \\
\hline time 2 & $3-5$ & 2 & 221 \\
\hline time 3 & $1-3$ & 1 & 274 \\
\hline time 4 & $1-3$ & 1 & 275 \\
\hline time 5 & $1-3$ & 1 & 334 \\
\hline
\end{tabular}

Tabela 7.11: Experiência e Tempo gasto com o desenvolvimento

Devido ao número baixo de amostras, optou-se por um teste não-paramétrico, que é o recomendado nesses casos. Um teste é não-paramétrico quando não há suposições formuladas sobre a natureza ou a forma das distribuições populacionais [Lir04]. Para a aplicação da correlação linear, mapeamos os intervalos de experiência para valores numéricos (classes). Assim, o intervalo "1-3" passou a ter valor 1 , o intervalo " $3-5$ ", valor 2 , e o intervalo "mais de 5 ", valor 3 . Com esse mapeamento, aplicou-se uma função de correlação linear com o método de Kendall para os vetores: $x=c(3,3,2,1,1,1)$ e $y=c(140,155,221,274,275,334)$, obtendo-se coeficiente $\mathbf{- 0 , 7 0 0 6 4 9}$, com pvalor 0,10. O método de Kendall é utilizado quando as variáveis analisadas são medidas em nível ordinal [Lir04]. Como pode ser observado na Tabela 7.11, os dados são expressos ordinalmente, as classes de experiência variam de 1 a 3 , ou seja, quanto maior a classe, maior a experiência da dupla.

$\mathrm{Na}$ análise de correlação linear [Lir04], o coeficiente obtido encontra-se sempre no intervalo entre -1 e 1. Quanto maior for o valor absoluto do coeficiente linear obtido, maior o relacionamento linear das variáveis analisadas. Caso o coeficiente seja positivo, a relação entre as variáveis é diretamente proporcional. Caso o coeficiente seja negativo, a relação entre as variáveis é inversamente proporcional. Além disso, caso o coeficiente seja igual a 1 ou a -1, a relação linear é dita perfeita. Se o coeficiente for 0 , as variáveis não possuem relacionamento linear.

$\mathrm{Na}$ análise realizada, o coeficiente foi -0,700649. Nesse caso, há forte relacionamento linear entre as variáveis estudadas. A relação existente entre a variáveis $v 1$ e $v 2$ é inversamente proporcional. Quanto maior $v 1$ (experiência em desenvolvimento de software), menor $v 2$ (tempo gasto para completar as tarefas do estudo). Como dito anteriormente, esse estudo foi essencialmente qualitativo, 
porém, essa correlação linear introduz indícios de que o não conhecimento prévio de composição de serviços pode não ser o fator determinante para o bom desempenho com a Rehearsal. Na segunda fase, na qual todos os participantes não tinham tal experiência, a dupla com maior $v 1$, atingiu menor tempo de desenvolvimento. Esta análise não é completa e apenas complementa os resultados qualitativos apresentados anteriormente. Uma análise mais completa das relações entre as variáveis mencionadas poderá ser conduzida em trabalhos futuros.

\subsection{Análise do código gerado}

O código fonte gerado pelos participantes em ambas as fases está disponível no pacote do estudo exploratório ${ }^{2}$. Em ambas as fases, todos os participantes completaram as 4 tarefas de desenvolvimento do estudo.

Na primeira fase, todos as duplas desenvolveram o código funcional corretamente. Em relação aos testes, foram identificados alguns erros na implementação do teste "shouldSendThe CorrectMessage To The CarParkingService()". Das quatro duplas, duas duplas não o implementaram. Uma dupla implementou-o corretamente, e a outra dupla implementou-o incorretamente. Neste caso, foi interceptado o serviço errado ("carParkingService"). Como este serviço já havia sido desenvolvido, os testes passaram. Provavelmente, as duplas não executaram o teste antes de implementar o código funcional, passo fundamental do TDD (vide Seção 2.5). Se o tivessem feito, notariam que o teste já estava passando antes da implementação e portanto, não estava testando a funcionalidade correta. Durante o desenvolvimento do protocolo da segunda fase do estudo, concluiu-se que a descrição do que deveria ser implementado nesse caso de teste não estava clara. Assim, redefiniu-se essa descrição para a segunda fase do estudo.

Em relação à segunda fase do estudo, todos as duplas também desenvolveram o código funcional corretamente. No entanto, alguns testes foram implementados incorretamente. Todos os erros foram cometidos nos testes pertecentes à tarefa 2 do estudo. Das 5 duplas, uma das duplas implementou incorretamente o caso de teste "shouldSendTheCorrectMessageToTheCarParkingService()". Esta dupla invocou o serviço "carParkingWS" ao invés de invocar o orquestrador "CarParkService".

Duas duplas implementaram incorretamente o caso de teste "shouldSendTheCorrectMessageToThe WebTripMock()". Nos testes implementados por essas duplas, o mock do serviço "WebTrip" foi invocado ao invés do orquestrador "FlightFinder". Em todos os casos de erro, os testes passaram pois as mensagens interceptadas foram as mensagens invocadas pelos testes, e não as mensagens trocadas na coreografia. Provavelmente, as duplas também não executaram o teste antes de implementar o código funcional. Mesmo com esses erros nos testes, todas as duplas implementaram corretamente a coreografia.

De modo geral, pode-se concluir que foram cometidos poucos erros durante o estudo. Na primeira fase, dos 11 testes que cada dupla devia realizar, apenas um deles foi implementado incorretamente. Em relação à segunda fase, foram apenas 2 testes implementados incorretamente. Para as tarefas que tinham que ser desenvolvidas no estudo, esses erros não atrapalharam a qualidade do código desenvolvido.

\subsection{Considerações finais desse capítulo}

Este capítulo apresentou as duas fases do estudo exploratório conduzido para avaliar o arcabouço Rehearsal e a proposta de metodologia TDD para coreografias. O protocolo completo que descreve a primeira fase do estudo é apresentado no Apêndice B. Dado que muitos elementos da primeira fase do estudo são semelhantes, tais como a coreografia utilizada, as tarefas de desenvolvimento e o tratamento do dados, são os mesmos para ambas as fases, o protocolo referente à segunda fase não é apresentado neste documento, mas encontra-se disponível no pacote do estudo exploratório.

\footnotetext{
${ }^{2}$ Pacote do estudo exploratório: http://ccsl.ime.usp.br/baile/VandV\#rehearsal-study
} 
Como pode ser observado, os resultados obtidos em ambas as fases do estudo foram positivos. Ao término da primeira fase, identificamos alguns problemas que dificultaram a utilização da Rehearsal. Esses problemas foram tratados para a segunda fase. Nela, mesmo não possuindo experiência prévia no desenvolvimento de composição de serviços, os participantes completaram as tarefas de desenvolvimento corretamente.

No próximo capítulo serão apresentadas as conclusões deste projeto de mestrado, suas principais contribuições e as possíveis continuações em trabalhos futuros. 


\section{Capítulo 8}

\section{Conclusão}

Neste capítulo final da dissertação, são apresentadas as principais contribuições do trabalho, considerações finais e sugestões para trabalhos de pesquisa futuros.

\subsection{Considerações finais}

Apesar das vantagens e benefícios decorrentes da aplicação de coreografias de serviços web, sua utilização ainda não é consolidada. Consequentemente, a existência de exemplos de coreografias em funcionamento é escassa. Para superar esse problema, implementações de especificações (modelos) de coreografias existentes e criação de novas coreografias foram geradas no decorrer do trabalho. Além disso, essa escassez foi uma das maiores motivações que tivemos: prover um arcabouço de testes automatizados para prática de Test-Driven Development (TDD) de coreografias, facilitando sua adoção.

Ao todo, foram utilizados quatro exemplos de coreografia de serviços web, que serviram de base para a criação e o refinamento do Rehearsal e da proposta de metodologia TDD desenvolvida. Inicialmente, uma coregrafia de serviços web para o planejamento de viagens (Seção 5.1), desenvolvida com a ferramenta OpenKnowledge, serviu como base para a criação do protótipo inicial. Em seguida, após o desenvolvimento do WSClient, com a implementação em BPEL da coreografia FutureMarket (Seção 3.4.1), levantamos os requisitos principais das demais funcionalidades do Rehearsal.

Com o Rehearsal completo, a coreografia, desenvolvida em SCA e utilizada no estudo exploratório (Seção B.3.4), foi utilizada para avaliar todas as funcionalidades da Rehearsal. Por fim, utilizou-se a Rehearsal para o teste offline de uma coreografia ${ }^{1}$ desenvolvida puramente em Java no projeto CHOReOS. É importante ressaltar que o arcabouço Rehearsal foi utilizado com sucesso no teste offline das quatro coreografias mencionadas. O fato das coreografias serem desenvolvidas em diferentes tecnologias não impediu a utilização do arcabouço.

O Rehearsal não é acoplado a uma tecnologia ou ambiente de execução de coreografias específico. Todos os tipos de teste aos quais o Rehearsal oferece apoio (unidade, integração, conformidade e aceitação), têm como "pré-requisito" a utilização de serviços web do tipo Soap/WSDL. Assim, contanto que esse tipo de serviço seja utilizado, os serviços participantes podem ser simulados e as mensagens e papéis podem ser validados, independente das tecnologias utilizadas para criação e execução da coreografia.

Com base nos resultados do estudo exploratório realizado, há bons indícios de que o Rehearsal é eficaz no suporte a TDD de coreografias e é de fácil utilização. Conforme apresentado, dos 21 participantes do estudo, oito possuíam experiência no desenvolvimento de coreografias. De acordo com eles, a ferramenta e a proposta de metodologia é adequada para o desenvolvimento de coreografias de serviços. Em relação aos demais participantes, todos eles foram capazes de aprender o Rehearsal e a metodologia e executaram corretamente as tarefas de desenvolvimento do estudo com apenas algumas poucas horas de estudo e prática.

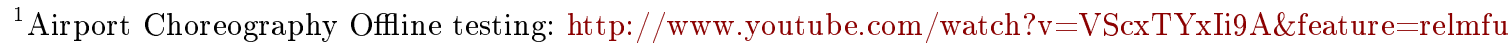


Desse modo, pode-se concluir que todos os objetivos propostos (Seção 1.2) foram alcançados. Para coreografias serem mais adotadas, o teste em tempo de desenvolvimento (offline) faz-se necessário para a criação de coreografias e serviços web que atendam de maneira sólida aos seus requisitos. Nesse contexto, com base nos resultados obtidos no estudo, considera-se que o arcabouço Rehearsal, juntamente com a metodologia TDD proposta, fornece as funcionalidades adequadas para o teste offline de coreografias de serviços web.

\subsection{Contribuições}

A principal contribuição deste trabalho é o arcabouço Rehearsal que está disponível publicamente sob a licença LGPL. A proposta de metodologia TDD para coreografias também é outra de nossas principais contribuições. Além desses dois artefatos, a coreografias e todos os serviços web gerados durante o projeto podem ser importantes para trabalhos de pesquisa relacionados. Em relação ao estudo exploratório, um pacote contendo todos os elementos do estudo está disponível publicamente ${ }^{2}$. No pacote podem ser encontrados slides de um minicurso sobre serviços web, orquestrações, coreografias e TDD, apresentado na segunda fase do estudo exploratório.

Em relação às publicações, foram produzidos, até o momento, os seguintes artigos:

- Felipe M. Besson, Pedro M.B. Leal, Fabio Kon, Alfredo Goldman e Dejan Milojicic. Towards automated testing of web service choreographies. In Proceeding of the 6th International Workshop on Automation of Software Test, AST '11, páginas 109-110, Waikiki, Honolulu, HI, USA, 2011. ACM

- Felipe M. Besson, Pedro M.B. Leal, Fabio Kon, Alfredo Goldman e Dejan Milojicic. Supporting Test-Driven Development of Web Service Choreographies. In the 5th International Open Cirrus Summit, Moscow, Russia, 2011. 30, 36

- Felipe M. Besson, Paulo Moura, Fabio Kon, Dejan Milojicic. Rehearsal: a framework for automated testing of web service choreographies. No III Congresso Brasileiro de Software, Teoria e Prática, Sessão de Ferramentas, Natal, Brasil, 2012.

Além das publicações, foram gerados relatórios técnicos para os projetos Baile e CHOReOS. Também foram apresentadas palestras sobre o Rehearsal e sobre orquestrações de serviços web no $11^{\circ}$ Fórum International do Software Livre (FISL 11). Todos esses documentos estão disponíveis na página do projeto Baile ${ }^{3}$.

\subsection{Sugestões para trabalhos futuros}

Em relação ao Rehearsal, todas as funcionalidades previstas foram implementadas, no entanto, elas ainda podem ser melhoradas.Além disso, acreditamos que tanto a metodologia TDD proposta, quanto o estudo explorátorio podem estendidos futuramente. A seguir apresentamos pontos de extensão futura para cada um desses artefatos.

\subsubsection{Rehearsal}

Como dito anteriormente, Rehearsal é parte integrante do projeto CHOReOS que contém linhas de pesquisa em andamento sobre adaptação dinâmica de coreografias. Rehearsal poderá ser integrado às ferramentas de adaptação dinâmica, facilitando, assim, a utilização das funcionalidades WSMock e interceptador de mensagens. Com essa integração, os objetos mocks e os proxies poderão ser introduzidos automaticamente de maneira transparente ao desenvolvedor.

\footnotetext{
${ }^{2}$ Estudo exploratório: http://ccsl.ime.usp.br/baile/VandV\#rehearsal-study

${ }^{3}$ Projeto Baile: http://ccsl.ime.usp.br/baile/publications
} 
Ainda em relação ao CHOReOS, um de seus subsistemas é o "Synthesis Processor". Por meio dele, código executável (e.g., Java) dos serviços e coordenadores da coreografia pode ser gerado automaticamente a partir de diagramas BPMN2 estendidos que descrevem uma coreografia. Rehearsal pode se integrado ao "Synthesis Processor", facilitando a utilização da funcionalidade de abstração de coreografia. Com essa integração, o arquivo descritor da coreografia (Apêndice A) poderá ser gerado automaticamente. Assim, o desenvolvedor não precisará definir os endpoints dos serviços participantes e dos papéis que descrevem a coreografia.

Para facilitar a escrita de testes de unidade para o Rehearsal, a ferramenta Item Explorer pode ser melhorada. Atualmente, o objetivo dessa ferramenta é gerar automaticamente os objetos Item a serem enviados na requisição das operações dos serviços e os objetos que são devolvidos por essas operações. Esses objetos são reaproveitados para a escrita de testes com o WSClient. A ferramenta pode ser melhorada para gerar automaticamente os testes com o WSClient e até mesmo permitir a execução dos testes na própria ferramenta. Com essa evolução, a ferramenta tornar-se-ia semelhante ao SoapUI, porém, os casos de testes seriam escritos em Java, ao invés de XML. Além dessas melhorias, a Item Explorer poderia ser integrada ao IDE (Integrated Development Environment) Eclipse, facilitando assim, o acesso a ferramenta por parte do desenvolvedor.

Em relação à arquitetura do arcabouço, esta pode ser melhorada para oferecer pontos de extensões das funcionalidades. Em particular, a implementação da WSClient pode ser redefinida para permitir a utilização de outras ferramentas, além do SoapUI, para a manipulação de envelopes Soap. O Message Interceptor pode ser estendido para suportar proxies definidos pelo desenvolvedor. Nesse caso, os proxies seguirão uma interface padrão, porém, poderão coletar métricas de interesse não disponíveis atualmente. Entre os exemplos de métricas possíveis, os proxies poderão coletar o tempo de resposta ou horário (timestamp) da interceptação, além de prover um log persistente das mensagens interceptadas.

\subsubsection{Metodologia TDD}

Este trabalho teve como objetivo o desenvolvimento do arcabouço Rehearsal. No entanto, para guiar o desenvolvedor na utilização esperada da ferramenta, uma metodologia para aplicação de TDD foi proposta. Em seguida, a proposta foi avaliada no estudo exploratório realizado.

Apesar dos bons resultados obtidos, vale ressaltar que a metodologia ainda precisa ser melhor embasada teoricamente para ser tornar mais abrangente. Esta dissertação apenas introduziu a metodologia, o aprimoramento desta metodologia é um trabalho futuro. Em particular, a metodologia não apresenta diretrizes para a integração dos modelos que descrevem a coreografia com as fases do desenvolvimento. Embora os modelos sejam específicos para as tecnologias utilizadas, uma fase adicional da metodologia que guiasse o desenvolvedor na utilização da funcionalidade de abstração da coreografia como diagramas BPMN2, por exemplo, poderia ser definida. Durante o desenvolvimento da proposta de metodologia, estudou-se a metodologia Savara (vide Seção 6.1). Para acrescentar mais fundamentação científica à proposta, estudos de casos práticos e reais, assim como novos trabalhos relacionados podem ser mais explorados.

\subsubsection{Avaliações do Rehearsal e metodologia}

O estudo exploratório qualitativo realizado foi satisfatório como ferramenta para avaliação do Rehearsal e da metodologia proposta. No entanto, experimentos em engenharia de software podem ser conduzidos para validar esses artefatos. Em particular, um experimento comparativo quantitativo pode ser conduzido. Neste futuro estudo, o tempo de desenvolvimento gasto por uma equipe utilizando o Rehearsal e a metodologia proposta poderá ser comparado ao tempo gasto por equipes utilizando outras ferramentas e processos de desenvolvimento. Entre as dificuldades deste experimento, destacam-se o tempo de aprendizado, a preparação do estudo e a seleção de ferramentas e processos de terceiros a serem utilizados. Em nosso estudo exploratório, a etapa de treinamento mostrou-se a mais extensa e a que demandou mais recursos. Como solução, esta proposta de experimento futuro poderia ser aplicada a profissionais com bastante experiência nos tópicos estudados. 
Além do experimento, o Rehearsal e a metodologia poderiam ser avaliados em um estudo de caso em um projeto industrial ou de software livre. Desse modo, pode-se estudar os benefícios e problemas encontrados no uso prolongado dessas técnicas e ferramentas em um ambiente real, contendo serviços, coreografias e problemas mais complexos.

Para o autor deste trabalho, no contexto de SOA, há a predominância de abordagens orientadas a contratos. Nesses casos, o contrato e a pré-implementação dos serviços são derivadas automaticamente da modelagem de requisitos de negócio. Como consequência, as fases de desenvolvimento de software tornam-se fortemente dependentes das fases de modelagem dos processos de negócio. Com isso, fatores como a adaptação rápida a mudanças, maior participação do desenvolvedores no refinamento dos requisitos e um processo iterativo de software, são comprometidos. Com base em tudo o que foi produzido neste projeto de mestrado, somando-se as projeções dos trabalhos futuros apresentados, o autor acredita no potencial do Rehearsal e da metodologia proposta como alternativas a este cenário exposto, agregando, assim, maior qualidade e importância às fases de desenvolvimento de uma coreografia. 


\section{Apêndice A}

\section{Exemplo de arquivo descritor para a coreografia FutureMarket}

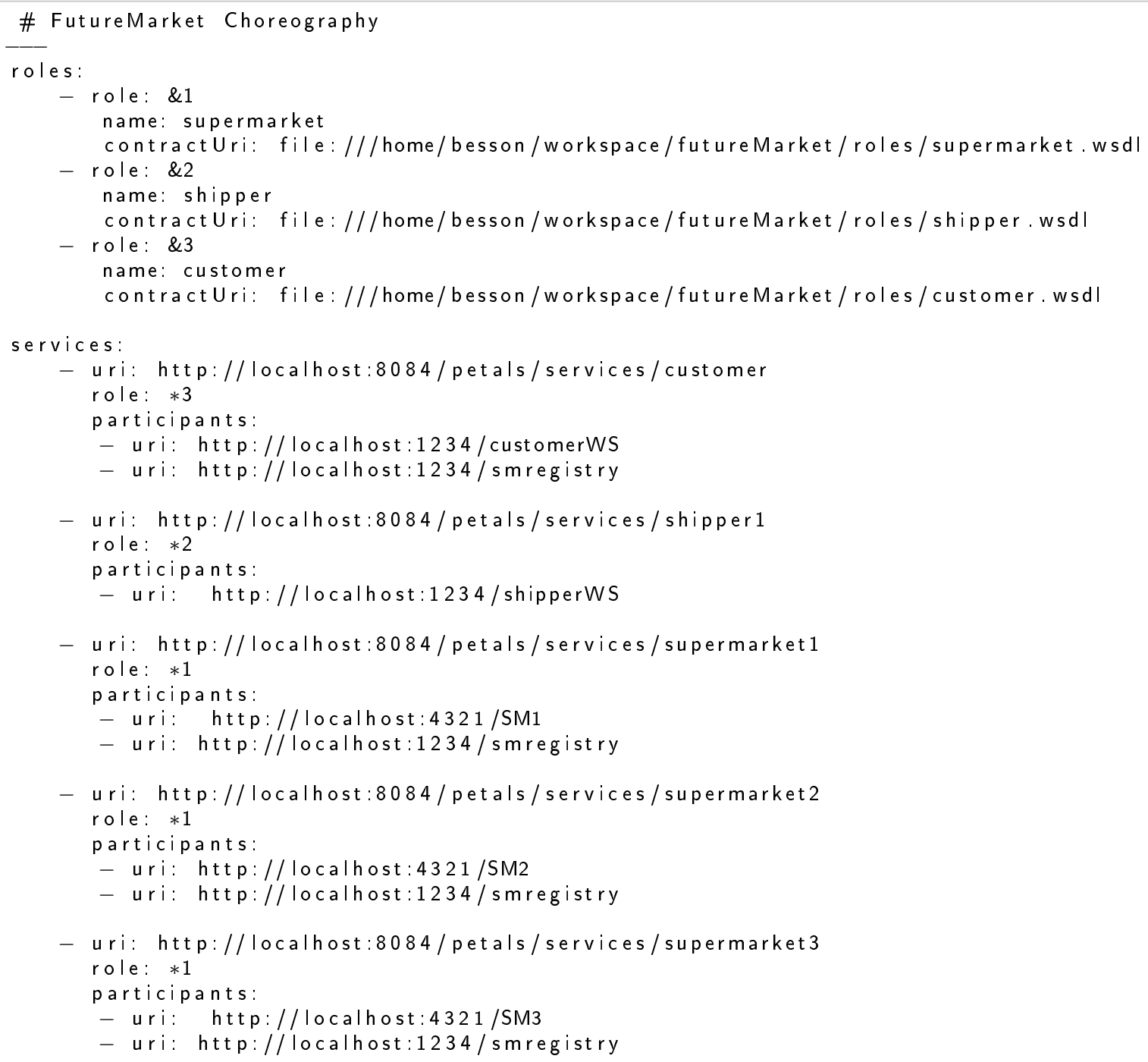

- uri: http://localhost:8084/petals/services/supermarket 2 role: $* 1$ participants:

- uri: http://localhost:8084/petals/services/supermarket 3 role: $* 1$ 
APÊNDICE A 


\section{Apêndice B}

\section{Assessment proposal for the Rehearsal framework and TDD methodology for choreographies - Phase 01}

\section{B.1 Change Record}

\begin{tabular}{|l|l|c|}
\hline Version & Description & Author \\
\hline \hline 0.1 & Initial version & Felipe Besson \\
\hline 0.2 & Claudia Melo review & Felipe Besson \\
\hline 0.3 & Fabio Kon review & Felipe Besson \\
\hline
\end{tabular}

\section{B.2 Introduction}

Rehearsal [BLK12] is a framework for the automated testing of web service choreographies. The goal of this tool is to support the Test-Driven Development (TDD) [Bec03, Ast03] of web service choreographies. To achieve this, the Rehearsal features have been developed to support automated unit, integration, and acceptance tests writing, and common TDD practices, such as double object usage [Mes07]. A framework is an incomplete system that must be extended or composed with other classes to create a concrete and executable application [JF88]. Thus, the use of Rehearsal alone does not imply the use of TDD for choreography development. For this reason, we prepared a methodology proposal [BLK11a] that guides the developer to apply TDD in choreographies using Rehearsal.

To assess the Rehearsal effectiveness when the proposed TDD methodology is applied for choreography development, we intend to conduct an exploratory study $\left[\mathrm{KPP}^{+} 02\right]$ consisting of two phases. Our methodology introduces novel concepts, such as the use of a test-driven instead of a contract-driven approach, to guide the choreography development. For this reason, in both phases of the study we aim at exploring the potential benefits and problems arising from the Rehearsal usage to support the TDD methodology.

The primary goal of this first phase is to investigate qualitatively the benefits and difficulties when Rehearsal is used to support TDD in choreographies. The secondary goal of this phase consists in refining and pre-validating the proposed TDD methodology. Since the methodology has been proposed by the Rehearsal authors, we intend to validate and incorporate feedback from the subjects to eliminate possible bias arising from the methodology conception. The subjects of this phase will be 6 experienced developers with previous knowledge of SOA concepts. To achieve these goals, we aim at exploring the following research questions: 


\section{RQ1: Does the Rehearsal features aid in the application of the proposed methodology steps? \\ RQ2: Does the proposed methodology provide adequate guidelines for developing a choreography?}

With the first research question (RQ1), we aim at studying how effective and easy to use the Rehearsal features are to cover the activities required by each methodology step. In the case of the second research question (RQ2), the goal is to study which steps of the proposed methodology assist or hamper the development of a choreography. Differently from traditional software development, web service development is exposed to different characteristics such as late binding, loose coupling between services, and third-party rules and constraints. The term "adequate guidelines" defined in the question refers to how the steps are compatible and useful to overcome characteristics such as the aforementioned.

After the first validation phase, Rehearsal and the TDD methodology will be refined based on the feedback received from experts and the results obtained. Then, in a second phase, a similar exploratory study will be conducted. In this second phase, the goal will be to assess the Rehearsal and the TDD methodology effectiveness when they are applied by non-specialists. To achieve this, the subjects of this study will be over 10 Computer Science students with basic or no knowledge of SOA.

This document consists on the first phase protocol of the exploratory study. In the sections below we described all the research elements and phases as well as a schedule for applying all of these phases.

\section{B.3 Exploratory study design}

The proposed exploratory study has been designed following the guidelines for this type of research method [Sea99, Kit96]. Even though we are proposing a qualitative study, the protocol definition was based on some procedures such as variables definition and data analysis presented in guidelines for Software Engineering experiments [WRH ${ }^{+} 00$, JM01]. Since the methodology, supported by Rehearsal, bring novel concepts in the development and composition of services, we aim at exploring possible and not predicted benefits arising from its adoption. For this reason, we opted for an exploratory study.

In addition, since we intend to analyze the benefits from the developer (human) point of view, qualitative data are adequate since we can have, as results, the perceptions (e.g., in words) of these developers. We intend to study Rehearsal and the methodology benefits when applied by developers with different levels of experience. To achieve that, this exploratory study wil be applied twice. In the first iteration, or phase, expert developers will be the subjects, and in the second, non-experts. After the two phases, the methodology will be improved with specialist and non-specialist perceptions. After this point, a controlled experiment can be conduct to compare the proposed methodology with ad-hoc or existing ones.

The first iteration (phase) of our exploratory study is composed of the research phases depicted in Figure B.1. Each phase is presented in detail in the next sections of this document.

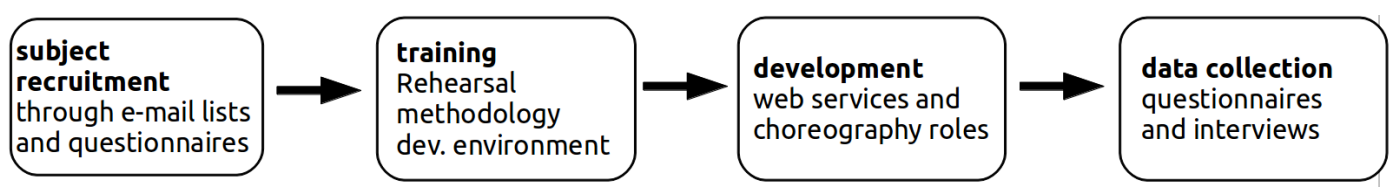

Figura B.1: Exploratory study phases. 


\section{B.3.1 Context description}

The following parameters belonging to the study subjects have been considered.

- Subject level of expertise: All selected subjects are experts in the problem domain. As described in detail in Section B.3.2, all subjects are members of research projects related to web service choreographies. Besides, the subjects answer a questionnaire during the recruitment.

- Familiarity of subjects with used IDEs, frameworks and programming languages: good familiarity (see Section B.3.2).

- Familiarity of subjects with the testing framework and process: All subjects will be equally trained in the Rehearsal and in the TDD methodology (see Section B.3.3).

We describe in details the unit of the study (choreography) in Section B.3.4). The following parameters belonging to the unit of study have been considered.

- Program size: The size of the choreography roles and services developed does not affect the study goals.

- Program Types: The subject will develop the same choreography roles (programs)

\section{B.3.2 Subject Recruitment}

The subjects of this study in phase 1 are 8 graduate students who are developers with experience in SOA and TDD. During the experiment, the subjects will work in pairs, which is a common practice in agile methods. Thus, we will have 4 groups of 2 developers each. The subjects will be recruited via an email list. An email describing the goals and the importance of the study may be sent to potential candidates. All recipients are Masters or PhD students of Computer Science in the Institute of Mathematics and Statistics (IME-USP) ${ }^{1}$ of the University of São Paulo. Besides, they are members of the research group conducting the CHOReOS ${ }^{2}$ and Baile ${ }^{3}$ projects. The goals of these projects are to study, to develop, and to use web service choreographies in large-scale environments, in particular, those related to Cloud Computing.

The experience of subjects will be identified by a questionnaire about TDD and web service choreography development. To assess the experience in TDD, the questionnaire contains questions related to software development, automated tests, and TDD. In the case of web service choreography development, the questionnaire contains questions related to tool, methods, and technologies that are normally used by the subjects. Besides, since Rehearsal is developed in Java, we added a question to assess the subject experience in this language. To have a more homogeneous sample of participants, the 8 candidates with the most similar and higher experience in questionnaire topics will be selected for the experiment. The entire questionnaire is presented in the Section B.8.

The study has been modeled following a within-subject [Mac12] design. In this case, each subject group may work under the same conditions.

\section{B.3.3 Subject Training}

Before the study execution, the students must be trained in the following skills:

- FraSCAti (30 min). We aim at providing a basic course of FraSCAti [Con12], an open source implementation of Service Component Architecture $(\mathrm{SCA})^{4}$, since our development environment will be based on this technology.

\footnotetext{
${ }^{1}$ IME-USP: http://www.ime.usp.br/

${ }^{2}$ CHOReOS project: http://www.choreos.eu

${ }^{3}$ Baile project: http://ccsl.ime.usp.br/baile

${ }^{4}$ SCA: http://www.oasis-opencsa.org/sca
} 
- Rehearsal features (60 $\mathbf{~ m i n ) . ~ T h e ~ s u b j e c t s ~ w i l l ~ b e ~ t r a i n e d ~ i n ~ t h e ~ m a i n ~ f e a t u r e s ~ o f ~ R e h e a r s a l : ~}$ dynamic generation of web service clients (WSClient), web service mocking (WSMock), message intercepting, and abstraction of choreography. This training will be a hands-on section.

- TDD methodology phases $(\mathbf{3 0}$ min). The subjects will be trained in the 4 methodology steps.

- Development environment and tasks that must be performed (30 min). A virtual machine with all the needed development environment will be provided. The subject will be instructed in how to use this virtual machine as well as in what must be developed. The development tasks are presented in Section B.3.4.

\section{B.3.4 Unit of analysis}

Our unit of analysis corresponds to a choreography based on the Passenger-friendly airport choreography [CLL11]. The goal of this choreography is to better serve the passengers by automating common activities involved in a trip such as the procedures of departure and arrival, airport shopping (e.g., duty-free), and redundancy plans arising from flight delays or cancellations. Many choreography scenarios are proposed to cover all these activities, for this study, we propose the development of the "Arrival at the airport" scenario. We based our scenario on the requirements described in the Section 5.1.3 of the choreography specification document [CLL11]. In the proposed scenario, the passenger, through a Mobile Internet Device (MID), retrieves the directions to his boarding terminal and where to park his car.

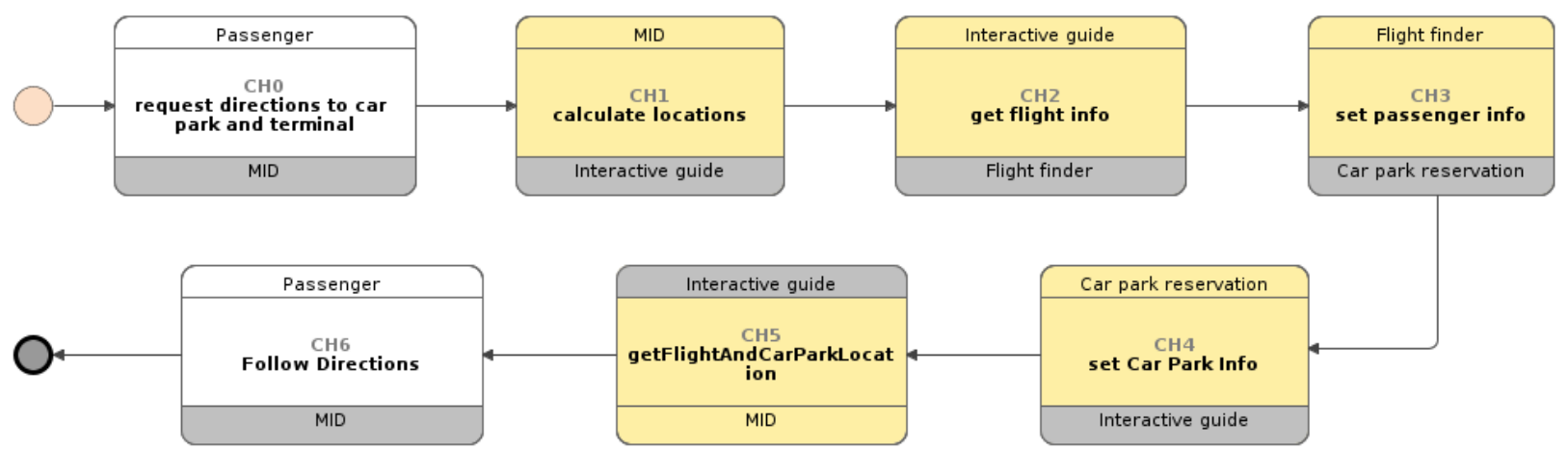

Figura B.2: Global view of the Arrival at the airport choreography.

As depicted in the BPMN2 diagram of Figure B.2, after receiving the request of directions, the Interactive guide partner interacts with the Flight Finder partner (CH2 message exchange) to retrieve the trip information. Then, in the CH3 message exchange, Flight Finder replies to the Interactive guide and forwards the flight information and the passenger ID to the Car park reservation partner. This latter service returns car park information to the Interactive guide partner that returns the final directions to the MID, closing the flow. In our scenario the passenger has performed the car park reservation before triggering this process. In the diagram, all messages exchanged are synchronous but the response were omitted to simplify the diagram.

The collaboration in the CH2 to CH5 message exchanges (in yellow) will be implemented in study and are detailed in Figure B.3. This Figure corresponds to a BPMN2 collaboration diagram where each horizontal lane describes a process that is executed by a partner during a specific collaboration point. Each process describes a role that must be played by a service or a group of services in the choreography. The behavior (process internal operation) of each role depicted in Figure B.3 is explained below:

- The Interactive Guide. Interacts with Flight Finder and Car park reservation to retrieve the flight information, which includes the boarding terminal and the location of where to 


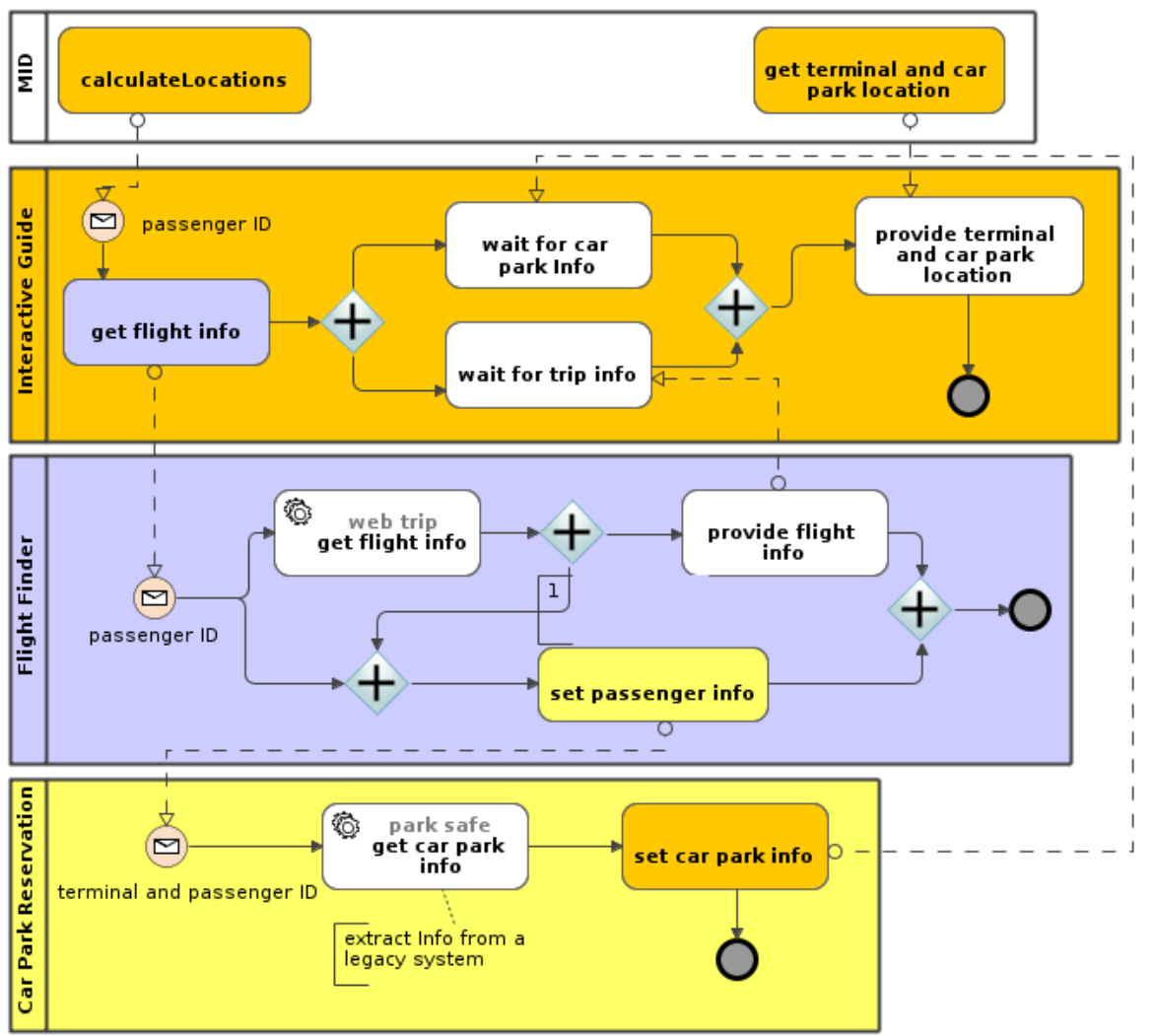

Figura B.3: Process view of the Arrival at the airport choreography.

park the car. Then, the directions from the central gate of the airport to these locations are calculated and returned. To simplify, these directions are return as text in our scenario.

- Flight Finder. When receiving the passenger ID, the web trip service is invoked and the trip information, which contains the flight number, boarding terminal, gate, and time, are retrieved and returned to the Interactive Guide partner. Besides, the boarding terminal number and passenger id are forwarded to the Car Park Reservation.

- Car Park Reservation. This partner aims at retrieving the closest vacancy to the passenger boarding terminal. To achieve this, the process interacts to web service that invokes a legacy system (park safe) to check the passenger reservation and retrieve the vacancy. After this point, the car park information is send to the Interactive Guide service.

After the training (see Section B.3.3), the subjects, using Rehearsal, must apply the proposed methodology to implement the Flight Finder and Car Park Reservation partners. The development scenario is composed by the following constraints:

- Interactive Guide: this partner is already developed and deployed in an offline environment which will be available to the developers during the study;

- Flight Finder: the WS1 service will be provided to the developers. However, this service is only available in a production environment which prevents its use in the tests. The contract (WSDL document) describing the interface of this role will also be provided;

- Car Park Reservation: the legacy system (a car reservation database system) will be provided. The web service WS2 must be developed and its interface can be defined by the developer. The contract (WSDL document) describing the interface of this role will also be provided. 


\section{B.3.5 Development Tasks}

Based on the diagrams above and under these constraints, the subjects must execute the development tasks below, which were elaborated based on the proposed TDD methodology phases [BLK11a]. Each task will be explained during the training stage (see Section B.3.3). In addition, during the development, each subject group will also receive a list with the following tasks. The list below gives an overwiew of each task, the detailed description of these tasks, that must be followed by the subjects, are available online ${ }^{5}$.

\section{Task 01 - Wrap the legacy system into a web service}

In this task, a new web service encapsulating the car reservation database system must be developed by using TDD. Thus, the following steps must be performed:

1. Writing test cases for the web service operations to be developed

2. Coding the new web service

\section{Task 02 - Create the processes to provide the roles}

This task contains the more complex development steps. To implement the roles following the provided contracts, the services must be integrated into a business process. To provide the Car Reservation role, the following steps must be performed for composing the business process:

1. Create a mock to simulate the Interactive Guide service

2. Writing test cases to validate the message exchange within the business process, i.e., messages received by the web service created in the step 01

3. Implement the business process

To provide the Flight Finder role, the following steps must be performed for composing the business process:

1. Create a mock to simulate the Flight Finder service. This mock must be dynamic.

2. Writing test cases to validate the message exchange within the business process, i.e., messages received by the Flight Finder mock

3. Implement the business process

Task 03 - Integrate the developed roles into the choreography

In this task, the developed processes must be deployed and integrated into the Interactive Guide service. To validate the integration with the Car Reservation, the following steps must be performed:

1. Create a message interceptor to get the messages sent to the Interactive Guide process

2. Writing test cases to validate the messages exchanged between Car Reservation and Interactive Guide

3. Deploying and integrating the Car Reservation process

4. Invoking the choreography running in an offline environment

To validate the integration with the Flight Finder, the following steps must be performed:

1. Writing test cases to validate the messages received by Flight Finder and Interactive Guide service;

\footnotetext{
${ }^{5}$ Development guide: http://www.ime.usp.br/ besson/rehearsal-study/instructions
} 
2. Deploying and integrate the Flight Finder service

3. Invoking the choreography which is running on an offline environments

\section{Task 04 - Apply acceptance tests}

In this task, the subjects must apply acceptance tests using predefined input and output parameters to validate the correct choreography functional behavior. We will provide the expected input an output parameters. The developers will only have to adjust a few parameters such as the service URIs.

\section{B.4 Data Preparation and Collection}

To achieve our study goals (see Section B.2), we aim at collecting data from questionnaires and interviews.

\section{B.4.1 Questionnaire}

At the end of the development phase, the developers will be invited to answer the questionnaire with answers for the questions provided in an ordinal scales. The first part of the questionnaire contains questions related to the research question RQ1 ("Do the Rehearsal features aid in the application of the proposed methodology steps?"). The questions below aim at investigating Rehearsal in isolation by studying how easy was to use each Rehearsal feature. To achieve our goals, the questions of Table B.1 are proposed.

\begin{tabular}{|l|l|}
\hline ID & Question \\
\hline \hline QR1 & It was easy to learn how to use the WSClient feature. $(1-5)$ \\
\hline QR2 & It was easy to learn how to use the WSMock feature. $(1-5)$ \\
\hline QR3 & It was easy to learn how to use the Message Interceptor feature. $(1-5)$ \\
\hline QR4 & It was easy to learn how to use the Abstraction Choreography feature. $(1-5)$ \\
\hline QR5 & The Abstraction Choreography feature helped me to use other Rehearsal features. $(1-5)$ \\
\hline QR6 & The Abstraction Choreography feature helped me to write the test cases. $(1-5)$ \\
\hline QR7 & The researcher provided adequate training in Rehearsal before the development. $(1-5)$ \\
\hline \hline & $1=$ strongly disagree, $2=$ partially disagree, $3=$ indifferent, $4=$ partially agree, $5=$ strongly agree \\
\hline
\end{tabular}

Tabela B.1: Questions to study $R Q 1$

In the case of the TDD methodology, we want to explore the RQ2 ("Does the proposed methodology provide adequate guidelines for developing a choreography?") by studying issues related to its suitability and acceptance of the methodology steps in the development of the choreography. Then, for each development task we aim at studying how ease and appropriate that task is in the choreography development. During the development phase, all Rehearsal features are used in different steps of the proposed methodology. Thus, we also aim at studying how easy and effective was to use each Rehearsal feature to execute the development tasks (see Section B.3.4). To achieve our goals, the questions of Table B.2 are proposed.

The complete questionnaire that will be filled up by the subjects in the study is presented in Section B.9.

\section{B.4.2 Interview}

The primary goal of the interviews is to complement the questionnaire questions. With the questionnaire we can discover if the Rehearsal features and the methodology steps are or are not easy to and useful for choreography development. With the interviews, we expect to collect subject criticisms, suggestions, and insights that can help to identify evidences of why specific features or methodology steps are or are not appropriate or useful for choreography development. To analyze 


\begin{tabular}{|c|c|}
\hline ID & Question \\
\hline QM1 & It was easy to follow the steps from Task 01. (1-5) \\
\hline QM2 & The steps of Task 01 are apropriate for the development of a choreography. (1-5) \\
\hline QM3 & The use of the WSClient feature is useful in Task 01. (1-5) \\
\hline$\overline{\mathrm{QM} 4}$ & 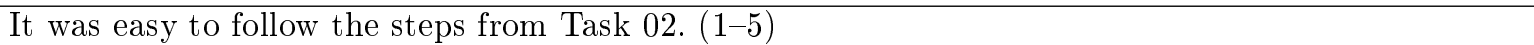 \\
\hline QM5 & The steps of Task 02 are apropriate for the development of a choreography. (1-5) \\
\hline QM6 & The use of the WSMock feature is useful in Task 02. (1-5) \\
\hline QM7 & The use of the Message Interceptor feature is useful in Task 02. (1-5) \\
\hline QM8 & It was easy to follow the steps from Task $03 .(1-5)$ \\
\hline QM9 & The steps of Task 03 are apropriate for the development of a choreography. (1-5) \\
\hline QM10 & The use of the Message Interceptor feature is useful in Task 03. (1-5) \\
\hline QM11 & It was easy to follow the steps from Task $04 .(1-5)$ \\
\hline QM12 & The steps of Task 04 are apropriate for the development of a choreography. (1-5) \\
\hline QM13 & The use of the WSClient feature is useful in Task 04. (1-5) \\
\hline QM14 & The use of the methodology and Rehearsal would be useful for projects I have participated. (1-5) \\
\hline QM15 & I would use the methodology and Rehearsal in future projects I may participate. (1-5) \\
\hline QM16 & The researcher provided adequate training in the methodology before the development. (1-5) \\
\hline & $1=$ strongly disagree, $2=$ partially disagree, $3=$ indifferent, $4=$ partially agree, $5=$ strongly agree \\
\hline
\end{tabular}

Tabela B.2: Questions to study RQ2

the subject answers deeply, the audio of the interview will be recorded, if authorized by the subjects. We propose the questions below for the interview. For some questions, such as QI3, if the answer is affirmative, questions such as "Which one" and "Why" can also be applied.

\begin{tabular}{|l|l|}
\hline ID & Question \\
\hline \hline QI1 & What are your overall perceptions about Rehearsal? \\
\hline QI2 & What are your overall perceptions about the proposed methodology? \\
\hline QI3 & Do you think the Rehearsal features are adequate for applying the methodology steps? \\
\hline QI4 & Would you change any Rehearsal feature? \\
\hline QI5 & Would you change any step in the proposed methodology? \\
\hline QI6 & In our opinion, what are the advantages and disadvantages in applying TDD in choreographies? \\
\hline QI7 & Is there any comment you would like to add? \\
\hline
\end{tabular}

The interview questions QI1, QI3, IQ4, and QI7 aim at extending the questionnaire about Rehearsal by identifying perceptions that cannot be covered in the questionnaire. In the case of the questionnaire about the methodology, the questions QI2, QI3, QI5, QI5, QI6 and QI7 complement it.

\section{B.5 Data Analysis}

As described previously (see Section B.4.1), the questionnaire answers are specified following a Likert scale [Har88] ( $1=$ strongly disagree, $2=$ partially disagree, $3=$ indifferent, $4=$ partially agree, $5=$ strongly agree). The data collected may be treated as ordinal. We can observe that option 3 is a central and neutral opinion. Besides, the distance between the options are symmetrical (e.g., the distance between partially and strongly disagree is the same as the one between partially and strongly agree). Given these characteristics, the collected data can be presented by using the following descriptive techniques [Har88]:

- Summarizing: use of median or mode instead of mean;

- Variability: in terms of the range or inter-quartile range instead of the standard deviation;

- Distribution display: use of a dot plot or bar chart. Histograms cannot be used since the data are not continuous. 
Following the constraints above, we aim at calculating the median, range and inter-quartile range of each questionnarie question. Then, we aim at presenting these metrics in a box plot chart since this type of chart is commonly used in exploratory data analysis [Eas97]. However, the questions presented in the Tables B.1 and B.2 will be presented and analyzed by groups of similarity. For each group, a box plot with its respective interpretation will be plotted.

\section{B.5.1 RQ1: Do the Rehearsal features aid in the application of the proposed methodology steps?}

To analyze the collected data related to this research question, we proposed a group for each Rehearsal feature as follows.

Dynamic generation of web service clients. Our first goal ist to study how easy was to learn this feature. Then, we aim at analyzing how useful the use of this feature was to write unit and acceptance testing in the steps 01 and 04 of our methodology, respectively. Thus, the questions presented in the Table B. 3 will be analyzed together.

\begin{tabular}{|l|l|}
\hline ID & Question \\
\hline \hline QR1 & It was easy to learn how to use the WSClient feature. \\
\hline QM3 & The use of the WSClient feature is useful in Task 01. \\
\hline QM13 & The use of the WSClient feature is useful in Task 04. \\
\hline
\end{tabular}

Tabela B.3: Questions to study the dynamic generation of web service client feature

Web service mocking. First, we aim at analyzing how easy was to learn this feature. In addition, we want to study how useful this feature was to mock web services is in the step 02 of our methodology. Thus, we will analyze the questions presented in the Table B.4.

\begin{tabular}{|l|l|}
\hline ID & Question \\
\hline \hline QR2 & It was easy to learn how to use the WSMock feature. \\
\hline QM6 & The use of the WSMock feature is useful in Task 02. \\
\hline
\end{tabular}

Tabela B.4: Questions to study the web service mocking feature

Message Interceptor. Message Interceptor is used in the steps 02 and 03 . First, we want to study how easy was to learn to use this feature. Then, how useful was the use of this feature to intercept messages in the integration tests applied in those methodology steps. To achieve this, the questions presented in the Table B.5 will be analyzed together.

\begin{tabular}{|l|l|}
\hline ID & Question \\
\hline \hline QR3 & It was easy to learn how to use the Message Interceptor feature. \\
\hline QM7 & The use of the Message Interceptor feature is useful in Task 02. \\
\hline QM10 & The use of the Message Interceptor feature is useful in Task 03. \\
\hline
\end{tabular}

Tabela B.5: Questions to study the message interceptor feature

Abstraction of choreography. First, we aim at investigating the difficulty in learning this feature. Then, we aim at analyzing how helpful this feature was to use the other Rehearsal feature and to write clearer test cases. Thus, the questions presented in the Table B.6 will be analyzed together.

\begin{tabular}{|l|l|}
\hline ID & Question \\
\hline \hline QR4 & It was easy to learn how to use the Abstraction Choreography feature. \\
\hline QR5 & The Abstraction Choreography feature helped me to use other Rehearsal features. \\
\hline QR6 & The Abstraction Choreography feature helped me to write the test cases. \\
\hline
\end{tabular}

Tabela B.6: Questions to study the abstraction of choreography feature 
Since one of our goals is to refine the Rehearsal framework, the answers of the interview questions QI1, QI3, QI4, and QI7 will be used to complement the analyzes performed above.

\section{B.5.2 RQ2: Does the proposed methodology provide adequate guidelines for developing a choreography?}

To analyze the collected data related to this research question, we proposed a group for each methodology step and a group representing all steps, or in other words, the methodology in general. Then, each table below represents a group of questions:

\begin{tabular}{|l|l|}
\hline ID & Question \\
\hline \hline QM1 & It was easy to follow the steps from Task 01. \\
\hline QM2 & The steps of Task 01 are apropriate for the development of a choreography. \\
\hline
\end{tabular}

Tabela B.7: Questions to study the step 01 of the proposed methodology

\begin{tabular}{|l|l|}
\hline ID & Question \\
\hline \hline QM4 & It was easy to follow the steps from Task 02. \\
\hline QM5 & The steps of Task 02 are apropriate for the development of a choreography. \\
\hline
\end{tabular}

Tabela B.8: Questions to study the step 02 of the proposed methodology

\begin{tabular}{|l|l|}
\hline ID & Question \\
\hline \hline QM8 & It was easy to follow the steps from Task 03. \\
\hline QM9 & The steps of Task 03 are apropriate for the development of a choreography. \\
\hline
\end{tabular}

Tabela B.9: Questions to study the step 03 of the proposed methodology

\begin{tabular}{|l|l|}
\hline ID & Question \\
\hline \hline QM11 & It was easy to follow the steps from Task 04. \\
\hline QM12 & The steps of Task 04 are apropriate for the development of a choreography. \\
\hline
\end{tabular}

Tabela B.10: Questions to study the step 04 of the proposed methodology

\begin{tabular}{|l|l|}
\hline ID & Question \\
\hline \hline QM14 & I think the use of the methodology and Rehearsal would be useful for projects I have participated. \\
\hline QM15 & I would use the methodology and Rehearsal in future projects I may participate. \\
\hline
\end{tabular}

Tabela B.11: Questions to study the acceptance of the proposed methodology

Since one of our goals is to refine the methodology proposal, the answers of the interview questions QI2, QI3, QI5, QI6, and QI7 will be used to complement the analyzes performed above.

\section{B.6 Study Limitations}

The proposed study may have limitations in its sample since the subjects of this study are Masters or PhD students in Computer Science with little experience in the industry. However, these students currently work with the development of web service choreographies and have experience contributing to open source projects. Moreover, almost all of them have attended the "eXtreme Programming (XP) Laboratory" course. In this one-semester course, the students have the opportunity to try the concepts of eXtreme Programming (XP) such as pair programming, TDD and automated testing in a real software project. Our study sample consists only of six subjects which 
may be insufficient to assess Rehearsal and the methodology properly. However, since our goal is to conduct only a exploratory study and to refine the tool and the methodology, the results obtained with this sample size may will be enough.

\section{B.7 Schedule}

The follow schedule is planned for applying the first phase of the proposed study:

\begin{tabular}{l|l|l|l|l||l|l|l|l}
\hline Activities & \multicolumn{3}{|c}{ March } & \multicolumn{5}{c}{ April } \\
\hline \hline Subject Recruitment & & & $\bullet$ & $\bullet$ & & & & \\
\hline Unit of Analysis Preparation & & & & $\bullet$ & $\bullet$ & & & \\
\hline Exploratory Study Execution & & & & & & $\bullet$ & & \\
\hline Results Analysis and Presentation & & & & & & & $\bullet$ & $\bullet$ \\
\hline
\end{tabular}

Tabela B.12: Schedule

The activity "Exploratory Study Execution" will be carried out in the two days:

- Day \#1: Training ( 3 hours) and beginning of development ( 1 hour) (4 hours)

- Day \#2: Development ( 3 hours) and completion of questionnaires ( 1 hour) (4 hours)

- Day \#3 and \#4: Interview with each subject ( 10 minutes) 


\section{B.8 Recruitment Questionnaire}

\section{Experience in Java, web services and TDD}

This questionnaire is part of a master thesis research at University of São Paulo.

Your name, e-mail and all other confidential data will not be revealed.

Anyway, thank you for filling it all out =]

* Required

\section{About you}

Your name: *

Your e-mail: *

Your age: *

Please provide your current student level: *

- Undergraduated student

- Masters student

○ PhD student

o Post-doctoral student

\section{About your technical experience}

How long have you been working with software development? (in years) *
o $1-3$
० $3-5$
o more than 5 
How long have you been practicing Test-Driven Development (TDD) ? (in years) *

० $0-2$

० $2-3$

o more than 3

\section{Where do you practice TDD?}

Please avoid this question if you have no experience in TDD.

$\circ$ University

- Industry

○ Open Source project

What is your experience in Java? (in years) *
o $1-3$
० $3-5$
o more than 5

Have you used any Java testing framework such as JUnit, TestNG, etc.. ? *

o yes

$\circ$ no

Which Java testing framework you know and what is your experience in each one? Please avoid this question if you answer "no" in the previous question.

What is your experience in web service development? (in years) *

If you do not have experience, please answer 0
$\circ 0$
० $0-1$
० $1-2$
- more than 2 
What technologies/tools/methods you know for web service development?

What is your experience in web service composition? (in years)

If you do not have experience, please answer 0

$\circ 0$

० $0-1$

○ $1-2$

o more than 2

What technologies/tools/methods you know for composing web services?

If you want to provide any additional information, please use the space below:

Submit

Powered by Google Docs

Report Abuse - Terms of Service - Additional Terms 
B.9 Study Questionnaire

\section{Exploratory Study to assess (1) Rehearsal and (2) a TDD methodolody proposal for web service choreographies}

This questionnaire is part of a Masters thesis research at University of São Paulo.

Your name will not be revealed.

The answers for questions must be provided following the scale:

1- strongly disagree

2- partially disagree

3- indifferent

4 - partially agree

5 - strongly agree

Thank you for your participation in this study and for filling it all out =]

* Required

\section{About you}

Your name *

\section{Rehearsal features}

The statements below are related to the Rehearsal features.

QR1. It was easy to learn how to use the WSClient feature.

$\begin{array}{lllll}1 & 2 & 3 & 4 & 5\end{array}$

strongly disagree $\odot \quad \circ \quad \circ \quad \circ \quad \circ$ strongly agree

QR2. It was easy to learn how to use the WSMock feature.

$\begin{array}{lllll}1 & 2 & 3 & 4 & 5\end{array}$ 
strongly disagree 0 o 0 o o strongly agree

QR3. It was easy to learn how to use the Message Interceptor feature.

$\begin{array}{lllll}1 & 2 & 3 & 4 & 5\end{array}$

strongly disagree $\bigcirc \circ \circ \bigcirc \quad 0$ strongly agree

QR4. It was easy to learn how to use the Abstraction Choreography feature.

$\begin{array}{lllll}1 & 2 & 3 & 4 & 5\end{array}$

strongly disagree $\bigcirc \circ \circ \bigcirc \circ$ strongly agree

QR5. The Abstraction Choreography feature helped me to use other Rehearsal features.

$\begin{array}{lllll}1 & 2 & 3 & 4 & 5\end{array}$

strongly disagree $\circ \circ \bigcirc \circ \circ$ strongly agree

QR6. The Abstraction Choreography feature helped me to write the test cases.

$\begin{array}{llllll}1 & 2 & 3 & 4 & 5\end{array}$

strongly disagree $\bigcirc \circ \circ \bigcirc \circ$ strongly agree

QR7. The researcher provided adequate training in Rehearsal before the development.

$\begin{array}{lllll}1 & 2 & 3 & 4 & 5\end{array}$

strongly disagree $\circ \circ \circ \circ$ strongly agree

\section{TDD methodology proposal}

The statements below are related to the TDD methodology proposal.

QM1. It was easy to follow the steps from Task 01.

$\begin{array}{lllll}1 & 2 & 3 & 4 & 5\end{array}$

strongly disagree $\bigcirc \circ \circ \circ \circ$ strongly agree 
QM2. The steps of Task 01 are apropriate for the development of a choreography.

$123 \quad 3 \quad 4 \quad 5$

strongly disagree $\circ \circ \circ \circ \circ$ strongly agree

QM3. The use of the WSClient feature is useful in Task 01.

$123 \quad 3 \quad 4 \quad 5$

strongly disagree $\bigcirc \circ \circ \quad \circ \quad \circ$ strongly agree

QM4. It was easy to follow the steps from Task 02.

$123 \quad 3 \quad 4 \quad 5$

strongly disagree $\odot \circ \circ \quad \circ \quad \circ$ strongly agree

QM5. The steps of Task 02 are apropriate for the development of a choreography.

$\begin{array}{lllll}1 & 2 & 3 & 4 & 5\end{array}$

strongly disagree $\circ \circ \circ \quad \circ \quad \circ$ strongly agree

QM6. The use of the WSMock feature is useful in Task 02.

$\begin{array}{lllll}1 & 2 & 3 & 4 & 5\end{array}$

strongly disagree $\circ \circ \circ \bigcirc \quad \circ$ strongly agree

QM7. The use of the Message Interceptor feature is useful in Task 02.

$\begin{array}{lllll}1 & 2 & 3 & 4 & 5\end{array}$

strongly disagree $\odot \circ \circ \circ \quad \circ$ strongly agree

QM8. It was easy to follow the steps from Task 03.

$\begin{array}{lllll}1 & 2 & 3 & 4 & 5\end{array}$

strongly disagree $\circ \circ \circ \quad \circ \quad \circ$ strongly agree

QM9. The steps of Task 03 are apropriate for the development of a choreography. 
$\begin{array}{lllll}1 & 2 & 3 & 4 & 5\end{array}$

strongly disagree

$\circ \circ \circ \circ$ strongly agree

QM10. The use of the Message Interceptor feature is useful in Task 03.

$\begin{array}{lllll}1 & 2 & 3 & 4 & 5\end{array}$

strongly disagree $\circ \circ \circ \circ \circ$ strongly agree

QM11. It was easy to follow the steps from Task 04.

$\begin{array}{lllll}1 & 2 & 3 & 4 & 5\end{array}$

strongly disagree $\circ \circ \odot \circ \circ$ strongly agree

QM12. The steps of Task 04 are apropriate for the development of a choreography.

$\begin{array}{lllll}1 & 2 & 3 & 4 & 5\end{array}$

strongly disagree $\odot \circ \circ \circ \circ$ strongly agree

QM13. The use of the WSClient feature is useful in Task 04.

$\begin{array}{lllll}1 & 2 & 3 & 4 & 5\end{array}$

strongly disagree $\bigcirc \circ \circ \circ \quad \circ$ strongly agree

QM14. The use of the methodology and Rehearsal would be useful for projects I have participated.

$\begin{array}{llllll}1 & 2 & 3 & 4 & 5\end{array}$

strongly disagree $\circ \circ \circ \circ \circ$ strongly agree

QM15. I would use the methodology and Rehearsal in future projects I may participate.

$\begin{array}{lllll}1 & 2 & 3 & 4 & 5\end{array}$

strongly disagree $\circ \circ \circ \bigcirc \circ$ strongly agree

QM16. The researcher provided adequate training in the methodology before the development. 
\begin{tabular}{lllllll}
\hline strongly disagree & 1 & 2 & 3 & 4 & 5 & \\
& 0 & 0 & 0 & 0 & 0 & strongly agree
\end{tabular}

Submit

Powered by Google Docs

Report Abuse - Terms of Service - Additional Terms 
APÊNDICE B 


\section{Referências Bibliográficas}

[AM04] Alain Abran e James W. Moore. Guide to the Software Engineering Body of Knowledge - SWEBOK. IEEE Press, 2005 edição, 2004. 5

[Ani12] Mauricio Aniche. Test-Driven Development - Teste e Design no Mundo Real. Casa do Código, 2012. 9

[Ast03] David Astels. Test-Driven Development: A Practical Guide. Prentice Hall PTR, July 2003. 9,87

[BAP11] Antonia Bertolino, Guglielmo De Angelis e Andre Polini. (role)CAST: A Framework for On-line Service Testing. Em 7th Internation Conference on Web Information Systems and Technologies, WEBIST, Noordwijkerhout, Netherlands, 2011. 19, 27, 34

[BBEM09] Cesare Bartolini, Antonia Bertolino, Sebastian Elbaum e Eda Marchetti. Whitening SOA testing. Em Proceedings of the the rth joint meeting of the European software engineering conference and the ACM SIGSOFT Symposium on The foundations of software engineering, ESEC/FSE '09, páginas 161-170, New York, NY, USA, 2009. ACM. 25, 34

[BBMP09] Cesare Bartolini, Antonia Bertolino, Eda Marchetti e Andrea Polini. WS-TAXI: A WSDL-based Testing Tool for Web Services. Software Testing, Verification, and Validation, 2008 International Conference on, 0:326-335, 2009. xi, 24, 34

[BBRW09] Adam Barker, Paolo Besana, David Robertson e Jon B. Weissman. The benefits of service choreography for data-intensive computing. Em Proceedings of the 7th international workshop on Challenges of large applications in distributed environments, CLADE '09, páginas 1-10, New York, NY, USA, 2009. ACM. 1, 16

[BDAP09] Antonia Bertolino, Guglielmo De Angelis e Andrea Polini. On-line validation of service oriented systems in the European Project TAS3. Em Proceedings of the 2009 ICSE Workshop on Principles of Engineering Service Oriented Systems, PESOS '09, Washington, DC, USA, 2009. IEEE Computer Society. 27, 34

[BD005] Alistair Barros, Marlon Dumas e Phillipa Oaks. A Critical Overview of the Web Services Choreography Description Language (WS-CDL). BPTrends Newsletter, 3(March), 2005. 16

[Bec94] Kent Beck. Simple Testing Framework: With Patterns. First Class Software, Inc. Available on: http://www.xprogramming.com/testfram.htm, 1994. 6

[Bec00] Kent Beck. Extreme programming explained: embrace change. Addison-Wesley Longman Publishing Co., Inc., Boston, MA, USA, 2000. 10

[Bec03] Kent Beck. Test-driven development: by example. Addison-Wesley, Boston, 2003. 2, 9, 87 
[Ber07] Antonia Bertolino. Software Testing Research: Achievements, Challenges, Dreams. Em 2007 Future of Software Engineering, FOSE '07, páginas 85-103, Washington, DC, USA, 2007. IEEE Computer Society. 19

[Ber11] Paulo Cheque Bernardo. Padrões de testes automatizados. Dissertação de Mestrado, Instituto de Matemática e Estatística da Universidade de São Paulo, São Paulo - Brasil, 2011. 6,8

$\left[\mathrm{BHM}^{+} 04\right]$ David Booth, Hugo Haas, Francis McCabe, Eric Newcomer, Michael Champion, Chris Ferris e David Orchard. W3C Note NOTE-ws-arch-20040211. Available on: $<$ www.w3.org/TR/ws-arch/wsa.pdf $>$, 2004. 11

[BK08] Paulo Cheque Bernardo e Fabio Kon. A Importância dos Testes Automatizados. Engenharia de Software Magazine, 1:54-57, 2008. 2

[BLK11a] Felipe Besson, Pedro Leal e Fabio Kon. Test-Driven Development Metodology Proposal for Web Service Choreographies. Available on: http://ccsl.ime.usp.br/baile/files/meth_proposal-2011.pdf, 2011. 87, 92

[BLK $\left.{ }^{+} 11 b\right]$ Felipe M. Besson, Pedro M.B. Leal, Fabio Kon, Alfredo Goldman e Dejan Milojicic. Supporting Test-Driven Development of Web Service Choreographies. Em The 5th International Open Cirrus Summit, Moscow, Russia, 2011. 33, 40

$\left[\mathrm{BLK}^{+} 11 \mathrm{c}\right]$ Felipe M. Besson, Pedro M.B. Leal, Fabio Kon, Alfredo Goldman e Dejan Milojicic. Towards automated testing of web service choreographies. Em Proceeding of the 6th international workshop on Automation of software test, AST '11, páginas 109-110, Waikiki, Honolulu, HI, USA, 2011. ACM. 33

[BLK12] Felipe Besson, Pedro Leal e Fabio Kon. Rehearsal: A framework for automated testing of web service choreographies. Relatório Técnico RT-MAC-2011-05, Department of Computer Science, Institute of Mathematics and Statistics, University of São Paulo, December 2012. 87

[BMS07] Antonio Bucchiarone, Hernán Melgratti e Francesco Severoni. Testing Service Composition. Em 8th Argentine Symposium on Software Engineering (ASSE'07), Mar del Plata, Argentina, 2007. 2, 19

[Boe79] B. Boehm. Software engineering; R \& D trends and defense needs. Em Research. directions in Software Technology. MIT, 1., páginas 44-86, Georgia, 1979. IEEE Press. 5

[BPRG09] Paolo Besana, Vivek Patkar, David Robertson e David Glasspool. Sharing Choreographies in OpenKnowledge: A Novel Approach to Interoperability. Journal of Software, 4:833-842, 2009. 1

[CDP09] Gerardo Canfora e Massimiliano Di Penta. Service-Oriented Architectures Testing: A Survey. Em Software Engineering, volume 5413 of Lecture Notes in Computer Science, páginas 78-105. Springer Berlin / Heidelberg, 2009. 2, 19

[Cha07] David Chappell. Introducing SCA. Available on: http://www.davidchappell.com/articles/introducing_sca.pdf, 2007. 15

[CHO11] CHOReOS. CHOReOS Perspective on the FI and initial conceptual model (D 1.2). http://choreos.eu/bin/Download/Deliverables, 2011. 16

[CK09] Sujit K. Chakrabarti e Prashant Kumar. Test-the-REST: An Approach to Testing RESTful Web-Services. Em Future Computing, Service Computation, Cognitive, Adaptive, Content, Patterns, 2009. COMPUTATIONWORLD '09. Computation World, páginas $302-308$, nov. 2009. 24, 34 
[CLL11] Pierre Chatel, Antoine Leger e James Lockerbie, editors. Passenger-friendly airport scenarios specification and requirements analysis (D6.1). Number Del. D6.1. The CHOReOS Consortium, 2011. 90

[Con12] OW2 Consortium. FraSCAti - Open SCA middleware platform. Available on: http://frascati.ow2.org, 2012. 89

[De197] Marcio Eduardo Delamaro. Mutação de interface: Um critério de adequação interprocedimental para o teste de integração. Tese de Doutorado, University of São Paulo Physics Institute, SP, Brazil, 1997. 6

[DKB08] Gero Decker, Oliver Kopp e Alistair Barros. An Introduction to Service Choreographies. Information Technology, 50(2):122-127, 2008. 13

[DMJ07] Márcio Eduardo Delamaro, José Carlos Maldonado e Mario Jino. Introdução ao teste de software. Elsevier Editora Ltda, 2007. 7, 8

[Eas97] Valerie J. Easton. Statistics glossary v1.1, 1997. 67, 68, 95

[EDMM10] Marcelo Medeiros Eler, Marcio Eduardo Delamaro, Jose Carlos Maldonado e Paulo Cesar Masiero. Built-In Structural Testing of Web Services. Em Proceedings of the 2010 Brazilian Symposium on Software Engineering, SBES '10. IEEE Computer Society, 2010. 26,34

[Er107] Thomas Erl. SOA Principles of Service Design. Prentice Hall PTR, Upper Saddle River, NJ, USA, 2007. 1, 13

[ESaSS08] André Takeshi Endo, Adenilso da Silva Simão, Simone do Rocio Senger de Souza e Paulo Sergio Lopes de Souza. Web Services Composition Testing: A Strategy Based on Structural Testing of Parallel Programs. Em Proceedings of the Testing: Academic and Industrial Conference - Practice and Research Techniques, TAIC-PART '08. IEEE Computer Society, 2008. 30, 34

[Evi10] Eviware. SoapUI, Web Services Functional Testing Tool. Available on: <http://http://www.soapui.org/>, 2010. 23, 34

[Fow99] Martin Fowler. Refactoring: Improving the Design of Existing Code. Addison-Wesley Professional, 1 edição, 1999. 9

[Fow07] Martin Fowler. Mocks Aren't Stubs. Available on: http://martinfowler.com/articles/mocksArentStubs.html, 2007. 9

[Fow11] Martin Fowler. Test-Driven Development. Available on: http://www.martinfowler.com/bliki/TestDrivenDevelopment.html, 2011. 9

[FP09] Steve Freeman e Nat Pryce. Growing Object-Oriented Software, Guided by Tests. Addison-Wesley Professional, 1 edição, 2009. 10

[GGKS02] K. Gottschalk, S. Graham, H. Kreger e J. Snell. Introduction to web services architecture. IBM Syst. J., 41(2), 2002. 13

[GGvD10] Michaela Greiler, Hans-Gerhard Gross e Arie van Deursen. Evaluation of online testing for services: a case study. Em Proceedings of the 2nd International Workshop on Principles of Engineering Service-Oriented Systems, PESOS '10, páginas 36-42. ACM, 2010. 19, 32, 34

[GHJV95] Erich Gamma, Richard Helm, Ralph E. Johnson e John Vlissides. Design Patterns: Elements of Reusable Object-Oriented Software. Addison-Wesley, 1995. 15 
[GKB12] Felipe Pontes Guimaraes, Eduardo Hideo Kuroda e Daniel Macedo Batista. Performance Evaluation of Choreographies and Orchestrations with a New Simulator for Service Compositions. Em The International Workshop on Computer-Aided Modeling Analysis and Design of Communication Links and Networks, CAMAD. IEEE, 2012. 1

[GW03] Boby George e Laurie Williams. An initial investigation of test driven development in industry. Em SAC '03: Proceedings of the 2003 ACM symposium on Applied computing, páginas 1135-1139, New York, NY, USA, 2003. ACM. 57

[Har88] Jen Harvey, editor. Evaluation Cookbook. Learning Technology Dissemination Initiative, 1988. 94

[Hew09] Eben Hewitt. Java Soa Cookbook. O’Reilly Media, 1 edição, March 2009. 1, 11

[HHL11] San-Yih Hwang, Wen-Fan Hsieh e Chien-Hsiang Lee. Verifying web services in a choreography environment. Em SOCA. IEEE, 2011. 30, 34

[HP11] HP. Loadrunner. Available on: <http://www8.hp.com/us/en/software/softwareproduct.html?compURI $=\mathrm{tcm}: 245-935779>, 2011.28$

[IBM11] IBM. Aglets. Available on: <http://www.trl.ibm.com/aglets $>$, 2011. 28

[Jef12] Ron Jeffries. What is Extreme Programming? Available on: http://xprogramming.com/xpmag/whatisXP\#test, 2012. 9

[JF88] Ralph E. Johnson e Brian Foote. Designing reusable classes. Journal of Object-Oriented Programming, 1:22-35, July 1988. 57, 87

[JM01] Natalia Juristo Juzgado e Ana María Moreno. Basics of software engineering experimentation. Kluwer, 2001. 66, 88

[Kit96] Barbara Kitchenham. Desmet: A method for evaluatingsoftware engineering methods and tools. Technical Report TR96-09, University of Keele - Department of Computer Science, 1996. 66, 88

$\left[\mathrm{KPP}^{+} 02\right]$ B. A. Kitchenham, S. L. Pfleeger, L. M. Pickard, P. W. Jones, D. C. Hoaglin, K. El Emam e J. Rosenberg. Preliminary guidelines for empirical research in software engineering. Software Engineering, IEEE Transactions on, 28(8):721-734, 2002. 63,87

[Lir04] Sachiko Araki Lira. Análise de correlação: Abordagem teórica e de construção dos coeficientes com aplicações. Dissertação de Mestrado, Universidade Federal do Paraná, Curitiba - Brasil, 2004. 78

[LVM12] Nuno Laranjeiro, Marco Vieira e Henrique Madeira. A Robustness Testing Approach for Soap Web Services. Journal of Internet Services and Applications, 4, 2012. 25, 34

[Mac12] I. Scott MacKenzie. Within-subjects vs. Between- subjects Designs: Which to Use? Available on: http://www.yorku.ca/mack/RN-Counterbalancing.html, 2012. Dept. of Computer Science, York University, Toronto, Ontario. 89

[Mad09] Bhavish Kumar Madurai. Getting serious about enterprise architecture (whitepaper on alignment between testable architectures and TOGAF), 2009. Available on: $<$ http://docs.jboss.org/savara/whitepapers/>. 57

[Mes07] Gerard Meszaros. xUnit Test Patterns: Refactoring Test Code. Addison-Wesley, May 2007. $3,6,8,87$ 
[ML06] Philip Mayer e Daniel Lübke. Towards a BPEL unit testing framework. Em Proceedings of the 2006 workshop on Testing, analysis, and verification of web services and applications, TAV-WEB '06, páginas 33-42, New York, NY, USA, 2006. ACM. 31, 34

[Mye04] Glenford J. Myers. The Art of Software Testing, Second Edition. Wiley, 2 edição, June 2004. 7

[NB006] Evaluating the efficacy of test-driven development: Industrial case studies, volume 2006, 2006. 57

[OAS11] OASIS. Service Component Architecture Assembly Model Specification Version 1.1. Available in: http://docs.oasis-open.org/opencsa/sca-assembly/sca-assembly-1.1spec.html, 2011. xi, 16

[OAS12] OASIS. Business Process Execution Language. www.oasisopen.org/committees/wsbpel, 2012. 14

[Pel03] Chris Peltz. Web Services Orchestration and Choreography. Computer, 36:46-52, October 2003. xi, 13, 17

[PGFT11] Marcos Palacios, José García-Fanjul e Javier Tuya. Testing in Service Oriented Architectures with dynamic binding: A mapping study. Information and Software Technology, páginas 171-189, March 2011. 13, 28

[Pi410] Pi4 Technologies Foundation. Pi4soa - pi calculus for SOA. Available on: http://sourceforge.net/projects/pi4soa/, 2010. 2, 29, 34

[Pre01] Roger S. Pressman. Software Engineering: A Practitioner's Approach. McGraw-Hill Higher Education, 5th edição, 2001. 6

[PZL08] Cesare Pautasso, Olaf Zimmermann e Frank Leymann. Restful web services vs. "big"web services: making the right architectural decision. Em Proceeding of the 17th international conference on World Wide Web, WWW'08, páginas 805-814, New York, NY, USA, 2008. ACM. 12

[Qui94] Michael J. Quinn. Parallel computing (2nd ed.): theory and practice. McGraw-Hill, 1994. 48

[Red10] Red Hat and Cognizant Technology Solutions. Savara: Testable architecture, 2010. Available on: <http://www.jboss.org/savara $>.57$

[RPIT11] Hazlifah Mohd Rusli, Mazidah Puteh, Suhaimi Ibrahim e Sayed Gholam Hassan Tabatabaei. A comparative evaluation of state-of-the-art web service composition testing approaches. Em Proceeding of the 6th international workshop on Automation of software test, AST '11, páginas 29-35, New York, NY, USA, 2011. ACM. 28

[Rt05] Stephen Ross-talbot. Orchestration and Choreography: Standards, Tools and Technologies for Distributed Workflows. Em NETTAB Workshop - Workflows management: new abilities for the biological information overflow, 2005. 16

[Sea99] Carolyn B. Seaman. Qualitative Methods in Empirical Studies of Software Engineering. IEEE Trans. Softw. Eng., 25:557-572, July 1999. 66, 88

[Sie75] Sidney Siegel. Estatística não-paramétrica: para as ciências do comportamento. McGraw-Hill do Brasil, 1975. 78 
[SMA05] Koushik Sen, Darko Marinov e Gul Agha. CUTE: a concolic unit testing engine for C. Em Proceedings of the 10th European software engineering conference held jointly with 13th ACM SIGSOFT international symposium on Foundations of software engineering, ESEC/FSE-13, páginas 263-272, New York, NY, USA, 2005. ACM. 29

[Som03] Ian Sommervile. Engenharia de Software. Addison-Wesley Brasil, 6 edição, 2003. 5

$\left[\mathrm{WRH}^{+} 00\right]$ Claes Wohlin, Per Runeson, Martin Höst, Magnus C. Ohlsson, Bjöorn Regnell e Anders Wesslén. Experimentation in software engineering: an introduction. Kluwer Academic Publishers, Norwell, MA, USA, 2000. 66, 88

$\left[W_{Z}{ }^{+} 10\right]$ Zheng Wang, Lei Zhou, Yongxin Zhao, Jing Ping, Hao Xiao, Geguang Pu e Huibiao Zhu. Web Services Choreography Validation. Service Oriented Computing Applications, 4, December 2010. 2, 29, 34

[Zha11] Jia Zhang. A Mobile Agent-Based Tool Supporting Web Services Testing. Wireless Personal Communications, 56:147-172, 2011. 28, 34

[ZPX $\left.{ }^{+} 10\right]$ Lei Zhou, Jing Ping, Hao Xiao, Zheng Wang, Geguang Pu e Zuohua Ding. Automatically testing web services choreography with assertions. Em Proceedings of the 12th international conference on Formal engineering methods and software engineering, ICFEM'10, páginas 138-154. Springer-Verlag, 2010. 2, 29 